Hydrological controls on salinity exposure and the effects on plants in lowland polders

Sija F. Stofberg 


\section{Thesis committee}

\section{Promotors}

Prof. Dr S.E.A.T.M. van der Zee

Personal chair Ecohydrology

Wageningen University \& Research

Prof. Dr J.P.M. Witte

Extraordinary Professor, Faculty of Earth and Life Sciences, Department of Ecological Science

VU Amsterdam

and Principal Scientist at KWR

Nieuwegein

\section{Other members}

Prof. Dr A.H. Weerts, Wageningen University \& Research

Dr G. van Wirdum

Dr K.T. Rebel, Utrecht University

Dr R.P. Bartholomeus, KWR Water, Nieuwegein

This research was conducted under the auspices of the Research School for SocioEconomic and Natural Sciences of the Environment (SENSE) 


\title{
Hydrological controls on salinity exposure and the effects on plants in lowland polders
}

\author{
Sija F. Stofberg
}

Thesis

submitted in fulfilment of the requirements for the degree of doctor

at Wageningen University

by the authority of the Rector Magnificus

Prof. Dr A.P.J. Mol

in the presence of the

Thesis Committee appointed by the Academic Board

to be defended in public

on Wednesday 07 June 2017

at 4 p.m. in the Aula. 
Sija F. Stofberg

Hydrological controls on salinity exposure and the effects on plants in lowland polders, 172 pages.

PhD thesis, Wageningen University, Wageningen, the Netherlands (2017) With references, with summary in English

ISBN: 978-94-6343-187-3

DOI: $\quad 10.18174 / 413397$ 


\section{Table of contents}

Chapter 1 General introduction .............................................................................. 7

Chapter 2 Fresh water lens persistence and root zone salinization hazard under

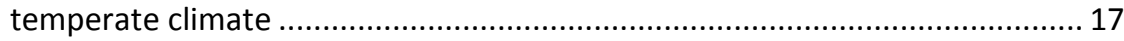

Chapter 3 Effects of root mat buoyancy and heterogeneity on floating fen hydrology ... 35

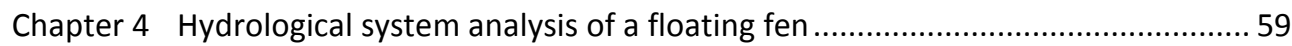

Chapter 5 Effects of salinity on growth of plant species from terrestrializing fens ........ 109

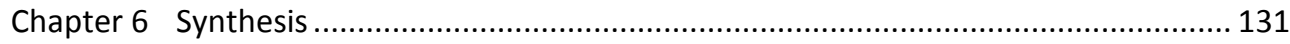

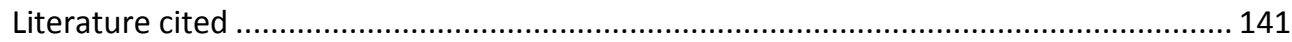

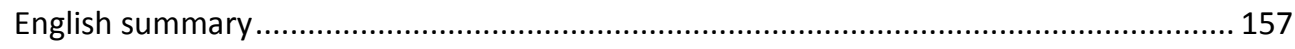

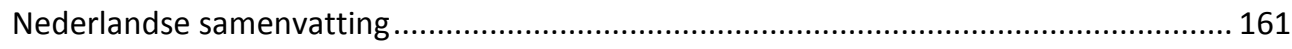

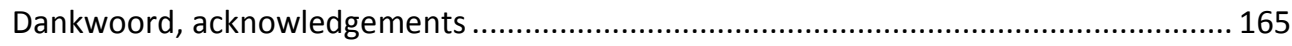

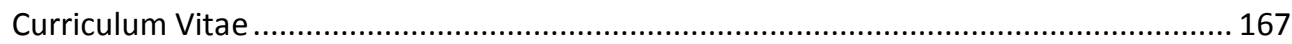

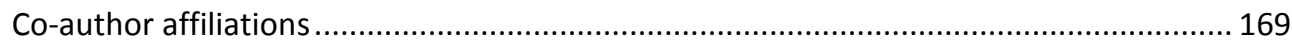

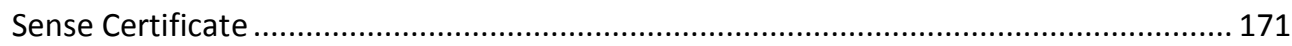




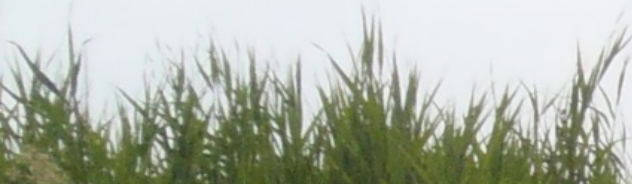

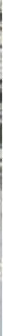

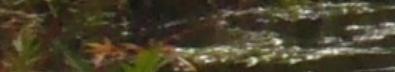

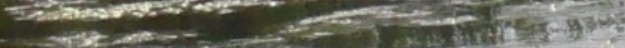

का

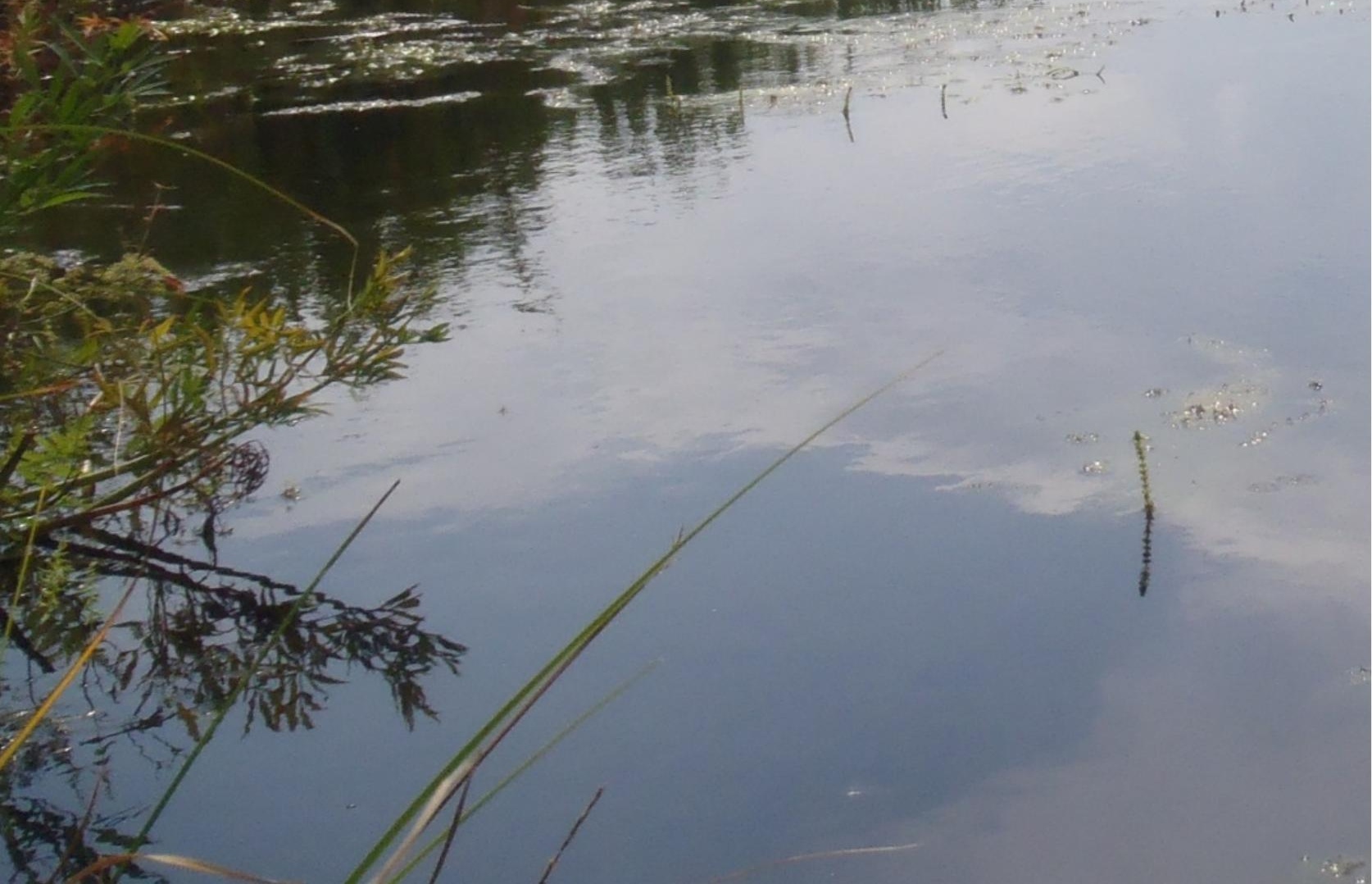




\section{General introduction}
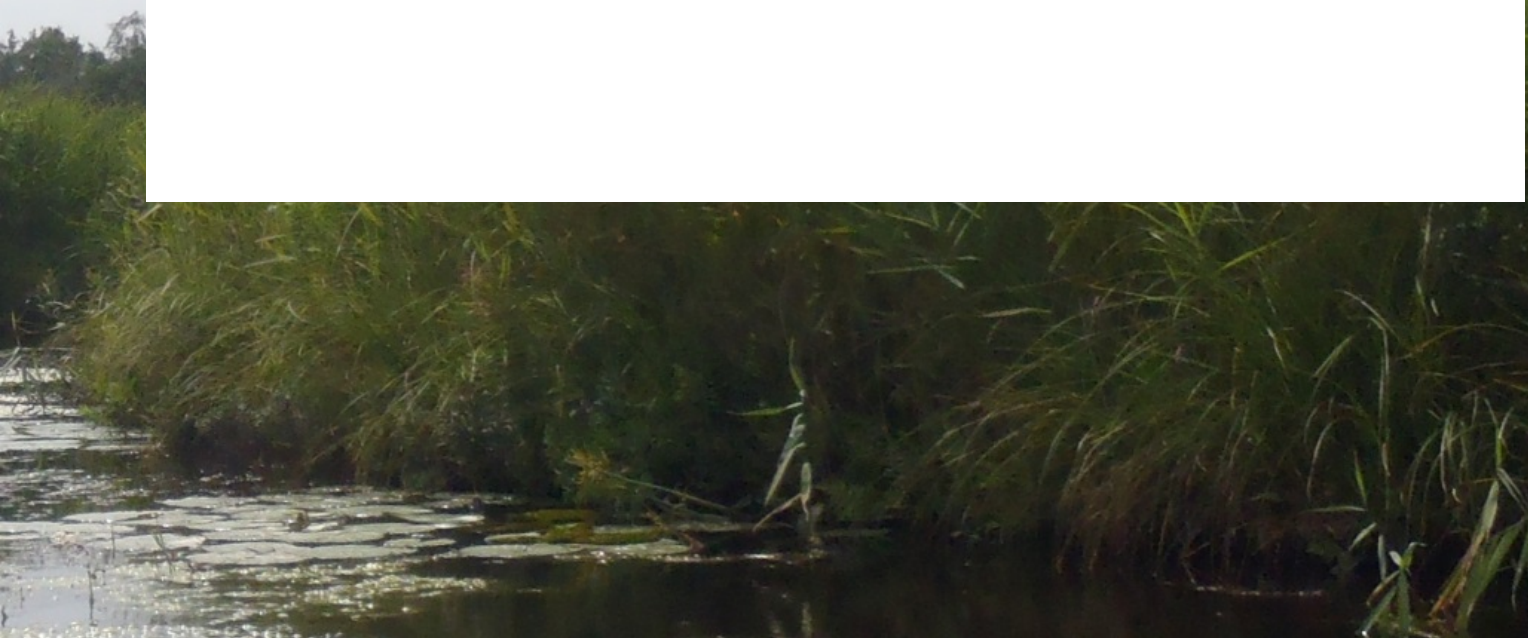

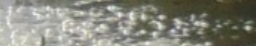

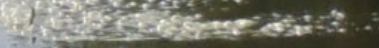

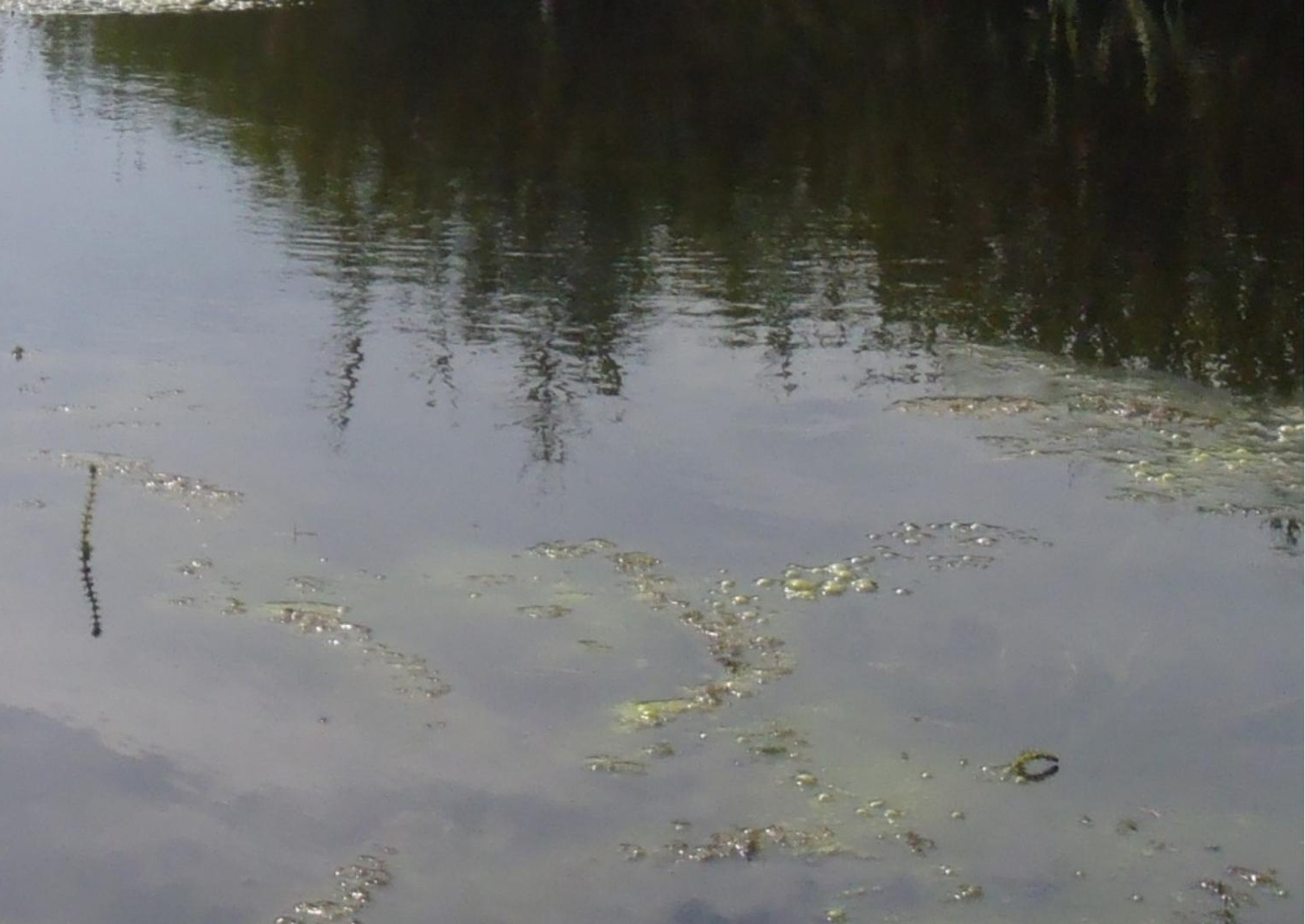




\subsection{Salinity in Dutch lowlands}

Many parts of the world are subject to salinization, meaning that soils and fresh-water resources are exposed to increased salt (mainly $\mathrm{Na}^{+}$and $\mathrm{Cl}^{-}$) concentrations (Abrol et al., 1988; Ghassemi et al., 1995). In coastal areas, salinization is often related to direct or indirect influence of the sea, such as salt spray, flooding, or sea water intrusion in groundwater aquifers or surface water. The Netherlands, which partly consists of coastal lowlands, has a long history of managing salinity (Raats, 2015), and currently, salinization is still a challenge for water managers.

The lowland part of the Netherlands is a delta with fluviatile and marine deposits as well as peat, in a temperate climate with a yearly precipitation surplus of about $300 \mathrm{~mm} \mathrm{y}$ (KNMI, 2015). Human activities have strongly influenced the landscape, as most of the land is managed as polders, which means that areas are surrounded by dikes and water levels are kept at a controlled level (van de Ven, 2004). Many areas with peat soils show the scars of peat mining. This activity resulted in landscapes of long turf ponds (also called turbaries, petgaten in Dutch), from where peat was taken, and baulks (legakkers in Dutch), where peat was spread out to dry before it was cut into peat briquettes (Lamers et al., 2002; Wirdum, 1993). In some cases, baulks were eroded by storms, resulting in lakes.

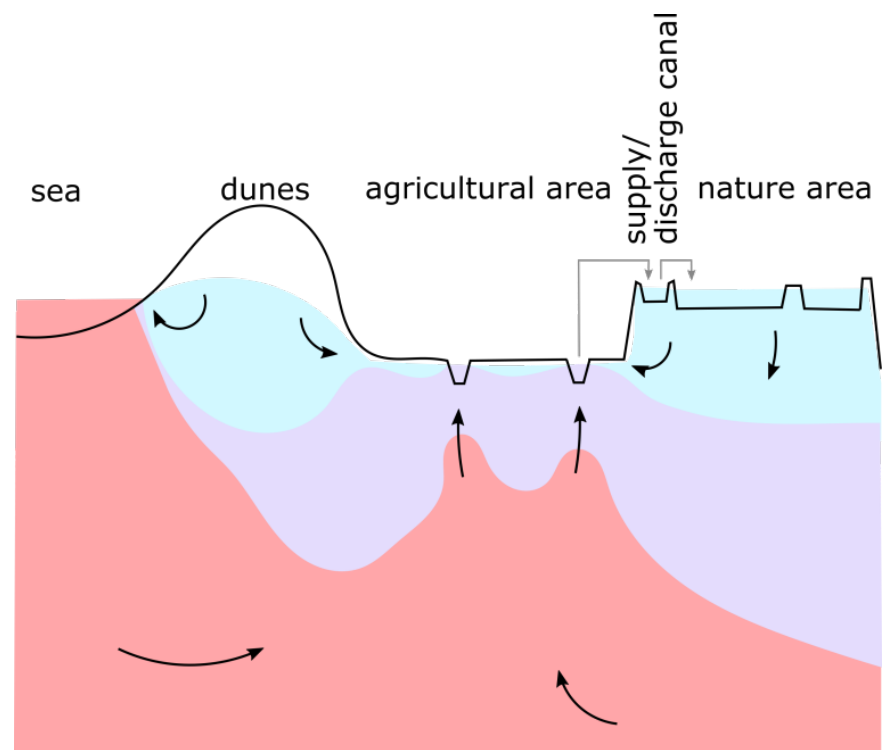

Figure 1.1 Schematic illustration of groundwater salinity in a cross section of the lowland part of the Netherlands. Fresh (light blue) recharge water forms lenses that are thinner in areas with lowered groundwater tables that receive significant upward seepage of saline (red) or brackish (purple) water. The surface water levels in the polders are managed by pumping water out or supplying it to polders through a network of canals. Freely adapted from Oude Essink et al. (2010) and Witte et al. (2012). 
Agriculture and other forms of land use demanded drainage of the land (Hoeksema, 2007; van de Ven, 2004). Centuries of drainage have led to soil subsidence, which resulted in the need for further drainage.

Peat mining and drainage have contributed to the current situation in which the surface of many polders lies several meters below mean sea level (Figure 1.1). Most of these polders are currently used as grassland or arable land. Areas that were not drained intensively, still have a relatively high position in the landscape (Figure 1.1). Most of them are nowadays designated as protected nature areas.

The strong differences in hydraulic heads between polders that were created this way, significantly influenced the regional hydrology. The deep polders are subject to seepage (upward groundwater flow), which originates from surrounding areas with higher water levels or from deep subsurface layers. As a result of changed coastlines and flow processes in past millennia, some of the groundwater at greater depths is brackish or saline (Delsman et al., 2013; Post, 2004). As this saline water flows upward, it may salinize the groundwater and surface water in the polders (Figure 1.1). The more elevated polders are infiltration areas, and therefore do not directly receive (saline) seepage, although they may receive it indirectly through surface water supply.

To keep water levels constant in polders, water is pumped out in case of a precipitation surplus, and supplied during periods with a precipitation deficit. This is done through a network of storage basins and canals, through which water is discharged to sea during winter and supplied from the rivers to the polders during dry summer periods. In case of saline seepage in deep polders, water from the storage basins may also be supplied to polders from one side, while being pumped out on the other side. This so-called 'flushing' of the polders is done to mitigate salinization and to provide relatively fresh irrigation water to farmers.

Salinization risks are expected to grow during the coming years, mainly as a result of climate change, in combination with ongoing soil subsidence and increased fresh water demands. Sea level rise may lead to more saline seepage, increasing the salt pressure in the deep polders (Oude Essink, 2001). Furthermore, the supply of fresh river water may become threatened during dry summers, as low discharge results in increased river salinity (Zwolsman and van Bokhoven, 2007), while the location where mixing with sea water occurs will shift further upriver (Beersma et al., 2005). Climate change scenarios predict that dry periods in spring and summer may become more frequent and of longer duration, which increases the risk of surface water salinization, possibly exceeding current concentration limits (in most areas $200 \mathrm{mg} \mathrm{L}^{-1} \mathrm{Cl}^{-}$) (Beersma et al., 2005; Klopstra et al., 
2005; Van Beek et al., 2008). Such periods typically coincide with increased evapotranspiration, putting even more pressure on available water resources. These processes can result in increased salt concentration in both the deep and elevated polders, which may pose a risk for agriculture and nature (Witte et al., 2012).

\subsection{Salinity and plants}

Salinity is considered a threat for agriculture and nature, which is due to it often having adverse effects on plant growth and survival. Osmotic effects are common, and occur when low salinity levels are exceeded. These effects are comparable to the effects of drought, as the osmotic pressure results in a lower hydraulic head within the root zone. The closure of stomata and subsequent reduced water uptake results in reduced plant photosynthesis and decreased growth, which may be observable within several days (Munns and Tester, 2008; Shani and Ben-gal, 2005). At higher concentrations and after longer timespans, toxic effects may occur as well, as ions (especially $\mathrm{Na}^{+}$) accumulate in the plant tissue. The toxicity causes tissue damage and leaf mortality (Munns and Tester, 2008). A third effect of salinity on plants is that it may affect nutrient uptake, as the availability of $\mathrm{Na}^{+}$and $\mathrm{Cl}^{-}$may interact with the uptake of $\mathrm{Ca}^{2+}, \mathrm{K}^{+}$and $\mathrm{NO}^{3-}$, which may lead to a variety of effects as these depend on the type of nutrient deficiency (Kaya et al., 2002; Munns and Tester, 2008).

Sensitivity to salinity differs strongly between plant species, depending on their physiological strategies for dealing with increased salt concentrations, through a wide variety of properties (Flowers et al., 2010; Parida and Das, 2005). Many fresh water species exclude salt from their roots, in that way preventing toxic amounts of salt from reaching the leaves. Osmotic stress tolerance is found in plants that are adapted to high levels of salinity (e.g. in coastal salt marshes), but many fresh water species can tolerate it to certain levels as well (Flowers et al., 2010; Munns and Tester, 2008).

Besides species-specific sensitivity, other factors may influence the physiological effect of salinity on plants. The growth stage is important, as seedlings and flowering plants can be more sensitive than plants in other growth stages (Katerji et al., 2003; Wilson, 2000). Furthermore, the effects increase with salinity concentration, and with the duration and rate of salinity increase over time (Munns and Tester, 2008; Shani and Ben-gal, 2005). Environmental factors may interact with the physiological effects of salinity as well, as these become stronger with less water availability and higher water demand for evapotranspiration (Parida and Das, 2005). 


\subsection{Salinity and lowland agriculture}

Agriculture in the Dutch lowlands consists mostly of grassland, field crops (e.g. potatoes, cereals, beets, flower bulbs) and greenhouse crops (e.g. vegetables and flowers) (CBS, 2016). The fields are relatively small, with several tens of meters width and several hundreds of meters length, separated by ditches. Additional drainage, consisting of furrows or tube drainage at regular intervals, is sometimes necessary to keep groundwater at desired levels.

In the deep polders (Section 1.1), crops can be exposed to salinity if they are irrigated with surface water with increased salt concentrations or if saline seepage reaches the root zone. The average yearly precipitation surplus often results in a layer of fresh water (a socalled fresh water lens) on top of the saline groundwater (Figure 1.1), providing fresh water to the root zone. In the absence of seepage, a so-called Ghijben-Herzberg fresh water lens would develop, and its shape would depend on the density differences between the fresh and the saline water (Badon-Ghijben, 1888; Herzberg, 1901). However, under the influence of seepage in combination with drainage, fresh water lenses become thinner (Maas, 2007). Furthermore, the thickness of these fresh water lenses is not constant over time, and differs per area as well (De Louw et al., 2013, 2011; Eeman et al., 2012; Vandenbohede et al., 2014). When fresh water lenses disappear, capillary rise can lead to salinization of the root zone.

In the Dutch lowland agricultural areas, there are two ways to respond to salinity risks. The first approach is to mitigate or prevent salinization by using hydrological interventions, while the alternative is to adapt to the salinization by changing the land use or choosing salt-tolerant crops. For agricultural crops, salinity tolerance levels can be identified using threshold-response curves, in which yield loss is a function of salinity (Maas and Hoffman, 1977). Threshold and response may differ significantly between species, with some species, such as flower bulbs being extremely sensitive, while other species such as sugar beets and several grain species are relatively tolerant (Shannon and Grieve, 1999; Tanji and Kielen, 2002; van Dam et al., 2007). In view of salinization, recent research shows the potential of halophytes, such as Salicornia spp., to be used as vegetable crops as well (Katschnig et al., 2013; Rozema and Flowers, 2008).

The first step in dealing with salinization is to identify risk areas and assess the potential severity of salinization in these areas. Large scale numerical modelling (Oude Essink, 2001) may identify regions with saline seepage, while smaller scale numerical modelling (De Louw et al., 2011; Eeman et al., 2012, 2011) can determine the size of the fresh water 
lenses at field scale. As using such models require much data and expertise, it would be useful to develop a relatively simple method to identify salinization risks.

a

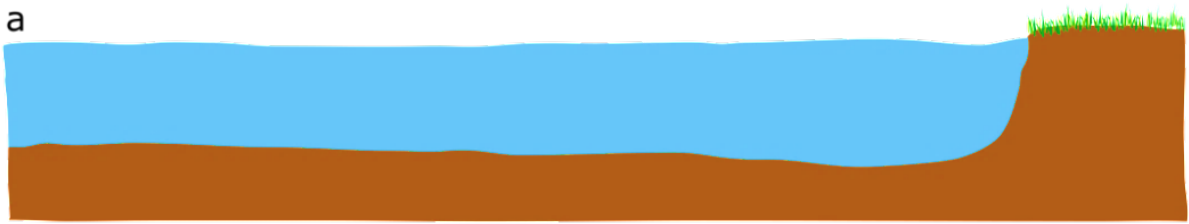

b

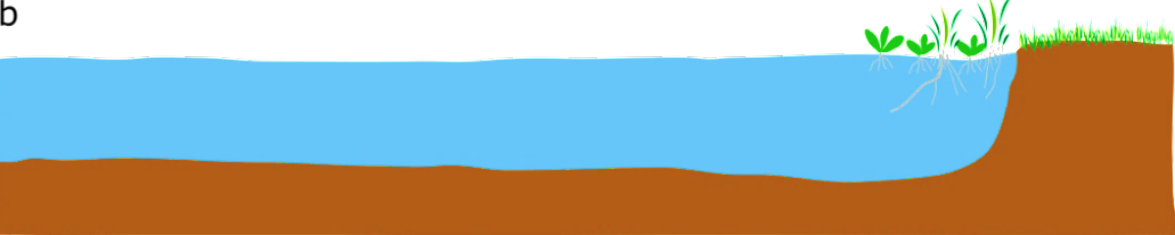

IIIII

C
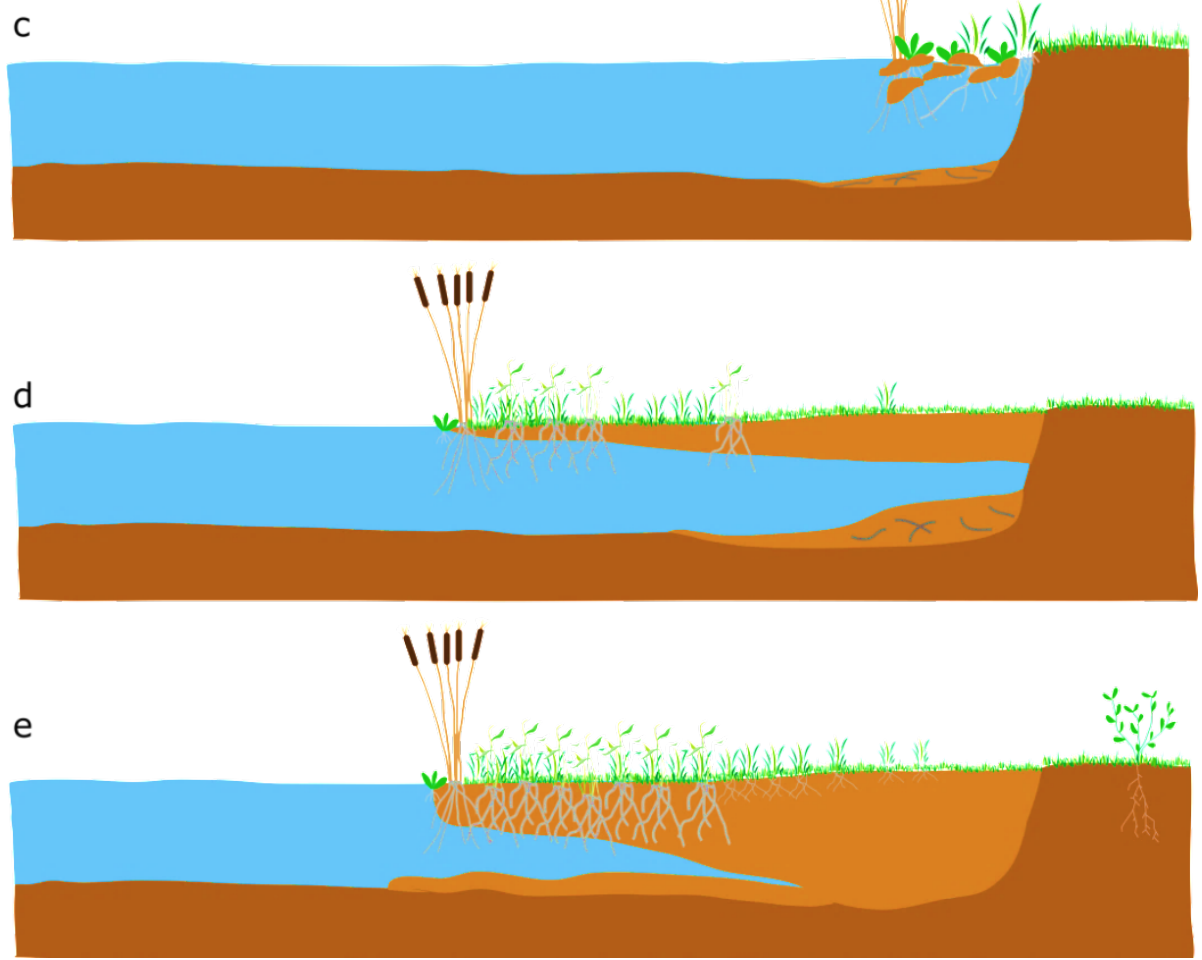

Figure 1.2 Schematic illustration of terrestrialization in a former turf pond. a. Turf pond. $b$. Helophytes colonize the open water. c. Organic matter accumulates and new plant species colonize the thin root mat. $d$. The root mat expands into the open water and different colonize the thicker parts. e. Over time, the root mat becomes thicker as more organic matter accumulates. A zonation of plant types can be recognized between the thin (early succession) and thick (late succession) parts of the root mat. 


\subsection{Salinity and lowland nature}

In the Dutch polder areas, the landscape is strongly influenced by human activities, and as such, pristine nature areas do not exist. However, in abandoned peat mining areas (Figure 1.1), semi-natural landscapes could develop, and which currently are protected as nature areas due to their large biodiversity. In turf ponds that were formed by peat excavation, terrestrialization processes could take place (Figure 1.2), starting with water plants and helophytes colonizing the open water (Wirdum, 1993). These provided a habitat for rich fen species, forming floating root mats. As these mats developed further into the open water, zones of poor fen or carr vegetation can develop on the older parts of the root mats. The end stage of succession may be bog or forest. Although the landscapes are influenced by humans, the species diversity of the different succession stages that are found in floating fen landscapes are similar to those in natural landscapes that have become very rare (Verhoeven and Bobbink, 2001). The different vegetation zones harbour a wide variety of plant species and provide a habitat to many others, including birds and insects. The high biodiversity is nowadays a major incentive to protect these areas as nature reserves.

As the earlier stages of succession are preferred over the later stages due to their biodiversity, management focuses on maintaining floating (rich) fens using several methods, including mowing and top soil removal, as well as digging new turf ponds in which new mats can develop (Lamers et al., 2014; van Diggelen et al., 2015). Decreased water quality as a result of water supply from the rivers during summer poses a challenge for managers as well. Increased nutrient concentrations and sulphates are associated with problems in the development of new root mats, and increased succession rates for existing root mats (Smolders et al., 2006).

The river water supply also makes it possible that floating fen systems will be exposed to increased salinity levels in the future, as was mentioned in section 1.1. The salt concentrations may vary between slightly higher concentrations over longer time (due to mixing with the water that was already present) to higher concentration peaks over short timespans (a pulse of brackish water passing through the area), depending on the sitespecific characteristics and management of the polder surface water systems. Understanding the risk of salinization in floating fens will help water and nature managers to determine to which extent floating fens need to be protected from supplying river water with increased salt concentrations. The risk of salinization in floating fens depends on the exposure and the effects of the increased salinity levels. 
The exposure is not only determined by the supply of salt through the surface water, but also by the hydrology of the floating fens, which determines the salt exposure of the root zone of each vegetation zone. There are some studies available about the hydrology of floating fens that describe long term or steady state water and solute exchange between the root mat and the surface water (Dekker et al., 2005; Koerselman, 1989; van Wirdum, 1991). However, very little is known about short term dynamics and how these may be different in different types of floating fens and different boundary conditions.

The effect of short term exposure to salinity on the vegetation depends on the response of individual species, while long term exposure may affect the vegetation as a whole as competitive advantages may shift and change the course of succession.

Long term successional processes can be understood by using observational data, such as vegetation records, from areas with different salinity levels. Floating fens in the Dutch lowlands are found in fresh and (slightly) brackish areas and their vegetation depends on the initial water quality, with the highest plant species richness occurring in the freshwater systems (Verhoeven and Bobbink, 2001; Wirdum, 1993). Species distribution data and indicator values show that $13-18 \%$ of fen species may tolerate brackish conditions, while a small group of other species is never found in (slightly) brackish conditions, which is possibly related to intolerance, although other factors cannot be excluded (Stofberg et al., 2014).

In general, few studies are available that assess more short term concentration-effect relationships for wild plant species. These studies show that similar to permanent exposure (Glenn et al., 1995; Hootsmans and Wiegman, 1998; Howard and Mendelssohn, 1999), short term exposure to salinity can have adverse effects on natural vegetation, although recovery may occur afterwards (Flynn et al., 1995; Goodman et al., 2010). Even very low concentrations can reduce growth in some aquatic macrophytes (Van den Brink and Van der Velde, 1993). However, these studies do not include species from (floating) fens, and therefore the relatively short term effects of salinity on these species remain unknown.

\subsection{Research objectives and outline}

To assess the risk of salinization, both the exposure of vegetation to salt and the effects of salt concentrations need to be understood. For both the deep agricultural polders and the high polders with the nature areas, a better understanding of potential exposure is desirable. For the deep polders that receive saline seepage, a generalized method to 
estimate salinization could help in pointing out areas that are subject to higher risks. For the floating fen nature areas, improved understanding of the hydrology of the root mats would allow the identification of vegetation zones that could be subject to salinization. While the effects of salinity on agricultural crops are rather well known, extremely little is known about the effects on natural species that are found in floating fens.

The objectives of this thesis are (1) to provide general methods to estimate root zone salinization under different conditions in saline seepage areas, and (2) to assess the risk of salinization in floating fens by understanding the hydrological processes as well as the effects of increased salt concentration on floating fen plant species.

Based on these objectives, research questions are formulated, that are addressed in the chapters of this thesis:

- How can the exposure of root zones to salinity as a result of saline seepage be generally estimated? (Chapter 2)

- Which processes and factors determine water flow within root mats? (Chapters 3 and 4)

- What is the effect of salinity on terrestrializing fen plant species? (Chapter 5)

The first research question focuses on the factors that determine salinity exposure in deep polders. In this chapter (Chapter 2), general approaches are used to provide insight in the risk of root zone salinization, depending on area characteristics and summer drought severity. To address the second research question, the hydrology of floating fen root mats is examined in Chapters 3 and 4. Chapter 3 discusses the need of taking heterogeneity and buoyancy into account when simulating water flow within root mats, while Chapter 4 provides a system analysis of root mat hydrology. The third research question is addressed in Chapter 5, in which relatively short term effects of low to moderately high salinity levels on five fen plant species are described. The results of these research questions and their implications are generally discussed, and remaining research challenges are identified in Chapter 6. 


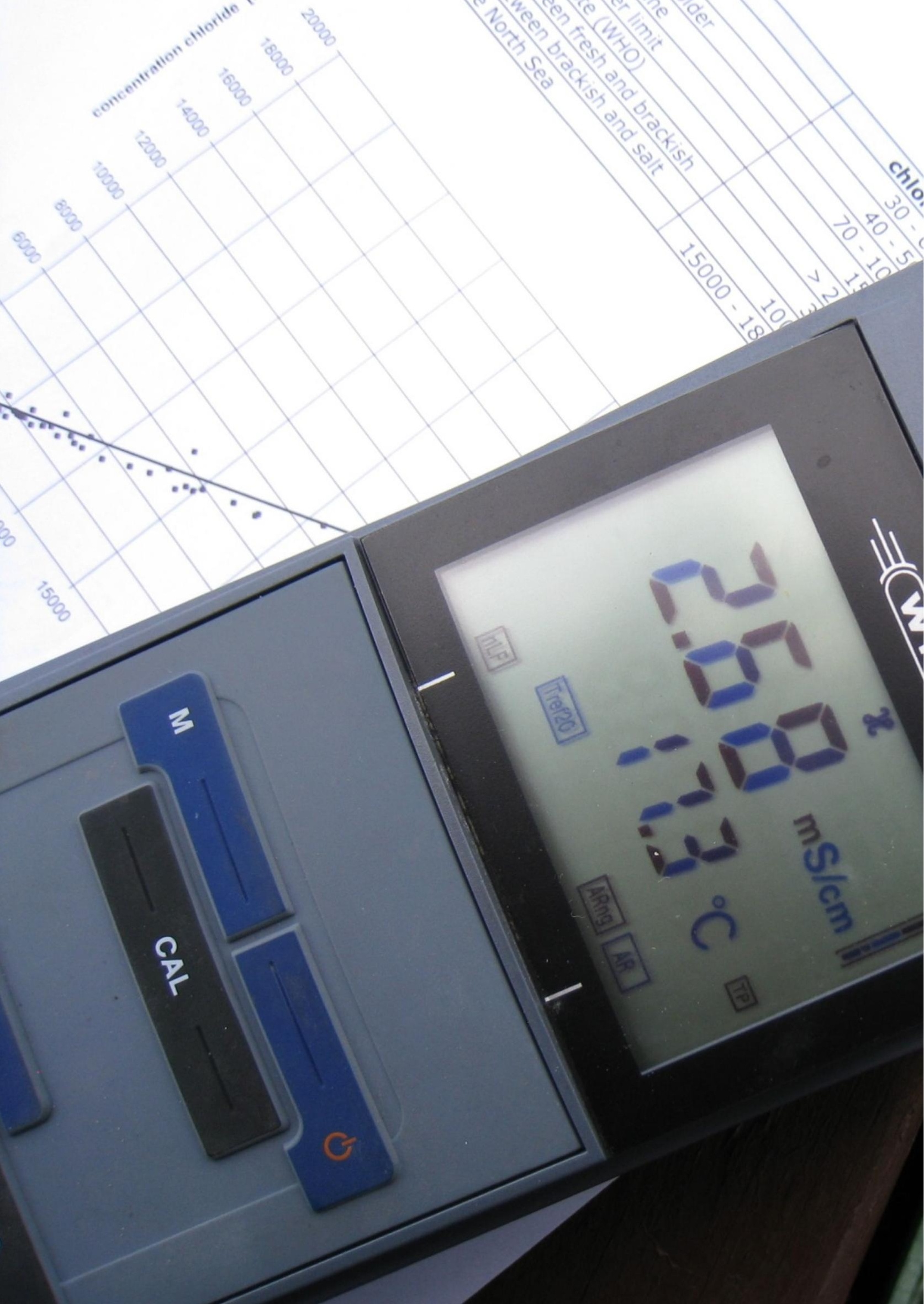




\section{Fresh water lens persistence and root zone salinization hazard under temperate climate}

\section{Based on:}

Stofberg, S.F., Essink, G.H.P.O., Pauw, P.S., de Louw, P.G.B., Leijnse, A., van der Zee, S.E.A.T.M., 2016. Fresh Water Lens Persistence and Root Zone Salinization Hazard Under Temperate Climate. Water Resources Management, 31(2), 689-702. doi: $10.1007 / s 11269-016-1315-9$ 


\begin{abstract}
In low lying deltaic areas in temperate climates, groundwater can be brackish to saline at shallow depth, even with a yearly rainfall excess. For primary production in horticulture, agriculture, and terrestrial nature areas, the fresh water availability may be restricted to so-called fresh water lenses: relatively thin pockets of fresh groundwater floating on top of saline groundwater. The persistence of such fresh water lenses, as well as the quantity and quality of surface water is expected to be under pressure due to climate change, as summer droughts may intensify in North-West Europe. Better understanding through modelling of these fresh water resources may help anticipate the impact of salinity on primary production.

We use a simple model to determine in which circumstances fresh water lenses may disappear during summer droughts, as that could give rise to enhanced root zone salinity. With a more involved combination of expert judgement and numerical simulations, it is possible to give an appraisal of the hazard that fresh water lenses disappear for the Dutch coastal regions. For such situations, we derive an analytical tool for anticipating the resulting salinization of the root zone, which agrees well with numerical simulations. The provided tools give a basis to quantify which lenses are in hazard of disappearing periodically, as well as an impression in which coastal areas this hazard is largest. Accordingly, these results and the followed procedure may assist water management decisions and prioritization strategies leading to a secure/robust fresh water supply on a national to regional scale.
\end{abstract}




\subsection{Introduction}

Soil and groundwater salinity have long been recognized as major problems for crop production worldwide (Maas and Hoffman, 1977; Rozema and Flowers, 2008; Tanji and Kielen, 2002). Whereas it may be most pressing in semi-arid regions (Allison (1964) mentions one third of agricultural land in arid and semi-arid regions), in temperate regions, salinity may cause problems as well (De Louw et al., 2013; Vandenbohede et al., 2014). Commonly, this is due to elevated salinity by seawater intrusion via groundwater or surface water, but it may also be significant by salt spray near the coast or by de-icing roads (Thunqvist, 2004). Due to climate change, the area that may be salt affected can increase. For temperate regions, particularly more frequent droughts may enhance salt stress in the growing season (KNMI, 2014).

Plants exposed to elevated salinity may experience different forms of stress. Due to the high osmotic value of saline solutions, soil water may become less available for plants to accommodate their transpiration and primary production (de Wit, 1958; Maas and Hoffman, 1977) in a similar way as drought. However, it is also well known that salts (e.g. involving $\mathrm{Na}^{+}, \mathrm{Cl}^{-}$) may be toxic for plants, or that toxic components such as boron (B) and selenium (Se) become more bio-available under saline conditions. In addition, induced nutrient deficiency has been well documented, e.g. for iron and nitrate (Grattan and Grieve, 1992; Schinas and Rowell, 1977). Salt tolerance has been investigated much for agricultural crops, both in field and greenhouse conditions, and particularly for the case that salts enter the root zone. Different plant species have different salt tolerances and strategies to deal with salinity (Munns and Tester, 2008; Parida and Das, 2005).

Because of the long awareness of the impact of salinity on primary production, research of salt affected soils has a long tradition. Two main routes for salts entering the root zone are (i) capillary rise from brackish to saline groundwater leading to primary salinization, and (ii) salt spray and irrigation causing secondary salinization (Szabolcs, 1989). For the case of secondary salinization, an important model concept has been developed, called the Leaching Requirement (Richards et al., 1954) and that is aimed at preventing too large salt concentrations in the root zone.

For temperate regions, where annual precipitation is usually sufficient for plant transpiration demands, infiltrating water can meet upward seeping groundwater, if the soil surface is close to the drainage level. In that case, the so-called fresh water lenses that develop on top of brackish or saline groundwater in coastal areas may become rather thin (De Louw et al., 2011; Eeman et al., 2011). If these lenses temporarily disappear in summer, this may lead to saline capillary rise water, that salinizes the root zone. 
Avoiding, mitigating or adapting to the adverse effects of groundwater salinity is possible if we recognize in which cases salts accumulate in the root zone. In this paper, we consider the hazard of root zone salinization due to depletion of fresh water lenses, as in that case, capillary rise of saline water to the root zone commences. We provide relatively simple tools that differ with respect to their data demand, to appraise this hazard.

\subsection{Fresh water lens persistence}

In low lying regions with shallow saline groundwater, such as in deltaic areas or small islands, saline water may enter the root zone due to capillary upward flow of groundwater. In case the annual rainfall is sufficient, precious fresh water lenses may develop preventing the underlying saline groundwater to reach the root zone via capillary rise. Experimental evidence of fresh water lenses on saline groundwater has been provided for different continents, (e.g. De Louw et al. 2011, Fetter 1972, Underwood et al. 1992), even for inland areas of Australia (Cendón et al., 2010; Jolly et al., 1998), Oman (Young et al., 2004) and Hungary (Szabolcs, 1989; Toth, 2008). Whether or not a fresh water lens protects primary production from salt induced yield depressions will depend on the persistence of such lenses in temperate climates in the dry season (often summer).

Fresh water lenses resemble large fresh water volumes in coastal dune areas (Martinez and Psuty, 2008) and analytical solutions have been found for different assumptions regarding e.g. the outflow zone at the dunes' periphery, or whether or not the salt underlying water is flowing, assuming a sharp fresh/salt interface (Badon-Ghijben, 1888; Herzberg, 1901; Maas, 2007; Van Der Veer, 1977). Investigating fresh water lenses in lowlying flat coastal regions, Eeman et al. (2011) revealed that the analytical solution provided by Maas (2007) is in close agreement with their numerical modelling using the model SUTRA-3D. The solution of Maas is given by:

$\sqrt{\frac{Z^{2}}{\left(L^{2}+Z^{2}\right)}}=\left[-\frac{S}{P}+\sqrt{\left(\frac{S}{P}\right)^{2}+4\left(1+\frac{S}{P}+R\right)}\right] /\left[2\left(1+\frac{S}{P}+R\right)\right]$

where $S$ is upward seepage rate $\left[\mathrm{LT}^{-1}\right], P$ is mean net precipitation or infiltration rate $\left[\mathrm{LT}^{-1}\right]$, $R$ is the Rayleigh number $(R=\kappa g \Delta \rho /(\mu P))$ with intrinsic permeability $\kappa\left[\mathrm{L}^{2}\right]$, gravity acceleration $g\left[\mathrm{LT}^{-2}\right]$, density difference $\Delta \rho\left[\mathrm{M} \mathrm{L}^{-3}\right]$, and dynamic viscosity $\mu\left[\mathrm{ML}^{-1} \mathrm{~T}^{-1}\right], L$ is the half spacing [ $\mathrm{L}]$ between two drains or ditches, i.e., the distance from drain or ditch to hydrological divide, and $Z$ is the largest thickness of the lens at the hydrological divide. For such a lens, the volume $V_{M}\left[L^{3}\right]$ is equal to 
$V_{M}=\frac{1}{4} \pi L Z$

The impact for upward seepage $S$ in (1) is a crucial one, as it is a major force that counters the development of a full Badon-Ghijben-Herzberg (BGH) lens that complies with Archimedes' law. Especially this occurs for low lying areas in e.g. delta regions, as in Dutch polders (De Louw et al., 2013, 2011) or the Po delta, Italy (Vandenbohede et al., 2014). In the absence of such seepage, other (simpler) solutions are available that are outside the scope of this paper, as here we are focusing on lowland areas with upward saline seepage rather than coastal dunes, where groundwater flow is predominantly downward and BGH lens thicknesses of tens of meters can develop.

For the case that the groundwater densities of the lens and the underlying groundwater are equal, the solution follows directly from (2.1) by setting the Rayleigh number equal to zero, giving for the right hand side $(1+S / P)^{-1}$. Such a situation is often found in topographically higher areas with upwelling fresh groundwater as in stream valleys (Cirkel et al., 2014). Then, lens thickness thicker than those for sea water salinity circumstances are found. From (2.1), we then obtain for any value of $R$, an expression for $Z$ :

$Z=\sqrt{ }\left(L^{2}\left[\frac{F^{2}}{1-F^{2}}\right]\right) ; \quad F=\left\{-m+\sqrt{m^{2}+4 r}\right\} / 2 r ; \quad m=\frac{s}{P} ; \quad r=1+m+R$

Impressions of lens properties are given for different parameter combinations in Figure 2.1 for a seepage/recharge ratio $S / P=1$, and a permeability $\mathrm{k}=10^{-12} \mathrm{~m}^{2}$ which is equivalent to a hydraulic conductivity of about $1 \mathrm{~m} \mathrm{day}^{-1}(K=\kappa \rho g / \mu)$. Lens thickness $Z$ is proportional to the half distance between drains or ditches $L$ and increases as the water density $\Delta \rho$ differences between lens and groundwater become smaller in agreement with a BGH lens.

Recognizing that both the lens thickness and the mixing zone thickness are important for the risk that brackish water from the mixing zone moves up by capillary rise into the root zone, an alternative to numerically estimating the critical mixing zone thickness is appealing. Based on the analysis of Cirkel et al. (2015) this thickness can be estimated easily. We consider a lens of thickness $Z$ where half of the mixing zone is situated in the lens, and the other half is in the saline groundwater below the lens.

This half thickness $\left(\sigma_{z}\right)$ can also be represented by the variance or second central spatial moment of vertical salt concentration change

$\sigma_{z}^{2}=2 \alpha_{L}\left\langle\left|v_{z}\right|\right\rangle t$ 
In (2.4), $\alpha_{L}$ is the longitudinal dispersivity $\left[\mathrm{L}^{2}\right]$ and in view of recent insights by Eeman et al. (2012) and Cirkel et al. (2015), we may interpret $\left\langle\left|v_{z}\right|\right\rangle t$ as the total distance that the mixing zone travels during one year (lens growing in winter, diminishing in summer). If the lens disappears at the end of each drought period and the fluctuation of the mixing zone is sinusoidal, the amplitude of vertical transition zone position is equal to $A_{z}=Z$. This leads to $\left\langle\left|v_{z}\right|\right\rangle=4 A_{z} f$ where $f$ is the seasonal frequency. We then obtain from (2.4)

$\sigma_{z}=\sqrt{8 \alpha_{L} A_{z}}=\sqrt{8 \alpha_{L} Z}$

In Figure $2.1 \mathrm{~b}$ we show how $\sigma_{z}$ increases as a function of lens thickness if the longitudinal dispersivity $\alpha_{L}$ increases. As these figures show, for relatively thin lenses, their thickness can be of the same order of magnitude as that of the mixing zone, which means that the water lens contains significant amounts of salts. This is also seen from the thickness of fresh water zone, when the mixing zone thickness within the lens, $\sigma_{Z}$ is subtracted from the lens thickness $Z$. In Figure 2.1c, $Z-\sigma_{Z}$ is shown as a function of $Z$ and for different longitudinal dispersivities. For thin lenses, the lens may become brackish throughout, as is implied by the negative values of $Z-\sigma_{z}$. This was also found by field measurements in the south-western Dutch delta which showed that almost all rainwater lenses lacked truly fresh water (De Louw et al., 2011). Since the lens thickness represents a volume of water, it is possible to assess for which thicknesses of the lens it will disappear as a function of rainfall deficit $E T-P$, longitudinal dispersivity $\alpha_{L}$, and specific yield $s_{y}$ (taken to be 0.1 ). For the Netherlands, a cumulative rainfall deficit of $200 \mathrm{~mm}$ is not uncommon, hence, lenses of 3-4 m thickness may disappear to such a degree, that brackish water can reach the root zone by capillary rise. With this in mind, we show in Figure $2.1 \mathrm{e}$, how the rainfall deficit for which the lens disappears will depend on the distance $L$ between drain and middle of the field, and the ratio of seepage and recharge $(S / P$, see eq. 2.1$)$. It is clear, that for the chosen parameters and a reasonable rainfall deficit, this is mostly the case for small fields and relatively large seepage rates. Underlying reason is that stronger upward groundwater seepage $(S)$ forces the interface between fresh and salt water upwards, i.e., leads to small $Z$-values. Such a combination may represent a wetland under native vegetation rather than an agricultural field. If, however, predictions for a substantial sea water level rise become true, this inevitably causes an increase in upward seepage (Oude Essink et al., 2010).

A factor that is somewhat hidden in the illustrations is the soil type. This can be illustrated with Figure $2.1 \mathrm{f}$ that shows how the rainfall deficit, where the lens disappears, depends on both half spacing $(L)$ and the soil hydraulic conductivity. Realistic values may be reached with high hydraulic conductivities or small $L$-values. In practice, ditch distances depend on the hydraulic conductivity of the soil, with smaller conductivities meaning smaller L- 
values, but also on desired drainage levels. In Figure 2.2, the lenses are shown for a clayey and for a peaty soil. Despite its larger conductivity, fields in peat soil are often more densely drained, in order to more accurately fix groundwater levels. If groundwater levels were allowed to fall significantly in peat, this might lead to mineralization of peat, irreversible consolidation and land subsidence. As Figure 2.2 shows, good control of groundwater level by intense drainage results in a thin and vulnerable fresh water lens. In our calculations it has not been taken into account that soil type may affect net infiltration, as larger hydraulic conductivities favour a large net infiltration rate, hence thicker fresh water lenses (De Louw et al. 2011). This may mean that in practice, the total salinization threshold differences between different soil types are slightly smaller than represented in Figure 2.1f.

With results as in Figure 2.1, it is also easy to see what the risk is that a lens will disappear completely during a dry period if we consider climate change projections. In the next decades, the average rainfall deficit in summer may increase from $144 \mathrm{~mm}$ to $187 \mathrm{~mm}$ in 2050, with 10-year extremes of $288 \mathrm{~mm}$ (KNMI, 2014). This implies that lenses with a thickness of $0.25 \mathrm{~m} / \mathrm{s}_{y}=2.5 \mathrm{~m}$ (for our default parameter values) may regularly disappear. A record dry year was 1976, in which the rainfall deficit grew to $360 \mathrm{~mm}$, and for a specific yield of 0.1 , even lenses of $3.6 \mathrm{~m}$ thick might disappear.

The approximations of Figure 2.1 are somewhat crude, because under water and salt stress, plants will cease to transpire at the potential rate. At which concentrations salt stress occurs depends on both crop and genotype. Also regarding evaporation from the bare soil surface, it is unlikely to continue at maximum rate as drought sets in. Instead, a drying front may cause a rapid decline of evaporation as soil dries out. In addition, water that flows upward from the declining fresh water lens towards the root zone will take time to travel that distance. This time is important in view of the frequency with which significant rainfall occurs, as such showers may leach salt that is underway. In other words, characteristic times of rainfall and water travel times between saturated groundwater and root zone become important. This is even more so the case if cumulative effects over years can be anticipated, e.g. due to summers that become drier due to climate change. For instance, a rainfall deficit requires time to be balanced by a rainfall excess, yet during this time, discharge to drains and ditches continues to remove fresh water. Accordingly, the risk of a succession of different dry summers is probably a factor to be accounted for. 
a
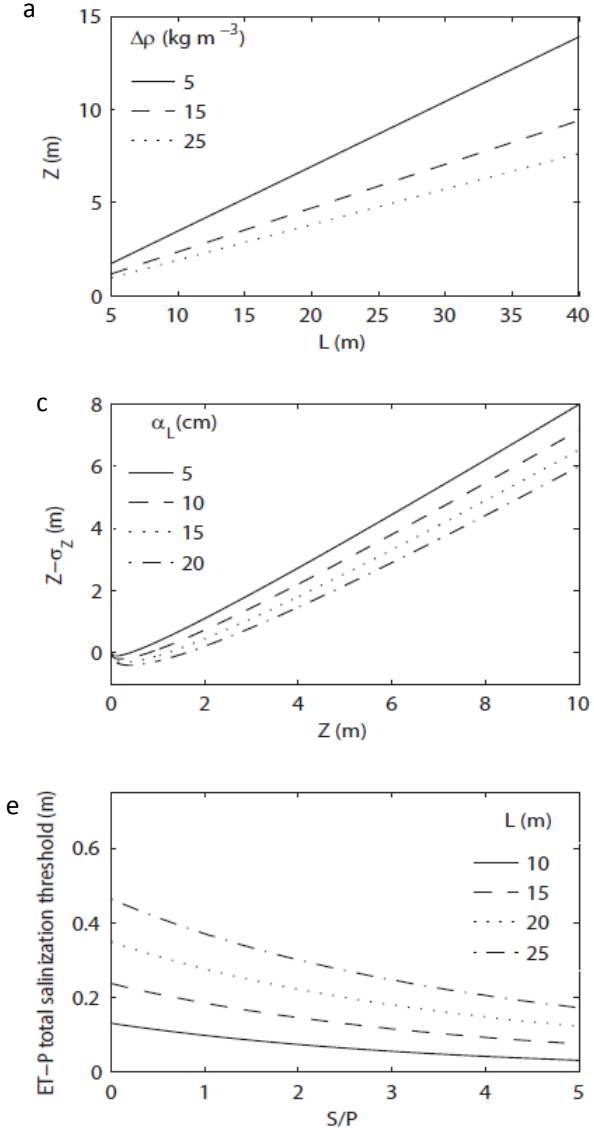

b

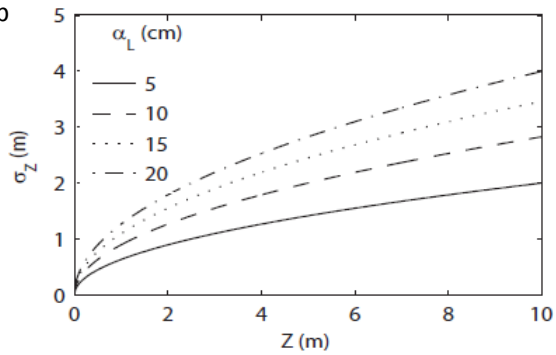

d
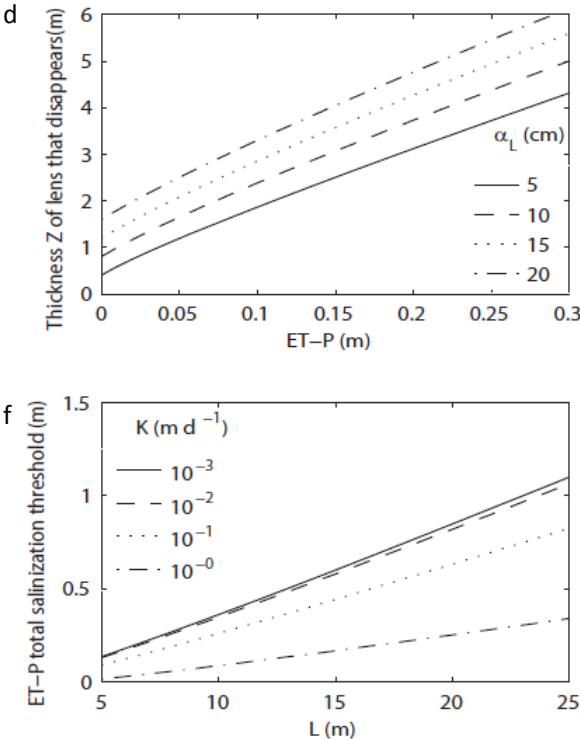

Figure 2.1 Lens properties as a function of system parameters: a. Lens thickness $Z$ as a function of half spacing between drains or ditches $L$ for several water density $\Delta \rho$ differences between lens and groundwater, seepage/recharge ratio $S / P=1, k=10^{-12} \mathrm{~m}^{2} . b$. Mixing zone thickness $\sigma_{z}$ as a function of lens thickness for different longitudinal dispersivity values $\alpha_{\mathrm{L}}$. c. Thickness of fresh water zone $Z-\sigma_{Z}$ as a function of $Z$ for different longitudinal dispersivity values. $d$. Thickness of lens $Z$ that may disappear as a function of rainfall deficit ET-P for different longitudinal dispersivity values, specific yield $s_{y}=0.1$. e. Threshold rainfall/precipitation deficit at which the total fresh water zone disappears as a function of seepage/recharge ratio for different half distances between ditches, a density difference as found in Dutch coastal subsoils of $\Delta \rho=15 \mathrm{~kg} \mathrm{~m}^{-3}, \kappa=10^{-12} \mathrm{~m}^{2}, \alpha_{L}=0.1 \mathrm{~m}, \mathrm{~s}_{y}=0.1$. $\mathrm{f}$. Threshold rainfall deficit at which the total fresh water zone disappears as a function of half distance between ditches, for different values of hydraulic conductivity, $S / P=1, \Delta \rho=15 \mathrm{~kg} \mathrm{~m}^{-3}, \alpha_{\mathrm{L}}=0.1 \mathrm{~m}, \mathrm{~s}_{\mathrm{y}}=0.1$.

Although simplifications have been made on the reaction of fresh water lenses to erratic rainfall, this is not the case with regard to the impact of erratic rainfall on the fresh/salt mixing zone. High frequency variations of lens recharge may affect the thickness of the lens and therefore the value of $Z$, but these variations do not affect the validity of (2.4) and (2.5), as was demonstrated (Cirkel et al., 2014). 
"Clay" field (50 m)

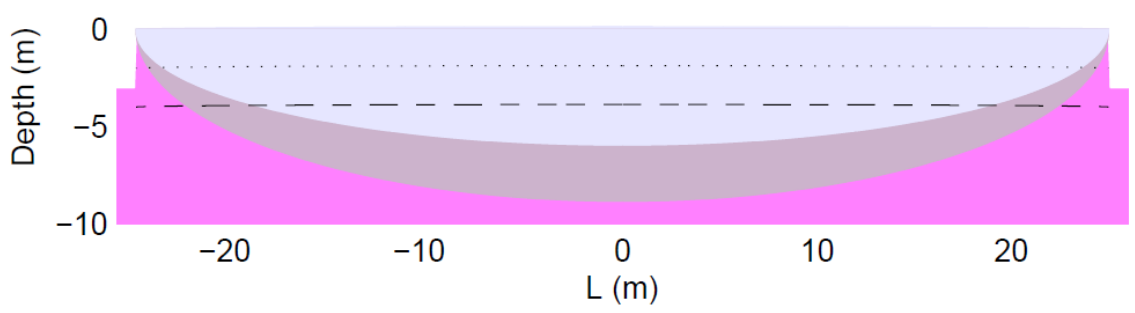

"Peat" field (30 m)
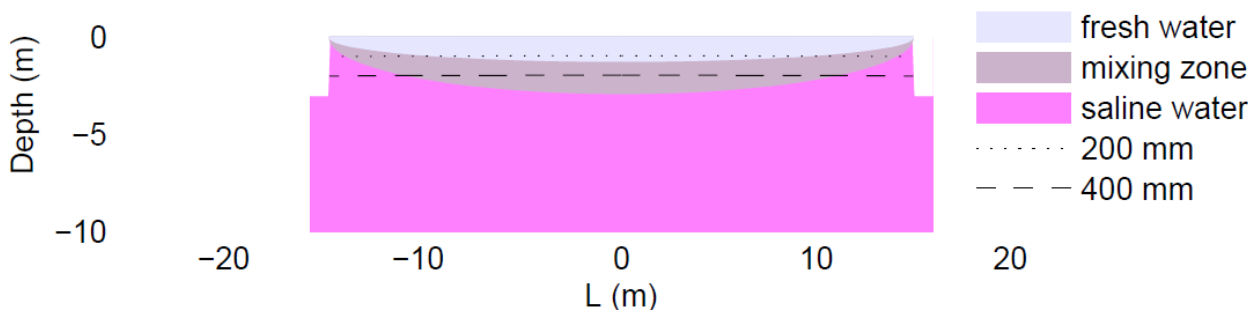

$-20$

$\mathrm{L}(\mathrm{m})$

Figure 2.2 Cross section of a fresh water lens in a large 'clay' field with low hydraulic conductivity ( $L=25 \mathrm{~m}$, $\left.K=0.01 \mathrm{~m} \mathrm{~d}^{-1}, s_{y}=0.1\right)$ and a smaller 'peat' field with higher hydraulic conductivity ( $L=15 \mathrm{~m}, K=1 \mathrm{md}^{-1}, s_{y}$ $=0.2$ ) in a situation in which $S / P=2, \Delta \rho=15 \mathrm{~kg} \mathrm{~m}^{-3}$ and $\alpha_{L}=0.12 \mathrm{~m}$. Dotted lines indicate which part may be depleted if the rainfall deficit increases to $200 \mathrm{~mm}$ and $400 \mathrm{~mm}$. Percentage of the field that is depleted of fresh water due to rainfall deficit is $6 \%(200 \mathrm{~mm})$ and $25 \%(400 \mathrm{~mm})$ in the clay field and $38 \%(200 \mathrm{~mm})$ and $100 \%$ (400 $\mathrm{mm}$ ) in the peat field.

\subsection{Regionalization of fresh water persistence}

The tools that were discussed in the previous section are based on analytical approximations that can be easily communicated. However, for management it is often attractive to present dependencies between environmental conditions and output of interest in the form of maps, as done by De Louw et al. (2011, 2013). With various numerical instruments, we made such a vulnerability map for regions with saline or brackish groundwater in The Netherlands.

The vulnerability map was inferred from the chloride concentration below the upper confining layer in the Netherlands (Oude Essink et al. 2010, De Lange et al. 2014). This data was retrieved from numerical models at the regional/national scale of the Netherlands (De Lange et al., 2014), with which future stresses were simulated. 
Comparing the results of this exercise with field data from for example De Louw et al. (2011) yielded acceptable results, except in the polder areas which used to be inland lakes and that were reclaimed relatively recently (i.e., later than $1800 \mathrm{AD}$ ). In these areas, this approach underestimated the thickness of the freshwater lenses. Therefore, a paleogeographical map (Vos, 2015) was used to delineate these 'recently' reclaimed polders and to assign them to the 'Low' class. The year 2000 was compared with 2100 , to indicate the effect of future stresses, such as land subsidence (Haasnoot et al., 1999), climate change and sea level rise.
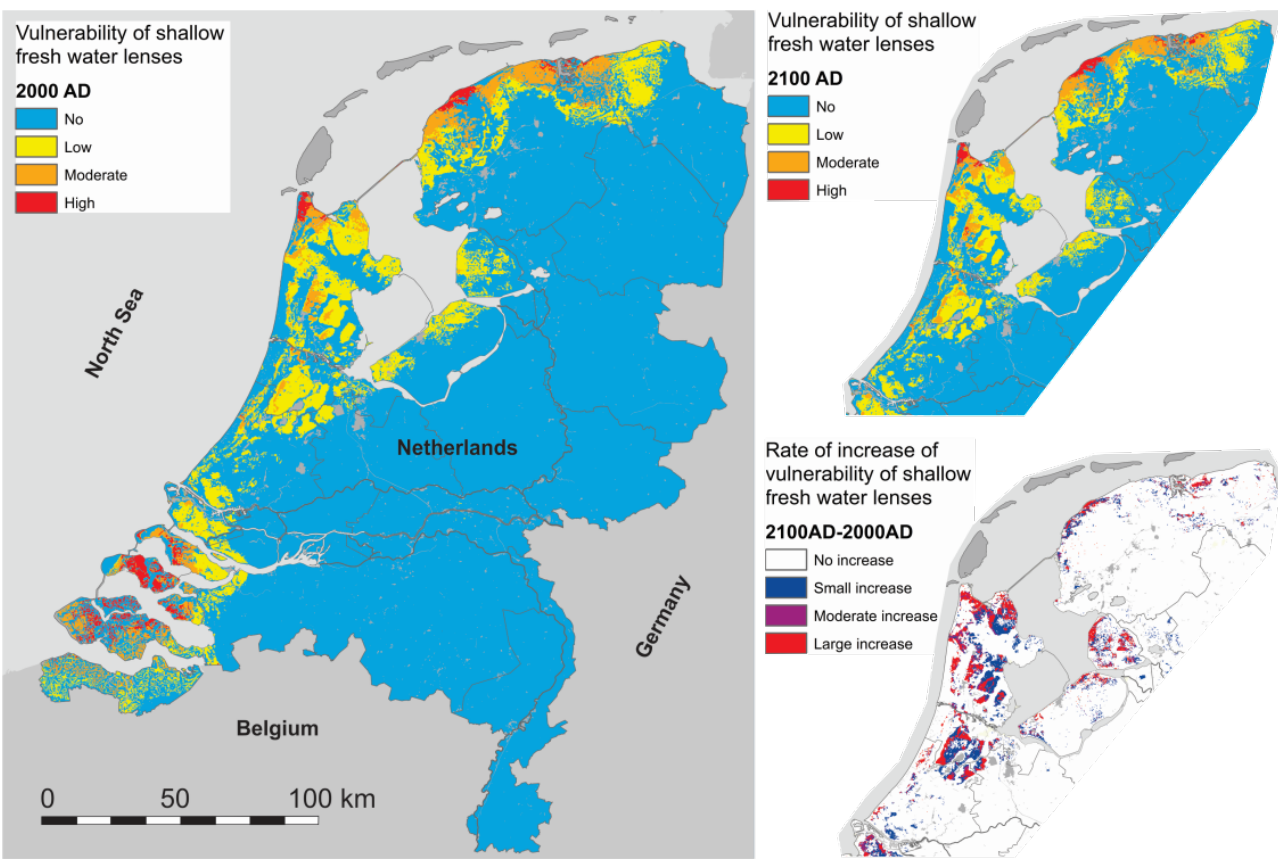

Figure 2.3 Vulnerability of shallow fresh water lenses in the Dutch coastal zone, on 2000 AD and $2100 A D$, as well as the rate of increase of the vulnerability of the fresh water lenses over this $2000 A D-2100 A D$ period, all based on a national numerical model and expert judgement. The vulnerability classes ' $N o^{\prime}$ ', 'Low', 'Moderate', and 'High' correspond with chloride concentrations below the upper confining layer of

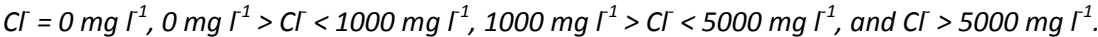

Figure 2.3 shows the vulnerability of shallow fresh water lenses, for the current situation as well as for the situation in year $2100 \mathrm{AD}$. For the year $2100 \mathrm{AD}$, climate change impacts on the chloride concentration below the upper confining layer were implemented using results of national groundwater flow model simulating effects due to sea level rise, changes in precipitation patterns and autonomous salinization (De Lange et al., 2014; Oude Essink et al., 2010). Land subsidence was incorporated using the map of Haasnoot et al. (1999) in the expert judgement analysis. Because this approach is in some aspects fuzzy, the results of the final maps should be used with care. On the other hand, this 
exercise does show how with limited time but with distributed data used in numerical models, a reasonable indication of the vulnerability of fresh water lenses can be obtained. A profound advantage is also, that parameters that co-vary (e.g. $L$ and $K$ in Figure 2.1f) are considered in their mutual dependency. Results as Figure 2.3 can then be used by water authorities and policy makers as first-step decision information.

\subsection{Modelling root zone}

As is already apparent from the previous sections, changes of precipitation and evapotranspiration affect the salinity of the shallowest groundwater that may enter the root zone by capillary rise if fresh water lenses disappear temporarily. This may introduce salts into the root zone. Though salinity has been investigated already for a long time (Richards et al., 1954, Bresler et al., 1982), the impact of erratic weather has not often been the focus.

Practically, a major problem is that weather can be predicted in a statistical sense (mean temperature, long term average rainfall), but actual weather may differ significantly from the average behaviour and is hardly predictable. It is nearly impossible to predict whether a year will be average, or dry or wet. However, for e.g. farmers and water managers, this type of information is crucial. For practice, it is important to deal with erratic weather, as it affects e.g. primary production (yield) and it is necessary to recognize the risk of crop failure.

To model soil, which is implied in predicting, the basis is usually the Richards' equation (for unsaturated water flow, see e.g. Kuhlmann et al. 2011) and the convection dispersion or CDE equation for salt transport. Despite improving hardware and data availability, combining these equations with e.g. GCM modelling of climate change is still a challenge. This is much less the case with the popular, though simplified, root zone 'bucket' approach, in which the root zone is assumed to be a perfectly homogenized (ploughed) soil layer (Rodriguez-Iturbe and Porporato, 2004).

Adopting this latter approach, taking into account the capillary upward flow from groundwater (Vervoort and van der Zee, 2008), the salt balance has been solved for the long term by Shah et al. (2011). Recently, this numerical analysis has been extended towards sodicity, which considers the relative accumulation of sodium in soil to levels where it may induce soil structure degradation (Bresler et al., 1982; van der Zee et al., 2014). Although soil sodicity is a long term threat to sustainable soil use because it is 
poorly reversible, we will not address this process in detail in this paper, to avoid duplication with the recent analysis using the model SODIC by van der Zee et al. (2014).

Due to the irregular rainfall and seasonal evapotranspiration, the root zone has periods of drought and of wetness. During drought, capillary rise of groundwater may replenish the root zone, while during wet periods, root zone water above the field capacity may readily drain. For different conditions, Shah et al. (2011) investigated how salt accumulates in the root zone if the groundwater is somewhat brackish. Likewise, Suweis et al. (2010) considered the situation where salt spray supplies salts to the root zone.

To give an impression of the impact of weather on salinity, we simulated water and salt balances. To efficiently simulate the water and salt balances, we adopted the approach of Vervoort and van der Zee (2008) and Shah et al. (2011), where a root zone was considered at some distance above the water table. Though the Netherlands are characterized by sufficient rainfall of about $800 \mathrm{~mm} \mathrm{y}^{-1}$, net recharge has a distinct seasonal variation, as evapotranspiration is mainly concentrated in the summer period. On average, net groundwater recharge is less than $1 \mathrm{~mm} \mathrm{~d}^{-1}$.

For Dutch conditions, it is quite well possible that groundwater at the water table is brackish, e.g. if fresh water lenses disappear in summer (De Louw et al., 2013, 2011). We considered a soil that initially is not saline. Due to alternation of rainfall and irrigation water entering the soil and of capillary rise of groundwater, the root zone will salinize to some degree. As demonstrated in earlier work (Shah et al., 2011; Suweis et al., 2010), this leads to irregular fluctuations of salt concentration (C) that builds up first and then stabilizes around a long term mean value. The resulting strongly erratic pattern of $C$ as a function of time, is a direct consequence of the erratic pattern of rainfall, irrigation, and other water balance terms. Therefore, this pattern as such is not tractable to real prediction. In a first assessment, it may be sufficient to assess the mean concentration around which $\mathrm{C}$ will vary through time, for comparison with the crop's tolerance. Such a first assessment was already developed much earlier (Richards et al., 1954), for the case that salts originate from brackish irrigation water. As its main concept, it used the socalled leaching requirement $(L R)$ given by

$L R=\frac{D_{d w}}{D_{i r r}}=\frac{\theta_{f c}}{\theta_{s p}} \cdot \frac{C_{i r r}}{C_{e}}$

written in terms of concentrations, instead of electrical conductivity as often used. In equation (2.6), $D$ is the quantity (in water layer thickness per year) of irrigation water applied (irr) and drainage water $\left(\mathrm{dw}_{\mathrm{w}}\right), C$ refers to the concentration of salts in irrigation water and in the saturated paste of soil (subscript $e$ ), and $\vartheta_{s p}$ and $\vartheta_{f c}$ are the volumetric 
water contents of the saturated paste and at field capacity $(\mathrm{pF}=2.5)$, respectively, and correspond with the water contents at the point of liquefaction and above which water drains due to gravity (Richards et al., 1954). The principle is that if the tolerance of a crop for salt is designated as $C_{e}$, then the leaching requirement tells us how much irrigation water excess for drainage is needed, to keep concentrations in this soil at this tolerance threshold. $L R$ is attractive, as it gives a simple and robust tool to predict salinity due to irrigation with water that contains some salts, in other words, it is simple tool to assess irrigation practice sustainability.

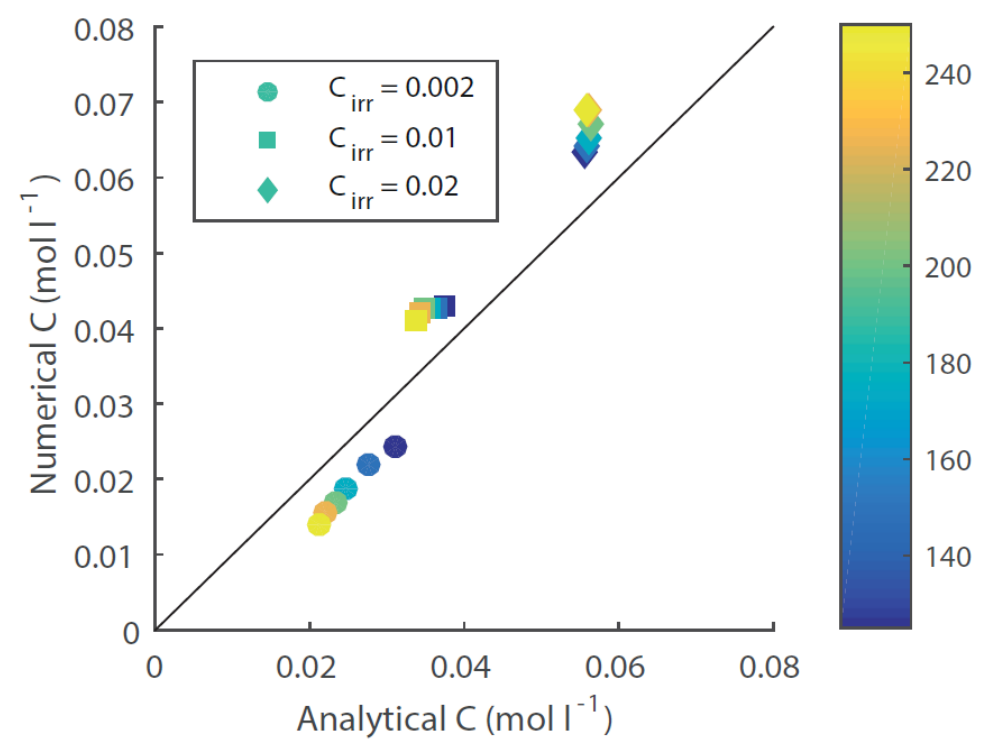

Figure 2.4 Root zone salt concentrations as modelled numerically for a root zone model, and as determined with the approximation of Eq. (2.8), for different groundwater levels $\left(Z_{f}\right.$ in $\mathrm{cm}$ below surface) indicated by the colour bar to the right, and a temperate climate as in The Netherlands. Irrigation water salinity given by $C_{\text {irr }}$ in $\mathrm{mol}^{1}$, and groundwater salt concentration of $0.02 \mathrm{~mol}^{1}$.

It is attractive to develop a similarly robust tool to predict salinity if salts originate from capillary upward flowing groundwater and erratic weather. Shah et al. (2011) investigated the long term salinity for a range of conditions, using the approach that has just been described. Using the same model SODIC, that was extended to account for sodicity, but for Dutch conditions, the long term average salt concentration was simulated numerically. It appeared that in its simplest form, if only groundwater is a source of salts, the long term root zone salinity can be estimated with

$\langle C\rangle=\frac{\left\langle D_{c r}\right\rangle}{\left\langle D_{d w}\right\rangle} C_{Z}$ 

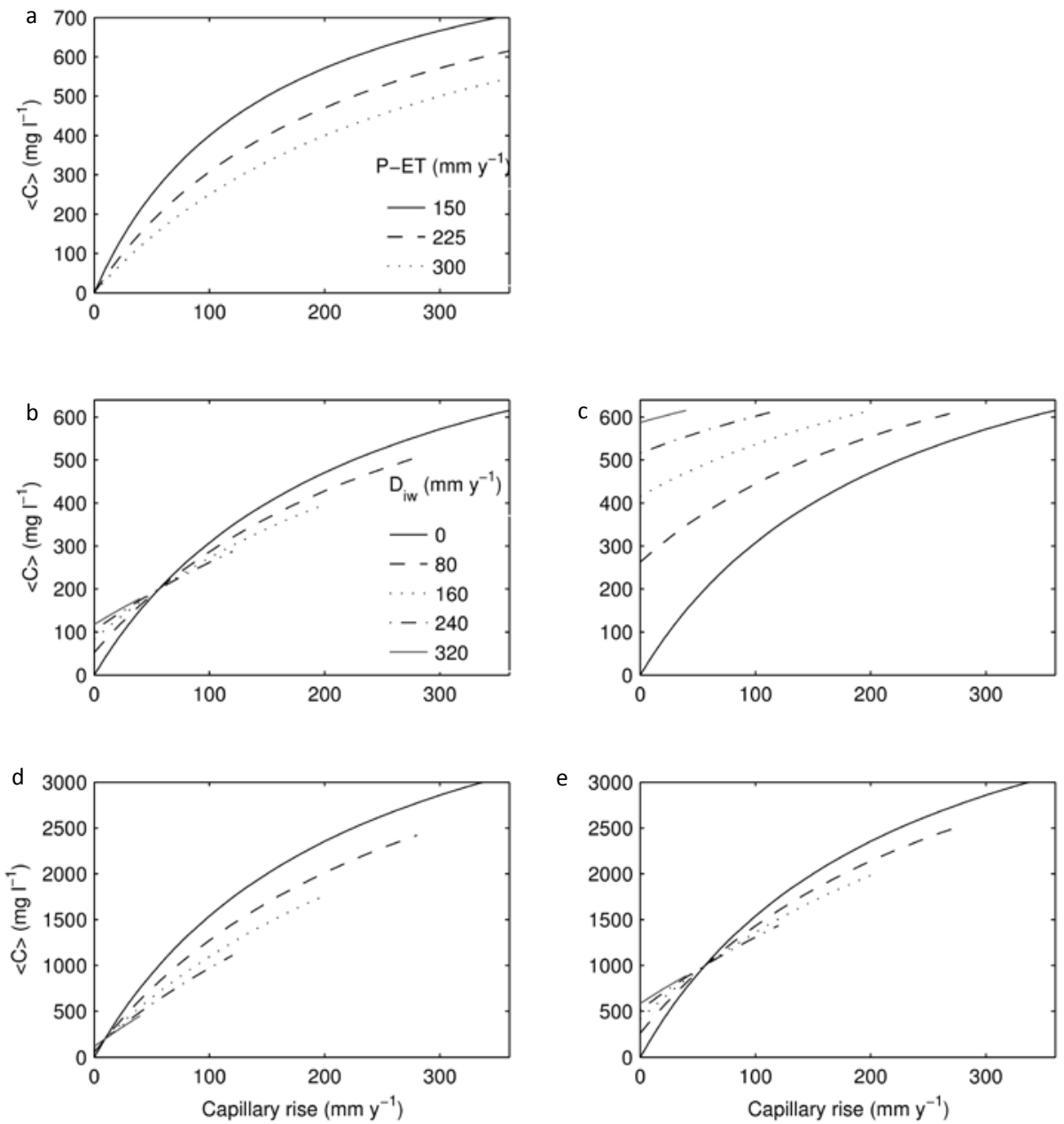

Figure 2.5 Average salt concentrations as calculated by Eq. 2.8. Drainage $\left(D_{d w}\right)$ is calculated as the sum of the precipitation surplus (P-ET), capillary rise $\left(D_{c r}\right)$ and irrigation $\left(D_{\text {irr }}\right)$. a. The effect of precipitation surplus on the average salt concentration as a function of capillary rise, in a situation without irrigation and a groundwater chloride concentration of $1000 \mathrm{mg} \mathrm{r}^{-1}$. b.-e. show the effect of irrigation on the average chloride concentration as a function of capillary rise. A precipitation surplus of $225 \mathrm{~mm} \mathrm{y}^{-1}$ is assumed and

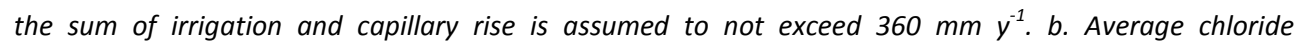

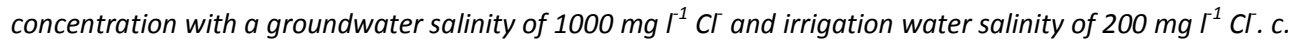
Average salt concentration with a groundwater salinity of $1000 \mathrm{mg} \mathrm{I}^{-1} \mathrm{Cl}$ and irrigation water salinity of $1000 \mathrm{mg} \mathrm{l}^{-1} \mathrm{Cl}$. d. Average salt concentration with a groundwater salinity of $5000 \mathrm{mg} \mathrm{l}^{-1} \mathrm{Cl}_{\text {and irrigation }}$ water salinity of $200 \mathrm{mg} \mathrm{I}^{1} \mathrm{Cl}$. e. Average salt concentration with a groundwater salinity of $5000 \mathrm{mg} \Gamma^{-1} \mathrm{Cl}$ and irrigation water salinity of $1000 \mathrm{mg} \mathrm{I}^{-1} \mathrm{Cl}^{-}$. 
where brackets <.> denote time-average, $D_{c r}$ stands for capillary rise flux of groundwater, $D_{d w}$ is the drainage water flux, and the phreatic groundwater concentration is $C_{Z}$.

In many agricultural regions, besides precipitation, both groundwater and irrigation water are used for evapotranspiration. Therefore, we take the result of Shah et al. (2011) as a point of departure to consider the case where irrigation water has a distinct salt concentration $C_{i r r}$, but also groundwater is (somewhat) saline. We consider a clayey soil covered with grass, with different groundwater levels below soil surface $\left(Z_{f}\right)$ in the range $100 \mathrm{~cm}<Z_{f}<250 \mathrm{~cm}$ and a root zone thickness of $25 \mathrm{~cm}$. By using the reasoning that resulted in (2.7), we obtain in analogy the following result

$\langle C\rangle=\frac{\left\langle D_{c r}\right\rangle C_{Z}+\left\langle D_{i w}\right\rangle C_{i r r}}{\left\langle D_{d w}\right\rangle}$

This expression, that ignores short term fluctuations, agrees quite well with numerical results, and only has a small systematic bias as can be seen from Figure 2.4.

Figure 2.5 illustrates the long-time average salt concentrations under various Dutch conditions as calculated with (2.8), assuming capillary rise of (moderately) saline groundwater after (partial) disappearance of a fresh water lens. Average salt concentrations do not exceed groundwater concentrations due to dilution (precipitation surplus, Figure 2.5a), although in practice, the concentrations would vary seasonally. The salinizing effects of capillary rise (during seasonal precipitation deficit, assuming no reduction of evapotranspiration) may be mitigated by irrigating with water that has a lower salt concentration than the average concentration that would have occurred without irrigation (Figure $2.5 \mathrm{~b}, \mathrm{~d}, \mathrm{e}$ ). Moreover, it should be noted that irrigation lead to decreased capillary rise as well, adding to the mitigating effect. If however, the concentration of irrigation water is equal to the groundwater salinity, irrigation leads to increased long-term average concentrations (Figure 2.5c).

More refined predictions of long term root zone concentrations can be made, based on projected future rainfall intensities and evapotranspiration demand. At this moment, it is not yet clear whether such predictions have to account for the travel time of capillary upward moving water and salt, and the probability that saline water is leached before it reaches the root zone, by incidental rainfall showers. 


\subsection{Summary and conclusions}

In managing fresh water scarcity and salinity in the deltaic areas, which may grow in importance due to climate change and related sea level rise, modelling of the behaviour of shallow fresh water lenses in relation to increased root zone salinities is an important tool to help us anticipate possible chances in primary food production. To be of use, models have to be aligned with experimental results, i.e., be properly parameterized. A main issue is that a proper assessment must be made of how crops respond to salinity. Despite that this has been under investigation for decades, quite basic issues such as compensation behaviour of plants in dealing with drought and salt stress are still frontiers in our science (Javaux et al., 2008; Kuhlmann et al., 2012).

Despite the recognition of scientific gaps in knowledge, for managing our resources, a robust prediction of broad features may be sufficient these coming decades. An example is given by predicting the persistency of fresh water lenses in saline, shallow groundwater situations such as in deltaic areas. Numerical modelling by Eeman et al. $(2011 ; 2012)$ revealed that analytical solutions of e.g. Maas (2007) describe the mean depth of the fresh/salt transition zone pretty well. With some approximations that are also founded on a good agreement with numerical simulations, we can judge also the thickness of the fresh water lens above the fresh/salt transition zone. In combination, this resulted in an assessment of the combination of factors for which fresh water lenses may disappear in drier summers as predicted for climate change on the European sub-continent. It appears that in practice, fresh water lenses have to be very thin or subject to large mixing at the interface to be threatened to disappear completely. However, near draining ditches or gullies, the risk may be larger as lens thickness decreases significantly in their vicinity.

Based on numerical models and available spatially distributed data from different sources, a relatively straightforward data assimilation is possible towards the vulnerability of fresh water lenses to temporarily disappear. Such an assessment was done for the Dutch coastal region, and this may provide a basis for later, more detailed predictions.

If the shallowest groundwater becomes brackish or saline, this can cause the root zone to become saline due to capillary rise of marginal water. With simulations that account for erratic aspects of weather, notably rainfall, it is possible to investigate the root zone salinity as a function of different factors such as vegetation or crop, root zone thickness, groundwater depth, and climate. Typically, this leads to a salt concentration that fluctuates much as a function of time. To predict which concentrations in root zone develop on the longer term, two very simple approximations (2.7) and (2.8) are presented that reproduce the main features obtained with detailed numerical simulations pretty 
well. Accordingly, the concept of Leaching Requirement, that has proven its use for practical soil water and salinity management during the last 7 decades, has been extended to more complex situations. However, despite the promise of the good agreement between numerical simulations and these approximations, it is necessary to confirm the applicability with experimental evidence. If that leads to favourable results, a very useful management tool is the result.

\section{Acknowledgements}

This research was funded by the Dutch Knowledge for Climate Program, Theme 2 Fresh Water Availability as well as the program WaterNexus, funded by the Technology Foundation of the Netherlands STW/NWO. 


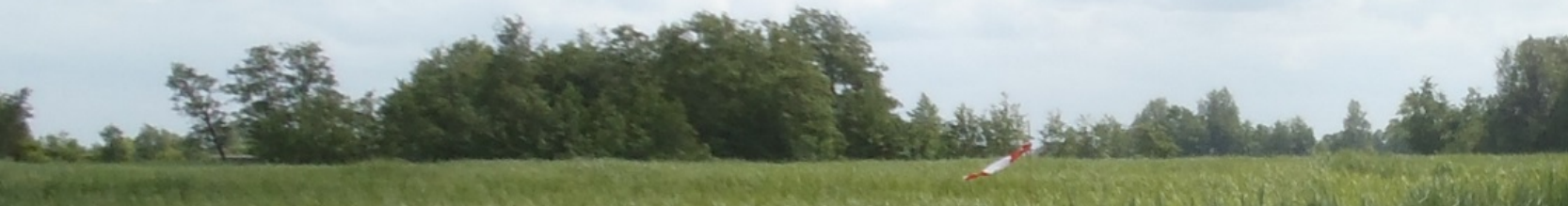

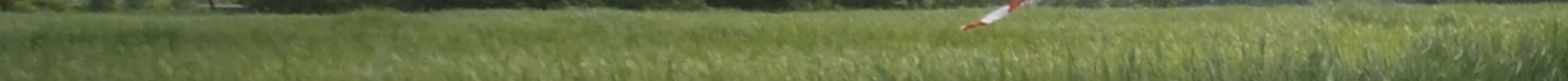




\section{Effects of root mat buoyancy and heterogeneity on floating fen hydrology}

\section{Based on:}

Stofberg, S.F., van Engelen, J., Witte, J.-P.M., van der Zee, S.E.A.T.M., 2016. Effects of root mat buoyancy and heterogeneity on floating fen hydrology. Ecohydrology 9, 12221234.

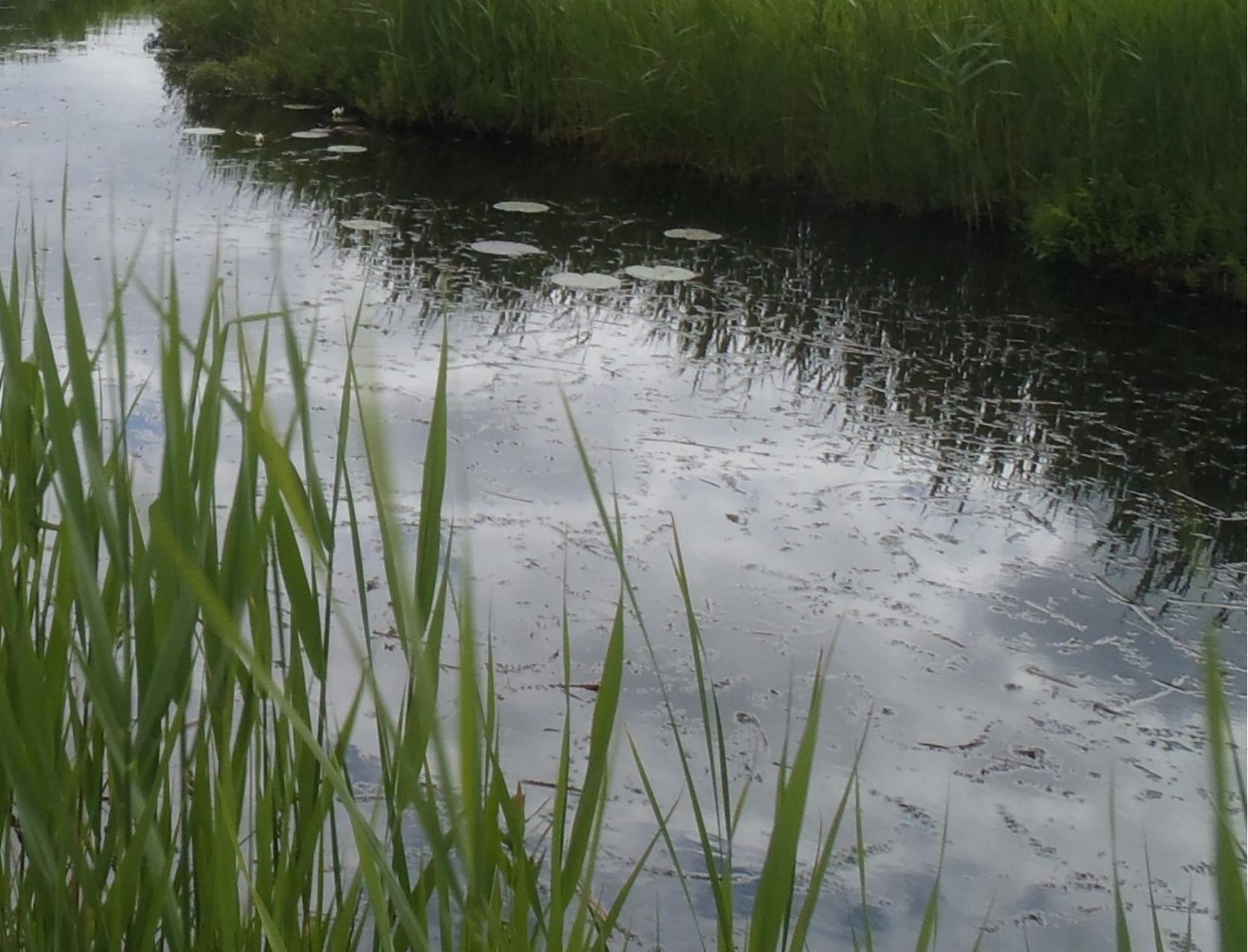




\begin{abstract}
Floating fen ecosystems are home to several protected habitats and species. Their development and conservation requires special attention regarding water management. Although they are known to be heterogeneous and partially buoyant, their root mats are simulated in hydrological models as homogeneous, static systems. The objective of this study is to quantify root mat heterogeneity and buoyancy and to assess their effects on groundwater flow and transport, and to determine if these factors need to be taken into account in modelling.
\end{abstract}

We conducted field measurements of root mat heterogeneity and buoyancy in the 'Nieuwkoopse Plassen', the Netherlands. We found that hydraulic conductivity varied over four orders of magnitude and negatively correlated with degree of decomposition, resulting in a zonation of high conductivity near the surface and low conductivity in the deeper layers. Also, we found that the root mat moved vertically with the surface water. It became more buoyant with higher temperatures, but less buoyant with increasing groundwater levels relative to the surface.

We implemented the findings in a semi-steady state hydrological model of a floating fen to compare the effects with other parameters. The profound heterogeneity had a limited effect on the water budget, but a clear effect on the flow lines and thus should be taken into account when modelling transport processes in floating fens. Although buoyancy affected the relative groundwater level near the root mat edge, it did not affect the water budget or the flow lines and may therefore be neglected in water budget modelling. 


\subsection{Introduction}

Floating fens are ecosystems that are found in deltas, lakes and inundated areas in many parts of the world, including Europe (e.g. Somodi \& Botta-Dukát, 2004), America (e.g. Sasser et al, 1995; Dubroeucq \& Volkoff, 1998; Bayley \& Mewhort, 2004), Africa (e.g. Ellery et al, 1990; Azza et al, 2006), and Oceania (e.g. Southern et al, 1986; Gippel, 1993). These wetlands, consisting of floating root mats, are an important resource of habitats, and are often protected as nature reserves, e.g. under the European Habitats Directive.

In lowland fen regions of Europe, including England, France, Germany and the Netherlands, floating fens are found in abandoned turf ponds, in which macrophytes formed root mats attached to baulks. In these regions, the hydrology has often been strongly affected by drainage for agricultural purposes, while the surface water became more enriched with nutrients. European policies that were introduced in the past decades (Habitats Directive and Water Framework Directive) require that the water management is optimised for the various functions. Since then, various publications have focused on identifying factors that may threaten fens, as well as conservation and restoration practices (e.g. Pfadenhauer \& Grootjans, 1999; McCartney \& de la Hera, 2004; Mälson et al, 2008; Meissner et al, 2008). Floating fens in particular are threatened by desiccation and insufficient water quality (Boar et al, 1989; Smolders et al, 2006; Lamers et al, 2014; van Diggelen et al, 2014). Their management often focuses on hydrological restoration, as well as various measures to slow down natural succession (Bootsma et al, 2002; van Diggelen et al, 2015).

Understanding root mat hydrology is essential to successful management of floating fens. Although much literature is available about fen management and restoration with a focus on biogeochemistry and ecology (e.g. van Belle et al, 2006; Cusell et al, 2013; van Diggelen et al, 2015), few studies have examined root mat hydrology. Therefore, it is not yet clear which properties of floating fens are the most important in modelling these systems.

Van Wirdum (1990) studied the hydrology of root mats in the Stobbenribben area in the Netherlands, and showed that during dry weather a hydraulic head gradient can be found between the open water and the root mats, resulting in lateral flow into the root mat. With his QUAGSOLVE model he simulated the lateral flow and transport of tracers in the 'preferential flow channel' under the root mat and vertical exchange between this channel and the root mat in steady state situations. He showed that not only the interaction between the atmospheric and surface water boundaries affected this flow, but that subsurface seepage is also a driver of transport of solutes below the root mat. 
Koerselman (1989) studied the hydraulic conductivity and water budgets of a floating fen in the Vechtplassen area, the Netherlands, and observed lateral flow between the ditch and the fen as well. He found that point measurements of hydraulic conductivity deviated significantly from those estimated by water budgets, and suggested that this may be related to strong heterogeneity. He also noted the buoyancy of the root mat, which was confirmed by the correlation between water levels and mat elevation.

As more advanced software became available, it became possible to simulate flow and transport in a more detailed way. Dekker et al (2005) simulated flow and conservative solute transport using a 2D numerical model of a root mat in the Ilperveld area, the Netherlands. They used literature parameters, which they calibrated to EC measurements. Their calibration results suggested anisotropy (horizontal conductivity / vertical conductivity $<1$ ), which they linked to the presence of a living moss layer and absence of layering of decomposed material. However, their work focused more on management options than flow and transport patterns.

Floating fens may develop through terrestrialization (water bodies become peatland through ecological succession) as root mats expand horizontally into the open water and accumulate new organic matter over time. As a result, older parts of the root mat may contain more decomposed material than the young edges. Hydraulic conductivity has been shown to negatively correlate with degree of decomposition, most often observed in bog peats (Rycroft et al, 1975; Grover \& Baldock, 2013), which has been explained by the decrease of the average pore size as a result of decomposition processes (Quinton et al, 2008; Morris et al, 2011). Hydraulic conductivity of root mats has been estimated or measured by several authors, and varies from 1 to over $75 \mathrm{~m} \mathrm{~d}^{-1}$ (Koerselman, 1989; van Wirdum, 1991; Baird et al, 2004), but significant differences in hydraulic conductivity within different parts of root mats have not been reported. Such differences would cause the older, further developed parts of the root mat to be less influenced by the surface water boundary with its relatively constant water levels, leading to stronger groundwater fluctuations as a result of atmospheric forcing. In turn, stronger groundwater level fluctuations may stimulate decomposition, thus enforcing this pattern.

Root mat material has a relatively low density, causing it to float, as it mainly consists of organic tissue and rhizomes with aerenchyma. This buoyancy may be very limited, partial or complete (direct vertical movement with the water table), depending on the type of material (Swarzenski et al, 1991). It may also depend on physical attachment to fixed soil, e.g. baulks, as mentioned by van Wirdum (1991), who observed root mats following 30$90 \%$ of the surface water level. Peat buoyancy depends on the formation of gas bubbles as well (Strack et al, 2005), which is thought to be of more importance in older, relatively 
thick root mats (Hogg \& Wein, 1988). As microbial processes and solubility of methane vary with temperature, buoyancy is expected to be stronger at the end of summer, which would result in seasonal patterns in groundwater level. On smaller timescales, gas bubbles in peat expand with drops in atmospheric pressure (Tokida et al, 2005), which could cause fluctuations in buoyancy as well. The buoyant behaviour may affect water flow within the root mat. As root mats move vertically with the surface water level, gradients between root mat and surface water would become smaller, causing the groundwater level relative to the root mat surface to be relatively stable.

From the described literature, especially the work of van Wirdum (1991), it became clear that three boundaries control flow and transport within root mats: (1) the relatively stable surface water, in which most of the root mat floats, (2) the variable atmospheric boundary and (3) the subsurface boundary where groundwater seepage or recharge occurs. Heterogeneity and buoyancy may play a role as well, although these have not been quantified.

The first objective of this paper is to quantify the heterogeneity of root mat hydraulic conductivity, as well as its buoyancy. The second objective is to determine if and how heterogeneity and root mat buoyancy must be taken into account when modelling flow and transport within the root mat. To achieve these objectives, we conducted field and laboratory measurements of root mat heterogeneity and buoyancy, and made a numerical model, simulating flow and transport within root mats. We compare model outcomes of the basic model that assumes a homogeneous, static root mat with outcomes of simulations with heterogeneous and buoyant root mats.

\subsection{Methods}

\subsubsection{Study site description}

The study site was located at the Natura 2000 nature reserve Nieuwkoopse Plassen, the Netherlands, at coordinates $52^{\circ} 8^{\prime} 49.56^{\prime \prime} \mathrm{N}$ and $4^{\circ} 48^{\prime} 51.67^{\prime \prime} \mathrm{E}$. The temperate maritime climate has yearly temperature averages between $3^{\circ} \mathrm{C}$ and $18^{\circ} \mathrm{C}$, with average yearly precipitation of $825 \mathrm{~mm} \mathrm{y}^{-1}$ and evapotranspiration of $580 \mathrm{~mm} \mathrm{y}^{-1}$ (KNMI, 2015). The landscape consists of turf ponds in which terrestrializing plant communities have formed floating mats, consisting of roots and organic material. As the surrounding areas have been intensively drained for agricultural purposes, causing the surface to subside, the Nieuwkoopse Plassen is relatively elevated in the landscape. The subsoil had a low conductivity, with thick peat (detritus, humified woody peat and Phragmites peat layers, 
Figure 3.1c) and clay layers (> $4.3 \mathrm{~m}$ depth), in which water infiltrates at a rate of $0.6 \mathrm{~mm}$ $\mathrm{d}^{-1}$, as estimated by a water balance (Zaadnoordijk \& Soetens, 2008).

On the root mats, different vegetation zones parallel to the edge with the surface water could be clearly distinguished. Such a zonation in floating fens is usually thought to be caused by hydrological processes that result in local differences in abiotic conditions, such as $\mathrm{pH}$, as well as water and nutrient availability (van Wirdum, 1990; van Diggelen et al, 1996). The first few meters of the edges had an estimated cover of $60-70 \%$ with higher plants, including root mat builders such as Typha angustifolia, Thelypteris palustris, Phragmites australis and Cladium mariscus, as well as many smaller species, including Juncus subnodulosus, Succisa pratensis and Carex paniculata. The moss layer $(70-80 \%$ cover) of the edges included Sphagnum palustre, Calliergonella cuspidata and Dicranum bonjeanii. In this zone, the root mat was relatively thin $(0.2-0.6 \mathrm{~m})$ and consisted mainly of roots and rhizomes, of which especially the Thelypteris and Phragmites rhizomes were easily recognized (Figure 3.1a).

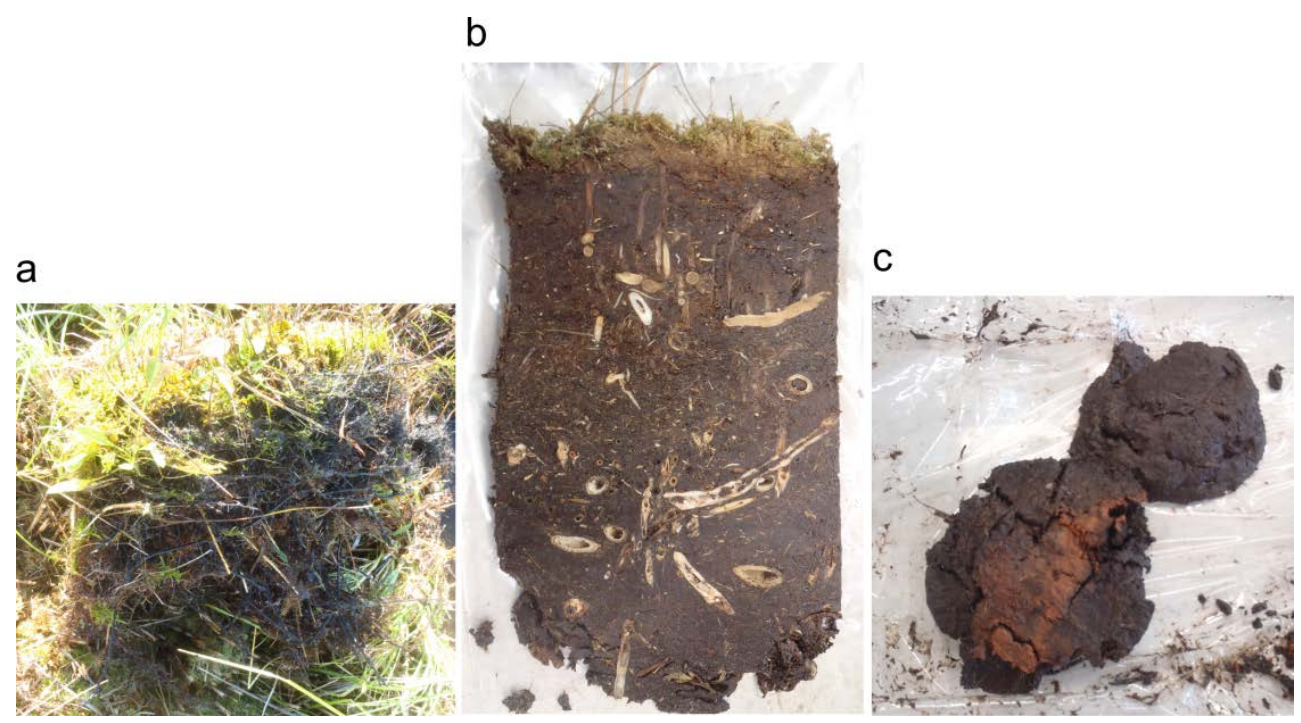

Figure 3.1 Photographs of the root mat and subsurface materials. a. Fibrous material from the edge of the root mat with black Thelypteris roots. b. Material from the fixed part of the root mat with moss, roots, more humified peat and light coloured Phragmites rhizomes. c. Humified peat from the subsurface, the red woody material is probably Alnus.

Further from the edge, in the middle of the field, we found less diverse vegetation. The higher plants covered about $25-75 \%$ of the area, including Phragmites australis, Erica tetralix, Eriophorum angustifolium and Drosera rotundifolia. In the moss layer (about 7090\% cover) of this zone, Sphagnum palustre and Sphagnum papillosum were abundant. The root mat in this zone was relatively thick, and consists of roots, moss and Phragmites 
rhizomes as well as more humified organic matter (Figure 3.1b). Despite some minor differences in species composition, these vegetation zones and root mat structures were found throughout the study site, without striking visible differences.

$\mathrm{pH}\left(\mathrm{H}_{2} \mathrm{O}\right)$ varied from 6.8 in the surface water to 4.0 in the shallow groundwater in the root mat (measured 12 March 2012). Vegetation height varied from $2.1 \mathrm{~m}$ at the edge to $0.4-$ $0.5 \mathrm{~m}$ in the ombrotrophic zone (measured July 2013). Aboveground dry biomass was 658 $\mathrm{g} \mathrm{m}^{-3}$ ( \pm SD $210 \mathrm{~g} \mathrm{~m}^{-3}$ ), without significant differences between vegetation zones (measured July 2013). The vegetation was managed by summer mowing, which took place in August-September, although this was not done for a radius of about $1 \mathrm{~m}$ around the measurement locations that are described in the next sections.

\subsubsection{Material characterization}

Soil samples were taken from three transects (sampling transects ST1, ST2 and ST3) that were perpendicular to the root mat edge. On each transect, five locations were sampled (Figure 3.2a), until a depth of about $1.2 \mathrm{~m}$ or the end of the root mat, using a fen peat sampler with a diameter of $10.4 \mathrm{~cm}$ (van Asselen \& Roosendaal, 2009), which was combined with a peristaltic pump to ease sample extraction. Samples were removed from the PVC cylinder and wrapped in plastic wrap and stored at $3^{\circ} \mathrm{C}$ until analysis. They were analysed for volumetric water content $\left(\vartheta_{s}\right)$, bulk density $\left(\rho_{\text {bulk }}\right)$, material density $\left(\rho_{\text {material }}\right)$ and loss on ignition (LOI). Table 3.1 lists the symbols of the used variables and parameters and their units. As the removal from the cylinder caused some drying and smearing of the outside of the samples, the nearly saturated samples were wetted with deionized water and cut into subsamples using an electric bread knife to prevent compression. Two large subsamples (about $300-500 \mathrm{~cm}^{3}$ ) and five smaller subsamples were weighed and dried at $60^{\circ} \mathrm{C}$ for five days, after which dry weight was determined. The two large subsamples were used to determine gravimetric water content. Volume of the five smaller subsamples was determined from the average of three volume measurements using an air pycnometer (Gerhardt, Germany). Density of the soil material was calculated from the dry mass and volume. Total volume of solids and water was calculated using the measured solid volume and mass and density of water, which was in turn used to calculate volumetric water content.

Degree of decomposition was determined in the field at each sampling point, for every 10 $\mathrm{cm}$ of depth until $2 \mathrm{~m}$, using the Von Post (VP) classification method as translated by Stanek \& Silc (1977). Small samples of soil were obtained from the edges of the sampling 
boreholes by hand or auger. In further analysis, the ranked scale of Stanek \& Silc (1977) is used, to account for the relative distances between the classes.

a.

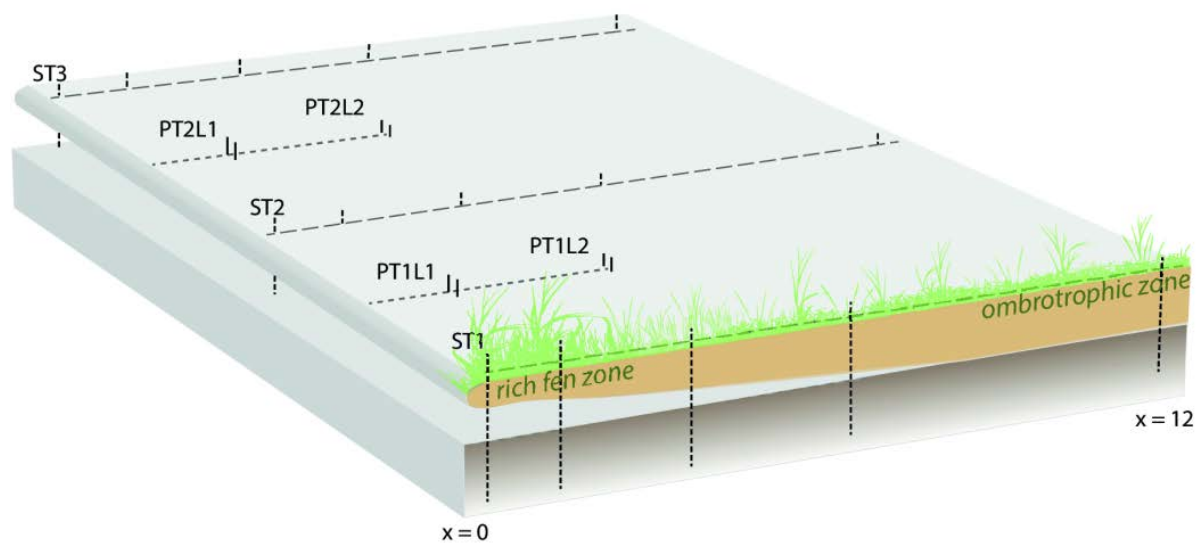

b.

\begin{tabular}{|l|l|}
\hline Water layer & Root mat \\
\hline & Subsoil \\
\hline
\end{tabular}

Figure 3.2 a. In colour: Schematic cross section of a floating fen root mat, as found at the field site, with rich-fen vegetation at the edges and vegetation related to ombrotrophic conditions where the root mat is fixed to the subsurface. In greyscale: Schematic overview of the field site. At sampling transects ST1, ST2 and ST3, slug tests were performed and samples were taken at 0.5, 1.5, 3.5, 6.5 and $12 \mathrm{~m}$ from the root mat edge. At piezometer transects PT1 and PT2, pairs of piezometers were installed at 2 locations $L 1$ and $L 2$, at 1.5 and 4 meters from the edge, respectively. $b$. Model schematization $(15 \times 3.1 \mathrm{~m})$, with the atmospheric boundary (green), surface water (blue), and subsurface fixed head boundary (red).

Table 3.1. List of symbols of variables and parameters and their units.

\begin{tabular}{lll}
\hline Symbol & Description & Unit \\
\hline$G W L_{r}$ & Groundwater level relative to root mat surface & $\mathrm{cm}$ \\
$K_{s}$ & Saturated hydraulic conductivity & $\mathrm{m} \mathrm{d}^{-1}$ \\
$L O I$ & Loss on ignition & $\mathrm{g} \mathrm{g}^{-1}$ \\
$S W L$ & Surface water level & $\mathrm{cm}$ \\
$T$ & Groundwater temperature & ${ }^{\circ} \mathrm{C}$ \\
$V P$ & Degree of decomposition on Von Post scale & - \\
$\Delta p_{a}$ & Change in atmospheric pressure & $\mathrm{Pa}$ \\
$\vartheta S$ & Volumetric water content & $\mathrm{cm}^{3} \mathrm{~cm}^{-3}$ \\
$\rho_{\text {bulk }}$ & Bulk density & $\mathrm{g} \mathrm{cm}^{-3}$ \\
$\rho_{\text {material }}$ & Material density & $\mathrm{g} \mathrm{cm}^{-3}$ \\
\hline
\end{tabular}




\subsubsection{Hydraulic conductivity}

We measured saturated hydraulic conductivity $\left(K_{s}\right)$ in situ using the piezometer method by Baird et al. (2004). Measurements were done at five locations in each of the three sampling transects (ST1, ST2 and ST3), at depths of $0.25,0.5,1$ and $1.5 \mathrm{~m}$ (Figure 3.2a), using PVC piezometers with a diameter of $4 \mathrm{~cm}$ and filters of $7 \mathrm{~cm}$ length. Pressuretemperature loggers (van Essen Instruments, Delft, Netherlands) measured water levels at intervals of 1 or $10 \mathrm{~s}$, depending on the expected rate. At each measuring point, at least three tests were performed, with subsequent withdrawal and insertion of water. Measurements that were made in the water layer under the root mat were discarded. Results were analysed according the Hvorslev method as described by Baird et al (2004) using MATLAB (MathWorks, Natick, MA, USA). The results were corrected for temperature effects on viscosity, resulting in an estimate for $K_{s}$ at $10^{\circ} \mathrm{C}$.

Statistical analysis was conducted with SAS (Cary, NC, USA) statistical software. Pearson correlation coefficients were calculated for each measured soil variable: $V P, \vartheta_{s}, \rho_{\text {bulk, }}$ $\rho_{\text {material }}$ and LOI. Results of the $K_{s}$ measurements were transformed to a log scale to reach a symmetric distribution and then analysed using a mixed regression model. The measurement location (transect*distance*depth) was used as a random variable, while degree of decomposition was a fixed variable.

As VP was known at a finer resolution than $K_{s}$, we used the results of the mixed regression model to create a two dimensional $K_{s}$ field. Ordinary kriging was used to interpolate the degree of decomposition, assuming a relatively strong autocorrelation in the horizontal direction. This was done for each transect separately and the average of the three transects together. The solution of the mixed regression model was then used to plot a $K_{s}$ field.

\subsubsection{Root mat buoyancy}

To assess vertical movement of the root mat, we measured groundwater levels in two ways: absolute level and the level relative to the root mat surface. The difference between these two measurements is equal to the vertical movement of the root mat, provided that the measurements are taken close enough to each other to assume the same groundwater level. Piezometers were installed in pairs, a short and a long one, about 0.2 $\mathrm{m}$ apart, in two transects (PT1 and PT2) at locations $\mathrm{x}=1.5$ and 4 meters from the surface water (Figure 3.2a). The long piezometers were installed into the subsurface, reaching a clay layer at about $5 \mathrm{~m}$ depth. We assumed these piezometers to be fixed in the 
subsurface, not moving vertically with the root mat. The short piezometers were fixed into the root mat, using thin metal rods. We assumed these piezometers to move vertically with the root mat. For both piezometers types, filters were located within the root mat, capturing groundwater level changes. Additionally, we installed piezometers in the fixed part of the root mat (at $x=12 \mathrm{~m}$, Fig. 3.1a), to observe groundwater fluctuations for model calibration purposes. Pressure-temperature loggers (van Essen Instruments, Delft, Netherlands) were installed and logged every 15 minutes between June 2012 to February 2014. For the same time interval, surface water levels were measured using a piezometer and pressure-temperature logger in the surface water besides the root mat. Air pressure was measured using an on-site barometric pressure logger, which was used to correct piezometer measurements for atmospheric pressure.

Data were processed using MATLAB (MathWorks, Natick, MA, USA). We compared linear models of vertical movement using different combinations of independent variables, which were: surface water level $(S W L)$, local groundwater temperature $(T)$, relative groundwater level $\left(G W L_{r}\right.$, relative to the root mat itself, as measured by the short piezometer) and change in atmospheric pressure during the past measurement interval $\left(\Delta p_{a}\right)$. The effect of surface water level would indicate buoyancy itself, while temperature effects would indicate seasonal variation, that may be related to gas production, but also to other seasonal variations, including standing crop biomass, moisture content above the water table and aerenchyma air content. An effect of the relative groundwater level would indicate an effect of mass changes within the root mat on its buoyancy. An effect of air pressure change could be related to gas bubbles expanding due to decreased atmospheric pressure.

\subsubsection{Hydrological model}

We started with a basic model of a floating fen, that had a homogeneous $K_{s}$, non-buoyant root mat. With this model we conducted a sensitivity analysis, by varying the most important model components. After that, we conducted simulations with a heterogeneous $\mathrm{K}_{\mathrm{s}}$ field and a buoyant root mat, respectively, which allowed us to assess the sensitivity to these factors compared to the other model components. All of these simulations were conducted for typical winter (average $P-E T=2.5 \mathrm{~mm} \mathrm{~d}^{-1}$ in December) and summer conditions ( $P-E T=-1 \mathrm{~mm} \mathrm{~d}^{-1}$ in June) (KNMI, 2015).

We used Hydrus 2D/3D (PC-Progress, Prague, Czech Republic) to develop the model of the floating fen system. As the software has no steady-state simulation mode, we chose to conduct semi-steady state simulations (with constant boundary conditions over 1000 
days), in order to limit the number of analyses and to avoid having to simulate a dynamic domain (in case of buoyancy), which would require custom-made software.

A schematic model of a floating fen system including subsurface was created (Figure 3.2b). Element sizes varied from $3.5-5 \mathrm{~cm}$ in the root mat to $8-10 \mathrm{~cm}$ in the subsurface. Hydraulic conductivities were based on the results of field measurements, except for the conductivity at the lower boundary, which was used together with the fixed head boundary as a Cauchy boundary, to result in a recharge of $0.6 \mathrm{~mm} \mathrm{~d}^{-1}$ in average conditions $\left(P=1 \mathrm{~mm} \mathrm{~d}^{-1}\right)$. The hydraulic conductivity of the water layer under the root mat was given a large value of $1000 \mathrm{~m} \mathrm{~d}^{-1}$ (van Wirdum, 1990), as it was too large to measure using slug tests. Root water uptake was distributed evenly throughout the root mat. The diffusion coefficient was $1.2 \mathrm{~cm}^{2} \mathrm{~d}^{-1}$, longitudinal dispersivity was $5 \mathrm{~cm}$ and transversal dispersivity was $1 \mathrm{~cm}$. For each parameter set, simulations were done for wet $(P=2.5$ $\left.\mathrm{mm} \mathrm{d}^{-1}, E T=0 \mathrm{~mm} \mathrm{~d}^{-1}\right)$ and dry $\left(P=0, E T=1 \mathrm{~mm} \mathrm{~d}^{-1}\right.$, which was implemented as $E=0.1 \mathrm{~mm}$ $\mathrm{d}^{-1}, T=0.9 \mathrm{~mm} \mathrm{~d}^{-1}$ ) scenarios.

The sensitivity analysis of the basic model was done by increasing and decreasing the following parameters by $25 \%$ and $50 \%$ : net atmospheric flux $(P-E T)$, lower boundary head and root mat $K_{s}$.

For the heterogeneous model, the $K_{s}$ field that resulted from the field measurements was incorporated in the root mat part of the basic model in the form of scaling factors. We calibrated the $K_{s}$ value of the root mat, such that the difference between the wet and dry scenarios was similar to the observed differences in wet and dry conditions. Homogeneous root mat $K_{s}$ fields were calibrated to result in the same groundwater levels at $x=15 \mathrm{~m}$ (right edge of the model) as the heterogeneous field, to be able to compare between these simulations.

We investigated buoyancy by focusing on the differences between non-buoyant and buoyant domains under different surface water level conditions. We conducted simulations of typical and extreme surface water levels, that rise during wet conditions and drop under dry conditions. The values used for this simulation were based on field measurements of surface water level fluctuations. The simulations were done for a nonbuoyant case (static root mat) and for the case where the floating part (left side in Figure 3.2) moves up and down with the surface water level, while the fixed part (right side in Figure 3.2) does not. The tolerated movement of the floating part was based on field measurements, and the amplitude of this movement decreases linearly to zero from left to right. For all simulations, we compared the effect on the extreme values of the groundwater level relative to the surface in the floating part of the root mat, groundwater 
level in the fixed part of the root mat, and the flow at each boundary. As the root mat may be buoyant, relative groundwater level is a more useful parameter than absolute groundwater level. To assess the effect on transport patterns within the root mat, we visually compared the flow lines that resulted from each simulation.

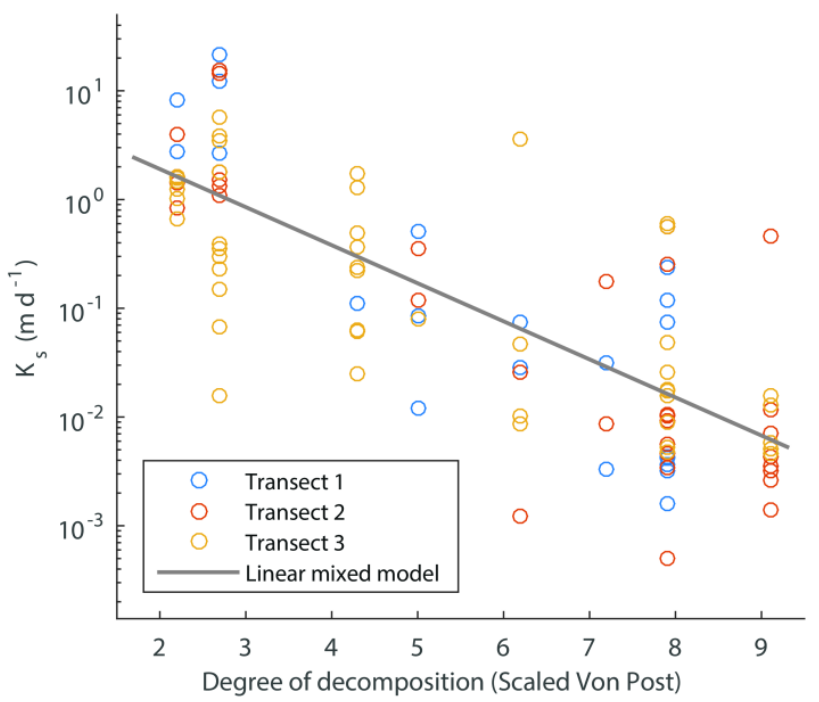

Figure 3.3 Saturated conductivity over degree of decomposition. Open circles: observations, line: mixed effects model, $\log 10\left(K_{s}\right)=0.98-0.35 \mathrm{VP}, d f=45, P<.0001$.

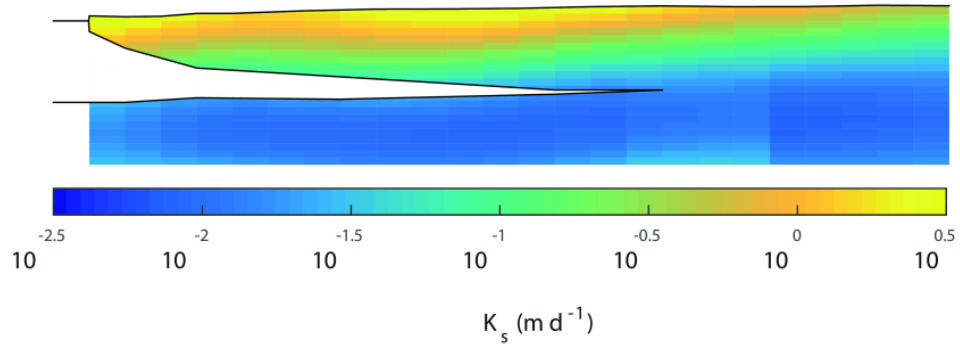

Figure 3.4 Estimated saturated conductivity in a cross section of a root mat.

\subsection{Results}

\subsubsection{Root mat heterogeneity}

Visual inspection in the field showed large differences between young and old peat material, particularly regarding colour and texture. Degree of decomposition varied between $\mathrm{H} 2$ and $\mathrm{H} 9$ on the Von Post scale, with a low degree of decomposition at the root 
mat edges and high degrees of decomposition in the subsurface. Table 3.2 shows the results and correlations between the variables that were measured in each soil sample. Most samples were highly organic and had high water contents and low densities. Two soil samples from the fixed part of the root mat $(x=12 \mathrm{~m}, 0.3-0.5 \mathrm{~m}$ below surface) were found to contain a clayey layer, and therefore showed values that differed strongly from the other columns. Increasing degree of decomposition correlated with increasing densities, lower LOI and volumetric water content.

Slug tests, after discarding measurements from under the root mat, provided 103 conductivity measurements on 47 locations within the transects. The Hvorslev plots showed small deviations of loglinearity, no corrections were made for this. Hydraulic conductivity varied over several orders of magnitude $\left(10^{-3}-10^{1} \mathrm{~m} \mathrm{~d}^{-1}\right)$, and the mixed regression model showed a decreasing trend with degree of decomposition (Figure 3.3). The $K_{s}$ field that resulted from the interpolation of VP values showed high conductivities at the root mat edges that decreased in downward direction, and very low conductivity values in the subsoil (Figure 3.4).

Table 3.2 Physical properties' Pearson correlation coefficients of the soil samples ( $n=35)$. n.s. not significant, all other coefficients have $P<0.001$.

\begin{tabular}{llllll}
\hline & Mean (SD) & VP & $\boldsymbol{\rho}_{\text {bulk }}$ & $\boldsymbol{\rho}_{\text {material }}$ & LOI \\
\hline$\rho_{\text {bulk }}\left(\mathrm{g} \mathrm{cm}^{-3}\right)$ & $0.12(0.07)$ & 0.50 & & & \\
$\rho_{\text {material }}\left(\mathrm{g} \mathrm{cm}^{-3}\right)$ & $1.25(0.34)$ & 0.45 & 0.66 & & \\
LOI $\left(\mathrm{g} \mathrm{g}^{-1}\right)$ & $0.82(0.15)$ & -0.44 & -0.92 & -0.51 & \\
$\vartheta_{s}\left(\mathrm{~cm}^{3} \mathrm{~cm}^{-3}\right)$ & $0.91(0.03)$ & -0.42 & -0.80 & n.s. & 0.70 \\
\hline
\end{tabular}

\subsubsection{Root mat buoyancy}

Surface water level showed a seasonal trend, as well as fluctuations on a shorter time scale related to precipitation and evapotranspiration (Figure 3.5a). Visually, the root mat edges (L1) show mostly short term fluctuations, while the vertical movement of areas further from the edge (L2) seems more seasonal. However, the trends of PT1L2 and PT2L2 seem different, as PT1L2 has its peak in $R M L$ in autumn and PT2L2, although some of the data are missing, seems to peak in early spring. During strong surface water level peaks, the edges of the root mat (L1) moved upward relatively strongly with the surface water level compared to the areas further from the edge (L2) (Figure 3.5b). 

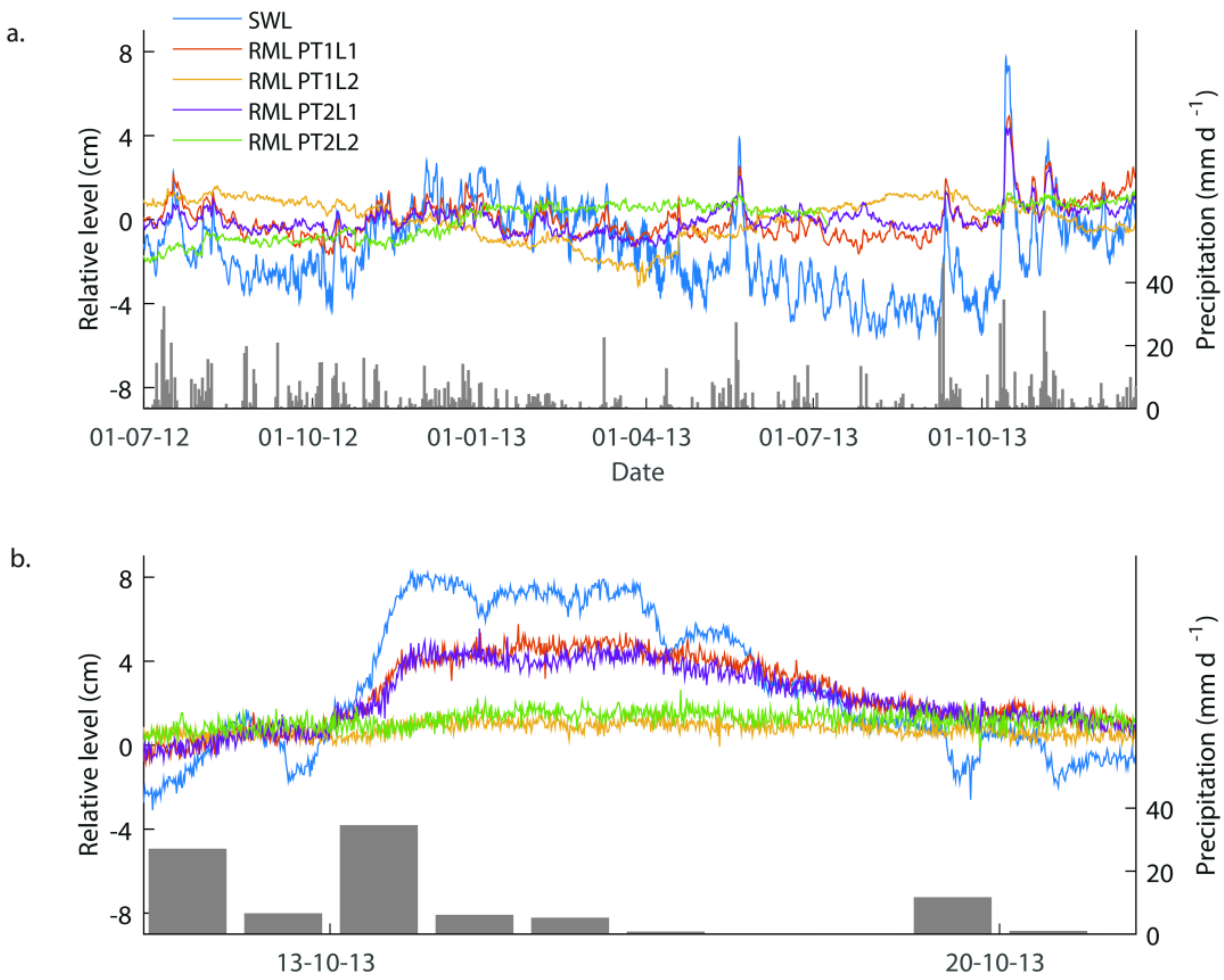

Date

Figure 3.5 Root mat level, relative to average level, (RML, in $\mathrm{cm}$ ) of each location and surface water level (SWL). a. From June 2012 until February 2014. Data are smoothed to improve visibility. Due to logger malfunction, measurements of PT2L2 are missing partially. Standard deviations of the relative levels were: SWL: $2.1 \mathrm{~cm}$; PT1L1: $1.1 \mathrm{~cm}$; PT1L2: $1.0 \mathrm{~cm}$; PT2L1: $0.8 \mathrm{~cm}$; PT2L2: $0.9 \mathrm{~cm}$. $b$. During a rainy period in October 2013.

Linear models with different sets of independent variables were used to explore the relative effects of each variable (Table 3.3). We did not find any significant effect for atmospheric pressure changes, and therefore do not show this parameter. For all locations, model performance was best when three variables ( $S W L, T$ and $G W L_{r}$ ) were used. In these models, surface water has a strong positive effect, while relative groundwater level has a negative effect on root mat level, almost as large as the effect of surface water, even though $G W L_{r}$ is physically and statistically correlated to $S W L$ (Pearson correlation coefficients 0.72 - 0.95). Including temperature in the model improves results by at least $22 \%$, except in location PT2L2. 
Table 3.3 Coefficients and their standard errors of different linear models of root mat level RML (cm, relative to average level) and their performance for each measurement location. Significance level of all coefficients is $P<0.001$. Effect of $\Delta p_{a}$ was not significant and is not shown.

\begin{tabular}{|c|c|c|c|c|c|}
\hline Location & Model & SWL $\left(\mathrm{cm} \mathrm{cm}^{-1}\right)$ & $\mathrm{T}\left(\mathrm{cm}^{\circ} \mathrm{C}^{-1}\right)$ & $\mathrm{GWL}_{\mathrm{r}}\left(\mathrm{cm} \mathrm{cm}^{-1}\right)$ & $\mathbf{R}^{2}$ \\
\hline \multirow[t]{5}{*}{ PT1L1 } & SWL & $0.3023(0.0039)$ & & & 0.43 \\
\hline & $S W L+T$ & $0.3769(0.0017)$ & $0.0672(0.0008)$ & & 0.50 \\
\hline & $S W L+G W L_{r}$ & $0.4731(0.0019)$ & & $-0.3811(0.0031)$ & 0.56 \\
\hline & $T+G W L_{r}$ & & $-0.0185(0.0020)$ & $0.0253(0.0049)$ & 0.00 \\
\hline & $S W L+T+G W L_{r}$ & $0.7377(0.0018)$ & $0.1367(0.0006)$ & $-0.6326(0.0025)$ & 0.78 \\
\hline \multirow[t]{5}{*}{ PT2L1 } & SWL & $0.1398(0.0015)$ & & & 0.15 \\
\hline & $S W L+T$ & $0.2135(0.0015)$ & $0.0903(0.0008)$ & & 0.29 \\
\hline & $S W L+G W L_{r}$ & $0.2340(0.0028)$ & & $-0.1585(0.0041)$ & 0.17 \\
\hline & $T+G W L_{r}$ & & $0.1005(0.0017)$ & $0.2260(0.0032)$ & 0.19 \\
\hline & $S W L+T+G W L_{r}$ & $0.5454(0.0030)$ & $0.1480(0.0009)$ & $-0.4796(0.0039)$ & 0.45 \\
\hline \multirow[t]{5}{*}{ PT1L2 } & SWL & $-0.1717(0.0020)$ & & & 0.10 \\
\hline & $S W L+T$ & $0.0477(0.0010)$ & $0.2847(0.0006)$ & & 0.82 \\
\hline & $S W L+G W L_{r}$ & $0.4871(0.0059)$ & & $-0.6776(0.0060)$ & 0.28 \\
\hline & $T+G W L_{r}$ & & $0.2178(0.0005)$ & $0.0600(0.0013)$ & 0.77 \\
\hline & $S W L+T+G W L_{r}$ & $0.2283(0.0029)$ & $0.2690(0.0006)$ & $-0.2029(0.0031)$ & 0.83 \\
\hline \multirow[t]{5}{*}{ PT2L2 } & SWL & $0.0957(0.0023)$ & & & 0.04 \\
\hline & $S W L+T$ & $0.0368(0.0019)$ & $-0.1941(0.0014)$ & & 0.33 \\
\hline & $S W L+G W L_{r}$ & $0.6321(0.0019)$ & & $-0.5911(0.0017)$ & 0.75 \\
\hline & $T+G W L_{r}$ & & $-0.1683(0.0009)$ & $-0.1297(0.0015)$ & 0.48 \\
\hline & $S W L+T+G W L_{r}$ & $0.6785(0.0026)$ & $0.0302(0.0012)$ & $-0.6322(0.0023)$ & 0.76 \\
\hline
\end{tabular}

\subsubsection{Modelling results}

The heterogeneous $\mathrm{K}_{\mathrm{s}}$ field was implemented in the root mat part of the model, and the $K_{s}$ of the upper layer of the subsurface was set to $0.0125 \mathrm{~m} \mathrm{~d}^{-1}$ based on the field measurements. The deep subsurface layer, that acted as a Cauchy boundary, had a hydraulic head of $-0.2 \mathrm{~m}$ relative to surface water level and a $K_{s}$ of $0.0035 \mathrm{~m} \mathrm{~d}^{-1}$ in order to obtain the desired recharge rate. The model calculation for $1000 \mathrm{~d}$ led to semi-steady state conditions for the wet and dry scenarios, respectively. Average hydraulic conductivity of the root mat was calibrated as twice the measured values, in order to result in a realistic difference in groundwater levels between wet and dry conditions (about $20 \mathrm{~cm}$ at $\mathrm{x}=12 \mathrm{~m}$ ).

Wet conditions resulted in a maximum groundwater level of $0.12 \mathrm{~m}$ relative to surface water level, while in dry conditions a minimum of $G W L_{r}=-0.15 \mathrm{~m}$ was reached. The calibrated values for the model with a homogeneous conductivity field were $K_{s}=0.38$ and $0.27 \mathrm{~m} \mathrm{~d}^{-1}$ for wet and dry scenarios, respectively. As flow was mainly horizontal, these values are in the order of the arithmetic mean of the heterogeneous $K_{s}$ values, averaged over depth in the fixed part of the root mat. To compare flow and transport with and 
without buoyancy effects, surface water level changes of 0.025 and $0.05 \mathrm{~m}$ were implemented in the model, with root mat level changes of 0.0125 and 0.025 , respectively.

a.

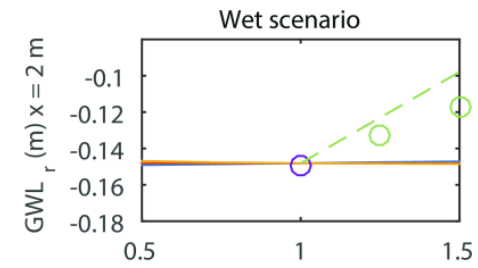

b.

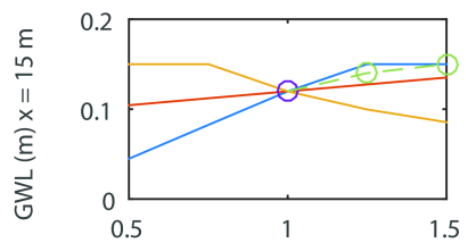

C.

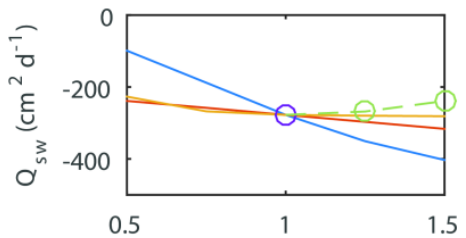

d.

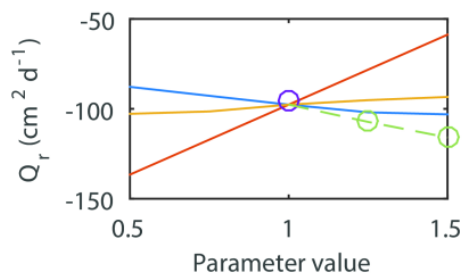

Dry scenario

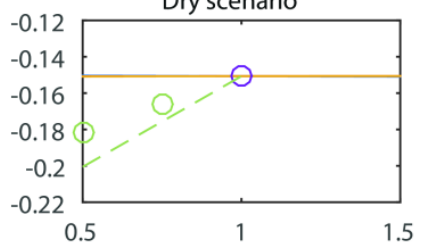

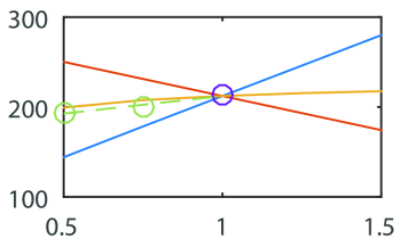
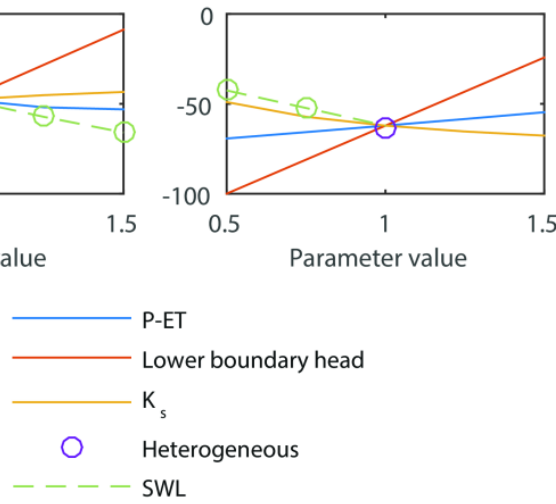

SWL Buoyancy

Figure 3.6 Sensitivity in the wet scenario (left) and the dry scenario (right) of four model results to net atmospheric flux (P-ET), lower boundary head, hydraulic conductivity $\left(K_{S}\right)$ and surface water level (SWL). The former three explaining variables have been varied $-50 \%,-25 \%, 0 \%+25 \%$ and $+50 \%$ times the reference value, while SWL has been varied relative to potential extreme values. The scatter plots show the effect of heterogeneity and buoyancy. Note that the $y$-axes have different scales for wet and dry scenarios. a. Relative groundwater level in the floating part of the root mat $\left(G W L_{r} x=2 \mathrm{~m}\right)$. $b$. Groundwater level in the fixed part of the root mat (GWL, $x=15 \mathrm{~m}$ ). As the root mat surface is located at $0.15 \mathrm{~m}$ above surface water level, groundwater levels do not become higher than this value. c. Flow at the surface water boundary ( $Q_{s w}$, positive is into the domain). d. Flow at the lower boundary $\left(Q_{r}\right.$, positive is into the domain). 
Figure 3.6 shows the results of all simulations for the water balance variables. Actual evapotranspiration was in all cases equal to potential evapotranspiration and is therefore not shown. The groundwater level relative to the root mat surface in the floating part is not sensitive to any parameter, except changes in surface water level, which effects are mitigated by root mat buoyancy. The groundwater level in the fixed part of the root mat and the flow at the surface water boundary are sensitive to atmospheric forcing and the $\mathrm{K}_{\mathrm{s}}$ value of the root mat. Obviously, flow at the lower boundary depends mostly on the hydraulic head at this boundary. As the homogeneous model was calibrated to result in the same groundwater levels as the heterogeneous model, no differences are observed for this variable. However, heterogeneity results in very small differences in boundary flow compared to the homogeneous model. The lower boundary flow was relatively sensitive to changes in the surface water level, but root mat buoyancy did not affect any of these variables.

\section{Transport in wet scenario}

Figure 3.7 shows the flow lines for the basic simulation and the extremes of the parameter sets. In the wet basic (homogeneous, non-buoyant) scenario, flow is mostly vertical in the floating part of the root mat, and diagonal in the part that is fixed to the subsurface, as the precipitation partially recharges the subsurface and is partially discharged into the surface water. This results in a rainwater layer in the upper part of the root mat, and a mixing zone in the lower layer of the fixed part of the root mat, as is illustrated in Figure 3.8. With parameter sets that lead to more flow to the surface water boundary ( $P-E T, L B H$ and $K_{s}$ $+50 \%$ ), flow lines within the fixed part of the root mat become more horizontal, but no changes are observed within the floating part of the root mat (Figure 3.7).

In the simulation with the heterogeneous $K_{s}$ field, the pattern of the flow lines is different compared to the basic simulation. As the boundary fluxes are similar to the basic simulation, the number of flow lines reaching each boundary are the same, however, most flow occurs horizontally through the upper layers of the root mat, in both the fixed and the floating parts of the root mat. The increased horizontal flow results in a thinner rain water layer and mixing zone in the fixed part of the root mat.

An increase of surface water level leads to more vertical flow lines in the fixed part of the root mat compared to the basic simulation, but no changes are observed in the floating part. In the simulation in which the root mat moves vertically with the surface water, the groundwater level relative to the root mat surface remains more similar to the basic simulation compared to the non-buoyant model. However, regarding the flow lines no differences become apparent between the two simulations with increased surface water levels, which is illustrated with the concentration patterns in Figure 3.8 as well. 

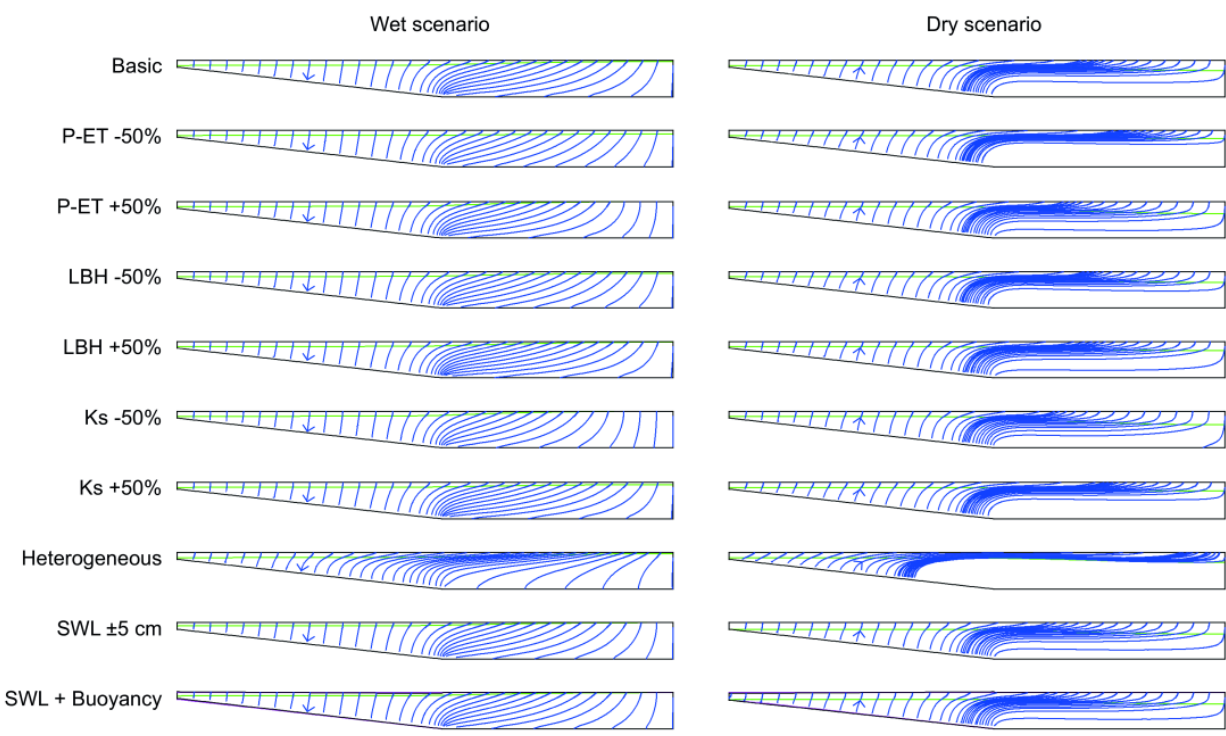

Figure 3.7 Flow lines for the basic (homogeneous, non-buoyant) simulations, the extremes of the parameters of the sensitivity analysis ( $P-E T$, lower boundary head (LBH) and $\left.K_{s}\right)$, the simulations with the heterogeneous $K_{s}$ field, the simulations with changed surface water levels and the simulations that include buoyancy effects. Blue lines are flow lines that were calculated from or to each $0.5 \mathrm{~m}$ at $\mathrm{z}=\mathrm{SWL}$, with a blue arrow showing the direction of the flow lines. Green lines are groundwater levels, black lines are the outline of the root mat and magenta lines are the outline of the previous position of the root mat in case of buoyancy.
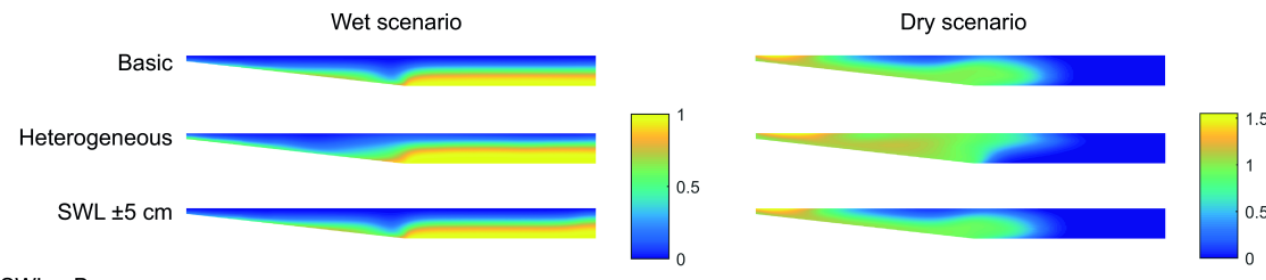

SWL + Buoyancy

Figure 3.8 Solute concentration for the basic homogeneous simulation, the heterogeneous simulation, the homogeneous simulation with risen surface water level and the simulation in which the root mat level changes with the risen surface water level. In the wet scenario (left, $t=200 \mathrm{~d})$, precipitation $(c=0)$ replaces groundwater $(c=1)$. In the dry scenario (right, $t=600 d)$, surface water $(c=1)$ replaces groundwater $(c=0)$.

\section{Transport in dry scenario}

In the dry basic scenario, surface water enters the root mat, mostly where the root mat almost connects with the subsurface, and flows towards the surface (Figure 3.7). This flow is slightly diagonal in the floating part, and mostly horizontal in the fixed part of the root mat, and results in high solute concentrations near the root mat edge and a plume at intermediate depth in the rest of the root mat (Figure 3.8). The three parameters of the sensitivity analysis affect the depth over which this flow occurs. This depth correlates with 
the depth of the groundwater table, as steeper gradients lead to horizontal flow in deeper root mat regions.

In the simulation with the heterogeneous $K_{s}$ field, this horizontal flow is much more concentrated in the upper layers of the root mat, and the origin of the flow lines shifts towards the floating part of the root mat (Figure 3.7). This is also illustrated in Figure 3.8, as these flow lines result in solute concentrations near the root mat surface.

Decreasing the surface water level leads to an increase of the flow depth, as the groundwater level decreases as well (Figure 3.7). A lowering of the root mat with the surface water leads to groundwater depths (relative to the root mat surface) more similar to the basic simulation. However, this did not result in clear changes in the flow lines compared non-buoyant model with a decreased surface water level, which was confirmed with the solute concentration patterns (Figure 3.8).

\subsection{Discussion}

\subsubsection{Root mat heterogeneity}

The $K_{s}$ orders of magnitude that we found are similar to those found in bogs (Fraser et al, 2001) and fens (Whittington \& Price, 2006), where $K_{s}$ strongly decreases within the first meter depth. They are also similar to values from other root mats (Baird et al, 2004), and smaller than values found in thinner, younger stage root mats (Koerselman, 1989; van Wirdum, 1990).

Our results confirm that saturated hydraulic conductivity of floating fen material negatively correlates with degree of decomposition. With higher degrees of decomposition the soil becomes more dense and contains proportionally less organic material and water, which may be related to a decrease in average pore size, explaining the decrease in conductivity. However, a large variation remains. This could be related to differences in parent material (species composition) or relative volume of gas bubbles (Kettridge et al, 2012), that may differ temporally and spatially (Kellner et al, 2005). Although degree of decomposition does not include effects of loading and compression (Price et al, 2005) on pore size distribution, both of these factors increase with depth, and therefore cannot be distinguished.

Although degree of decomposition does not explain all $K_{s}$ variation, it is a quick and easy method for assessing root mat heterogeneity. To use this relationship in other floating fens, it would be necessary to confirm its validity in other cases and to assess whether its 
predictive capabilities can be improved by incorporating other parameters such as bulk density and peat origin.

\subsubsection{Root mat buoyancy}

Our results show that the root mat in part moves vertically with the surface water, which was especially clear at the edges in case of large surface water level peaks. In all locations, the relative groundwater level seemed to dampen the root mat oscillation with the surface water. This may be due to increased loading due to precipitation, but may also be a result of the partial fixation of the root mat to the subsurface. Contrary to what was expected from studies in bogs (Tokida et al, 2007; Waddington et al, 2009), we did not find effects of atmospheric pressure changes on the root mat level. The reason might be that pore structure or gas production due to organic matter mineralization differs between Sphagnum spp. based bog peat on one hand and fen peat originating from mostly higher plant species such as Phragmites australis and Thelypteris palustris on the other hand.

Rising temperatures correlated clearly with elevated root mat levels, in congruence with Kellner et al (2005) in all but one location (PT2L2). Other variables, including vegetation composition, degree of decomposition or $K_{s}$ measurements did not give any clues that could explain the lack of correlation at this location. Strack \& Mierau (2010) found clear differences in gas content between hummocks and hollows in a Canadian bog, showing that microtopography may affect gas content in peat systems, but it is not clear if such effects could apply to floating fens as well. Other explanations may include local differences in material, root mat attachment to the subsurface or root mat thickness, affecting the mobility of the root mat. Additionally, the presence of macropores may allow easier ebullition of gas bubbles, decreasing the effect of temperature. Furthermore, we did not take into account the potential effect of the vegetation itself. Growth of rhizomes could increase buoyancy in spring, while the aboveground biomass increases the loading of the root mat in summer. However, Hogg \& Wein (1988) found that this effect is relatively small compared to the effect of gas in rather developed root mats $(50 \mathrm{~cm}$ thickness).

\subsubsection{Effects of heterogeneity and buoyancy on flow and transport}

Our results show that heterogeneity has a very small influence on the water fluxes in floating fens, indicating that homogeneous models would suffice for most water balance 
related purposes. Nevertheless, using a single value of $K_{s}$ would imply that it depends on groundwater level, as higher groundwater levels allow more flow through the highly conductive layers filled in those wet periods. Calibrated values during one period, would give errors during other periods, although these errors would probably be small, relative to the uncertainty in $K_{s}$ itself.

Heterogeneity has a large effect on flow lines and, consequently, on solute transport. As more horizontal flow occurs in the upper layer of the root mat, rain water flows away more easily in lateral direction, while more solute transport occurs in the root mat surface in dry conditions. Under real atmospheric forcing, when wet and dry conditions alternate continuously, these processes may eventually affect the size of the rain water lens and the distribution of solutes, such as local nutrient availability and base-richness. As these factors affect vegetation succession (van Diggelen et al, 1996), we think hydrological models for these purposes should include heterogeneity. Moreover, to accurately simulate these processes, realistic transport parameters should be implemented in a transient model, which should ideally be coupled with a biogeochemical model.

While surface water level changes have a relatively large effect on root mat hydrology, the effects of buoyancy remain limited to the floating part of the root mat, where groundwater levels relative to the surface remain more stable. From the perspective of a plant, buoyancy leads to more constant moisture conditions, which may be of importance to the plant species and vegetation types that are found in the floating zone.

Regarding solute transport, we found that flow lines and long term solute concentration patterns are barely affected by buoyancy. With dynamic boundary forcing, a model that includes buoyancy would not lead to significant differences in distribution of solutes compared to a model that does not include buoyancy.

For completely floating mats, buoyancy changes could be modelled as transient boundary conditions influencing a steady domain. However, for semi-floating mats such as the type we studied, this is not an option because the domain itself changes shape. Modelling of transient domains is not a trivial task, as it is currently, to our knowledge, not supported by any available software. Unless modelling purposes include accurate prediction of the relative groundwater level to simulate moisture conditions in the floating part, it may not be worthwhile to include buoyancy in a hydrological model of a floating fen. 


\section{Acknowledgements}

We would like to thank our colleagues Henny Gertsen and Harm Gooren for their technical assistance in the field, as well as MSc student Federica Pegoraro for her work in this project. We are grateful to our colleague Toon Leijnse, for giving us advice on the modelling. We would also like to thank Agata Klimkowska and Rienk-Jan Bijlsma for identifying plant and moss species respectively, as well as Geert van Wirdum for his help with a first characterization of the field site. Furthermore we would like to thank Chris Roosendaal of Utrecht University for lending their peat sampler and Vereniging Natuurmonumenten for allowing us to do our field measurements in the Nieuwkoopse Plassen. This research project (Climate Proof Fresh Water Supply: Nature and Salinity) is carried out in the framework of the Dutch National Research Programme Knowledge for Climate (www.knowledgeforclimate.org). 


\section{Hydrological system analysis of a floating fen}

In preparation:

Stofberg, S.F., Leijnse, A., van der Zee, S.E.A.T.M., 2017. Hydrological system analysis of a floating fen. 


\begin{abstract}
Floating fens are (partially) floating, often species-rich, wetland systems that are threatened by various processes. Root zone water quality is affected by local biogeochemical processes, but also by flow and transport processes. Very little is known about short term flow dynamics, while these are relevant for the exchange of root zone water and surface water of different quality.
\end{abstract}

We measured groundwater levels and hydraulic properties of a partially floating fen in the Nieuwkoopse Plassen, the Netherlands. A 2D hydrological model was calibrated and validated to this data. Our model explained most of the observed variation: groundwater levels of the floating parts vary synchronously with the surface water, while the levels in the fixed parts responded to the atmospheric forcing.

To further examine the system's behaviour, we developed a nondimensional model and conducted a sensitivity analysis. We found that geometry is a key property: any floating part is only subject to vertical flow and groundwater levels will remain at the same level as the surface water. Non-floating parts are influenced by boundary flux intensities, the effects of which may be dampened by the surface water level, depending on the lateral flow path resistance between groundwater and the surface water. Example simulations show the hydrological changes over the course of succession, from a purely floating type to one that is almost completely connected to the subsurface.

The strong interaction with the surface water in floating (parts of) root mats allows quick exchange with the water layer below the root mat, and the water quality in the layer below the root mat may determine the water quality within the root mat. In the parts of root mats that are fixed to the subsurface, exchange with the surface water will occur as well due to larger gradients, but the longer flow paths should not result in strong mixing within the root mat. 


\subsection{Introduction}

Worldwide, wetland ecosystems are threatened by human activities, both directly (e.g. habitat loss, contamination, eutrophication) and indirectly (e.g. as a result of climate change effects) (Erwin, 2008; Verhoeven, 2013; Zedler and Kercher, 2005). In response to widespread ecosystem loss and degradation, measures are taken to mitigate the effects or to restore systems to desired states. These measures are often focused on conditions that influence the boundary conditions of the ecosystem (water management, nutrient or contaminant input) or on changing system characteristics themselves (nutrient management, afforestation) (Rey Benayas et al., 2009). Choosing successful ecosystem management measures requires sufficient system understanding (Mitsch and Wilson, 1996).

Floating fens are wetland systems that consist of (partially) floating root mats, that develop as helophytes laterally colonize surface water. These type of fens are found all over the world. In north western Europe, they are found in abandoned turf ponds that are nowadays often protected nature areas, as they harbour a wide variety and provide a habitat to many endangered species. During succession, the root mats become wider and thicker as organic material accumulates. The earlier succession stages (comprising rich-fen vegetation) are often preferred by nature managers, due to their high biodiversity, which is associated with base-rich groundwater (van Diggelen et al., 2015). Eventually, the root mats become attached to the subsurface, and the abiotic conditions become more ombrotrophic (Rydin and Jeglum, 2013; Verhoeven and Bobbink, 2001).

There are several factors threatening floating fen systems (Lamers et al., 2014). Human interventions on drainage or recharge have caused loss or degradation of many fen areas. Furthermore, natural succession is considered a major threat, leading to desiccation and acidification, and may eventually lead to more bog-like or forested systems. The succession process can be accelerated by decreased water quality, as that may lead to (internal) eutrophication. To counter the adverse effects, measures are taken to slow down this process (mowing, burning, liming, top soil removal, digging ditches or trenches, surface water fluctuations) (Beltman et al., 1996; Cusell et al., 2013; van Diggelen et al., 2015) or restore the fen landscapes to earlier stages of succession (digging new turf ponds). Contamination of surface water or groundwater with saline water may affect floating fen systems as well, as common salts may affect plant growth (Stofberg et al., 2014) or biogeochemical processes (van Dijk et al., 2015).

Much research on the conservation and restoration of floating fens focuses on improving local chemistry to stimulate the growth of desired species. For this, they use different 
measures, including hydrological ones such as drainage, but without looking into flow processes affecting these measures (Beltman et al., 1996; Bootsma et al., 2002; Lamers et al., 2002). Considering the important role of hydrology with regard to direct effects (wetness, drought) and indirect effects (transport processes affecting water biogeochemical processes), the hydrological system needs to be well understood. Previous research focused on steady state analyses (Stofberg et al., 2016; van Wirdum, 1991) or such long term budgets, that variations in time became underemphasized (Koerselman, 1989). However, for shallow systems as floating fens, dynamics are likely to occur at relatively small timescales, which are not well understood.

The objective of this study is to provide a hydrological system analysis of floating fens, that may be used to characterize the behaviour (groundwater levels, exchange with surface water and flow dynamics) that is typical for root mat systems. Furthermore, we aim to provide perspective on the differences between floating fens in various stages of succession and different locations, which may be useful for successful management. In this paper, we provide a simulation of a case study area, and examine the system behaviour using a dimensionless model.

\subsection{Methods}

\subsubsection{General approach}

We developed a hydrological model to simulate groundwater and soil water dynamics of a floating fen, using hydrological field measurements of a study area in the Netherlands, in combination with data of a previous study (Stofberg et al., 2016). The model was calibrated and validated using groundwater level data that were collected in the field. To systematically assess the effect of the different system components, we developed a simplified, non-dimensional hydrological model of a floating fen system, on which we could perform an efficient sensitivity analysis. This model was then further used to illustrate the hydrological behaviour of various types of floating fens or different circumstances.

\subsubsection{Field measurements}

We conducted field measurements at a field site in the Nieuwkoopse Plassen nature reserve, the Netherlands, located at coordinates $52^{\circ} 8^{\prime} 49.56^{\prime \prime} \mathrm{N}$ and $4^{\circ} 48^{\prime} 51.67^{\prime \prime} \mathrm{E}$. The site consists of a partially floating root mat of about 370 by 20 meters, which was formed 
when in 2011 a new ditch parallel to the surface water and about halfway the originally 50 $\mathrm{m}$ wide root mat was excavated. A cross-section is shown in Figure 4.1. In the study site, the new ditch (on the right hand side in Figure 4.1) is located at a distance of 20 meters from the original root mat edge (left hand side in Figure 4.1). In 2013, the new ditch was connected with the surface water. At the original edge, the root mat is covered by macrophytes such as Typha angustifola, Cladium mariscus and Thelypteris palustris, which are considered root mat builders. Further from the original edge of the root mat, the vegetation becomes more ombrothrophic, and includes Sphagnum spp., Erica tetralix and Drosera rotundifolia. At the newly created edge, the vegetation has so far remained ombrotrophic. The root mat material consists of peat in various stages of humification, as described in Stofberg et al. (2016). The topography was determined in three transects perpendicular to surface water edge, using a level and rod, and the root mat thickness was estimated using augers and a device that can be unfolded after it is pushed into the soft soil, making it possible to feel where the root mat begins when it is pulled upwards.

We measured groundwater levels at four locations in two transects (eight in total, see Figure 4.1), using piezometers with filters in the root mat, installed with pressuretemperature loggers ('divers', van Essen Instruments, Delft, Netherlands). Levels and temperatures were recorded every 15 minutes between June 2012 and February 2014. Surface water levels and air pressure values were recorded as well, using the same type of instruments, for the same time interval. Air pressure measurements were used to correct the measured water levels for atmospheric pressure. Precipitation was recorded every 15 minutes using a tipping bucket rain gauge (Spectrum Technologies, USA) which was installed in the middle of the field between the two piezometer transects. For a description of hydraulic conductivity measurements and the quantification of its spatial variation, we refer to Chapter 3.

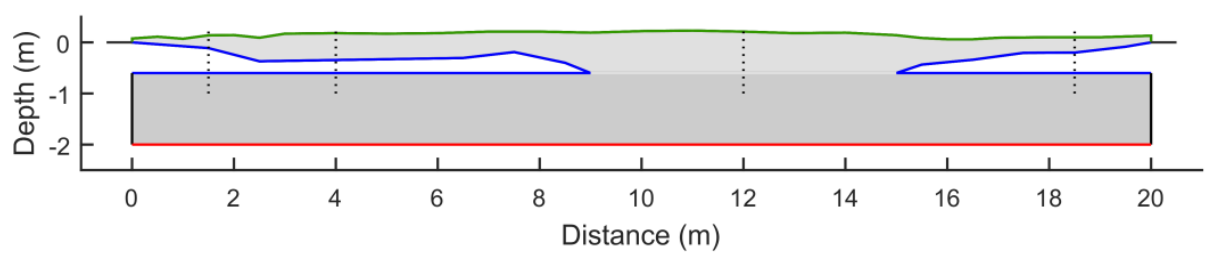

Figure 4.1 Cross section of the root mat model. The left side is the original root mat edge. The mat used to be fixed to the subsurface, from distance $15 \mathrm{~m}$ and further to the right side, until a new ditch was dug in 2011. The new ditch (at distance $20 \mathrm{~m}$ ) was connected to the surface water in 2013, and the right side became partially buoyant, as some of the soft, humified deeper peat material seemed to have spread into the newly dug ditch. The reference surface water level is at $0 \mathrm{~m}$. The dotted lines indicate the four locations of piezometers. The coloured lines represent the model boundaries. Green line: atmospheric boundary, blue line: surface water boundary, red line: Cauchy boundary, black line: no flow boundary. 
For the assessment of the so-called evaporation experiment, we collected two sets of three samples of the upper layer of the root mat (at 5 and 18 meters from the left edge in Figure 4.1), using a hand saw.

\subsubsection{Evaporation experiment}

Soil hydraulic properties were measured using the automated Wind evaporation method (Boels et al., 1978; Wind, 1968). In the laboratory, we fitted each sample in a PVC ring with a diameter of $10.2 \mathrm{~cm}$ and a length of $8 \mathrm{~cm}$. The field-wet samples were wetted with deionized water, after which the bottom of the rings were closed with lids. Each sample was placed on a balance in a temperature and humidity controlled room $\left(16 \pm 1^{\circ} \mathrm{C}\right.$, $34 \pm 1 \% \mathrm{RH})$. Four tensiometers were placed horizontally in each sample, at $1,3,5$, and $7 \mathrm{~cm}$ height, after which the samples were allowed to dry to the air. Tension and mass were measured continuously, until the measurement limit of the tensiometers was reached. The data processing was done according to Bakker et al. (2015). From each dataset, 100150 datapoints were selected for maximum $h$ gradients, to improve $K(h)$ estimates. The selected data were initially fitted to a Mualem van Genuchten model, after which $K(h)$ estimates are incorporated in the fit (if $K>0$ ). The final fitting procedure makes use of the RETC code (van Genuchten et al., 1991). The fitted parameters were compared using analysis of variance, using SAS statistical software (Cary, NC, USA), to test for differences between the locations.

\subsubsection{Nieuwkoopse Plassen root mat model}

Saturated and unsaturated flow was simulated using Hydrus 2D/3D software (PC-Progress, Prague, Czech Republic) in which the Richard's equation is solved. The 2D domain (Figure 4.1) was discretized into elements, of which the size varied between $15 \mathrm{~cm}$ in the deep subsurface to $3-5 \mathrm{~cm}$ in the root mat. At the atmospheric boundary precipitation, potential evaporation and transpiration was applied. For potential evapotranspiration we used the daily Makkink potential evapotranspiration (KNMI, 2016a) that was downscaled using hourly radiation data from the meteo station at Schiphol. A crop factor of 1 was assumed for the total potential evapotranspiration (Koerselman and Beltman, 1988; Lafleur, 1990) and the moss layer evaporation (modelled as soil evaporation, Voortman et al., 2014) was assumed to be $10 \%$ of that, based on the estimated area cover of vascular plants. For precipitation, we used measured values. Both precipitation and potential transpiration were corrected for interception (based on Burgy and Pomeroy, 1958). 
At the surface water boundary the measured surface water levels were prescribed. A Cauchy boundary was prescribed at the bottom of the model, to account for vertical downward percolation. This recharge for the whole nature area was estimated at $0.6 \mathrm{~mm}$ $\mathrm{d}^{-1}$ (Zaadnoordijk and Soetens, 2008). To find the local recharge, it was attempted to use temperature as a tracer (using seasonal temperature fluctuations, unpublished data). This resulted in the same value, but had large uncertainty due to a small Peclet number. The soil hydraulic properties were based on the results of the evaporation experiment that was described in the previous section. The saturated conductivity was multiplied with a scaling field that is shown in Figure 4 in Stofberg et al. (2016) to account for the heterogeneity in the root mat.

The model was calibrated for parameters that were considered uncertain and expected to affect calibration results, by varying these parameters with regular intervals and conducting simulations for all permutations. These simulations were done for a time series from the 1st of August 2013 until 13 September 2013, and included wet and dry periods. The validation period was from 16 February 2013 to the 1st of August 2013 and also included wet and dry periods. In both simulation sets, the first 10 days of results were disregarded as a warming up phase. Performance of calibration and validation runs was assessed by comparing the modelled groundwater levels with the measured levels, using the Nash Sutcliffe model efficiency coefficient.

Table 4.1 List of variables and parameters.

\begin{tabular}{|c|c|c|c|c|c|c|}
\hline Symbol & Name & Unit & $\begin{array}{l}\text { Reference } \\
\text { value }\end{array}$ & $\begin{array}{l}\text { Low } \\
\text { extreme }\end{array}$ & $\begin{array}{l}\text { High } \\
\text { extreme }\end{array}$ & $\begin{array}{l}\text { Notes and } \\
\text { references }\end{array}$ \\
\hline$K$ & Hydraulic conductivity & $\mathrm{m} \mathrm{d}^{-1}$ & & & & \\
\hline$K_{\text {evap }}$ & $\begin{array}{l}\text { K fitted using evaporation } \\
\text { method }\end{array}$ & $m d^{-1}$ & & & & \\
\hline$K_{c}$ & K of Cauchy boundary layer & $m d^{-1}$ & 0.0035 & & & \\
\hline$K_{s}$ & $\mathrm{~K}$ of top of root mat & $m d^{-1}$ & 11.62 & 2 & 50 & $\begin{array}{l}\text { (Gnatowski et al., } \\
\text { 2010; van Wirdum, } \\
\text { 1991) }\end{array}$ \\
\hline$L_{c}$ & $\begin{array}{l}\text { Thickness of Cauchy boundary } \\
\text { layer }\end{array}$ & $\mathrm{m}$ & 1 & & & \\
\hline$L_{e}$ & Depth of root mat edge & $\mathrm{m}$ & 0.2 & - & - & \\
\hline$L_{f}$ & $\begin{array}{l}\text { Length of floating part of root } \\
\text { mat }\end{array}$ & $\mathrm{m}$ & $0.75 * L_{x}$ & 0 & $L_{x}$ & \\
\hline$L_{g w}$ & Groundwater level & $\mathrm{m}$ & & & & \\
\hline$L_{r m}$ & Depth of root mat & $\mathrm{m}$ & 0.75 & - & - & \\
\hline$L_{\text {vmax_x }}$ & $\begin{array}{l}\text { Position of highest flow velocity } \\
\text { in } \mathrm{x} \text { dimension }\end{array}$ & $\mathrm{m}$ & & & & \\
\hline$L_{v 0.5 \_z}$ & $\begin{array}{l}\text { Position of } 50 \% \text { of the highest } \\
\text { flow velocity in } z \text { dimension }\end{array}$ & $\mathrm{m}$ & & & & \\
\hline$L_{x}$ & $\begin{array}{l}\text { Length of domain from edge to } \\
\text { water divide }\end{array}$ & $\mathrm{m}$ & 12 & 6 & 75 & \\
\hline$P_{i}$ & $\begin{array}{l}\text { Precipitation intensity (during } \\
\text { event) }\end{array}$ & $\mathrm{m} \mathrm{d}^{-1}$ & 0.01 & 0.005 & 0.05 & (KNMI, 2016b) \\
\hline
\end{tabular}


Table 4.1 Continued

\begin{tabular}{|c|c|c|c|c|c|c|}
\hline Symbol & Name & Unit & $\begin{array}{l}\text { Reference } \\
\text { value }\end{array}$ & $\begin{array}{l}\text { Low } \\
\text { extreme }\end{array}$ & $\begin{array}{l}\text { High } \\
\text { extreme }\end{array}$ & $\begin{array}{l}\text { Notes and } \\
\text { references }\end{array}$ \\
\hline$P E T_{i}$ & $\begin{array}{l}\text { Potential evapotranspiration rate } \\
\text { (over } 0.5 t_{\text {day }} \text { ) }\end{array}$ & $\mathrm{m} \mathrm{d}^{-1}$ & 0.007 & 0.0005 & 0.028 & (KNMI, 2016a) \\
\hline$Q_{s w}$ & $\begin{array}{l}\text { Flow from surface water into root } \\
\text { mat }\end{array}$ & $m^{2} d^{-1}$ & & & & \\
\hline$s$ & Sink (root water uptake) & $d^{-1}$ & & & & \\
\hline$S_{e}$ & Saturation & - & & & & \\
\hline$T$ & Transpiration & $\mathrm{m} \mathrm{d}^{-1}$ & & & & \\
\hline$c$ & Resistance of Cauchy boundary & $d$ & 286 & - & - & \\
\hline$c_{f}$ & Crop factor & - & 1 & 0.8 & 1.2 & $\begin{array}{l}\text { (Koerselman and } \\
\text { Beltman, 1988; } \\
\text { Lafleur, 1990) }\end{array}$ \\
\hline$f_{t}$ & $\begin{array}{l}\text { Fraction of PET that is } \\
\text { transpiration }\end{array}$ & - & 0.9 & 0.5 & 1 & \\
\hline$h$ & Pressure head & $\mathrm{m}$ & & & & \\
\hline$h_{\text {fluctuation }}$ & Fluctuation of surface water & $\mathrm{m}$ & 0.1 & 0 & 0.2 & \\
\hline$h_{1}$ & Pressure head at lower boundary & $\mathrm{m}$ & 2.325 & 0.9 & 3.9 & \\
\hline$h_{s}$ & Surface water pressure head & $\mathrm{m}$ & 0.6 & - & - & \\
\hline I & MvG parameter & - & -5 & -8 & 8 & \\
\hline$n$ & MvG parameter & - & 1.53 & 1.11 & 2.53 & $\begin{array}{l}\text { (Price et al., 2008; } \\
\text { Schwärzel et al., } \\
2006 \text { ) }\end{array}$ \\
\hline$n_{i}$ & Vector normal to boundary & - & & & & \\
\hline$q$ & Flux density & $\mathrm{m} \mathrm{d}^{-1}$ & & & & \\
\hline$t$ & Time & $d$ & & & & \\
\hline$t_{d a y}$ & Duration of a day & $d$ & & & & \\
\hline$t_{\text {pduration }}$ & Duration of precipitation & $d$ & 0.17 & 0.01 & 0.75 & (KNMI, 2016a) \\
\hline$T_{q 0.75}$ & $\begin{array}{l}\text { Duration of } 75 \% \text { of flow recession } \\
\text { time }\end{array}$ & $d$ & & & & \\
\hline$x$ & Distance in $\mathrm{x}$ direction & $\mathrm{m}$ & & & & \\
\hline$z$ & Distance in z direction & $\mathrm{m}$ & & & & \\
\hline$\alpha$ & MvG parameter & $\mathrm{m}^{-1}$ & 0.037 & 0.0021 & 10.47 & \\
\hline$\vartheta$ & Volumetric water content & - & & & & \\
\hline$\vartheta_{s}-\vartheta_{r}$ & $\begin{array}{l}\text { Saturated - residual vol. water } \\
\text { content }\end{array}$ & - & 0.82 & 0.2 & 0.99 & $\begin{array}{l}\text { (Gnatowski et al., } \\
\text { 2010; Schwärzel et } \\
\text { al., 2006; Voortman } \\
\text { et al., 2014) }\end{array}$ \\
\hline$\mu$ & Parameter to scale $\mathrm{K}$ with depth & $m^{-1}$ & 2.14 & 0 & 3 & $\begin{array}{l}\text { (Stofberg et al., } \\
\text { 2016; van Wirdum, } \\
\text { 1991) }\end{array}$ \\
\hline
\end{tabular}




\subsubsection{Nondimensional root mat model}

This model is a schematic version of the Nieuwkoopse Plassen root mat model. To reduce the number of parameters and to expose intrinsic system characteristics, the model has been made nondimensional. This was done by scaling dimensional variables and parameters, as illustrated here for the pressure head variable:

$h=h_{r} h^{\prime}$

Each variable, in this case the pressure head variable $h(\mathrm{~m})$, is equal to the product of a reference value $h_{r}(\mathrm{~m})$ and the scaled variable $h^{\prime}(-)$. In the model equations, the dimensional reference values have been combined into dimensionless groups (with asterisk). The used symbols and the dimensionless groups (marked with an asterisk) have been listed in Tables 4.1 and 4.2 respectively. The step-by-step derivation of the dimensionless model is described in Appendix 4A. The resulting model equations are the dimensionless Richards equation with the sink term for root water uptake

$\frac{\partial \theta \prime}{\partial t^{\prime}}=X^{*} D^{*} \frac{\partial}{\partial x^{\prime}}\left(K^{\prime}\left(\frac{\partial h^{\prime}}{\partial x^{\prime}}\right)\right)+\frac{X^{*}}{D^{*}} \frac{\partial}{\partial z^{\prime}}\left(K^{\prime}\left(\frac{\partial h^{\prime}}{\partial z^{\prime}}+1\right)\right)-U^{*} S^{\prime}$

Using the Mualem-van Genuchten (MvG) model to describe the soil hydraulic functions, the retention function is:

$S_{e}=\left(1+\left|A^{*} h^{\prime}\right|^{N^{*}}\right)^{-\left(1-\frac{1}{N^{*}}\right)}$

The unsaturated hydraulic conductivity of the peat material is described by the MvG model. As $K_{s}$ decreases strongly with depth in root mat systems (Stofberg et al., 2016), we applied an exponential decrease with increasing depth within the peat soil $\left(10^{\left(J^{*} z \prime\right)}\right)$ and multiplied this to the dimensionless $K(h)$ model

$K^{\prime}=10^{\left(J^{*} Z^{\prime}\right)} S_{e}^{L^{*}}\left(1-\left(1-S_{e}^{\frac{1}{1-\frac{1}{\mathrm{~N}^{*}}}}\right)^{1-\frac{1}{\mathrm{~N}^{*}}}\right)^{2}$

The model consists of a root mat, that is partially floating (Figure 4.2). All lengths in the $x$ and $z$ dimensions have been scaled to the domain width $L_{x}$ and the domain height $L_{z}$ respectively. The model boundaries are schematized as shown in Figure 4.2. The boundary conditions for the sensitivity analysis consisted of a synthetic time series of 30 reference 
times (days), of three 10-day periods with increasing complexity (Figure 4.5a). The time series starts with a 10-day period of surface water fluctuations (small daily and large 10day fluctuations), and no precipitation or potential evapotranspiration. In the second 10day period, potential evapotranspiration was added to the repeated surface water fluctuations, and in the third period, precipitation was added, which occurs in showers during different times of the day, as effects may differ between day (with ET) and night (no ET).

The surface water boundary is located on the line with $x^{\prime}, z^{\prime}$ coordinates $(0,0),\left(0, E^{*}\right),\left(F^{*}, M^{*}\right)$ and $\left(0, M^{*}\right)$. The time variable pressure head at the surface water boundary fluctuates around a mean pressure head:

$h^{\prime}\left(z^{\prime}, t^{\prime}\right)=H^{*}+M^{*}-z^{\prime}+0.5 S^{*} \sin \left(0.2 \pi t^{\prime}\right)+0.1 S^{*} \sin \left(2 \pi t^{\prime}\right)$

@ the boundary between surface water and root mat: $x^{\prime}=0, z^{\prime}=0$ to $x^{\prime}=0, z^{\prime}=E^{*}$ to $x^{\prime}=F^{*}, z^{\prime}=M^{*}$ to $x^{\prime}=0, z^{\prime}=M^{*}$.

On the atmospheric boundary, precipitation and evaporation (Figure 4.5a) are described as

$\left|K^{*} K^{\prime}\left(\frac{\partial h^{\prime}}{\partial z^{\prime}}+1\right) n_{i}\right| \leq q^{\prime}=P^{\prime}\left(t^{\prime}\right)-\left(1-G^{*}\right) P E T^{\prime}\left(t^{\prime}\right)$

$P^{\prime}\left(t^{\prime}\right)= \begin{cases}I^{*} & \bmod \left(t^{\prime},\left\{t^{\prime}, \frac{\text { floor }\left(t^{\prime}\right)-19}{11}-0.5 P^{*}\right) \leq P^{*} A N D t^{\prime}>20\right. \\ 0 & \text { else }\end{cases}$

$\operatorname{PET}^{\prime}\left(t^{\prime}\right)= \begin{cases}1 & \bmod \left(t^{\prime}, 1\right) \leq 0.5 \text { AND } t^{\prime}>10 \\ 0 & \bmod \left(t^{\prime}, 1\right)>0.5\end{cases}$

@ $\quad x^{\prime}=0, z^{\prime}=0$ to $x^{\prime}=1, z^{\prime}=0$

The sink term of Eq. 4.2 that is applied over the root mat (Figure 4.2 ) is given by

$S^{\prime}(t)=G^{*} P E T^{\prime}(t)$

@ the area of the root mat with $0<x^{\prime}<1$ and $0<z^{\prime}<M^{*}$

At the lower boundary, recharge or seepage is simulated using a Cauchy boundary

$q^{\prime}=\frac{C^{*}}{R^{*}}\left(B^{*}-h^{\prime}+R^{*}\right)$ 
@ $\quad x^{\prime}=0, z^{\prime}=-1$ to $x^{\prime}=1, z^{\prime}=-1$

As initial condition, the pressure head of the model domain is in hydrostatic equilibrium with the surface water:

$h^{\prime}\left(t^{\prime}=0\right)=H^{*}+M^{*}-z^{\prime}$

Table 4.2 List of dimensionless groups.

\begin{tabular}{|c|c|c|c|}
\hline Symbol & Nondimensional group & Description & Sensitivity analysis category \\
\hline$D^{*}$ & $\frac{L_{z}}{L_{x}}$ & Domain aspect ratio & Geometry \\
\hline$F^{*}$ & $\frac{L_{f}}{L_{x}}$ & $\begin{array}{l}\text { Relative length of floating part of root } \\
\text { mat }\end{array}$ & \\
\hline$I^{*}$ & $\frac{P_{i}}{P E T}$ & Relative precipitation intensity & \\
\hline$P^{*}$ & $\frac{t_{\text {pduration }}}{t_{\text {day }}}$ & Precipitation duration & \\
\hline$G^{*}$ & $f_{t}$ & Transpiration factor & Boundary conditions \\
\hline$U^{*}$ & $\frac{L_{x} c_{f} t_{d a y} P E T_{i}}{\left(L_{r m} L_{x}-0.5\left(L_{r m}-L_{e}\right) L_{f}\right)\left(\theta_{s}-\theta_{r}\right)}$ & Relative root uptake & \\
\hline$B^{*}$ & $\frac{h_{l}}{L_{z}}$ & Relative Cauchy boundary pressure head & \\
\hline$S^{*}$ & $\frac{h_{\text {fluctuation }}}{L_{z}}$ & Surface water fluctuation & \\
\hline$X^{*}$ & $\frac{t_{\text {day }} K_{s}}{\left(\theta_{s}-\theta_{r}\right) L_{x}}$ & Water displacement & \\
\hline$K^{*}$ & $\frac{K_{S}}{P E T}$ & $\begin{array}{l}\text { Relative hydraulic conductivity of root } \\
\text { mat }\end{array}$ & \\
\hline$J^{*}$ & $\mu L_{z}$ & $\begin{array}{l}\text { Relative change of conductivity over } \\
\text { depth }\end{array}$ & Medium characteristics \\
\hline$N^{*}$ & $n$ & MvG parameter $n$ & \\
\hline$L^{*}$ & $l$ & MvG parameter I & \\
\hline$A^{*}$ & $\alpha L_{z}$ & $\begin{array}{l}\text { Relative MvG parameter } \alpha \text {-inverse air } \\
\text { entry value }\end{array}$ & \\
\hline$C^{*}$ & $\frac{K_{C}}{P E T_{i}}$ & Relative Cauchy boundary conductance & \\
\hline$E^{*}$ & $\frac{-L_{e}}{L_{z}}$ & Relative root mat edge thickness & \\
\hline$H^{*}$ & $\frac{h_{s}}{L_{z}}$ & $\begin{array}{l}\text { Relative mean surface water pressure } \\
\text { head }\end{array}$ & $\begin{array}{l}\text { Not included in sensitivity } \\
\text { analysis }\end{array}$ \\
\hline$M^{*}$ & $\frac{-L_{r m}}{L_{z}}$ & Relative root mat thickness & \\
\hline$R^{*}$ & $\frac{L_{c}}{L_{z}}$ & $\begin{array}{l}\text { Relative thickness of Cauchy resistance } \\
\text { layer }\end{array}$ & \\
\hline
\end{tabular}


0

Distance $x^{\prime}$

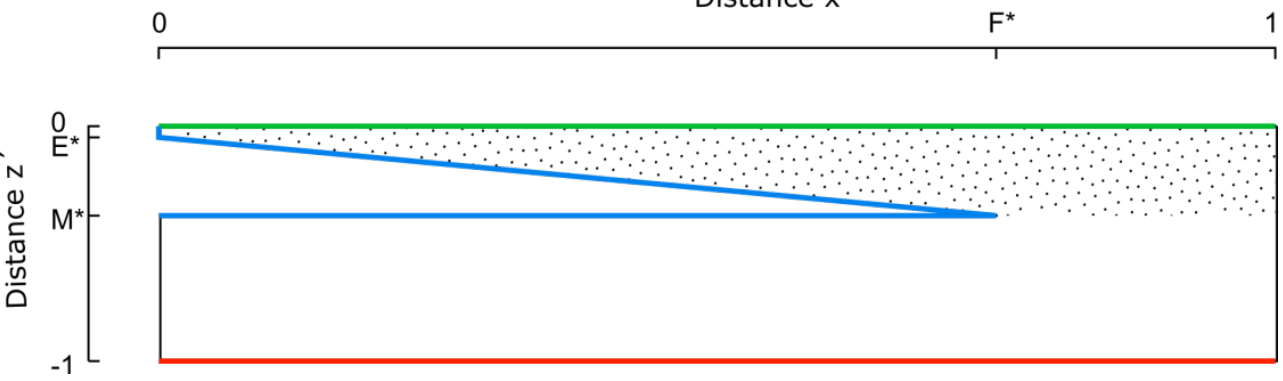

Figure 4.2. Schematization and boundary conditions of the floating fen model. The length coordinates $x^{\prime}$ range from 0 (root mat edge) to 1 (water divide). The depth $z^{\prime}$ ranges from 0 (surface) to -1 (depth of Cauchy boundary). The root mat (dotted) floats partially on open water (blue) and is partially connected to the subsurface (white). $F^{*}$ represents the relative length of the root mat that is floating. The maximum relative thickness of the root mat is described by $\mathrm{M}^{*}$, while the relative thickness of the root mat edge is described by $E^{*}$. The model boundaries consist of the atmospheric boundary (green thick line), the surface water (blue thick line) and a Cauchy boundary (thick red line) for recharge and of seepage from the subsurface. The other boundaries (black lines) are no flow boundaries. Root water uptake takes place from the root mat (dotted area).

\subsubsection{Sensitivity analysis}

The reference parameters for the sensitivity analysis were based on the Nieuwkoopse Plassen root mat, and converted into values for each dimensionless parameter group. Extreme values (smaller and larger) for each parameter were motivated by literature and all value permutations were calculated to identify the total range of possible values for each group. Simulations were conducted for each group, varying it $-20 \%,-10 \%,+10 \%$ and $+20 \%$ of the range (on log-scale if applicable) added to the reference values. Sensitivity analysis was only conducted for groups that were expected to vary in reality.

We selected dimensionless output variables to compare the output of the sensitivity analysis (Table 4.3). The first two (SD $W_{e}{ }^{*}$ and SD $W_{w d}{ }^{*}$ ) represent the groundwater level fluctuations that are found in the root mat, at a distance of $25 \%$ of the domain $\left(0.25 L_{x}\right)$, which is in the floating part of the root mat, and at the water divide $\left(L_{x}\right)$. The nondimensional output variables are the standard deviation of the scaled groundwater levels. Small fluctuations indicate a relatively stable groundwater level, while large fluctuations indicate strong level changes as a result of time-variable boundary conditions. The next variable, $\left(W_{w d}{ }^{*}\right)$ represents the average groundwater level at the water divide. Groundwater levels are an indicator of water availability for vegetation, but also affect biogeochemical processes by affecting oxygen availability. 
The next two nondimensional output variables $\left(Q_{s w}{ }^{*}\right.$ and $\left.Q_{d}{ }^{*}\right)$ are related to the average flow from or towards the root mat. $Q_{s w}$ * represents the average flow between the surface water and the root mat. The average volume of water that enters or leaves the root mat during a day is scaled with the total water storage volume within the root mat, which means that this variable is an indicator of how strongly the root mat water chemistry is affected by surface water. The exchange between the root mat and the subsurface $\left(Q_{d}{ }^{*}\right)$ that takes place at a depth of $L_{r m}$ between $L_{f}$ and $L_{x}$, is scaled over the length of the interface and the reference flow $P E T_{i}$. This variable is a measure of recharge or seepage taking place, which may be used to explain other hydrological phenomena, but it may also affect the hydrochemistry directly in the case of upward seepage.

The other nondimensional output variables focus on flow dynamics within the root mat. The first variable $\left(V^{*}\right)$ is the Darcian flow velocity, averaged over space and time, and scaled to the reference flow rate $P E T_{i}$. Higher values indicate higher flow velocities or increased flow over a larger area of the root mat. The next two variables provide an indication of the location of the position of the area of increased flow within the root mat. The position of the highest flow velocity over the length of the root mat is described by $V_{\text {max }} x^{*}$, while $V_{0.5_{z}}{ }^{*}$ gives an indication of the depth at which most of the flow occurs. The last variable represents the lag of flow after atmospheric forcing (evapotranspiration or precipitation) has ceased, by scaling the duration of $75 \%$ of the recession curve by the reference time.

To illustrate the hydrological behaviour of different types of floating fens, several additional simulations were done of examples of floating fens that could occur in reality (Table 4.4). The first three examples include different stages of succession, which is determined by the length of the root mat and the portion of it that is fixed to the subsurface, as well as the decrease in conductivity over depth. Furthermore, we show the effects of more intense precipitation and evapotranspiration, representing climate change, as well as a setting in which seepage (upward flow from the subsurface) occurs instead of recharge. Additionally, we simulated a situation in which the vegetation would be mostly mossy, with a relative increase of evaporation compared to transpiration and a decreased potential evapotranspiration. Finally, an example was included of a root mat of which the top $5 \mathrm{~cm}$ were removed, without changing other properties. 
Table 4.3 Dimensionless output variables of sensitivity analysis.

\begin{tabular}{|c|c|c|}
\hline Symbol & Nondimensional output variable & Description \\
\hline$S D W_{e}^{*}$ & $\mathrm{SD}\left(\frac{L_{g w}}{L_{z}}\right) @ 0.25 \mathrm{Lx}$ & Groundwater fluctuations \\
\hline$S D W_{w d}^{*}$ & $\mathrm{SD}\left(\frac{L_{g w}}{L_{z}}\right) @ \mathrm{~L}_{\mathrm{x}}$ & Groundwater fluctuations \\
\hline$W_{w d} *$ & $\operatorname{mean}\left(\frac{L_{g w}}{L_{z}}\right) @ \mathrm{~L}_{\mathrm{x}}$ & Mean groundwater level \\
\hline$Q_{s w}{ }^{*}$ & $\frac{\overline{Q_{s w}} t_{d a y}}{\left(L_{r m} L_{x}-0.5\left(L_{r m}-L_{e}\right) L_{f}\right)\left(\theta_{s}-\theta_{r}\right)}$ & $\begin{array}{l}\text { Exchange with surface water, relative to root mat water } \\
\text { volume }\end{array}$ \\
\hline$Q_{d}^{*}$ & $\frac{\overline{Q_{d}}}{\left(L_{x}-L_{f}\right) P E T_{i}}$ & $\begin{array}{l}\text { Downward flow from root mat to subsurface, scaled to } \\
\text { reference flow and boundary width }\end{array}$ \\
\hline$V^{*}$ & $\frac{\bar{q}}{P E T_{i}}$ & $\begin{array}{l}\text { Average Darcian flow velocity, scaled to reference flow } \\
\text { PET }\end{array}$ \\
\hline$V_{\text {max_x }} *$ & $\frac{L_{v m a x \_} x}{L_{x}}$ & $\begin{array}{l}\text { Position of highest flow velocity in } \mathrm{x} \text { dimension, scaled to } \\
\text { domain length }\end{array}$ \\
\hline$V_{0.5 \_}{ }^{*}$ & $\frac{L_{v 0.5 \_Z}}{L_{z}}$ & $\begin{array}{l}\text { Position of } 50 \% \text { of the highest flow velocity in } z \\
\text { dimension, scaled to domain depth }\end{array}$ \\
\hline$T_{q}^{*}$ & $\frac{t_{q 0.75}}{t_{\text {day }}}$ & $\begin{array}{l}\text { Duration of } 75 \% \text { of flow recession time, scaled to } \\
\text { reference time }\end{array}$ \\
\hline
\end{tabular}

Table 4.4 Example simulations.

\begin{tabular}{|c|c|c|}
\hline Example simulation & Description & $\begin{array}{l}\text { Parameters (different from reference } \\
\text { model) }\end{array}$ \\
\hline Early succession & $\begin{array}{l}\text { Small, completely floating root mat with no } \\
\text { decrease of conductivity with depth }\end{array}$ & $L_{x}=6 \mathrm{~m}, L_{f}=6 \mathrm{~m}, \mu=0$ \\
\hline Late succession & $\begin{array}{l}\text { Longer root mat that is for a large part fixed to } \\
\text { the subsurface }\end{array}$ & $L_{x}=20 \mathrm{~m}, L_{f}=10$ \\
\hline Long thin root mat & Long, thin root mat, that is mostly floating & $L_{x}=40 \mathrm{~m}, L_{f}=36 \mathrm{~m}$ \\
\hline Climate change & $\begin{array}{l}\text { More potential evapotranspiration and higher } \\
\text { rainfall intensity }\end{array}$ & $P E T_{i}=0.014 \mathrm{~m} \mathrm{~d}^{-1}, P_{i}=0.02 \mathrm{~m} \mathrm{~d}^{-1}$ \\
\hline Seepage & Upward seepage of $1 \mathrm{~mm} \mathrm{~d}^{-1}$ & $h_{l}=3.5 \mathrm{~m}$ \\
\hline Vegetation change & $\begin{array}{l}\text { More moss cover with smaller crop factor and } \\
\text { relatively more evaporation }\end{array}$ & $c_{f}=0.9, f_{t}=0.5$ \\
\hline Top soil removal & $\begin{array}{l}\text { The upper } 5 \mathrm{~cm} \text { of the root mat are removed, } \\
\text { the hydraulic conductivity of the top layer is } \\
\text { adjusted accordingly and the MvG parameters } \\
\text { are adapted to represent deeper layers (Grover } \\
\text { and Baldock, 2013) }\end{array}$ & $\begin{array}{l}L_{r m}=0.7 \mathrm{~m}, L_{e}=0.15 \mathrm{~m}, K_{s}=K_{s}^{-0.05 \mu} \mathrm{m} \mathrm{d}^{-1}, \\
n=1.3, \alpha=0.03\end{array}$ \\
\hline
\end{tabular}

\subsection{Results}

\subsubsection{Field data and evaporation experiment}

The measured groundwater levels show a clear difference between the floating parts of the root mat and the fixed part. In the floating part, the groundwater levels fluctuate mostly with the surface water (Figure 4.3). In the non-floating part, groundwater levels 
deviate from the surface water levels, with higher levels during wet periods, and lower during dry periods (Figure 4.3 and 4.4). In the fixed part, two types of patterns can be distinguished: peaks and recline after precipitation, and diurnal fluctuation in periods without rain. The groundwater level responds very fast to both precipitation and evapotranspiration. The patterns of both transects were very similar.

The evaporation experiment was conducted in the suction range of $3-5 \mathrm{~cm}$ until $200-500$ $\mathrm{cm}$, with the upper values being maximum of the measuring range of the tensiometers and also the main range of interest as higher values of suction are not likely to occur due to the high groundwater levels. The $p F$ curves that were fitted $\left(R^{2}=0.99\right.$ for all curves) with the results showed no significant differences between the two locations in the root mat. Therefore, the averages of the soil hydraulic parameters were used for the whole model domain (Table 4.5). The measured $K(h)$ curves variated much within and between samples, and the fitted curves did not fit the data very well $\left(R^{2}\right.$ values between 0.12 and $0.68)$, due to the variability. For that reason, the $K(h)$ curves were considered uncertain and the I parameter was varied widely in the calibration (within physical constraints). The $K_{\text {evap }}$ value that was found using the evaporation experiment is a fitted $K_{s}$ value based on measurements in unsaturated conditions, which may exclude large macropores, and should therefore not be compared with the $K_{s}$ values that were measured or calibrated in the saturated root mat.

Table 4.5 Averages and standard errors of soil hydraulic parameters as obtained by the evaporation experiment.

\begin{tabular}{ll}
\hline Parameter & Value (SE) \\
\hline $\mathrm{K}_{\text {evap }}\left(\mathrm{m} \mathrm{d}^{-1}\right)$ & $0.18(0.05)$ \\
$n(-)$ & $1.53(0.05)$ \\
$I(-)$ & $-1.09(0.44)$ \\
$\alpha\left(\mathrm{cm}^{-1}\right)$ & $0.042(0.007)$ \\
$\vartheta_{\mathrm{r}}(-)$ & $0.14(0.04)$ \\
$\vartheta_{s}(-)$ & $0.96(0.01)$ \\
\hline
\end{tabular}

\subsubsection{Model calibration and validation}

The model was initially calibrated freely for the relatively uncertain parameters $K_{s}$ and $K_{c}$ (affecting recharge rate). Since the diurnal fluctuations during dry periods remained structurally smaller than the measured fluctuations, $c_{f}$ and the MvG parameters were varied as well (within the constraints of the standard errors of the measurement results, except I). Comparison with measurement data was done for piezometer 3 (located at the fixed part of the root mat), as the water levels at the other locations fluctuated with the 

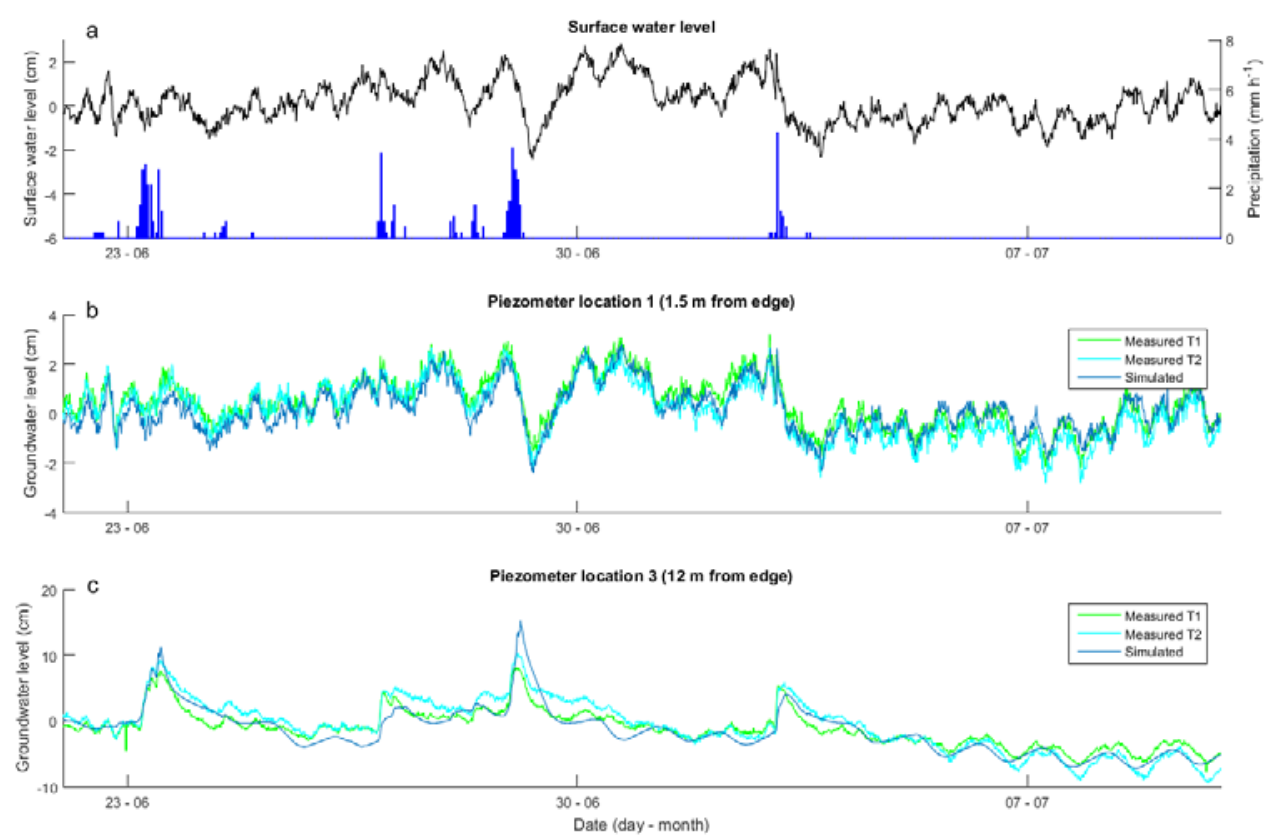

Figure 4.3 a. Measured surface water levels and hourly precipitation. $b$. Measured and simulated groundwater levels at piezometer location 1, 1.5 meter from the root mat edge, in both transects. Results for the piezometers at 4 and $18.5 \mathrm{~m}$ were very similar and are therefore not shown c. Measured and simulated groundwater levels at piezometer location 3, 12 meter from the root mat edge, in both transects.

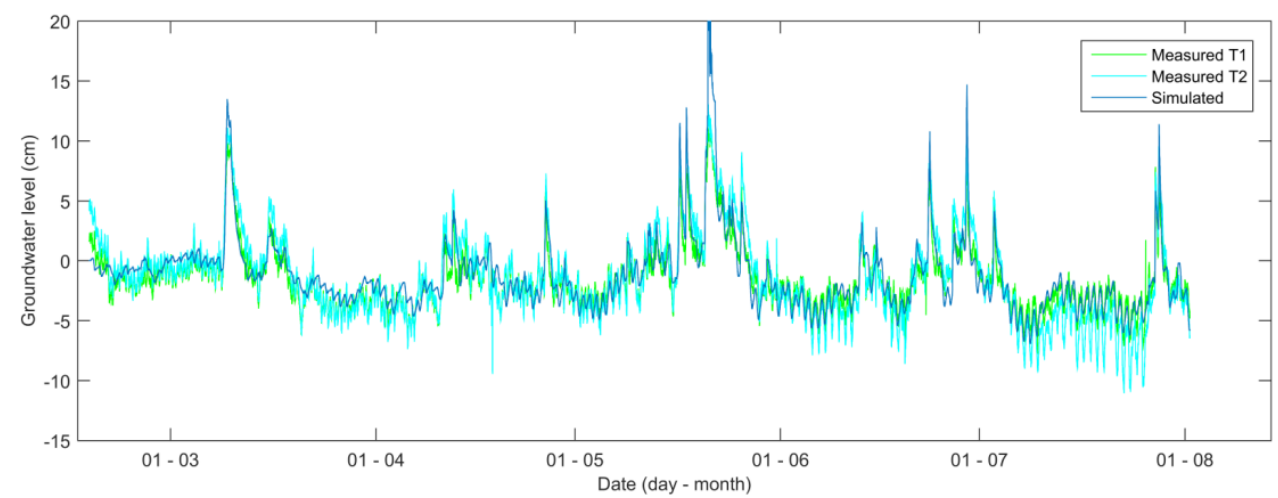

Figure 4.4 Validation model results using calibrated parameters compared to field observations in both transects (NS $=0.72$ and 0.76 respectively). 
surface water and were barely influenced by the parameters and the atmospheric forcing. The best calibration run resulted in Nash-Sutcliffe (NS) scores of 0.83 and 0.85 for transect 1 and 2 respectively, with an average root mat Ks of $3.57 \mathrm{~m} \mathrm{~d}^{-1}$ (with strong heterogeneity between the layers using the scaling field from (Stofberg et al., 2016), resulting in a $K_{s}$. value of $11.62 \mathrm{~m} \mathrm{~d}^{-1}$ at the root mat surface and $0.29 \mathrm{~m} \mathrm{~d}^{-1}$ in the lowest layer of the root mat) and an average recharge flux of $0.024 \mathrm{~mm} \mathrm{~d}^{-1}$. Adding $c_{f}$ and $\vartheta_{s}$ to the calibration did not improve results. Using these parameters (Table 4.1 ) in the validation simulation resulted in NS scores of 0.72 and 0.76 (Figure 4.4).

\subsubsection{Sensitivity analysis of nondimensional model and example simulations}

The calibrated parameters were used in the reference model of the sensitivity analysis. For the heterogeneous $K_{s}$ field, we fitted the exponential decrease with depth of the saturated conductivity (part of Eq. 4.4) to the scaling field. The fitted values for the top layer conductivity and the parameter $\mu$ are shown in Table 4.1. Initially, the group values were varied by two different combinations of dimensional parameter values, to test the robustness of the dimensionless model. This did not result in different outcomes.

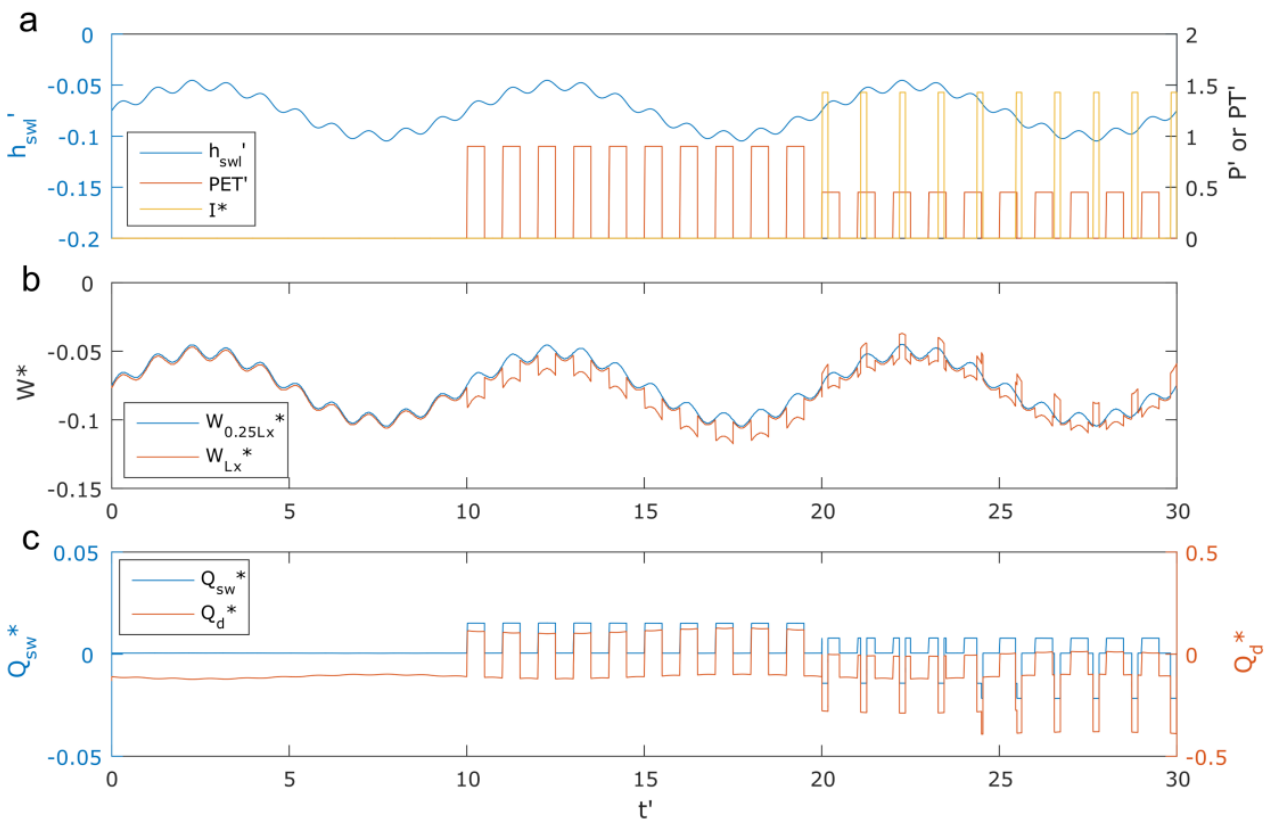

Figure 4.5 a. Scaled boundary conditions of the nondimensional reference model. b. Scaled groundwater levels at $0.25 L_{x}\left(W_{e}^{*}\right)$ and at $L_{x}$ (water divide, $W_{w d}{ }^{*}$ ) as simulated using the nondimensional reference model c. Scaled flow between the root mat and the surface water $Q_{s w}{ }^{*}$ and the root mat and the subsurface $\left(Q_{d}{ }^{*}\right)$ (positive flow is into the root mat) for the reference model. 

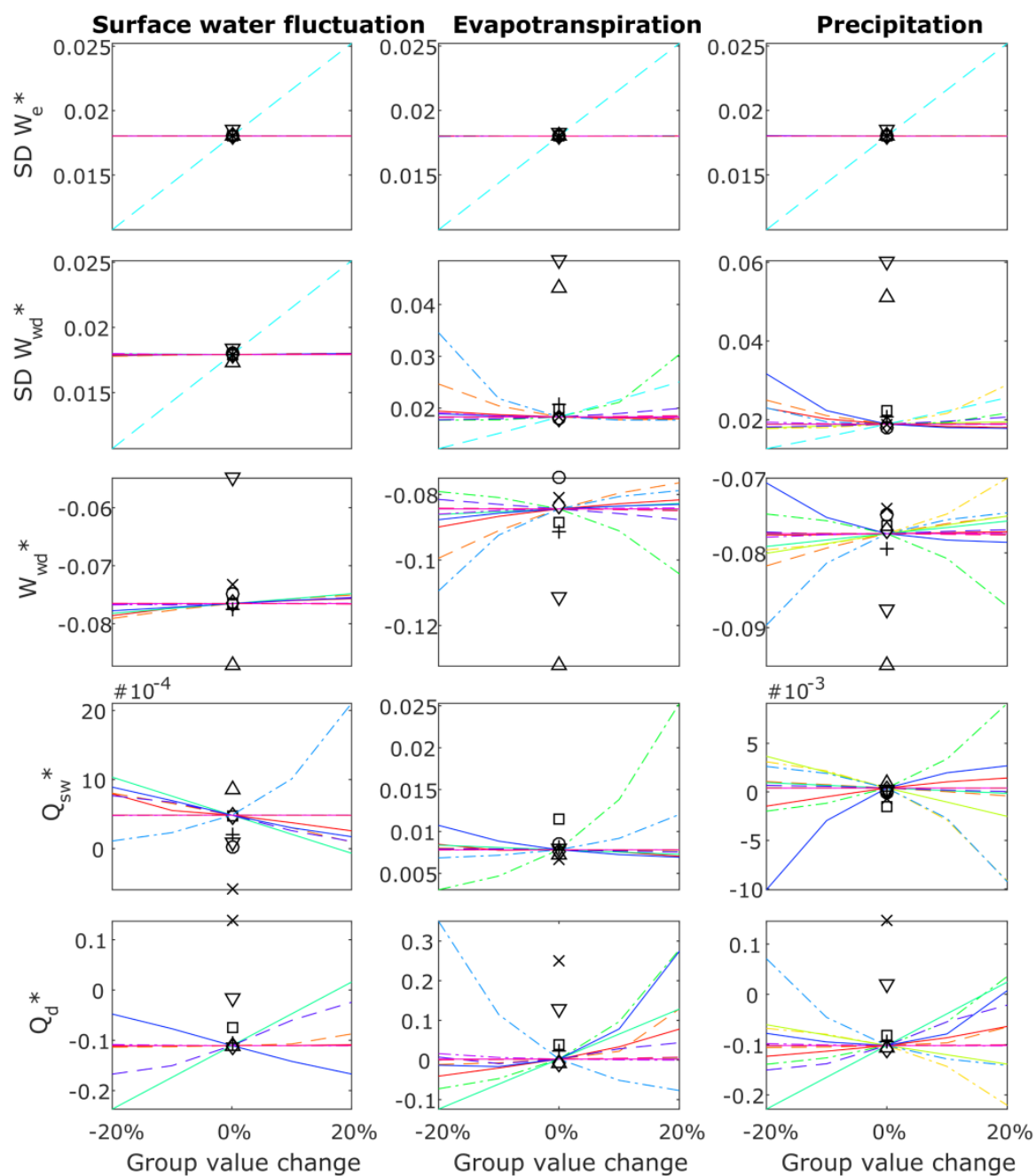

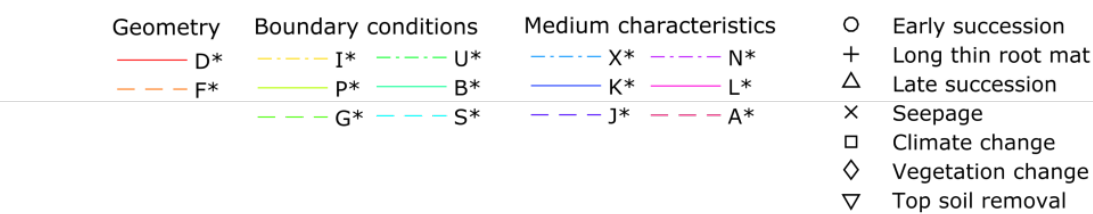

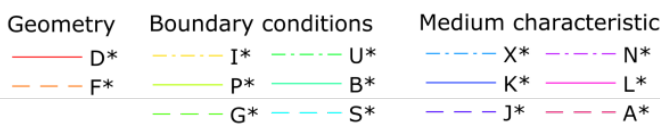

Figure 4.6 Results of the sensitivity analysis. The line plots show the effects of varying the dimensionless groups (legend) $-20 \%,-10 \%, 0 \%,+10 \%$ and $+20 \%$ and the symbols show the effects of the example simulations. The effects are shown for the standard deviation of the groundwater levels in the floating edge of the root mat (SD $W_{e}{ }^{*}$, first row), and at the water divide (SD $W_{w d}{ }^{*}$, second row), the average groundwater level $\left(W_{w d}^{*}\right.$, third row), the flow of water between surface water and root mat (scaled over root mat pore volume, $Q_{s w}{ }^{*}$, fourth row) and flow between the root mat and the deeper subsoil (scaled over root mat volume, $Q_{d}{ }^{*}$, last row). Flow into the root mat is positive. The results are shown for the scenarios of just surface water fluctuations (left column), evapotranspiration (middle column), and precipitation (right column). 


\section{Groundwater fluctuations}

In the nondimensional model, the groundwater levels in the floating part of the root mat fluctuated at the same level as the surface water (Figure 4.5). The groundwater level at the water divide fluctuates with the surface water in the absence of atmospheric forcing (albeit at a slightly lower level and with a very small lag), but also responds clearly to the evapotranspiration and precipitation. The patterns caused by the atmospheric forcing mask the patterns caused by the small, short timescale surface water fluctuations, but not the larger ones. The results of the sensitivity analysis show that groundwater levels (not shown), as well as their fluctuations (Figure 4.6), in the floating part of the root mat are not sensitive to any parameter groups, except for changes in surface water fluctuations $\left(S^{*}\right)$. At the water divide, surface water fluctuations have the same effect on the fluctuations, while the average water levels are slightly affected by the resistance between the water divide and the surface water (as a result of geometry $F^{*}$ and $D^{*}$ or conductivity $\left.K^{*}\right)$ as well as the subsurface boundary $\left(B^{*}\right)$. In the evapotranspiration and precipitation scenarios, groundwater fluctuations become much stronger at the water divide than in the floating part or in the simulations without atmospheric forcing. The fluctuations and average groundwater levels at the water divide are strongly affected by increased atmospheric forcing $\left(U^{*}\right.$ and $\left.I^{*}\right)$ and increased resistance to flow as a result of changed medium characteristics $\left(X^{*}, K^{*}\right.$ and $\left.J^{*}\right)$ or changed root mat geometry $\left(F^{*}\right.$ and $\left.D^{*}\right)$.

\section{Water exchange between root mat and boundaries}

When only surface water fluctuation is considered, the exchange between the root mat and the surface water $\left(Q_{s w}{ }^{*}\right)$ generally shows small positive values $(0.5 \%$ per day of the water in the root mat is replaced by surface water), which indicates that water flows into the root mat (Figures 4.5 and 4.6). This flow direction is forced by the downward flow into the subsurface that takes place in the part of the root mat that is fixed to the subsurface $\left(Q_{d}{ }^{*}\right)$. With evapotranspiration, the flow into the root mat becomes stronger (about $1 \%$ per day on average), and the downward flow decreases. Precipitation decreases the net inflow or results in net outflow from the root mat into the surface water, while increasing the downward flow from the root mat into the subsurface.

The results of the sensitivity analysis show that the relative amount of exchange between root mat and surface water is strongly affected by the atmospheric forcing intensity $\left(U^{*}\right.$, $\left.I^{*}\right)$, as well as duration $\left(P^{*}\right)$. Increased net inflow into the root mat as a result of these parameter groups correlates with decreased downward flow (or even net upwards flow) as a result of negative gradients that occur towards the water divide. The forcing from the subsurface boundary $\left(B^{*}\right)$ affects the system in a different way, as increased downward flow results in increased net inflow from the surface water. 

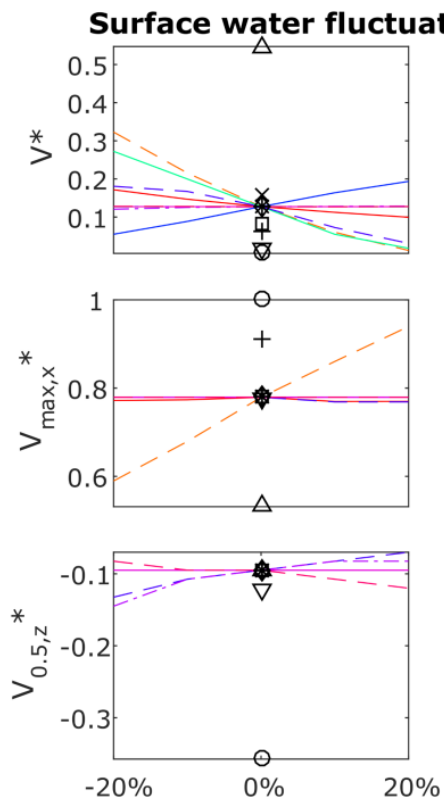

Group value change
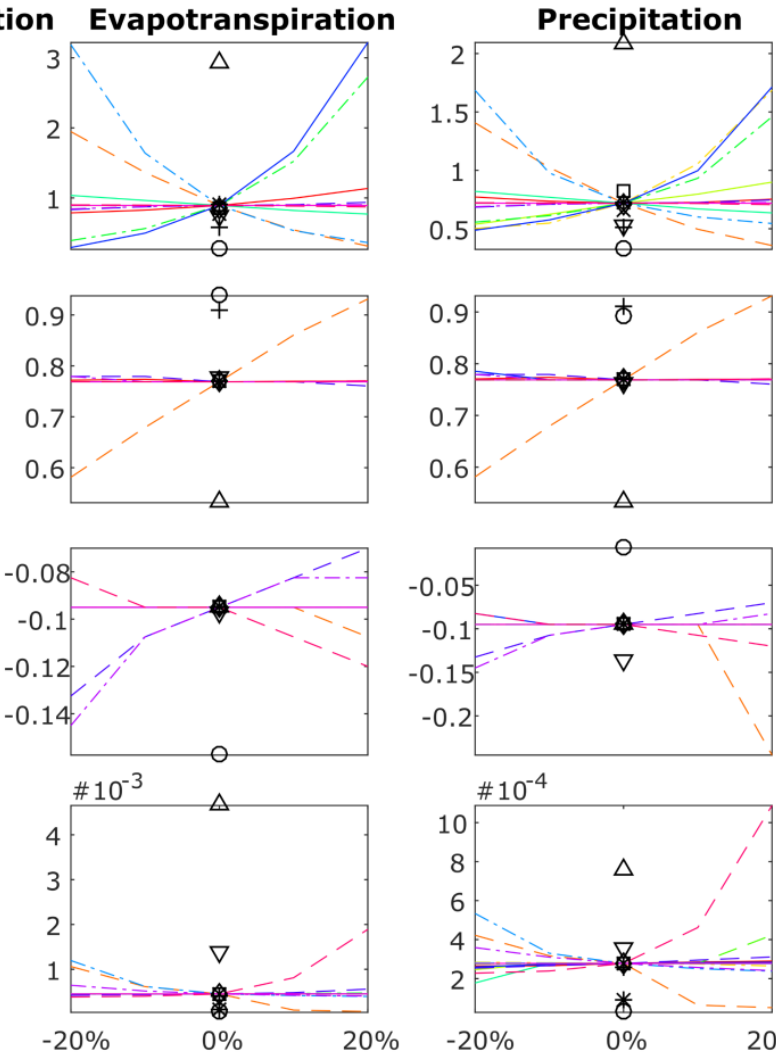

Group value change

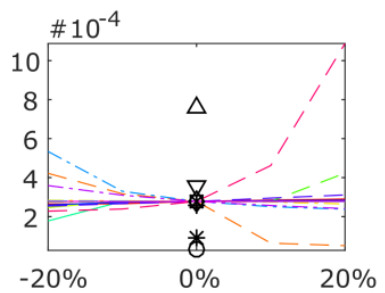

Group value change

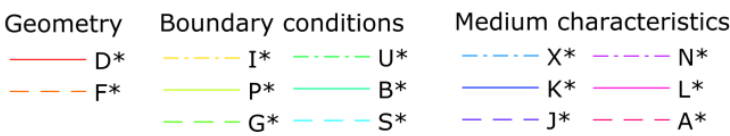

Figure 4.7 Results of the sensitivity analysis. The line plots show the effects of varying the dimensionless groups (legend) $-20 \%,-10 \%, 0 \%,+10 \%$ and $+20 \%$ and the symbols show the effects of the example simulations. The effects are shown for the average Darcian flow velocity ( $V^{*}$, first row), the position of the highest flow $\left(V_{\max , x}{ }^{*}\right.$, second row), the depth of half the flow velocity $\left(V_{0.52}{ }^{*}\right.$, third row) and the time that it takes for $75 \%$ of a flow peak to recede $\left(T_{q}{ }^{*}\right.$, last row). The results are shown for the scenarios of just surface water fluctuations (left column), evapotranspiration (middle column), and precipitation (right column).

Flow from and towards the root mat is also affected by parameter groups that control the properties of the root mat. With higher values of $X^{*}$ (less storage within the root mat, relative to conductivity) a higher percentage of the water in the root mat is exchanged with the surface water as a result of external forcing, while relative downward flow 
increases as well. $K^{*}$ generally has the opposite effect, as it scales conductivity to the atmospheric fluxes, which results in decreased exchange with the surface water and decreased relative downward flow with atmospheric forcing with higher values of $K^{*}$. Root mat heterogeneity $\left(J^{*}\right)$ has a small effect on flow in and out of the root mat as increased root mat resistance at deeper layers results in less exchange with the subsurface and surface water boundaries.

Furthermore, the root mat geometry has a small effect on boundary flow, as a more floating root mat $\left(F^{*}\right)$ has more exchange with the surface water and less with the subsurface, while a decreased aspect ratio $\left(D^{*}\right)$ leads to a (slight) relative increase of exchange over both boundaries.

\section{Flow and dynamics}

Average flow velocity in the root mat is relatively small under only surface water fluctuations, and becomes much stronger when atmospheric forcing is taken into account (Figure 4.8). For precipitation, this effect is smaller, due to the relatively short duration of precipitation events. Most of the flow is concentrated in the upper layer of the root mat, near the point where the mat becomes attached to the subsurface $\left(F^{*}\right)$. While the direction of flow depends on the boundary forcing, the flow in this region is lateral, transporting water to and from the fixed part of the root mat (Figure 4.9).

The sensitivity analysis (Figure 4.7) shows that also for this output variable, the effects are the strongest for the root mat properties, the upper and lower boundaries, as well as the root mat geometry, as flow rates and flow path lengths are affected. Relative flow velocity within the root mat becomes larger with relatively higher conductivity $\left(K^{*}\right)$ and more storage $\left(X^{*}\right)$. Stronger external forcing leads to higher $\left(U^{*}, I^{*}\right.$, and $\left.B^{*}\right)$ or prolonged high $\left(P^{*}\right)$ relative velocities as well, while less floating $\left(F^{*}\right)$ or wider root mats lead to longer flow paths and therefore result in higher average velocities.

In almost all simulations the area of maximum flow was located near the surface of the root mat (above $-0.1 z^{\prime}$, which equals to $20 \mathrm{~cm}$ depth in the reference simulation), not far from the distance at which the root mat becomes attached to the subsurface $\left(F^{*}\right.$, Figures 4.7, 4.8 and 4.9). The results of the sensitivity analysis show that the attachment to the subsurface $\left(F^{*}\right)$ is the determining parameter of the location of the highest flow velocities $\left(V_{\max , x}{ }^{*}\right)$, and has an effect on the depth of flow as well, with deeper flow with a more floating root mat. With lower heterogeneity $\left(J^{*}\right)$, the flow depth becomes also deeper. The MvG parameter related groups $\left(A^{*}\right.$ and $\left.N^{*}\right)$ also control the flow depth, with deeper flow occurring with smaller air entry values (larger $A^{*}$ ) and smaller values of $N^{*}$, which can be 
explained by steeper decrease of conductivity with negative pressure heads, which forces the flow to occur at greater depths.

Flow recession times $\left(T_{q}{ }^{*}\right)$ are in the order of minutes for all simulations, with most of the flow recession occurring in less than 3 minutes (Figure 4.7). This variable is mostly affected by the nondimensional groups that affect the unsaturated properties, as the slope of the $K(h)$ function $\left(A^{*}\right.$ and $\left.N^{*}\right)$ or storage $\left.X^{*}\right)$ is affected. The root mat geometry $\left(F^{*}\right)$ plays a role as well, with increased floatation leading to smaller recession times (reaching a threshold close to 0 , which is related to the minimum simulation time step) due to shorter flow paths.

Surface water level fluctuations

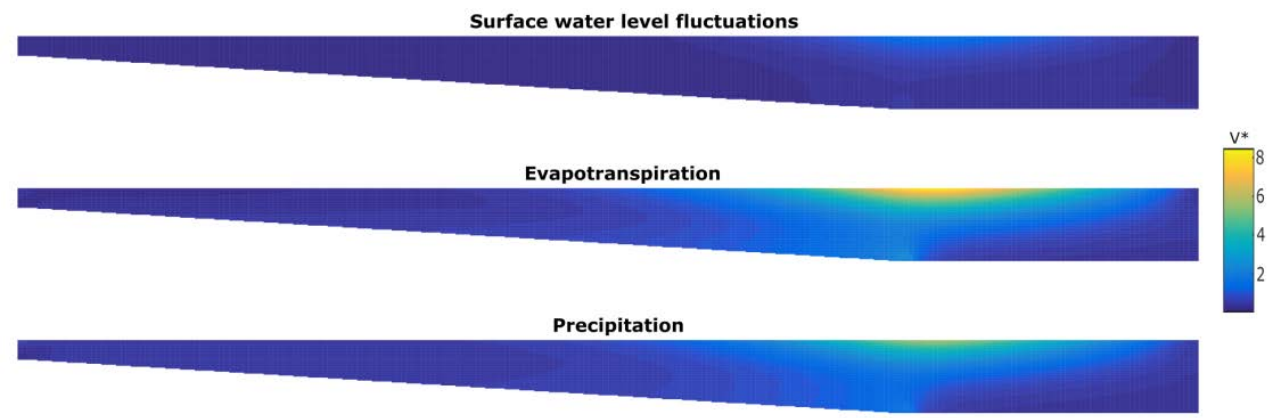

Figure 4.8 Time-averaged scaled velocity $\left(V^{*}\right)$ in the root mat during the three types of boundary conditions.

Surface water fluctuation

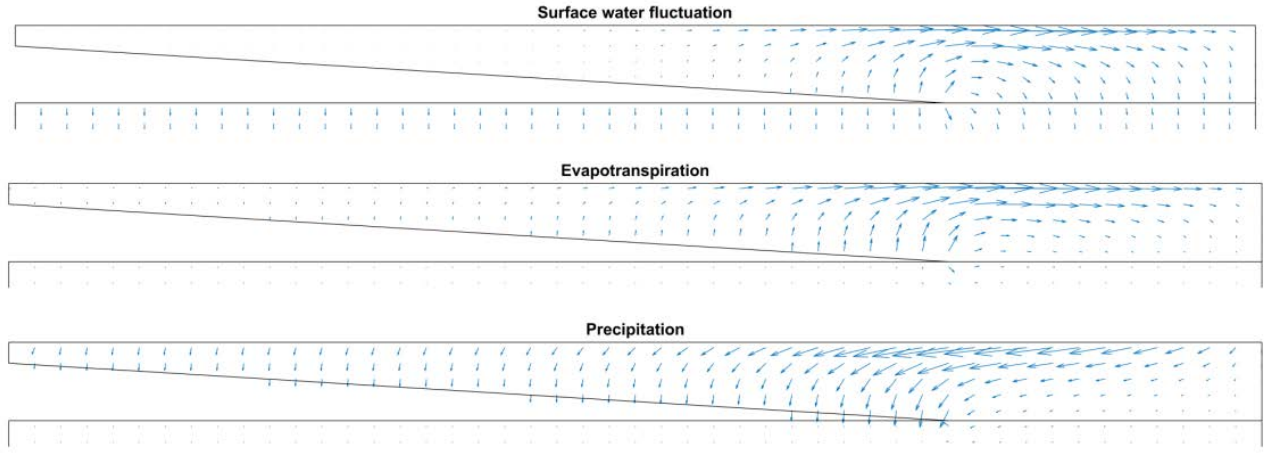

Figure 4.9 Snapshot of flow vectors in and below the root mat in the reference simulation during surface water fluctuation, an evapotranspiration event and during a precipitation event. The scale of the flow vectors differs between images. 


\subsubsection{Example simulations}

The example simulations (Figures 4.6 and 4.7) show how combinations of different parameter groups may affect the hydrology of different types of root mats. Early in the succession, root mats are small, thin, conductive and floating. They have relatively high and constant groundwater levels, and the exchange with the surface water is only affected by the atmospheric forcing, as there is no exchange with the subsurface. The short, vertical flow paths (Figure 4.10) result in low flow velocities, with the highest flow rates close to the water divide and very short recession times. As succession continues, root mats may develop into wider, thicker systems (such as the reference simulation) or into much wider, mostly floating systems. These long, thin root mats systems behave in a very similar way as the early succession root mats, except for lower groundwater levels around the water divide, as this root mat is attached to the subsurface. It also has slightly more exchange with the boundaries (as a small part is now attached to the subsurface) and subsequent slightly larger velocities and recession times. Late succession root mats are large as well, and for a large part attached to the subsurface. As a consequence of the increased resistance between the water divide and the surface water, the groundwater levels are much lower as a result of the precipitation deficit in combination with the recharge. They experience stronger groundwater fluctuations and longer recession times. As the lateral flow paths have become very long (Figure 4.11), the average flow rate within the root mat is large, with the maximum flow rates occurring close to the distance where the root mat becomes attached to the subsurface $\left(F^{*}\right)$.

In the other example simulations, the effects of root mats under various circumstances are investigated. As was already seen in the sensitivity analysis, the subsurface boundary has an effect on the groundwater level and water flow to or from the root mat. In the example of a root mat receiving seepage from the subsurface, this effect is mostly visible for the groundwater level and the water exchange variables as well. Seepage leads to an increased groundwater level at the water divide, and increased outflow (or decreased inflow) between the root mat and the surface water. The seepage intensity itself is affected by the atmospheric gradient, which affects the gradients for flow into the root mat, but flow patterns and dynamics are not affected, except for the flow direction. In the example that represents climate change, with increased evapotranspiration and precipitation intensity, we observe a small increase in groundwater fluctuations. Additionally, an increase of water exchange with the surface water and a decrease of subsurface flow relative to the atmospheric flow were observed, but no changes in the flow paths or the dynamics of the system. Similar to the lack of effect of $G^{*}$ in the sensitivity analysis, which represents the division between evaporation and transpiration, the example with changed vegetation did not affect any of the output variables. Top soil 
removal has strong effects on several variables, including groundwater fluctuation, which becomes stronger as the highly conductive upper layer is removed, leading to more resistance to flow, and overland flow in the case of precipitation (no ponding was simulated) and reduced subsurface recharge. Average flow becomes slower, at deeper layers, thereby increasing recession times.

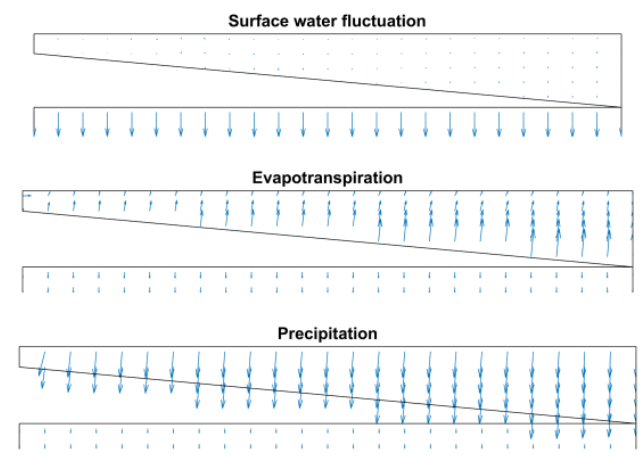

Figure 4.10 Snapshot of flow vectors in the Example 1 simulation during surface water fluctuation, an evapotranspiration event and during a precipitation event. The scale of the flow vectors differs between images.

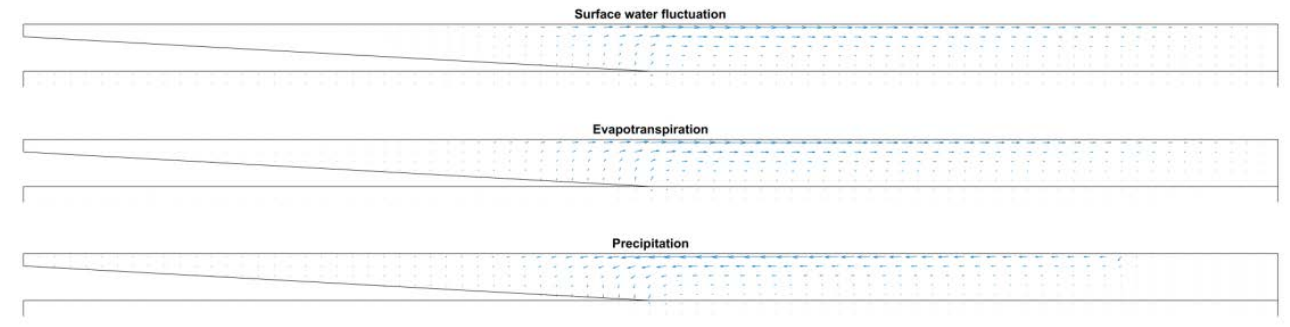

Figure 4.11 Snapshot of flow vectors in the Example 2 simulation during surface water fluctuation, an evapotranspiration event and during a precipitation event. The scale of the flow vectors differs between images.

\subsection{Discussion}

\subsubsection{Model results and field observations}

As the field observations showed good agreement between the two transects, twodimensional modelling of the root mat transect is justified. The validation results revealed that the model of the Nieuwkoopse Plassen root mat could explain most of the observed variation. 
The calibrated average root mat hydraulic conductivity was $3.57 \mathrm{~m} \mathrm{~d}^{-1}$, with an average of $8.11 \mathrm{~m} \mathrm{~d}^{-1}$ in the upper $20 \mathrm{~cm}$ of the root mat and $0.35 \mathrm{~m} \mathrm{~d}^{-1}$ in the lowest $20 \mathrm{~cm}$ of the root mat. This $K_{s}$ value is larger than the $K_{s}$ value that was measured by Stofberg et al. (2016). A similar issue was also mentioned by Koerselman (1989). Kettridge et al. (2012) found that near surface peat layers are especially susceptible to seasonal changes in conductivity as a result of changes in gas content and volume. Besides anisotropy and uncertainties regarding the root mat geometry, such factors may help explain the differences between the measured and calibrated conductivity values. Including such processes in a hydrological model would not be a trivial task, both from a modelling perspective and regarding the parameterization.

Some of the remaining differences between the observations and the simulations can probably be attributed to uncertainties in the atmospheric forcing, to which the system is very sensitive. Grover and Baldock (2013) showed that soil water retention curves differed between surface peat and deeper, more decomposed layers, which stems from the different pore size distributions. Such a heterogeneity is not unexpected, considering previous observations in hydraulic conductivity and degree of decomposition of the field area (Stofberg et al., 2016). However, the sensitivity analysis showed that differences in most of the unsaturated hydraulic properties $\left(N^{*}, L^{*}, A^{*}\right)$ do not affect the groundwater levels, and therefore, just as hysteresis, do not explain the residuals. However, it may be possible that effective porosity $\left(X^{*}\right)$ may be different between the layers, and could explain some of the differences between observation and simulation.

\subsubsection{Hydrological system characterization}

On a general level, our results show that the groundwater dynamics between the floating and the fixed part of the root mat differ strongly. The floating parts are mainly influenced by the surface water, even in the less conductive floating part at the newly created edge (right edge in Figure 4.1). The sensitivity analysis confirms this observation of robustness, showing that the thickness or conductivity of a floating root mat may not be important. In practice, the surface water fluctuations should have a smaller influence than our results suggest, as the root mat moves up and down with the surface water (Cusell et al., 2015; Stofberg et al., 2016). Therefore, the vegetation of the floating part experiences few changes over time. In younger stages of succession, this behaviour is found all over the root mat, and only vertical exchange with the surface water layer below the root mat occurs. In such systems, as well as in long, mostly floating, systems, simulating flow within the root mat using a one-dimensional model, such as was done by van Wirdum (1991), is justified. 
In the part of the root mat that is fixed to the subsurface, groundwater fluctuations are much stronger, as they become strongly affected by atmospheric forcing and root mat hydraulic properties. This is also reflected in the flow patterns within the root mat: the flow is lateral and concentrated close to the more conductive root mat surface. The more the groundwater becomes isolated from the surface water (by distance or low conductivity), the more the groundwater becomes affected by vertical fluxes (atmospheric forcing and recharge or seepage). In late stages of succession, lateral flow has to occur over long flow paths, leading to stronger groundwater level fluctuations, and more dependence on atmospheric forcing. However, in all simulations including this example, total storage does not show strong changes over time as the system responds very quickly to changes in boundary conditions, which seems to be typical of floating fens.

While root mat hydrology is very sensitive to the geometry and conductivity affecting the resistance, as well as the intensity of boundary flow, it is not sensitive to other parameter types. It is barely affected by the duration of precipitation $\left(P^{*}\right)$ or partitioning between transpiration and evaporation $\left(G^{*}\right)$, which can be explained by the fast responses and short flow paths within the system. Flow in periods of alternating evapotranspiration and precipitation could probably be estimated using a sequence of steady states. The unsaturated hydraulic properties seem to have a very limited effect as well, which may be explained by the limited thickness of the unsaturated zone.

\subsubsection{Flow and transport}

In floating (parts of) root mats where only vertical flow occurs, water exchange with the surface water will occur purely as a result of precipitation and evapotranspiration. In theory, the average precipitation excess or deficit would determine the average water quality within the root mat. However, in the case that precipitation and surface water below the root mat have a different composition, the alternating flow directions could lead to temporally fluctuating concentrations, as well as to significant mixing (Cirkel et al., 2015).

Van Wirdum (1991) described that buffered surface water is pulled into the water layer below the root mat as a result of significant downward flow into the subsurface (recharge). With root mats that are partially connected to the subsurface, this pattern is extended into the root mat itself, as recharge or seepage provide a driving force for water exchange between the root mat and the surface water, albeit a relatively small one. The average net flow in or out of the root mat is determined by the difference between the precipitation surplus and the recharge flux into the subsurface. Similar to the floating part 
of the root mat, fluctuations and mixing will occur here as well, but as flow paths are longer, water quality on most parts of this area of the root mat will be determined by the average flow direction. In our Nieuwkoopse Plassen reference case, with a precipitation surplus and very little recharge, the fixed part of the root mat should be mostly influenced by rain water.

The hydrological flow patterns we found cannot directly be translated into transport processes, as additional phenomena such as preferential or bypass flow (e.g. Baird and Gaffney, 2000; Liu et al., 2016), and reactive transport must be taken into account. For example, during relatively intense precipitation events, water may quickly flow through macropores, bypassing most of the soil matrix, while transpired water may be replaced by slower flow through the bulk soil matrix.

To predict actual water quality within the root mat, the concentrations at the boundaries should be known as well. While precipitation and seepage (if applicable) can be assumed to have a similar quality over their entire boundaries, for the surface water, this may not be the case. van Wirdum, (1991) showed that the flow in the water layer below the root mat is driven by the difference between the precipitation surplus and the recharge to the subsurface. If there is little recharge compared to the precipitation surplus, such as is the case in the Nieuwkoopse Plassen, the water layer below the floating part of the root mat will mainly be rain water quality, with a mixing zone with surface water quality close to the edge of the root mat. With strong recharge, as was the case in Van Wirdum's study area, most of the water layer below the root mat will be similar to surface water quality.

\subsubsection{Implications for management}

One of the main challenges faced by nature managers regarding (floating) fens, is the conservation of early successional rich fen vegetation, which depends on the influence of base-rich seepage or surface water. In the Nieuwkoopse Plassen study area, this type of vegetation is only found close to the (original) root mat edge. A few meters from the edge, the hydrology does not seem to significantly differ from the edge itself (consisting of vertical flow), but the vegetation has already become more ombrotrophic, consisting of Erica tetralix and Sphagnum species. A likely explanation would be that the layer below the root mat does not contain base-rich water, as the very small recharge flux into the subsurface is not enough to counteract the outward flux as a result of the average precipitation surplus. This mechanism also explains the existence of long thin root mats with rich-fen vegetation in areas with relatively strong recharge (van Wirdum, 1991) or seepage (Beltman et al., 1996), as discussed by van Diggelen et al. (1996), since both lead 
to increased water exchange between the root mat and the environment. In (mostly) floating root mats, measures regarding restoring rich-fen vegetation should focus on the availability of base-rich water below the root mat, however, recharge and seepage rates are difficult to control, and any measures to influence this should be considered in view of the regional hydrology. In the absence of strong recharge or seepage, as is the case in the Nieuwkoopse Plassen, digging new turf ponds seems like a potentially useful strategy to expand areas where exchange with base-rich surface water may actually happen. At the study site, we observed that some of the old root mat, close to the newly dug ditch, had started to float again, which meant that the hydrological behaviour became similar to the young edge, despite its different properties (further decomposed peat). However, it will depend on the water quality of the layer below as well as on transport properties if base rich water can reach this area of the root mat. Rich fen vegetation is more likely to develop as the new turf pond becomes colonized, although this process can be complicated by multiple factors, including insufficient water quality and adverse landscape characteristics (Beltman et al., 2011; Geurts et al., 2009; Sarneel et al., 2011).

Other types of restoration measures in floating and non-floating parts of root mats often focus on bringing base-rich water into the root mat, by creating conductive flow paths (ditches or trenches) or by imposing gradients (temporarily increase surface water levels). Ditches or trenches are meant to quickly discharge rain water and to allow surface water to enter the root mat during evapotranspiration (Beltman et al., 1996; Bootsma et al., 2002). The volume of water in such ditches should be small enough to make sure that buffered water will reach far enough into the root mat. In combination with other measures, ditches may be effective, although their effect is limited to a few meters around the ditch (Beltman et al., 1996; Bootsma et al., 2002). Cusell et al. (2015) temporarily increased the surface water levels in a floating fen area, and observed that base-rich water flowed into the root mat for non-floating root mats that were not completely saturated, in other words, when there was a hydraulic gradient towards the root mat. Our results showed that in general, increased surface water level fluctuations do not lead to increased net inflow (as increased inflow of $0.2 \%$ was compensated with increased outflow), but a strong increase in surface water level, combined with a low groundwater level could provide a temporarily strong influx. Top soil removal is sometimes carried out as a measure against widespread Sphagnum cover, giving vascular plants more room to germinate and grow (Beltman et al., 1996; Bootsma et al., 2002; van Diggelen et al., 2015). As the highly conductive upper layer is removed, the connection with the surface water may be weakened, causing stronger relative level fluctuations in the fixed part of the root mat, and overland flow in the case of precipitation. However, this is only a temporary stage, as new plants will create new layers. Top soil removal can only be effective if supply of base-rich water is restored as well, making the fixed part of 
the root mat not a very promising location to apply this measure, unless it leads to floating conditions or if other measures are applied.

On the fixed part of the root mat, succession may proceed from poor fen vegetation to (embryonic) bog or forest, depending on the management (Verhoeven and Bobbink, 2001). The hydrology could play a role as well, as desiccation is associated with increased nutrient availability, which gives vascular plants an advantage over Sphagnum mosses. A good connection with the surface water (through a short connection or conductive layer) may help to keep groundwater levels more constant, as they are lowered by atmospheric forcing. Although areas with strong seepage have generally higher groundwater levels, the fluctuations over time are not affected, which means these areas have no advantage compared to recharge areas.

Besides dealing with ongoing succession, nature managers may be faced by other challenges, including surface water contamination and the effects of climate change. As discussed above, exchange between groundwater and surface water depends not only on the flow paths within the floating and non-floating parts of the root mat, but also on the actual concentrations in the layer below the root mat. Dry periods during summer are more likely to coincide with contamination, due to increased river water supply (to maintain surface water levels constant) and increased risk of salinization. The combination of these two factors (dry weather and contamination) may lead to more exposure than would normally be anticipated.

\subsection{Conclusion}

Floating fens are quickly responding systems in which two types of hydrological behaviour may be observed. The floating part is an extremely robust subsystem, with vertical flow, leading to practically instantaneous exchange with the upper and lower boundaries and subsequent stable conditions. The part that is fixed to the subsurface is more strongly affected by the atmospheric forcing and (less) by seepage or recharge. The effects of these boundaries are dampened by the surface water, which influence depends on the resistance to the lateral flow between groundwater and surface water.

Over the course of succession, floating fens shift from the first type of conditions to the second. Besides water flow and dynamics, chemical conditions affect the vegetation. As no differences in hydrology are observed within different vegetation zones in floating parts of root mats, concentration differences within the water layer below the root mat are proposed as a potential explanation. As root mats become attached to the subsurface, 
the exchange with the surface water takes place over longer flow paths, reducing its influence and increasing the dependence on atmospheric forcing as a driving force.

Acknowledgements

The authors would like to thank our colleagues Henny Gertsen and Harm Gooren for their technical assistance, and Jan Wesseling for advice regarding model calibration. We are grateful to Vereniging Natuurmonumenten for allowing us to conduct measurements in the Nieuwkoopse Plassen nature reserve. Furthermore, we thank the Dutch Knowledge for Climate program, Theme 2 Fresh Water Supply, STW/lenM through project WaterNexus (STW contract 14299), and NWO IPPSI-KIEM for funding this research. 


\section{Appendix 4A Derivation of the nondimensional root mat model}

\section{A.1 General approach}

All model equations, schematization, boundary and initial conditions and output variables are made nondimensional. This is done by replacing all model variables and parameters by the product of a reference value and a dimensionless parameter, such as is shown here for the pressure head $h$ :

$h=h_{r} h^{\prime}$

All reference parameters are then grouped into nondimensional parameter groups that represent system characteristics. As some groups may overlap, and by choosing reference values, the number of groups is reduced.

\section{A.2 Model equations}

Flow is simulated with the $2 \mathrm{D}$ Richards equation with a sink term for the root water uptake

$\frac{\partial \theta}{\partial t}=\frac{\partial}{\partial x}\left(K(h, z)\left(\frac{\partial h}{\partial x}\right)\right)+\frac{\partial}{\partial z}\left(K(h, z)\left(\frac{\partial h}{\partial z}+1\right)\right)-S$

In the Richards equation, we substituted $\theta$ using the definition of saturation

$S_{e}=\frac{\theta(h)-\theta_{r}}{\theta_{s}-\theta_{r}}=\left(1+|\alpha h|^{n}\right)^{-m}$

$\theta=S_{e}\left(\theta_{s}-\theta_{r}\right)+\theta_{r}$

In the differential equation, the added constant $\theta_{r}$ can be removed, as it does not affect the differential. Saturation is then the dimensionless representation of $\theta$, while $\theta_{s}-\theta_{r}$ represents the reference value. Further separating the parameters and variables in the Richards equation results in:

$\frac{\left(\theta_{S}-\theta_{r}\right)}{t_{r}} \frac{\partial S_{e}}{\partial t^{\prime}}=\frac{1}{x_{r}} \frac{\partial}{\partial x^{\prime}}\left(K\left(h_{r} h^{\prime} z_{r} z^{\prime}\right) \frac{h_{r}}{x_{r}}\left(\frac{\partial h^{\prime}}{\partial x^{\prime}}\right)\right)+\frac{1}{z_{r}} \frac{\partial}{\partial z^{\prime}}\left(K\left(h_{r} h^{\prime} z_{r} z^{\prime}\right) \frac{h_{r}}{z_{r}}\left(\frac{\partial h^{\prime}}{\partial z^{\prime}}+\frac{z_{r}}{h_{r}}\right)\right)-S_{r} S^{\prime}$

Which can be rearranged into: 
$\frac{\partial S_{e}}{\partial t^{\prime}}=\frac{h_{r} t_{r}}{\left(\theta_{S}-\theta_{r}\right) x_{r}^{2}} \frac{\partial}{\partial x^{\prime}}\left(K\left(h_{r} h^{\prime} z_{r} z^{\prime}\right)\left(\frac{\partial h^{\prime}}{\partial x^{\prime}}\right)\right)+\frac{h_{r} t_{r}}{\left(\theta_{s}-\theta_{r}\right) z_{r}^{2}} \frac{\partial}{\partial z^{\prime}}\left(K\left(h_{r} h^{\prime} z_{r} z^{\prime}\right)\left(\frac{\partial h^{\prime}}{\partial z^{\prime}}+\frac{z_{r}}{h_{r}}\right)\right)-$

$\frac{s_{r} t_{r}}{\left(\theta_{s}-\theta_{r}\right)} S^{\prime}$

in which we can define preliminary dimensionless groups:

$C_{1}=\frac{h_{r} t_{r} K_{r}}{\left(\theta_{s}-\theta_{r}\right) x_{r}^{2}}$

$C_{2}=\frac{h_{r} t_{r} K_{r}}{\left(\theta_{s}-\theta_{r}\right) z_{r}^{2}}$

$C_{3}=\frac{s_{r} t_{r}}{\left(\theta_{s}-\theta_{r}\right)}$

$C_{4}=\frac{z_{r}}{h_{r}}$

We define:

$C_{5}{ }^{2}=\frac{C_{1}}{C_{2}}=\frac{z_{r}^{2}}{x_{r}^{2}}$

$C_{5}$ is then a length ratio

$C_{5}=\frac{z_{r}}{x_{r}}$

By using $C_{5}$ we do not need $C_{2}$ anymore

$C_{2}=\frac{C_{1}}{C_{5}^{2}}$

Substitution results in

$\frac{\partial \theta \prime}{\partial t^{\prime}}=C_{1} \frac{\partial}{\partial x^{\prime}}\left(K^{\prime}\left(\frac{\partial h^{\prime}}{\partial x^{\prime}}\right)\right)+\frac{C_{1}}{C_{5}{ }^{2}} \frac{\partial}{\partial z^{\prime}}\left(K^{\prime}\left(\frac{\partial h^{\prime}}{\partial z^{\prime}}+C_{4}\right)\right)-C_{3} S^{\prime}$

\section{A.3 Soil hydraulic functions}

The Mualem van Genuchten model describes the soil water retention curve

$\theta(h)= \begin{cases}\theta_{r}+\frac{\theta_{s}-\theta_{r}}{\left[1+|\alpha h|^{n}\right]^{m}} & h<0 \\ \theta_{s} & h \geq 0\end{cases}$ 
In which $m=1-\frac{1}{n}$ and $n>1$. Saturation is described in Eq. 4A3. We define $C_{6}=n$

$C_{7}=\alpha$

We do not need $h_{r}$ anymore. The equation then becomes:

$\theta\left(h^{\prime}\right)= \begin{cases}\theta_{r}+\frac{\theta_{s}-\theta_{r}}{\left[1+\left|C_{7} h^{\prime}\right| C_{6}\right]^{1-\frac{1}{C_{6}}}} & h^{\prime}<0 \\ \theta_{s} & h^{\prime} \geq 0\end{cases}$

We define $\vartheta$ in terms of $S_{e}$, as it is a dimensionless expression of theta:

$\theta=S_{e}\left(\theta_{s}-\theta_{r}\right)+\theta_{r}$

Substituting:

$S_{e}\left(\theta_{s}-\theta_{r}\right)+\theta_{r}= \begin{cases}\theta_{r}+\frac{\theta_{s}-\theta_{r}}{\left[1+\left|C_{7} h^{\prime}\right|^{C_{6}}\right]^{1-\frac{1}{C_{6}}}} & h^{\prime}<0 \\ \theta_{s} & h^{\prime} \geq 0\end{cases}$

Which can be rearranged into the other, $h$ dependent definition of $S_{e}$.

$S_{e}=\left(1+\left|C_{7} h^{\prime}\right|^{C_{6}}\right)^{-\left(1-\frac{1}{C_{6}}\right)}$

The saturated conductivity decreases exponentially with depth

$K_{s}(z)=K_{r} 10^{\mu z}$

The unsaturated hydraulic conductivity depends on the saturated conductivity and the saturation:

$K(h, z)=K_{S}(z) S_{e}^{l}\left(1-\left(1-S_{e}^{\frac{1}{m}}\right)^{m}\right)^{2}$

Substituting with Eq. 4A22 results in 
$K\left(S_{e}\right)=K_{r} 10^{\mu z} S_{e}^{l}\left(1-\left(1-S_{e}^{\frac{1}{m}}\right)^{m}\right)^{2}$

Let's define

$C_{8}=l$

$C_{9}=\mu z_{r}$

Substitution results in

$K=K_{r} 10^{C_{9} z^{\prime}} S_{e}^{C_{8}}\left(1-\left(1-S_{e}^{\frac{1}{1-\frac{1}{C_{6}}}}\right)^{1-\frac{1}{C_{6}}}\right)^{2}$

\section{A.4 Schematization}

$x=0$

$\mathrm{x}=\mathrm{L}_{\mathrm{f}}$

$\mathrm{x}=\mathrm{L}_{\mathrm{x}}$
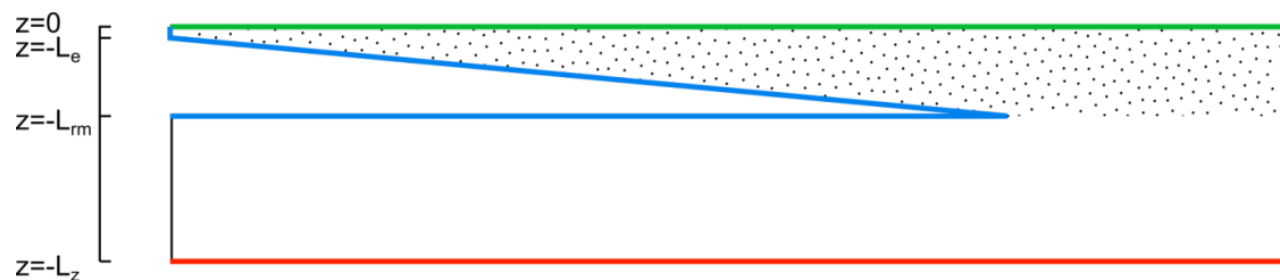

Figure 4A1. Model domain and boundaries. The spatial schematization is determined by the $x$ and $z$ length parameters $L_{e}, L_{r m}, L_{z}, L_{f}$ and $L_{x}$. The green line represents an atmospheric boundary, the blue line is the surface water boundary and the red line is the Cauchy boundary. The black lines are no flow boundaries. The dotted area (the root mat) is the area where root water uptake takes place.

Domain in $\mathrm{x}$ direction: $\mathrm{x}=0$ until $x=L_{x}$

$C_{10}=\frac{L_{x}}{x_{r}}$

Domain in $z$ direction $z=0$ (surface) until $z=-L_{z}$

$C_{11}=\frac{-L_{z}}{z_{r}}$ 
Root mat depth

$C_{12}=\frac{-L_{r m}}{z_{r}}$

Edge depth

$C_{13}=\frac{-L_{e}}{z_{r}}$

Length of floating part of root mat $L_{f}$

$C_{14}=\frac{L_{f}}{x_{r}}$

Temporal domain

The simulations will run from $t=0$ to $t=t_{\text {end }}$.

$C_{15}=\frac{t_{\text {end }}}{t_{r}}$

\section{A.5 Boundary conditions}

4A.5.1 Precipitation and evaporation

Infiltration of precipitation and evaporation from the soil is described by

$\left|K\left(\frac{\partial h}{\partial z}+1\right) n_{i}\right| \leq q(t) \quad @$ atmospheric boundary

$n_{i}$ is unit vector outward normal to boundary, $q$ is the maximum potential atmospheric flux density, the rate of infiltration or evaporation under the atmospheric conditions. The pressure head is limited $h_{a} \leq h \leq h_{\text {sat }}$, with no evaporation below a critical value $h_{a}$ and no infiltration when the soil has reached saturation. The atmospheric boundary is located from $x^{\prime}=0$ to $x^{\prime}=L_{x}$ at $z^{\prime}=0$.

$q(t)=P(t)-E(t)$

The partitioning between evaporation and transpiration is based on an estimated transpiration partitioning factor $\mathrm{f}_{\mathrm{t}}$.

$E(t)=\left(1-f_{t}\right) \operatorname{PET}(t)$ 


$$
\operatorname{PET}(t)= \begin{cases}P E T_{i} & \bmod \left(t, t_{\text {day }}\right) \leq t_{\text {PETduration }} A N D t>\frac{1}{3} t_{\text {end }} \\ 0 & \bmod \left(t, t_{\text {day }}\right)>t_{\text {PETduration }}\end{cases}
$$

In which $t_{\text {day }}$ is the duration of one day (1) and $t_{\text {PETduration }}$ is the duration of PET during a day $\left(t_{\text {PETduration }}=0.5 t_{\text {day }}\right) . P E T_{i}$ is the potential evapotranspiration rate.

Precipitation is a function of time as well (Figure A2)

$$
P(t)= \begin{cases}P_{i} & \bmod \left(t, t_{\text {offset }}\right) \leq t_{\text {pduration }} \text { AND } t>\frac{2}{3} t_{\text {end }} \\ 0 & \text { else }\end{cases}
$$

In which $P_{i}$ is the precipitation intensity, $t_{\text {offset }}$ determines the time of day that precipitation occurs, and $t_{\text {pduration }}$ is the duration of precipitation events. The mod function returns the remainder after dividing $t$ by the return time.

$t_{\text {offset }}(t)=\frac{\text { floor }(t)-19}{11}-0.5 t_{\text {pduration }}$

By defining the reference variables and parameters we obtain

$$
\left|K^{\prime} K_{r}\left(\frac{\partial h^{\prime} h_{r}}{\partial z^{\prime} z_{r}}+1\right) n_{i}\right| \leq P_{r} P^{\prime}\left(t_{r} t^{\prime}\right)-\left(1-f_{t}\right) P E T_{r} P E T^{\prime}\left(t_{r} t^{\prime}\right)
$$

We already defined $C_{4}=\frac{z_{r}}{h_{r}}$

$$
\left|\frac{K_{r} h_{r}}{z_{r}} K^{\prime}\left(\frac{\partial h^{\prime}}{\partial z^{\prime}}+C_{4}\right) n_{i}\right| \leq q_{r} q^{\prime}\left(t_{r} t^{\prime}\right)=P_{r} P^{\prime}\left(t_{r} t^{\prime}\right)-\left(1-f_{t}\right) P E T_{r} P E T^{\prime}\left(t_{r} t^{\prime}\right)
$$

For evaporation we define

$$
\operatorname{PET}_{r} P E T^{\prime}\left(t^{\prime}\right)= \begin{cases}P E T_{i} & \bmod \left(t_{r} t^{\prime}, t_{\text {day }}\right) \leq 0.5 t_{\text {day }} A N D t_{r} t^{\prime}>\frac{t_{\text {end }}}{3} \\ 0 & \bmod \left(t_{r} t^{\prime}, t_{\text {day }}\right)>0.5 t_{\text {day }}\end{cases}
$$

In which we can aggregate the dimensional variables

$$
\operatorname{PET}^{\prime}\left(t^{\prime}\right)= \begin{cases}\frac{P E T_{i}}{P E T_{r}} & \bmod \left(t^{\prime}, \frac{t_{\text {day }}}{t_{r}}\right) \leq \frac{0.5 t_{\text {day }}}{t_{r}} \text { AND } t^{\prime}>\frac{t_{\text {end }}}{3 t_{r}} \\ 0 & \bmod \left(t^{\prime}, \frac{t_{\text {day }}}{t_{r}}\right)>\frac{0.5 t_{\text {day }}}{t_{r}}\end{cases}
$$

And define the dimensionless groups 
$C_{16}=\frac{P E T_{i}}{P E T_{r}}$

$C_{17}=\frac{t_{\text {day }}}{t_{r}}$

Which results in

$\operatorname{PET}^{\prime}\left(t^{\prime}\right)= \begin{cases}C_{16} & \bmod \left(t^{\prime}, C_{17}\right) \leq 0.5 C_{17} \text { AND } t^{\prime}>\frac{\mathrm{C}_{15}}{3} \\ 0 & \bmod \left(t^{\prime}, C_{17}\right)>0.5 C_{17}\end{cases}$

For precipitation we define

$P_{r} P^{\prime}\left(t^{\prime}\right)= \begin{cases}P_{i} & \bmod \left(t_{r} t^{\prime}, t_{\text {offset }}\right) \leq t_{\text {pduration }} \text { AND } t_{r} t^{\prime}>\frac{2}{3} t_{\text {end }} \\ 0 & \text { else }\end{cases}$

In which the dimensionless groups can be aggregated

$P^{\prime}\left(t^{\prime}\right)= \begin{cases}\frac{P_{i}}{P_{r}} & \bmod \left(t^{\prime}, \frac{t_{\text {offset }}}{t_{r}}\right) \leq \frac{t_{\text {pduration }}}{t_{r}} \text { AND } t^{\prime}>\frac{2 t_{\text {end }}}{3 t_{r}} \\ 0 & \text { else }\end{cases}$

Which means that

$\frac{t_{\text {offset }}\left(t^{\prime}\right)}{t_{r}}=\frac{\text { floor }\left(t^{\prime}\right)-19}{11}-0.5 \frac{t_{\text {pduration }}}{t_{r}}$

For precipitation, we define the groups

$C_{18}=\frac{P_{i}}{P_{r}}$

$C_{19}=\frac{t_{\text {pduration }}}{t_{r}}$

Which results in the dimensionless equation

$P^{\prime}\left(t^{\prime}\right)= \begin{cases}C_{18} & \bmod \left(t^{\prime}, \frac{\text { floor }\left(t^{\prime}\right)-19}{11}-0.5 C_{19}\right) \leq C_{19} A N D t^{\prime}>\frac{2}{3} C_{15} \\ 0 & \text { else }\end{cases}$

To make the boundary condition Eq. 4A41 dimensionless, we formulate the following definitions 
$C_{20}=f_{t}$

And by defining all boundary flow reference values the same, we only need to add one dimensionless group

$q_{r}=P_{r}=P E T_{r}$

$C_{21}=\frac{K_{r} h_{r}}{z_{r} q_{r}}$

Which results in:

$\left|C_{21} K^{\prime}\left(\frac{\partial h^{\prime}}{\partial z^{\prime}}+1\right) n_{i}\right| \leq q^{\prime}=P^{\prime}\left(t^{\prime}\right)-\left(1-C_{20}\right) P E T^{\prime}\left(t^{\prime}\right)$

@ $\quad x^{\prime}=0, z^{\prime}=0$ to $x^{\prime}=C_{10}, z^{\prime}=0$

\section{A.5.2. Transpiration}

Transpiration occurs through root water uptake $S$, the sink in the Richards equation. Root water uptake happens in the root mat, where the roots are assumed to be equally distributed. Root uptake limitation according to the Feddes function is disregarded as water availability is high and due to aerenchyma, no oxygen stress occurs.

$S(t)=\frac{1}{A_{r m}} L_{x} T_{p}(t)$

$T_{p}=c_{f} f_{t} P E T$

Transpiration is assumed to occur over the whole surface $L_{x} . A_{r m}$ is the $x, z$ area over which the roots are distributed (the dotted part in Figure A1), which is the area of the root mat, $c_{f}$ is the crop factor. The area is described by

$A_{r m}=L_{r m} L_{x}-0.5\left(L_{r m}-L_{e}\right) L_{f}$

Making A57-A58 nondimensional:

$S_{r} S^{\prime}(t)=\frac{1}{L_{r m} L_{x}-0.5\left(L_{r m}-L_{e}\right) L_{f}} L_{x} C_{f} C_{20} q_{r} P E T^{\prime}(t)$

The group is defined as 
$C_{22}=\frac{L_{x} c_{f} q_{r}}{S_{r}\left(L_{r m} L_{x}-0.5\left(L_{r m}-L_{e}\right) L_{f}\right)}$

The dimensionless boundary condition is

$S^{\prime}(t)=C_{22} C_{19} P E T^{\prime}\left(t^{\prime}\right)$

@ the area within the $x^{\prime}, z^{\prime}$ coordinates $(0,0),(1,0),(1, C 12),(C 14, C 12),(0, C 13)$.

In which $P E T^{\prime}\left(t^{\prime}\right)$ is defined as in Eq. 4A46.

\section{A.5.3 Surface water boundary}

At the surface water boundary, time variable hydrostatic pressure is prescribed, depending on the surface water level fluctuations

$h(z, t)=h_{s}(t)-L_{r m}-z$

in which $h_{s}$ is the pressure head of the surface water level, measured in the surface water, at $z=-L_{r m}$. The surface water boundary is located on the line with $x, y$ coordinates $(0,0),(0,-$ $\left.L_{e}\right),\left(L_{f},-L_{r m}\right)$ to $\left(0,-L_{r m}\right)$.

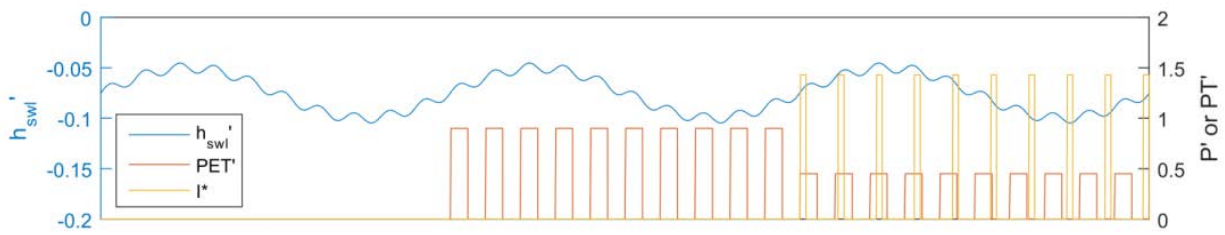

Figure 4A2. Surface water pressure head over time with reference values.

For each of the three 10-day periods of time, we apply one large and 10 small surface water fluctuations (Fig 4A2)

$h(z, t)=h_{s}+0.5 h_{\text {fluctuation }} * \sin \left(\frac{6 \pi t}{t_{\text {end }}}\right)+0.1 h_{\text {fluctuation }} * \sin \left(\frac{60 \pi t}{t_{\text {end }}}\right)-L_{r m}-z$

$h_{s}$, is the average surface water level and $h_{\text {fluctuation }}$ is the fluctuation amplitude. Defining the reference variables results in 
$h_{r} h^{\prime}\left(z^{\prime}, t^{\prime}\right)=h_{s}+0.5 h_{\text {fluctuation }} * \sin \left(\frac{6 \pi t^{\prime} t_{r}}{t_{\text {end }}}\right)+0.1 h_{\text {fluctuation }} * \sin \left(\frac{60 \pi t^{\prime} t_{r}}{t_{\text {end }}}\right)-$

$L_{r m}-z_{r} z^{\prime}$

The groups can be defined as

$C_{23}=\frac{h_{s}}{h_{r}}$

$C_{24}=\frac{h_{\text {fluctuation }}}{h_{r}}$

$C_{25}=\frac{L_{r m}}{h_{r}}$

Substitution results in

$h^{\prime}\left(z^{\prime}, t^{\prime}\right)=C_{23}+0.5 C_{24} * \sin \left(\frac{6 \pi t \prime}{C_{15}}\right)+0.1 C_{24} * \sin \left(\frac{60 \pi t \prime}{C_{15}}\right)-C_{25}-C_{4} z^{\prime}$

@ $x^{\prime}=0, z^{\prime}=0$ to $x^{\prime}=0, z^{\prime}=C_{13}$ to $x^{\prime}=C_{14}, z^{\prime}=C_{12}$ to $x^{\prime}=0, z^{\prime}=C_{12}$

\section{A.5.4 Neumann no flow boundary}

At vertical boundary at the right hand, and at the left hand side below the surface water boundary.

$K\left(\frac{\partial h}{\partial x}\right) n_{i}=0$

At $x=0$ and $z=-L_{r m}$ to $z=-L_{z}$ and $x=L_{x}$ and $z=0$ to $z=-L_{z}$

In dimensionless form this becomes

$\frac{\partial h^{\prime}}{\partial x^{\prime}} n_{i}=0$

@ $x^{\prime}=0$ and $z^{\prime}=C_{12}$ to $z^{\prime}=C_{11}$

And @ $x^{\prime}=\frac{L_{x}}{x_{r}}=C_{10}$ and $z^{\prime}=0$ to $z^{\prime}=C_{11}$

\section{A.5.5 Lower 'Cauchy' boundary}

As Hydrus does not have a built-in Cauchy boundary, we created a resistance layer and applied a fixed pressure head at the lower boundary. This layer is outside of the defined model domain, but is explicitly modelled in Hydrus. 
The prescribed pressure head at lower boundary is

$h=h_{l}$

$@ x=0$ to $L_{x}$, at $z=-L_{z}-L_{c}$

The flow over the boundary is described by

$q=-K_{c} \frac{(\Delta h+\Delta z)}{\Delta z}=-K_{c} \frac{\left(h_{l}-h+L_{z}-L_{c}-L_{z}\right)}{-L_{c}}=-K_{c}\left(\frac{\left(h_{l}-h\right)}{-L_{c}}+1\right)$

In which $K_{c}$ is the conductivity of the layer with thickness $L_{c}$. Defining the reference values

$q_{r} q^{\prime}=-K_{c}\left(\frac{\left(h_{l}-h_{r} h^{\prime}\right)}{-L_{c}}+1\right)$

The groups can be aggregated

$q^{\prime}=\frac{K_{c} h_{r}}{q_{r} L_{c}}\left(\frac{h_{l}}{h_{r}}-h^{\prime}+\frac{L_{c}}{h_{r}}\right)$

Defining the groups:

$C_{26}=\frac{K_{c}}{q_{r}}$

$C_{27}=\frac{h_{l}}{h_{r}}$

$C_{28}=\frac{L_{c}}{h_{r}}$

Results in

$q^{\prime}=\frac{C_{26}}{C_{28}}\left(C_{27}-h^{\prime}+C_{28}\right)$

@ $\quad x^{\prime}=0$ to $x^{\prime}=C_{10}$ and $z^{\prime}=C_{11}$ 


\section{A.6 Initial conditions}

The initial conditions are a hydrostatic equilibrium based on the initial surface water level, which is the same as the average surface water level $h_{s, r}$ that is applied in the boundary condition .

$h(z, t=0)=h_{s}-L_{r m}-z$

$h_{r} h(z, t=0)=h_{s}-L_{r m}-z_{r} z^{\prime}$

Aggregating the dimensionless groups

$h^{\prime}\left(t^{\prime}=0\right)=\frac{h_{s}}{h_{r}}-\frac{L_{r m}}{h_{r}}-\frac{z_{r} Z^{\prime}}{h_{r}}$

The dimensionless groups have been previously defined, resulting in

$h^{\prime}\left(z^{\prime}, t^{\prime}=0\right)=C_{23}-C_{25}-C_{4} z^{\prime}$

\section{A.7 Simplifying the model}

So far, 27 dimensionless groups have been defined. In Table 4A1 we provide an overview of all groups and will reduce the number of groups by further defining the reference values.

Table 4A1 Overview of dimensionless groups so far

Dimensionless groups

$$
\begin{gathered}
C_{1}=\frac{h_{r} t_{r} K_{r}}{\left(\theta_{s}-\theta_{r}\right) x_{r}{ }^{2}} \\
C_{2}=\frac{C_{1}}{C_{5}{ }^{2}} \\
C_{3}=\frac{S_{r} t_{r}}{\left(\theta_{s}-\theta_{r}\right)} \\
C_{4}=\frac{z_{r}}{h_{r}} \\
C_{5}=\frac{z_{r}}{x_{r}} \\
C_{6}=n \\
C_{7}=\alpha h_{r} \\
C_{8}=l \\
C_{9}=\mu z_{r} \\
C_{10}=\frac{L_{x}}{x_{r}}
\end{gathered}
$$




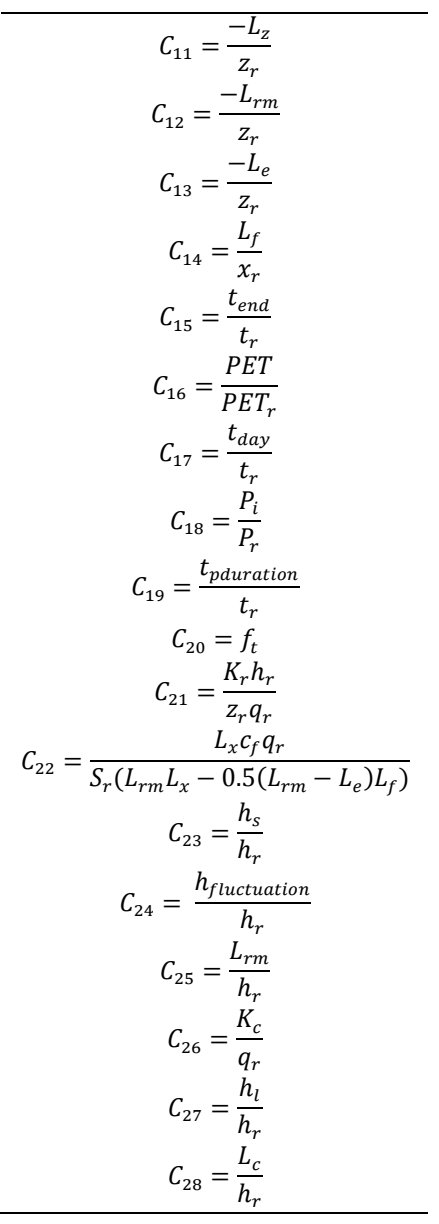

With the definitions in Table 4A2, these groups can be simplified. The potential evapotranspiration rate is the reference value for all flux related variables. $L_{z}$ is the reference value for all lengths in $z$ direction, while the domain length $L_{x}$ is the reference value for all lengths in $x$ direction. The reference root water uptake is the reference potential evapotranspiration over the root zone. The reference value for time is the duration of a day. A new group, $C_{29}$, is introduced to allow simplification and easier interpretation of what otherwise would be $C_{1}$. The resulting groups are shown in Table 4 A3.

Table 4A2 Definitions of reference values.

\begin{tabular}{c} 
Table 4A2 Definitions of reference values. \\
\hline Definitions \\
$P_{r}=P E T_{r}=q_{r}=P E T_{i}$ \\
$h_{r}=z_{r}=L_{z}$ \\
$x_{r}=L_{x}$
\end{tabular}




$$
\begin{gathered}
S_{r}=\frac{L_{x} q_{r} c_{f}}{L_{r m} L_{x}-0.5\left(L_{r m}-L_{e}\right) L_{f}} \\
t_{r}=t_{\text {day }} \\
\frac{t_{\text {end }}}{t_{\text {day }}}=30 \\
C_{29}=\frac{t_{\text {day }} K_{r}}{\left(\theta_{s}-\theta_{r}\right) L_{x}}
\end{gathered}
$$

Table 4A3 Simplification of dimensionless parameter groups.

$$
\begin{aligned}
& \text { Dimensionless parameter groups } \\
& C_{1}=\frac{L_{z} t_{d a y} K_{r}}{\left(\theta_{s}-\theta_{r}\right) L_{x}{ }^{2}}=\frac{t_{d a y} K_{r}}{\left(\theta_{s}-\theta_{r}\right) L_{x}} C_{5}=C_{29} C_{5} \\
& C_{2}=\frac{C_{1}}{C_{5}^{2}}=\frac{C_{29}}{C_{5}} \\
& C_{3}=\frac{S_{r} t_{d a y}}{\left(\theta_{s}-\theta_{r}\right)}=\frac{L_{x} P E T_{i} c_{f} t_{d a y}}{L_{r m} L_{x}-0.5\left(L_{r m}-L_{e}\right) L_{f}\left(\theta_{s}-\theta_{r}\right)} \\
& C_{4}=\frac{L_{z}}{L_{z}}=1 \\
& C_{5}=\frac{L_{z}}{L_{x}} \\
& C_{6}=n \\
& C_{7}=\alpha L_{z} \\
& C_{8}=l \\
& C_{9}=\mu L_{z} \\
& C_{10}=\frac{L_{x}}{L_{x}}=1 \\
& C_{11}=\frac{-L_{z}}{L_{z}}=-1 \\
& C_{12}=\frac{-L_{r m}}{L_{z}} \\
& C_{13}=\frac{-L_{e}}{L_{z}} \\
& C_{14}=\frac{L_{f}}{L_{x}} \\
& C_{15}=\frac{t_{\text {end }}}{t_{\text {day }}}=30 \\
& C_{16}=\frac{P E T_{i}}{P E T_{i}}=1 \\
& C_{17}=\frac{t_{\text {day }}}{t_{\text {day }}}=1 \\
& C_{18}=\frac{P_{i}}{P E T_{i}} \\
& C_{19}=\frac{t_{\text {pduration }}}{t_{\text {day }}} \\
& C_{20}=f_{t} \\
& C_{21}=\frac{K_{r} L_{z}}{L_{z} q_{r}}=\frac{K_{r}}{P E T_{i}} \\
& C_{22}=\frac{L_{x} c_{f} q_{r}}{S_{r}\left(L_{r m} L_{x}-0.5\left(L_{r m}-L_{e}\right) L_{f}\right)} \frac{L_{x} c_{f} q_{r}}{\frac{L_{x} q_{r} C_{f}}{L_{r m} L_{x}-0.5\left(L_{r m}-L_{e}\right) L_{f}}\left(L_{r m} L_{x}-0.5\left(1-L_{e}\right) L_{f}\right)}=1 \\
& C_{23}=\frac{h_{s}}{L_{z}} \\
& C_{24}=\frac{h_{\text {fluctuation }}}{L_{z}}
\end{aligned}
$$




$$
\begin{gathered}
C_{25}=\frac{L_{r m}}{L_{z}}=-C_{12} \\
C_{26}=\frac{K_{c}}{P E T_{i}} \\
C_{27}=\frac{h_{l}}{L_{z}} \\
C_{28}=\frac{L_{c}}{L_{z}} \\
C_{29}=\frac{t_{d a y} K_{r}}{\left(\theta_{s}-\theta_{r}\right) L_{x}}
\end{gathered}
$$

\begin{tabular}{|c|c|}
\hline Dimensionless parameter groups & Symbol \\
\hline$C_{3}=\frac{L_{x} P E T_{i} c_{f} t_{d a y}}{L_{r m} L_{x}-0.5\left(L_{r m}-L_{e}\right) L_{f}\left(\theta_{s}-\theta_{r}\right)}$ & $U^{*}$ \\
\hline$C_{5}=\frac{L_{z}}{L_{x}}$ & $D^{*}$ \\
\hline$C_{6}=n$ & $N^{*}$ \\
\hline$C_{7}=\alpha L_{z}$ & $A^{*}$ \\
\hline$C_{8}=l$ & $L^{*}$ \\
\hline$C_{9}=\mu L_{z}$ & $J^{*}$ \\
\hline$C_{12}=\frac{-L_{r m}}{L_{z}}$ & $M^{*}$ \\
\hline$C_{13}=\frac{-L_{e}}{L_{z}}$ & $E^{*}$ \\
\hline$C_{14}=\frac{L_{f}}{L_{x}}$ & $F^{*}$ \\
\hline$C_{18}=\frac{P_{i}}{P E T_{i}}$ & $I^{*}$ \\
\hline$C_{19}=\frac{t_{\text {pduration }}}{t_{\text {day }}}$ & $P^{*}$ \\
\hline$C_{20}=f_{t}$ & $G^{*}$ \\
\hline$C_{21}=\frac{K_{r}}{P E T_{i}}$ & $K^{*}$ \\
\hline
\end{tabular}

As many groups are simplified by the definitions, the effective number of groups is now reduced to 19. The groups are shown in Table 4A4. In the paper we use letter symbols to represent the dimensionless groups, these are shown in the table as well.

Table 4A4 Dimensionless parameter groups. 


$$
\begin{array}{cc}
C_{23}=\frac{h_{s}}{L_{z}} & H^{*} \\
C_{24}=\frac{h_{\text {fluctuation }}}{L_{z}} & S^{*} \\
C_{27}=\frac{h_{l}}{L_{z}} & B^{*} \\
C_{26}=\frac{K_{c}}{P E T_{i}} & C^{*} \\
C_{28}=\frac{L_{c}}{L_{z}} & R^{*} \\
C_{29}=\frac{t_{\text {day }} K_{r}}{\left(\theta_{s}-\theta_{r}\right) L_{x}} & X^{*}
\end{array}
$$

\section{A.8 Overview of the dimensionless model}

\section{Model equations}

$\frac{\partial \theta^{\prime}}{\partial t^{\prime}}=C_{29} C_{5} \frac{\partial}{\partial x^{\prime}}\left(K^{\prime}\left(\frac{\partial h^{\prime}}{\partial x^{\prime}}\right)\right)+\frac{C_{29}}{C_{5}} \frac{\partial}{\partial z^{\prime}}\left(K^{\prime}\left(\frac{\partial h^{\prime}}{\partial z^{\prime}}+1\right)\right)-C_{3} S^{\prime}$

$S_{e}=\left(1+\left|C_{7} h^{\prime}\right|^{C_{6}}\right)^{-\left(1-\frac{1}{C_{6}}\right)}$

$K=K_{r} 10^{C_{9} z^{\prime}} S_{e}^{C_{8}}\left(1-\left(1-S_{e}^{\frac{1}{1-\frac{1}{C_{6}}}}\right)^{1-\frac{1}{C_{6}}}\right)^{2}$

\section{Schematization}

$$
x^{\prime}=0
$$

$\mathrm{x}^{\prime}=\mathrm{C}_{14}$

$x^{\prime}=1$

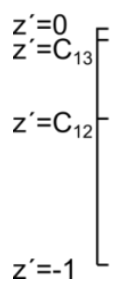

Figure 4A3. Dimensionless domain and boundaries. The spatial schematization is determined by the $x^{\prime}$ and $z^{\prime}$ coordinates that are represented by the dimensionless groups. The green line represents an atmospheric 
boundary, the blue line is the surface water boundary and the red line is the Cauchy boundary. The black lines are no flow boundaries. The dotted area (the root mat) is the area where root water uptake takes place.

The simulations will run from $t^{\prime}=0$ to $t^{\prime}=30$

\section{Boundaries}

The atmospheric boundary (green line in Figure $4 A 3$ ) is

$$
\begin{aligned}
& \left|C_{21} K^{\prime}\left(\frac{\partial h^{\prime}}{\partial z^{\prime}}+1\right) n_{i}\right| \leq q^{\prime}=P^{\prime}\left(t^{\prime}\right)-\left(1-C_{20}\right) P E T^{\prime}\left(t^{\prime}\right) \\
& @ \quad x^{\prime}=0, z^{\prime}=0 \text { to } x^{\prime}=1, z^{\prime}=0 \\
& P^{\prime}\left(t^{\prime}\right)= \begin{cases}C_{18} & \bmod \left(t^{\prime}, \frac{\text { floor }\left(t^{\prime}\right)-19}{11}-0.5 C_{19}\right) \leq C_{19} A N D t^{\prime}>\frac{2}{3} C_{15} \\
0 & \text { else }\end{cases} \\
& \operatorname{PET}^{\prime}\left(t^{\prime}\right)= \begin{cases}1 & \bmod \left(t^{\prime}, 1\right) \leq 0.5 \\
0 & \bmod \left(t^{\prime}, 1\right)>0.5\end{cases}
\end{aligned}
$$

The root water uptake as a result of transpiration is

$S^{\prime}(t)=C_{19} P E T^{\prime}\left(t^{\prime}\right)$

@ the area within $x^{\prime}=0, z^{\prime}=0$ to $x^{\prime}=1, z^{\prime}=0$ to $x^{\prime}=1, z^{\prime}=C_{12}$ to $x^{\prime}=C_{14}$, $z^{\prime}=C_{12}$ to $x^{\prime}=0, z^{\prime}=C_{13}$ to $x^{\prime}=0, z^{\prime}=0$.

The surface water boundary is

$$
\begin{aligned}
& h^{\prime}\left(z^{\prime}, t^{\prime}\right)=C_{23}+C_{12}-z^{\prime}+0.5 C_{24} * \sin \left(0.2 \pi t^{\prime}\right)+0.1 C_{24} * \sin \left(2 \pi t^{\prime}\right) \\
& @ \quad x^{\prime}=0, z^{\prime}=0 \text { to } x^{\prime}=0, z^{\prime}=C_{13} \text { to } x^{\prime}=C_{14}, z^{\prime}=C_{12} \text { to } x^{\prime}=0, z^{\prime}=C_{12}
\end{aligned}
$$

The Cauchy boundary is

$$
\begin{aligned}
& q^{\prime}=\frac{C_{26}}{C_{28}}\left(C_{27}-h^{\prime}+C_{28}\right) \\
& @ \quad x^{\prime}=0, z^{\prime}=-1 \text { to } x^{\prime}=1, z^{\prime}=-1
\end{aligned}
$$

The no flow boundaries are 
$\frac{\partial h^{\prime}}{\partial x^{\prime}} n_{i}=0$

$@ x^{\prime}=0, z^{\prime}=C_{12}$ to $x^{\prime}=0, z^{\prime}=-1$ and $@ x^{\prime}=1, z^{\prime}=0$ to $x^{\prime}=1, z^{\prime}=-1$

\section{Initial conditions}

The initial conditions of the domain are

$h^{\prime}\left(z^{\prime}, t^{\prime}=0\right)=C_{23}+C_{12}-z^{\prime}$ 



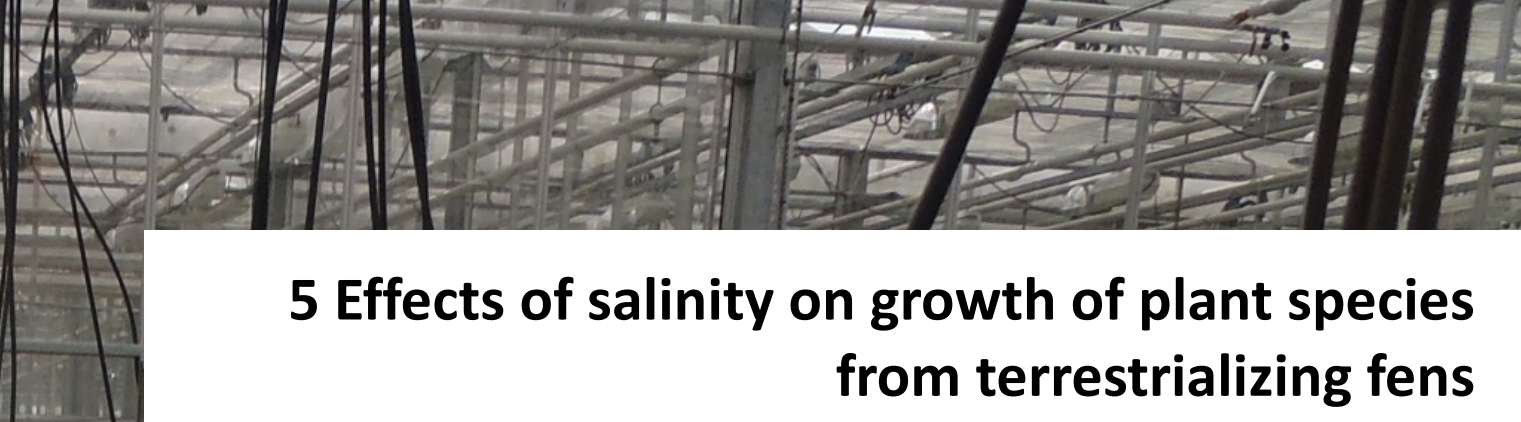

Based on:

Stofberg, S.F., Klimkowska, A., Paulissen, M.P.C.P., Witte, J.P.M., van der Zee, S.E.A.T.M., 2015. Effects of salinity on growth of plant species from terrestrializing fens. Aquatic Botany 121, 83-90.

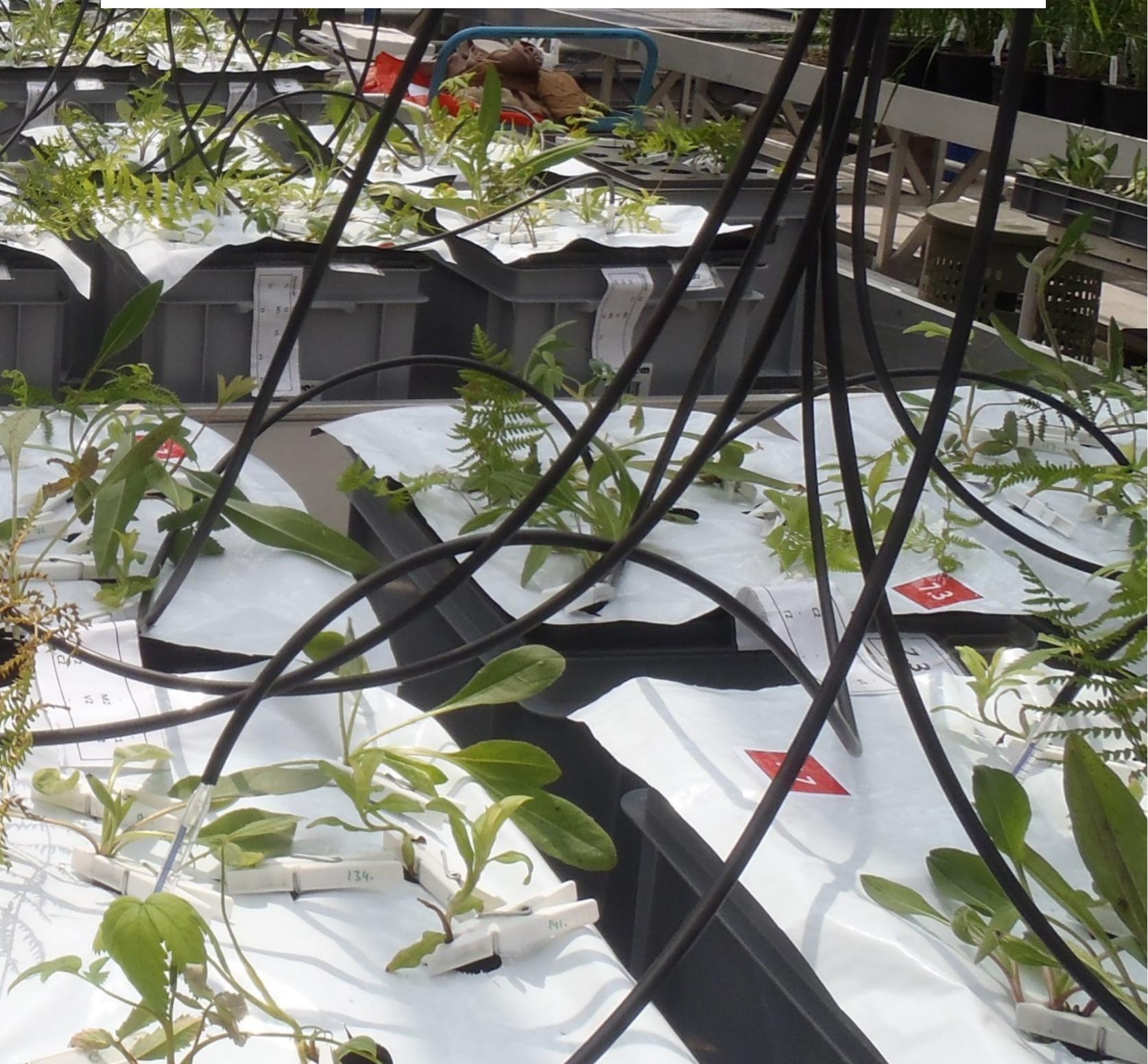




\section{Abstract}

Terrestrializing lowland fens may be temporarily exposed to elevated surface water salinity, which may have serious consequences for nature conservation. We investigated the response of five fresh water fen plant species to elevated salinity.

In a controlled greenhouse experiment, these species were exposed to salt concentrations up to $3000 \mathrm{mg} \mathrm{Cl}^{-1}$.

Total biomass of the five species together was significantly reduced for salinity levels from $200 \mathrm{mg} \mathrm{Cl}^{-1-1}$. Four individual species showed leaf death and relative growth rate reduction, with effects at $1000 \mathrm{mg} \mathrm{Cl}^{-1}$ for Succisa pratensis, Thelypteris palustris and Viola palustris, and $3000 \mathrm{mg} \mathrm{Cl}^{-1} \mathrm{l}^{-1}$ for Myosotis scorpioides. Comarum palustre showed no significant (.05 level) sensitivity.

Biomass distribution was investigated as well. Root-shoot ratio of four species was affected by salinity, which in at least two cases seemed to be related to leaf death. Differences in specific leaf area as a result of salinity were only observed for Comarum palustre. Dry matter content increased in four species as a result of salinity.

Salinity tolerance did not correspond to the environmental distributions of the species, nor could species traits be related to tolerance.

Surface water salinity may affect vegetation development in terrestrializing fens at low concentrations. A reduction of plant growth would cause reduced fitness of some species and may lead to reduced root mat growth. Exposure to higher concentrations could eventually lead to a decrease of species richness. 


\subsection{Introduction}

Worldwide, delta regions experience increased salinity of groundwater and surface water. Causes include drainage for agricultural and urban purposes, which invokes upwelling of brackish and saline groundwater, and seawater intrusion in rivers (Werner et al., 2013). Climate change may lead to increased evapotranspiration, while fresh water discharge of rivers may reduce. This enhances salinity pressure on wetland ecosystems that are typical for delta regions. The Dutch lowlands are one of those regions at risk of salinity. Water from the river Rhine is used to maintain high water levels in channels and ditches of the polder areas during summers, to suppress land subsidence and saline upward groundwater seepage (De Louw et al., 2010). Salt concentrations in supply water may increase due to low river discharge (Zwolsman and van Bokhoven, 2007) and high sea water levels.

As a result of this increased salinity pressure, dry summers could lead to increased salt concentrations in freshwater fens in the Dutch lowland region. Terrestrializing lowland fens, found in former turf ponds, are known for their high biodiversity and typical structure of floating root mats, in which gradients of abiotic conditions allow for coexisting successional stages varying from rich fen to poor fen (Verhoeven and Bobbink, 2001). Current standards protect these areas against supplying water with concentrations exceeding $200 \mathrm{mg} \mathrm{Cl}^{-1}$. It is uncertain whether these standards can be maintained, when supply water salinity may become as high as $1500 \mathrm{mg} \mathrm{Cl}^{-1}$. Whereas it has been recognized that supply water may cause adverse effects on these ecosystems, due to nutrient loads and internal eutrophication (Smolders et al., 2006), salinity has been identified as a risk (Witte et al., 2012), but its potential effects are mostly unknown.

Salinity effects on plant communities depend on the response of species. Salinity can affect plant performance in several ways: through osmotic effects, toxicity, and nutrient interactions (Munns and Tester, 2008). Increased electrolyte concentrations decrease the osmotic head in the root zone and decrease water availability for transpiration, resulting in effects similar to drought. Toxicity occurs when salts build up in leaf tissue. Sensitivity to these processes can differ substantially between species. Plants have different mechanisms to deal with salinity, such as closing of stomata to limit transpiration, production of solutes to decrease osmotic pressure in leaves, and the exclusion of salts from sensitive tissue to prevent damage (Parida and Das, 2005). Osmotic stress may cause reduced growth rates and phenotype adjustments, while toxicity will cause chlorosis, necrosis, and death of older leaves (Parida and Das, 2005). Leaf death reduces the photosynthetic surface of a plant and therefore adversely affects its growth rate and competitiveness. Salinity often affects aboveground tissue more strongly than 
belowground tissue (Munns and Tester, 2008), and may therefore result in increased rootshoot ratio (RSR). Salinity can affect nutrient uptake and partitioning within tissue as well, which may result in additional stress or even nutrient deficiency symptoms for nutrients such as $\mathrm{Ca}^{2+}, \mathrm{K}^{+}$, and $\mathrm{NO}_{3}{ }^{-}$(Grattan and Grieve, 1999).

Salt tolerance has been investigated for crop species (e.g. Shannon and Grieve, 1999) and for species from brackish and saline environments (e.g. Pennings et al., 2005; Macek and Rejmánková, 2007). However, few studies exist about the effects of low salt concentrations on species from freshwater ecosystems, even though these studies show that the effects may be significant (Van den Brink and Van der Velde, 1993).

An explanatory approach to predicting the effects of environmental change is found in the analysis of plant functional traits. These preferably easy to measure parameters can be linked to processes or strategies that affect competitive performance under certain abiotic conditions. Traits, such as leaf mass per area or specific leaf area, have been shown to correlate well with large scale environmental gradients, such as temperature and rainfall (Wright et al., 2004). Eallonardo et al. (2013) found that leaf N content per area correlated with salinity tolerance, and C4 photosynthetic pathway, small leaf size and succulence correlated with salinity gradients in a salt marsh. They suggest these traits could be related to relatively high water use efficiency. No literature has been found regarding traits that are related to salinity tolerance in low salinity environments. In freshwater fen terrestrialization systems, where water level is constant, there is no necessity for plants to have adaptations to deal with salinity or drought.

In this study, we investigate the effects of elevated salinity on plant species from Dutch terrestrializing fens. Since exposure is likely to occur seasonally, we focus on the direct effects that salt can have on individual species in the growing season, although we are aware that competition processes will play a role as well, especially on longer time scales. We assume that species that are found in more brackish areas will be scarcely affected, therefore we are interested in the effects on species that are almost exclusively found in fresh water conditions $\left(<200 \mathrm{mg} \mathrm{Cl} \mathrm{I}^{-1}\right)$. We selected five fen species that do not occur in saline environments and exposed them to salinity in a greenhouse experiment to test the following hypotheses:

1. Moderate salinity levels (up to $3000 \mathrm{mg} \mathrm{Cl}^{-1}$ ) will cause growth reduction and mortality of freshwater plant species.

2. Moderate salinity levels will cause changes in biomass distribution of freshwater plant species, as a result of tissue damage.

3. Differences of salinity tolerance between freshwater species are related to their species traits. 


\subsection{Materials and Methods}

We exposed the plants to different levels of salinity on a hydroponic setup in a controlled greenhouse experiment. The warm environment of a greenhouse resembles warm summers with little precipitation, when salinity exposure is most likely to occur. Hydroponics allow for good control of exposure to saline solutions. As the selected species grow at edges of root mats that float in surface water (Figs. 5.1 and 5.2), we considered hydroponic setup a realistic approximation of field conditions.

\subsubsection{Plant species selection}

We compiled a list of characteristic plant species from fen terrestrialization habitats, and selected five species that represent the diversity of species that is found in these habitats and that exclusively occur in areas with low salinity (Akkerman et al., 2013): Comarum palustre L. (internationally known as Potentilla palustris L.), Myosotis scorpioides L., Succisa pratensis Moench, Thelypteris palustris Schott, and Viola palustris L. (names after van der Meijden, 2005). For brevity, we call these by their genus: Comarum, Myosotis, Succisa, Thelypteris and Viola. All species typically occur in wet, relatively nutrient-poor environments, such as fen meadows, except Myosotis, which is frequently found in eutrophic environments.

Locally, Comarum and Thelypteris are both found at the edges of root mats and function as ecosystem engineers: they form dense root systems, that make up the basis of the root mat, allowing other species to settle. Myosotis is often found growing near, or in the surface water, while Viola grows on the edge of the root mat. The rosette species Succisa does not colonize the surface water and is typically found in slightly more elevated conditions at the edge of the root mats and is considered an indicator of higher species richness (Zelnik and Čarni, 2013). The four higher plants and one fern are all perennial and herbaceous, although Comarum has lignifying stolons (Macek and Lepš, 2007). None of the species show succulence and all of them are $C_{3}$ species (Fitter and Peat, 1994). An overview of plant characteristics is shown in Table 5.1.

Table 5.1 Plant characteristics (Kühn \& Klotz 2002).

\begin{tabular}{llll}
\hline Species & Family & Life form & Anatomy \\
\hline Comarum palustre & Rosaceae & Chamaephyte & Helomorphic \\
Myosotis scorpioides & Boraginaceae & Hemicryptophyte & Hygro/helomorphic \\
Succisa pratensis & Dipsacaceae & Hemicryptophyte & Mesomorphic \\
Thelypteris palustris & Thelypteridaceae & Geophyte & Hygro/helomorphic \\
Viola palustris & Violaceae & Hemicryptophyte & Hygro/helomorphic \\
\hline
\end{tabular}




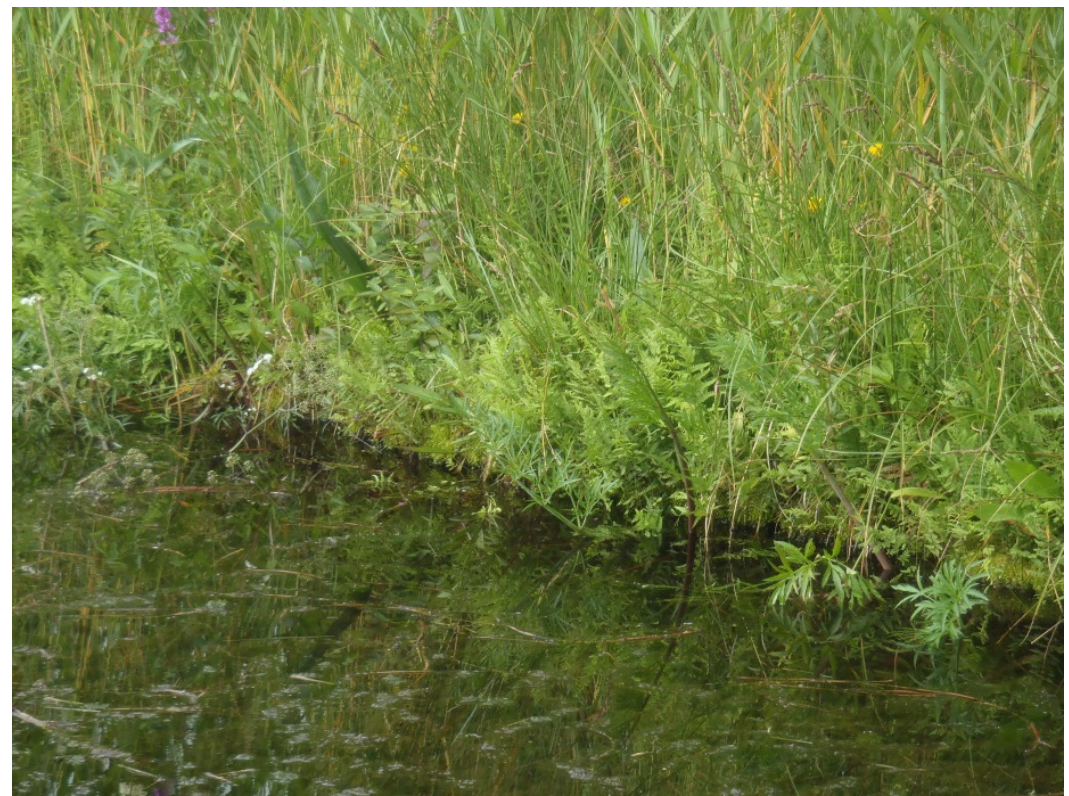

Figure 5.1 Photograph of root mat edge. Root mat edge in Nieuwkoopse Plassen (the Netherlands), with among others: Thelypteris palustris, Filipendula ulmaria, Cicuta virosa, Carex paniculata, Phragmites australis and Juncus subnodulosus.

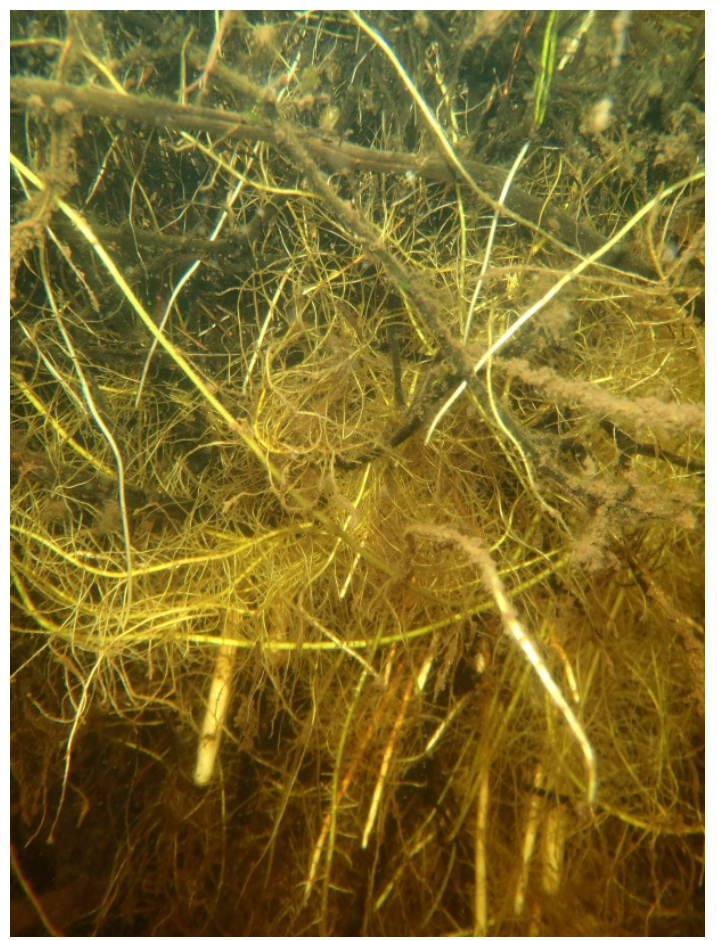

Figure 5.2 Edge of a root mat under water. 


\subsubsection{Plant collection and settling}

We collected the plants in the fourth week of May 2013 from Nieuwkoopse Plassen (the Netherlands), a Natura 2000 fen nature reserve with a terrestrialization landscape. Approximately 200 small clones of each species were collected from the edges of different root mats and transported to the greenhouse, where they were temporarily kept in containers with a nutrient solution ( $5 x$ the concentration that was used in the experiment) to recover from handling damage. After three weeks, all plants were weighed (initial fresh weight) and 112 individuals of each species of similar weight were selected for the experiment and randomly assigned to treatments and containers (plastic, 25 I). Each plant's position on the container was randomly selected to avoid systematic shading effects. Supported by clothespins, the plants were placed in holes in the lid of the container, so the roots could grow freely in the nutrient solution, and the stems were not pressed. An opaque plastic foil cover protected against algal growth and temperature rise. The water was aerated through a tube.

The nutrient solution was made by adding nutrients and salts to tap water (ion concentrations were analysed), which was preferred over rain water due to its constant quality and $\mathrm{pH}$ buffering. Total concentrations were in $\mathrm{mM}: \mathrm{NH}_{4}{ }^{+}, 0.05 ; \mathrm{NO}_{3}{ }^{-}, 0.1 ; \mathrm{K}^{+}, 0.18$; $\mathrm{Na}^{+}, 1.15 ; \mathrm{Ca}^{2+}, 1.2 ; \mathrm{Mg}^{3+}, 0.3 ; \mathrm{Cl}^{-}, 1.91 ; \mathrm{SO}_{4}{ }^{2-} 0.36 ; \mathrm{HCO}_{3}{ }^{-}, 1.3, \mathrm{PO}_{4}{ }^{3-}, 0.05 ; \mathrm{Si}, 0.19 ;$ and in $\mu \mathrm{M}$ : Fe (EDDHA), 10; $\mathrm{Mn}^{2+}, 2 ; \mathrm{Zn}^{2+}, 0.5 ; \mathrm{BO}_{3}{ }^{3-}, 10 ; \mathrm{Cu}^{2+}, 0.3 ; \mathrm{Mo}^{2+}, 0.1$. Nutrient levels were kept in the range as found in moderately rich fens (Bourbonniere, 2009). Nutrient concentrations in the surface water of the study site were lower, but preliminary experiments using these low concentrations showed very little growth, suggesting that nutrient concentrations at the root mat are higher due to mineralization. The concentrations of sodium and chloride for the control group were chosen to mimic the background salinity of the study area during the growing season. In 2011 and 2012, average surface water salinity during the growing season was $40 \mathrm{mg} \mathrm{l}^{-1}$ for sodium and 67 $\mathrm{mg} \mathrm{l}^{-1}$ for chloride, in winter these concentrations are generally lower. Containers were cleaned and nutrient solutions were completely replaced every week. Containers of each treatment were assigned a randomly selected spot, and moved to a new spot every week, to reduce effects of differences in light conditions. After a week of aeration adjustment, $\mathrm{pH}$ stabilized at 6.3-6.5, and plants were allowed to settle for two weeks.

\subsubsection{Experiment set up and conditions}

The experiment had a split plot design (Table 5.2). On the whole plot level, the design was completely randomized, with six salinity treatment levels that were each applied to eight 
containers. Each container had two individuals of five species (sub plot). The plants were allowed to acclimatize for three weeks. Spare plants were kept on the same type of containers, in the same room; damaged plants were replaced throughout the acclimatisation period. Besides the six treatments, one extra group of eight containers was grown during the acclimatization period. These plants were harvested at the start of the experiment, to assess growth during the settling period. In the first week of July, the salinity treatments were started. Treatment concentrations were increased from the background concentration ( $67 \mathrm{mg} \mathrm{Cl}^{-1}$ ) by adding $\mathrm{NaCl}$ in steps over a period of five days, until final salinities were reached (in $\mathrm{mg} \mathrm{Cl}^{-1}$ ): 200, 500, 1000, 1500, 3000 for the respective treatments. The treatments lasted 7 weeks in total. With each nutrient replacement, salt was added to each container and mixed into the solution to maintain constant salinity. Average room temperature was $26 \pm 5{ }^{\circ} \mathrm{C}$ during the days and $20 \pm 3{ }^{\circ} \mathrm{C}$ at night. Average relative humidity was $59 \pm 11 \%$ during the days and $75 \pm 6 \%$ at night. Light conditions were natural, supplemented with additional lighting of $100 \mu \mathrm{mol} \mathrm{m}^{-2} \mathrm{~s}^{-1}$, which automatically switched on in the morning if incoming radiation was below $150 \mathrm{~W} \mathrm{~m}^{-2}$ and was switched off when incoming radiation reached $250 \mathrm{~W} \mathrm{~m}^{-2}$. Water temperature was measured weekly. Average water temperature was $26 \pm 3^{\circ} \mathrm{C}$, which is $4^{\circ} \mathrm{C}$ higher than we measured in a root mat edge at the field location on August $9^{\text {th }} 2013$.

Table 5.2 Experiment design

The experiment consists of 48 containers, that are divided over six salinity treatments. On the whole plot, each container is an experimental unit. Each container holds 10 plants; two individuals of each species. $R G R$ was analysed using this design to find effects of salinity, species and its interaction. Furthermore, all variables were analysed for each species separately. This analysis was done one the whole plot level, taking each container as a separate subject.

\begin{tabular}{lll}
\hline & Source of variance & df \\
\hline Whole plot & Salinity & 5 \\
& Whole plot error & 42 \\
\cline { 2 - 3 } & Whole plot total & 47 \\
\hline Sub plot & Species & 4 \\
& Species * Salinity & 20 \\
& Split plot error & 408 \\
\cline { 2 - 3 } & Total Split plot & 479 \\
\hline
\end{tabular}

\subsubsection{Measured variables}

Each week, plants were checked for mortality: plants with brown discoloration of over $95 \%$ of the leaf area were considered dead and removed from the experiment, to prevent any problems that could be caused by decomposing plant material. Seven weeks after the start of the salinity treatments, plants were harvested one species at a time. Each plant was washed in demineralized water to remove any external salt residues and patted dry 
with a paper towel. Each plant was separated into three parts and weighed: green aboveground material, dead aboveground material and belowground material. Leaves were considered dead when brown discoloration exceeded 50\%. For Comarum the woody part of the belowground material was weighed separately as well. From each plant, two fully grown green top leaves were weighed separately and their leaf area was measured using a LI-3100 area meter (Li-Cor, Lincoln, NE, USA). If no fully green leaf was available, no measurement was made. All plant material was dried at 70 degrees for 48 hours, and weighed for dry biomass.

\subsubsection{Data processing}

Growth is expressed as relative growth rate $(R G R)$, as it can account for differences in initial mass of the plants. $R G R\left(\mathrm{mg} \mathrm{g}^{-1} \mathrm{~d}^{-1}\right)$ was computed as follows:

$R G R=\left(\ln \left(M_{e}\right)-\ln \left(M_{s}\right)\right) /\left(t_{e}-t_{s}\right)$

in which $M_{e}$ is the biomass in grams at the end of the experiment, $M_{s}$ is the biomass at the start of the treatment, and $t_{e}$ and $t_{s}$ are the times in days at the end and start of the experiment, respectively. Dead material was not taken into account. $M_{s}$ was estimated using the mean $R G R$ and dry fresh ratio after the settling period, as determined from the plants that were harvested at the start of the treatments.

Dead mass fraction $(D M F)$ is the ratio between dead aboveground dry biomass $\left(M_{a d}\right)$ and total aboveground dry biomass $\left(M_{a}+M_{a d}\right)$ :

$D M F=M_{a d} /\left(M_{a}+M_{a d}\right)$

The percentage of biomass reduction that can be explained by dead aboveground biomass is calculated as the difference between the total biomass (scaled to control) including and excluding dead tissue.

Root-shoot ratio $\left(R S R_{a}\right)$ reflects the biomass of a plant in belowground tissue relative to aboveground tissue. Changes in $R S R_{a}$ mostly reflect tissue loss due to leaf mortality. When belowground tissue is related to all aboveground biomass (including dead material, $M_{a d}$ ), $R S R_{t}$ may indicate changes in resource allocation as a response to salinity. Both ways of calculating $R S R$ have been done. RSR (-) is calculated by dividing belowground dry biomass $\left(M_{b}\right)$ by aboveground dry biomass: 
$R S R_{a}=M_{b} / M_{a}$

$R S R_{t}=M_{b} /\left(M_{a}+M_{a d}\right)$

Aboveground dry matter content $(D M C)$ is the ratio of dry aboveground biomass and fresh aboveground biomass $\left(M_{a f}\right)$. DMC is measured as an indicator for phenotype effects, as it reflects changes in tissue water content as a result of salinity. Dead biomass is not taken into account, as it contains almost no water by definition.

$D M C=M_{a} / M_{a f}$

Specific leaf area $(S L A)$ is the ratio of leaf area $\left(A_{l}\right)$ with dry leaf mass $\left(M_{l}\right)$ :

$S L A=A_{l} / M_{l}$

SLA is measured as a species trait in the control groups. Some plants adapt to salinity by growing smaller, thicker leaves (Munns and Tester, 2008). In the salinity treatment groups, it is used as an indicator for short term adaptive response, and indicates changes in leaf size and thickness.

\subsubsection{Statistical analysis}

Results were analysed with SAS 9.3 statistical software (SAS Institute, Cary, NC, USA). Data was checked for normality and homogeneity of variance. If necessary, data was log transformed. RGR (scaled to mean of control group) was analysed according to the split plot design (Table 5.2) to find effects of salinity, species and its interaction using ANOVA for mixed models (PROC MIXED), in which salinity was a fixed factor and container was a random factor. Besides that, all variables were analysed for each species separately on the whole plot level, using PROC MIXED with salinity as a fixed factor and container as a random factor. Furthermore, the total biomass per container was analysed using ANOVA with salinity as the fixed factor. When results of Levene's test were significant, heterogeneity of variance was accounted for as described in Littell et al. (2006). TukeyKramer's comparison was performed to identify differences between treatments. Results were considered significant if $P<0.05$. As the $D M F$ is a percentage and therefore not normally distributed, generalized linear mixed models (PROC GLIMMIX) was used, and a beta distribution was assumed. Survival analysis was done using PROC LIFETEST. Pearson correlation coefficients between all variables were calculated for each species using PROC 
CORR. Non-parametric Spearman's rank correlation between the species traits (on control group) and ranked salinity tolerance were calculated using PROC CORR.

Table 5.3. Survival (out of 16 plants) and means of dry matter content (DMC) and specific leaf area (SLA). Standard errors between brackets. ${ }^{*}, P<0.05 ; * *, P<0.01 ; * *, P<0.001$.

\begin{tabular}{|c|c|c|c|c|}
\hline Species & Salinity $\left(\mathrm{mg} \mathrm{Cl}^{-1}\right)$ & Survival & \multirow{2}{*}{$\begin{array}{l}\text { DMC }\left(\mathrm{g} \mathrm{g}^{-1}\right) \\
\log 10\end{array}$} & \multirow{2}{*}{$\begin{array}{l}\text { SLA }\left(\mathrm{mm}^{2} \mathrm{mg}^{-1}\right) \\
\log 10\end{array}$} \\
\hline \multicolumn{3}{|c|}{ Transformation } & & \\
\hline \multicolumn{3}{|c|}{ Comarum palustre } & $\mathrm{F}=5.36(* * *)$ & $\mathrm{F}=9.11(* * *)$ \\
\hline & 67 & 16 & $-0.45(0.011)$ & $1.06(0.015)$ \\
\hline & 200 & 16 & $-0.50(0.008)$ & $1.06(0.010)$ \\
\hline & 500 & 16 & $-0.50(0.005)$ & $1.05(0.016)$ \\
\hline & 1000 & 16 & $-0.50(0.006)$ & $1.06(0.016)$ \\
\hline & 1500 & 16 & $-0.50(0.006)$ & $1.09(0.013)$ \\
\hline & 3000 & 16 & $-0.52(0.011)$ & $1.15(0.012)$ \\
\hline \multicolumn{3}{|c|}{ Myosotis scorpioides } & $\mathrm{F}=4.46(* *)$ & $\mathrm{F}=0.45$ (n.s.) \\
\hline & 67 & 16 & $-0.82(0.007)$ & $1.35(0.022)$ \\
\hline & 200 & 16 & $-0.79(0.010)$ & $1.32(0.025)$ \\
\hline & 500 & 16 & $-0.80(0.007)$ & $1.32(0.019)$ \\
\hline & 1000 & 16 & $-0.83(0.007)$ & $1.34(0.021)$ \\
\hline & 1500 & 16 & $-0.83(0.011)$ & $1.36(0.020)$ \\
\hline & 3000 & 11 & $-0.92(0.059)$ & $1.34(0.032)$ \\
\hline \multicolumn{3}{|c|}{ Succisa pratensis } & $\mathrm{F}=6.39(* * *)$ & $\mathrm{F}=0.41$ (n.s.) \\
\hline & 67 & 16 & $-0.58(0.013)$ & $1.01(0.014)$ \\
\hline & 200 & 16 & $-0.62(0.015)$ & $0.99(0.022)$ \\
\hline & 500 & 16 & $-0.64(0.011)$ & $1.03(0.019)$ \\
\hline & 1000 & 16 & $-0.67(0.011)$ & $1.01(0.013)$ \\
\hline & 1500 & 16 & $-0.64(0.019)$ & $1.02(0.017)$ \\
\hline & 3000 & 13 & $-0.66(0.016)$ & $1.03(0.021)$ \\
\hline \multicolumn{3}{|c|}{ Thelypteris palustris } & $\mathrm{F}=3.40\left(^{* *}\right)$ & $\mathrm{F}=2.39$ (n.s.) \\
\hline & 67 & 16 & $-0.50(0.024)$ & $1.14(0.036)$ \\
\hline & 200 & 16 & $-0.50(0.049)$ & $1.08(0.026)$ \\
\hline & 500 & 16 & $-0.40(0.036)$ & $1.07(0.033)$ \\
\hline & 1000 & 15 & $-0.42(0.028)$ & $1.19(0.037)$ \\
\hline & 1500 & 13 & $-0.39(0.020)$ & $1.04(0.052)$ \\
\hline & 3000 & 10 & $-0.58(0.086)$ & $1.18(0.051)$ \\
\hline \multicolumn{3}{|c|}{ Viola palustris } & $\mathrm{F}=2.45$ (n.s.) & $\mathrm{F}=2.06$ (n.s.) \\
\hline & 67 & 16 & $-0.67(0.014)$ & $1.10(0.016)$ \\
\hline & 200 & 16 & $-0.70(0.020)$ & $1.18(0.023)$ \\
\hline & 500 & 16 & $-0.69(0.020)$ & $1.11(0.038)$ \\
\hline & 1000 & 15 & $-0.76(0.029)$ & $1.16(0.022)$ \\
\hline & 1500 & 11 & $-0.74(0.023)$ & $1.18(0.064)$ \\
\hline & 3000 & 1 & $-0.76(-)$ & $1.09(-)$ \\
\hline
\end{tabular}




\subsection{Results}

\subsubsection{Effects of salinity on mortality, growth and leaf death}

On the three lowest salinity treatments all plants survived, while at the higher salinity levels some mortality occurred (Table 5.3). At the highest salinity level, individuals of all species died, except for Comarum. The effect was greatest for Viola, of which all individuals, but one, died at a concentration of $3000 \mathrm{mg} \mathrm{Cl}^{-1}$. Survival analysis showed a significant decrease of probability of survival in the highest salinity treatment for Myosotis, Succisa, Thelypteris, and Viola. The total biomass per container was significantly lower on elevated salinity levels $(F=80.82, P<.0001)$, with significant effects occurring even at the lowest treatment of $200 \mathrm{mg} \mathrm{Cl}^{-1} \mathrm{I}^{-1}$ (Fig. 5.3).

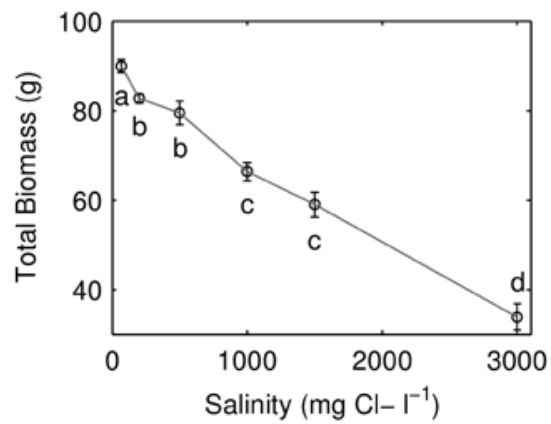

Figure 5.3 Total dry biomass per container $\pm S E$ (8 replicates). Same letters mean no significant difference in Tukey comparison.

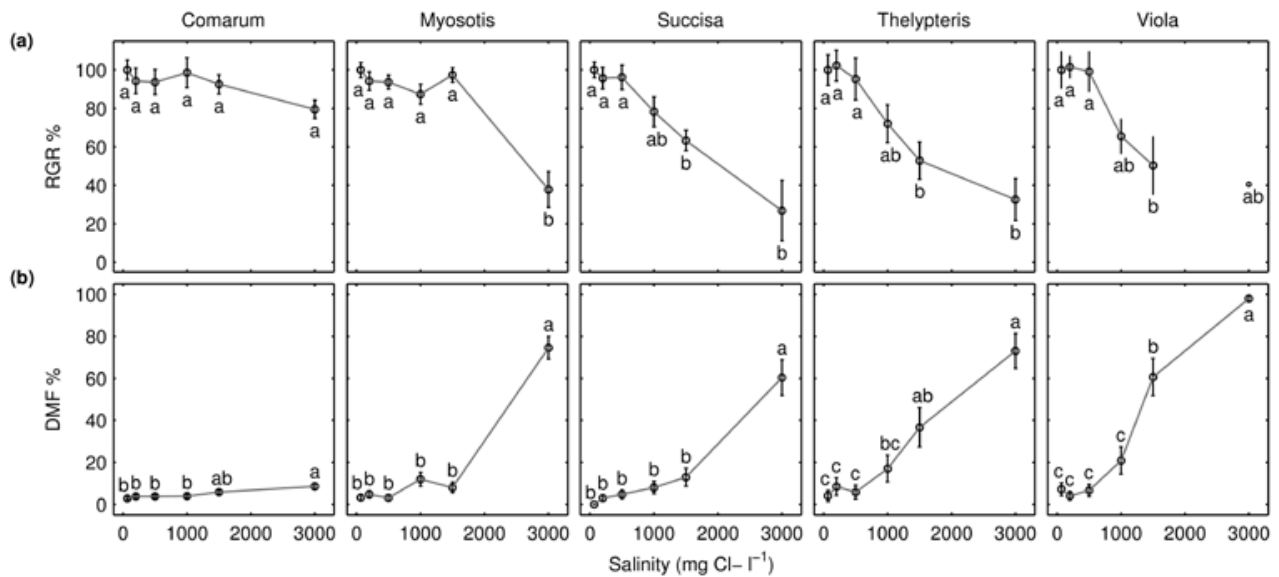

Figure 5.4 a. Relative growth rate (RGR), mean \pm SE for each species (10 - 16 plants), scaled to the mean $R G R$ at background concentration (67 $\mathrm{mg} \mathrm{Cl} \mathrm{I}^{-1}$ ). As only one individual was left for Viola on the highest treatment, no error bar is shown. $b$. Dead mass fraction (DMF): mass partition of the leaves that had a brown discoloration at harvest or removal (in case of mortality), mean $\pm S E$ (16 plants). Same letters mean no significant difference in Tukey comparison. 
Table 5.4 Pearson correlation coefficients of measured plant characteristics. RGR: relative growth rate, $M_{a}$ : aboveground dry biomass, $M_{b}$ : belowground dry biomass, DMF: Dead mass fraction, RSR: root-shoot ratio, DMC: dry matter content, SLA: specific leaf area, $M_{l}$ : leaf mass, $A_{l}$ : leaf area. ${ }^{*}, P<0.05 ;{ }^{* *}, P<0.01 ;{ }^{* * *}, P$ $<0.001$

\begin{tabular}{|c|c|c|c|c|c|c|c|c|}
\hline & RGR & $M_{a}$ & $M_{b}$ & DMF & RSR $_{\mathrm{a}}$ & DMC & SLA & $M_{1}$ \\
\hline \multicolumn{9}{|c|}{ Comarum palustre } \\
\hline$M_{a}$ & $0.72 * * *$ & & & & & & & \\
\hline $\mathrm{M}_{\mathrm{b}}$ & $0.69 * * *$ & $0.85^{* * *}$ & & & & & & \\
\hline DMF & $-0.36 * * *$ & $-0.26 *$ & $-0.23 *$ & & & & & \\
\hline $\mathrm{RSR}_{\mathrm{a}}$ & $-0.20 *$ & $-0.39 * * *$ & n.s. & n.s. & & & & \\
\hline DMC & n.s. & n.s. & n.s. & n.s. & n.s. & & & \\
\hline SLA & $-0.23^{*}$ & n.s. & $-0.32 * *$ & $0.40 * * *$ & $-0.22 *$ & $-0.46 * * *$ & & \\
\hline$M_{1}$ & $0.42 * * *$ & $0.37 * * *$ & $0.47^{* * *}$ & n.s. & n.s. & n.s. & n.s. & \\
\hline$A_{l}$ & $0.34^{*}$ & $0.29 * *$ & $0.33 * *$ & n.s. & n.s. & $-0.30 * *$ & $0.36 * *$ & $0.93 * * *$ \\
\hline \multicolumn{9}{|c|}{ Myosotis scorpioides } \\
\hline$M_{a}$ & $0.73^{* * *}$ & & & & & & & \\
\hline$M_{b}$ & $0.68 * * *$ & $0.93 * * *$ & & & & & & \\
\hline DMF & $-0.84 * * *$ & $-0.57 * * *$ & $-0.51 * * *$ & & & & & \\
\hline $\mathrm{RSR}_{\mathrm{a}}$ & $-0.56 * * *$ & $-0.34 *$ & $-0.21 *$ & $0.72 * * *$ & & & & \\
\hline DMC & $0.69 * * *$ & $-0.33 * *$ & $-0.28 * *$ & $0.78 * * *$ & $0.71 * * *$ & & & \\
\hline SLA & $-0.24 *$ & $-0.22 *$ & n.s. & n.s. & n.s. & n.s. & & \\
\hline$M_{1}$ & $0.31 * *$ & $-0.32 * *$ & $0.33^{* *}$ & n.s. & n.s. & n.s. & $-0.29 * *$ & \\
\hline$A_{1}$ & n.s. & n.s. & n.s. & n.s. & n.s. & n.s. & $0.30 * *$ & $0.82 * * *$ \\
\hline \multicolumn{9}{|c|}{ Succisa pratentis } \\
\hline$M_{a}$ & $0.72 * * *$ & & & & & & & \\
\hline$M_{b}$ & $0.67 * * *$ & $0.62 * * *$ & & & & & & \\
\hline DMF & $-0.81 * * *$ & $-0.54 * * *$ & $-0.40 * * *$ & & & & & \\
\hline $\mathrm{RSR}_{\mathrm{a}}$ & n.s. & $0.52 * * *$ & $0.28 * *$ & n.s. & & & & \\
\hline DMC & $-0.52 * * *$ & n.s. & $-0.36 * * *$ & $0.62 * * *$ & $-0.53 * * *$ & & & \\
\hline SLA & n.s. & n.s. & n.s. & n.s. & n.s. & n.s. & & \\
\hline$M_{1}$ & $0.49 * * *$ & $0.34 * *$ & $0.46^{* * *}$ & n.s. & n.s. & n.s. & $-0.44 * * *$ & \\
\hline$A_{l}$ & $0.48^{* * *}$ & $0.32 * *$ & $0.45^{* * *}$ & n.s. & n.s. & n.s. & n.s. & $0.90 * * *$ \\
\hline \multicolumn{9}{|c|}{ Thelypteris palustris } \\
\hline$M_{a}$ & $0.67 * * *$ & & & & & & & \\
\hline $\mathrm{M}_{\mathrm{b}}$ & $0.65 * * *$ & $0.73 * * *$ & & & & & & \\
\hline DMF & $-0.54 * * *$ & $-0.50 * * *$ & $-0.37 * * *$ & & & & & \\
\hline $\mathrm{RSR}_{\mathrm{a}}$ & $-0.36 * * *$ & $-0.62 * * *$ & n.s. & $0.53^{* * *}$ & & & & \\
\hline DMC & $-0.32 * *$ & $-0.29 * *$ & $-0.25 *$ & $0.40 * * *$ & n.s. & & & \\
\hline SLA & $-0.23^{*}$ & $-0.35 * *$ & $-0.31 * *$ & n.s. & n.s. & n.s. & & \\
\hline$M_{1}$ & $0.48^{* * *}$ & $0.53^{* * *}$ & $0.58 * * *$ & $-0.26 *$ & $-0.26 *$ & n.s. & $-0.62 * * *$ & \\
\hline$A_{1}$ & $0.45^{* * *}$ & $0.42 * * *$ & $0.64 * * *$ & n.s. & n.s. & n.s. & $-0.26 *$ & $0.87 * * *$ \\
\hline \multicolumn{9}{|c|}{ Viola palustris } \\
\hline$M_{a}$ & $0.75^{* * *}$ & & & & & & & \\
\hline$M_{b}$ & $0.62 * * *$ & $0.77^{* * *}$ & & & & & & \\
\hline DMF & $-0.55 * * *$ & $-0.49 * * *$ & n.s. & & & & & \\
\hline $\mathrm{RSR}_{\mathrm{a}}$ & $-0.51 * * *$ & $-0.54 * * *$ & n.s. & $0.79 * * *$ & & & & \\
\hline DMC & $-0.29 *$ & n.s. & n.s. & $0.44 * * *$ & $0.28 *$ & & & \\
\hline SLA & n.s. & n.s. & n.s. & n.s. & n.s. & $-0.32 * *$ & & \\
\hline$M_{1}$ & $0.44^{* * *}$ & $0.52^{* * *}$ & $0.53^{* * *}$ & $-0.32 * *$ & n.s. & n.s. & $-0.50 * * *$ & \\
\hline$A_{l}$ & $0.40 * * *$ & $0.52^{* * *}$ & $0.56^{* * *}$ & $-0.36^{* *}$ & n.s. & n.s. & n.s. & $0.86 * * *$ \\
\hline
\end{tabular}


We found a significant effect of salinity $(F=17.99, P<.0001)$ and species $(F=5.18, P<$ $0.001)$ on $R G R$, as well as a significant effect of species*treatment $(F=2.56, P<.001)$, indicating that salinity response differed between species. Response of $R G R$ to salt concentrations were similar to the results for biomass. Analysis for each separate species revealed clear effects of salinity on the RGR and DMF of four species (Fig. 5.4). For Succisa, Thelypteris and Viola, RGR was significantly smaller at a concentration of $1000 \mathrm{mg} \mathrm{Cl}^{-1}$, and decreased further for higher salinity. For Myosotis, the RGR on the highest treatment had a similar value to that of the other affected species, but no significant effect was observed at lower salinity levels. The relative growth rate of Comarum was slightly lower for the highest treatment, but this effect was not significant.

The percentage of dead aboveground biomass increased for higher salinities for all species, but the threshold at which tissue death was observed differed per species (Fig. 5.4). For Myosotis and Succisa, a significant fraction of the aboveground biomass died at a concentration of $3000 \mathrm{mg} \mathrm{Cl} \mathrm{I}^{-1}$, while for the other species, the percentage increased more gradually as salt concentration increased. Although few leaves of Comarum died, we found significant effects of salinity on DMF as well. Pearson correlation coefficients for each species are shown in Table 5.4. Tissue death was negatively correlated to RGR for each species, which implies that biomass reduction could partly be explained by loss of aboveground tissue. On average, $29 \%$ of the relative biomass reduction of Myosotis on the highest salinity treatment was attributed to leaf death. For Succisa, this was $11 \%, 15 \%$ and $37 \%$ on the 1000,1500 and $3000 \mathrm{mg} \mathrm{Cl}^{-1}$ salinity treatments, respectively. On these treatments, $10 \%, 21 \%$ and $19 \%$ of the relative biomass reduction was attributed to leaf mortality for Thelypteris. $16 \%$ and $28 \%$ was attributed to dead aboveground biomass for Viola on 1000 and $1500 \mathrm{mg} \mathrm{Cl}^{-1}$ and $87 \%$ for the last remaining plant on the highest treatment.

\subsubsection{Effects of salinity on biomass distribution}

We found significant effects of salinity on $R S R_{a}$ for all species except Myosotis (Fig. 5.5). For Comarum, belowground biomass decreased slightly in the highest salinity treatment, while aboveground biomass remained the same, resulting in a decreased $R S R_{a}$. No correlation was found with the (relative) mass of the woody stolon. For Succisa, aboveground biomass decreased with every salinity level, but belowground biomass increased on the lower salinity treatments, and decreased on the two highest treatments. This resulted in an increasing $R S R_{a}$ with concentrations up to $1000 \mathrm{mg} \mathrm{Cl}^{-1}$, while at higher salinity no significant differences to control were found. For both Comarum and Succisa, the pattern of $R S R_{t}$ was similar to that of $R S R_{a}$. For Thelypteris and Viola, 
aboveground biomass decreased more with salinity than belowground biomass, which resulted in an increase of $R S R_{a}$ on higher salinity treatments. Comparison of $R S R_{a}$ with $R S R_{t}$ shows that for Myosotis, Thelypteris and Viola, the increase of $R S R_{a}$ can be attributed to leaf death, which is confirmed by the positive correlation with DMF (Table 5.4).

Significant effects of salinity on DMC were found for all species except Viola (Table 5.3). For Comarum and Succisa, DMC was smaller at the salinity treatments, compared to the control group, but did not become increasingly lower with higher salinity levels. However, for Comarum, DMC correlated negatively with SLA. For Myosotis, DMC also became lower on higher salinity treatments. For all species, except Comarum, DMC had a positive correlation with DMF.

The results of the SLA measurements are listed in Table 5.3. In the control group, all species had a SLA of around $10-15 \mathrm{~mm}^{2} \mathrm{mg}^{-1}$, except for Myosotis, which had an average SLA of $22.6 \mathrm{~mm}^{2} \mathrm{mg}^{-1}$. Only Comarum showed a dependence of SLA on salinity (Fig. 5.6). For this species, leaf area increased gradually with salinity levels. Leaf mass increased with salinity as well, but decreased at the highest salinity treatment, resulting in a significant increase of SLA. For Succisa, Thelypteris and Viola, both leaf area and leaf mass were lower on the salinity treatments from $1000 \mathrm{mg} \mathrm{Cl}^{-1}$ (although not in all cases significant), resulting in no significant differences in SLA. For Myosotis, leaf area and mass did not differ significantly between the salinity treatments either, and did not result in significant differences in SLA.

The Spearman's rank correlations resulted in no significant correlation between any of the measured species traits and its salinity tolerance.

\subsection{Discussion}

Salinity adversely affected Myosotis, Succisa, Thelypteris and Viola by causing mortality, and reducing growth with an average of $60-73 \%$ on the highest salinity treatment. Salinity tolerance can be defined as the RGR at increased salinity relative to the RGR at low salinity. Thus defined, tolerance differed significantly between these species at 1000 and $1500 \mathrm{mg} \mathrm{Cl}^{-1} \mathrm{I}^{-1}$, but not at $3000 \mathrm{mg} \mathrm{Cl} \mathrm{I}^{-1}$. However, this definition does not account for mortality. As mortality was highest in Viola, we consider this species to be the least tolerant to salinity, followed by Thelypteris, Succisa, and Myosotis. Their tolerance is within the same range as sensitive vegetable crops, such as turnip and lettuce (Shannon and Grieve, 1999). 


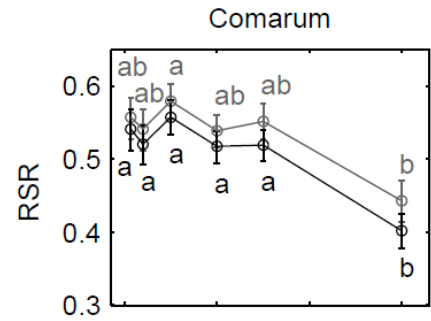

Myosotis

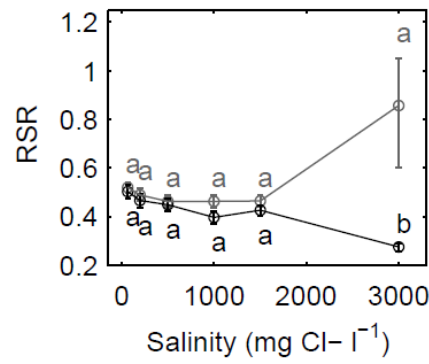

Succisa

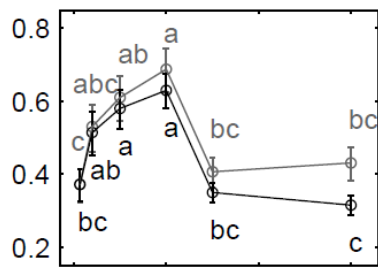

Thelypteris

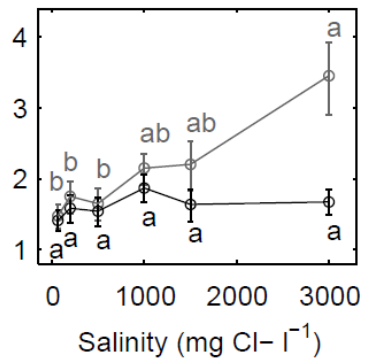

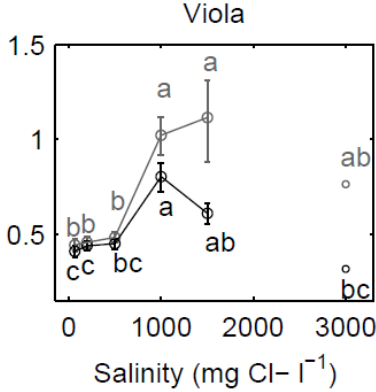

Salinity $\left(\mathrm{mg} \mathrm{Cl}-\mathrm{I}^{-1}\right)$

Figure 5.5 Graph of root-shoot ratio (RSR). RSR $\pm S E$ (10 - 16 plants). As only one individual was left for Viola on the highest treatment, no error bar is shown. Gray lines: $R S R_{a}, R S R$ of live biomass $\left(M_{b} / M_{a}\right)$, black lines: $R S R_{t}, R S R$ of all biomass, including dead leaves $\left(M_{b} /\left(M_{a}+M_{a d}\right)\right)$. Same letters mean no significant difference in Tukey comparison.

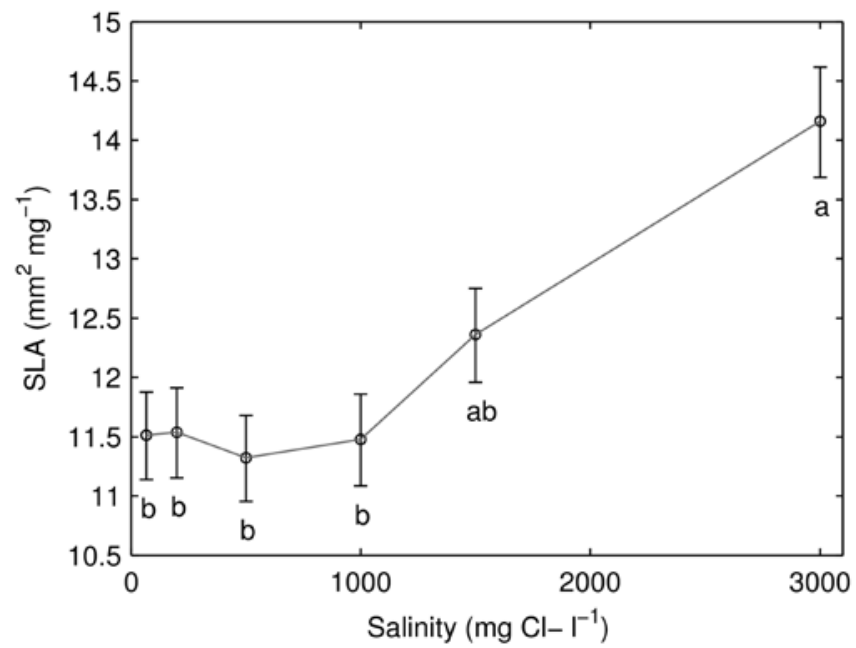

Figure 5.6 Specific leaf area of Comarum \pm SE (16 plants). Same letters mean no significant differences in Tukey comparison. Significant differences in specific leaf area were only found for this species.

The observed effects can potentially be attributed to osmotic stress, toxicity and nutrient interactions, such as $\mathrm{Ca}^{2+}$ deficiency. Osmotic stress can cause growth reduction and is considered a main cause of salinity stress at low concentrations (Munns and Tester, 2008). However, yellow and brown discoloration of older leaves is commonly associated with 
$\mathrm{NaCl}$ toxicity, as ions accumulate in leaf tissue (Parida and Das, 2005). The decrease of biomass and photosynthetic surface by leaf death may also limit growth and is therefore difficult to separate from osmotic effects. For Comarum, Myosotis and Succisa, it was visually confirmed that the affected leaves were mainly older ones (lowest and outer leaves, respectively), indicating that toxicity may have played a role. For Thelypteris and Viola this could not be confirmed, since the leaves grow directly from the rhizomes / lateral shoots. At the highest salinity, the youngest leaves of Succisa (at the rosette centre) were affected as well, which may be due to extreme stress, but could also be a symptom of $\mathrm{Ca}^{2+}$ deficiency (Simon, 1978).

Salinity can influence plant performance by affecting its biomass distribution. The increase of RSR with salinity of Viola and Thelypteris, is mainly due to leaf death and in agreement with aboveground tissue being more affected by salinity than the root system. Aboveground tissue death could not explain the RSR response found for Succisa; the individuals from high salinity treatments had less fine roots, and remaining roots had a brown discoloration (Fig. 5.7), hence, both aboveground tissue and roots may be damaged by high salinities.

Salinity can result in smaller and thicker leaves in some species (Munns and Tester, 2008). Plasticity has been observed in Myosotis and Viola in response to waterlogging (Lenssen et al., 2003) and mowing (Jensen and Meyer, 2001), respectively. We found that these sensitive species in our experiment did not show much plasticity for the measured traits as a result of salinity, although the duration may have been too short for these effects to emerge. Although leaf mass decreased with salinity for Succisa, Thelypteris and Viola, and leaf area decreased for Viola as well, no significant effects on SLA were observed for any of these species. On the other hand, Comarum showed significant plasticity, as its SLA increased. Besides salinity, reduced plant cover may have played a role in the increase of SLA on higher treatments, as this can result in larger leaves for Comarum (Macek and Lepš, 2007).

The lower DMC that we found for both Comarum and Succisa, could be related to less investment in stem biomass, and suggests that it may be worthwhile to measure stem biomass in detail. For the other species, the effect of salinity on DMC did not show clear patterns, although this variable was correlated with $D M F$.

Considering the traits that Eallonardo et al. (2013) linked to salinity, the five investigated species are not likely to show salinity tolerance. The SLA values are rather high, yet comparable to the SLA of other Dutch herbaceous species (Ordoñez et al., 2010), which could be related to a general absence of drought and salinity. Salinity tolerance of the five 
investigated species did not correspond with any of the measured traits. Only woodiness matched with the relative tolerance of Comarum. Species with lignified stems can sustain lower leaf water potentials than herbaceous species at the same water supply (Lambers et al., 2008), which would make them less vulnerable to osmotic stress.

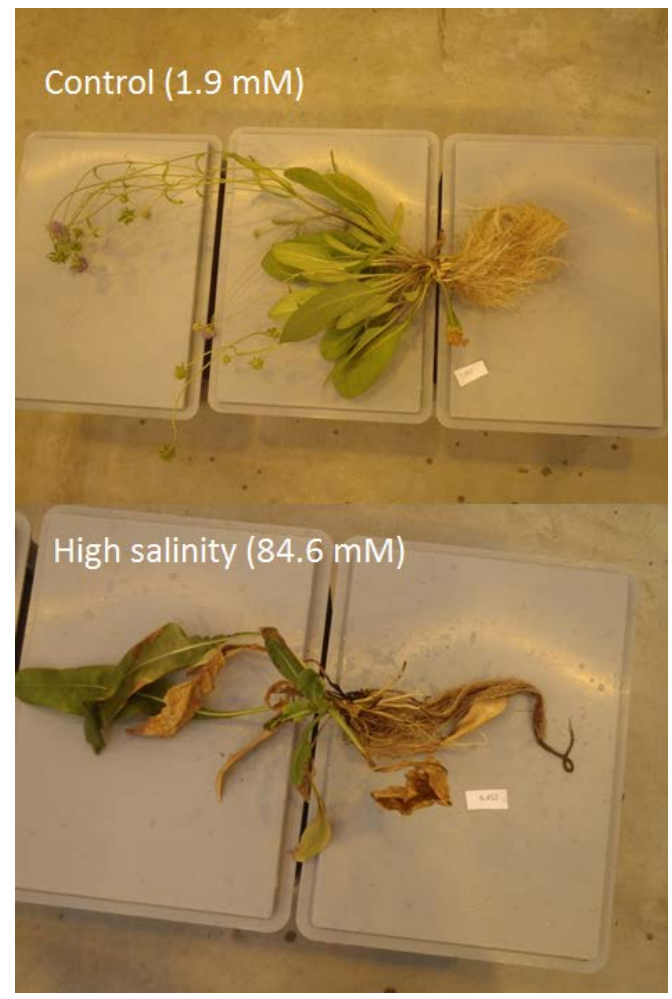

Figure 5.7 Succisa individuals at harvest. Compared to control, salt affected Succisa has less fine roots, with a dark discoloration.

As an alternative to trait analysis, Chevin et al. (2010) proposed to implement phenotypic plasticity into models that predict the effects of environmental change. They explain how plasticity could affect tolerance curves, although this may come at a cost of reduced fitness in optimum conditions. In general, phenotypic plasticity is favourable in variable environments (Allaway and Ennings, 2003). Plasticity as a result of salinity has been observed as a sign of salinity stress (Hroudová et al., 2014), but for Comarum, the only species that was not sensitive to salinity, we observed plasticity that did not seem to be the result of tissue damage. Although we have no evidence of a functional relationship, it could be interesting to take plasticity into account as an explanatory variable, when investigating relatively small, or temporary salinity changes in multiple species. 
The response to short term salinity of the fen species in our experiment showed a different pattern than their distribution in field situations. Comarum, Myosotis, Thelypteris and Viola are most often found on chloride levels below $61-161 \mathrm{mg} \mathrm{Cl}^{-1} \mathrm{I}^{-1}$ (90 percentile of their distribution; Akkerman et al. 2013). Especially the root mat builders Comarum and Thelypteris are associated with strictly fresh conditions (Runhaar, 2006), which is thought to be a potential cause of a lack of root mat growth in brackish conditions (Lieffers, 1984). This difference between field and experimental results may have several reasons. Possibly, the measured field salinities do not cover extreme values, as salinity varies seasonally. Furthermore, the response to permanent field conditions may be more severe. For instance, if environmental exposure occurs during early growth stages, when species can be less tolerant (Maas and Poss, 1989), competition may result in disappearance of salt sensitive species. Furthermore, if plants are exposed to elevated salinity over longer timespans, effects, such as growth reduction and salt accumulation, will become more severe (Munns and Tester, 2008). This was illustrated by Flynn et al. (1995), who showed with a mesocosm experiment that residual salinity after exposure was an important factor, determining the number of species that would regrow after their aboveground tissue had died. In our experiment, low salt concentrations of $200 \mathrm{mg} \mathrm{Cl}^{-1} \mathrm{l}^{-1}$ resulted in reduced biomass in seven weeks. In natural conditions, these effects on biomass might result in changes in species composition over longer timescales, because more salt tolerant species, such as Phragmites australis, are found in these environments as well. An alternative reason is that another process or environmental factor could be responsible for the spatial distribution of plant species, such as eutrophication or limited dispersal due to fragmentation. For example, increased salinity is often associated with increased availability of nitrogen, phosphate and sulphate, which may have a negative impact on wetland species, including Thelypteris (Geurts et al., 2009).

Our findings show that increased salinity may pose a threat to fen communities, as growth of some plant species can be diminished. Such results have also been found for other wetland types, resulting in decreases of species richness or decreased resilience to other stress factors (Richburg et al., 2001; Nielsen and Brock, 2009; Johns et al., 2014). Exposing fen ecosystems to temporary salinity exceeding $200 \mathrm{mg} \mathrm{Cl}^{-1} \mathrm{I}^{-1}$ might negatively affect performance of several species, including the root mat builder Thelypteris. Short term effects may include delay of root mat expansion and a decrease of species abundance that grow on the thin edges of root mats, although more tolerant species such as Comarum may continue root mat expansion. For (hemi)cryptophytes, belowground organs are likely to survive, allowing regrowth after temporary salt exposure. The total biomass decrease at $200 \mathrm{mg} \mathrm{Cl}^{-1} \mathrm{I}^{-1}$ indicated that even at very low concentrations, effects may occur. These effects could accumulate over longer timescales. Duration of exposure may not only depend on surface water management, but also on processes within the root mat, such as 
sorption of ions to organic soil particles (Gustafsson and Kleja, 2005) and pore water immobility (Ours et al., 1997).

In conclusion, surface water salinity could affect vegetation development in Dutch terrestrializing fens at concentrations as low as $200 \mathrm{mg} \mathrm{Cl}^{-1} \mathrm{l}^{-1}$. A reduction of plant growth would cause reduced fitness of some species and may lead to reduced root mat growth. Exposure to higher concentrations will affect some species severely and could eventually lead to a decrease of species richness.

Acknowledgements

We are grateful to our colleagues Ad Hermsen and Andre Maassen of Unifarm for their help and advice during the experiment, Henny Gertsen, Piet Peters and Harm Gooren for their technical and practical assistance and Trudy Lucas for her assistance with plant collection. We are grateful to Vereniging Natuurmonumenten for allowing us to collect plants at the Nieuwkoopse Plassen. This research project (Climate Proof Fresh Water Supply: Nature and Salinity) is carried out in the framework of the Dutch National Research Programme Knowledge for Climate (www.knowledgeforclimate.org). 


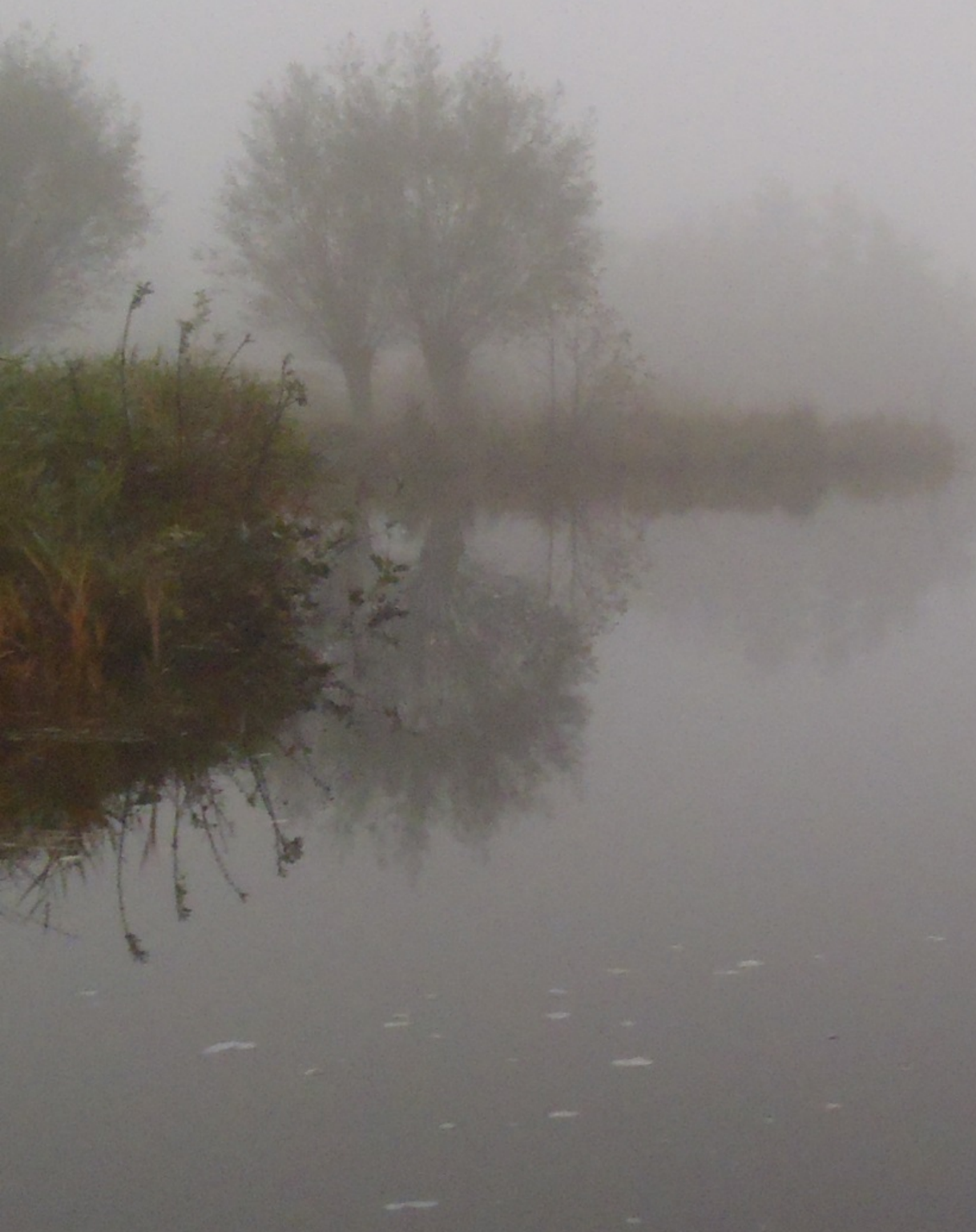




\section{Synthesis}




\subsection{General discussion}

\subsubsection{Salinization in polders with fresh water lenses and saline seepage}

Fresh water lenses have been of interest to hydrologists for many years (e.g. BadonGhijben, 1888; Herzberg, 1901), as they are important for the drinking water and agricultural water resources on islands, coastal regions and other areas with saline groundwater (De Louw et al., 2011; Nielsen et al., 2007; White and Falkland, 2010). For modelling these lenses, the density difference between the saline groundwater and the fresh water lenses introduces an additional complication, besides the schematization and scaling problems that are usually encountered in hydrogeology. Numerical codes, such as SEAWAT (Langevin et al., 2008) or SUTRA (Voss and Provost, 2010), can simulate density dependent flow processes, and have been used for the study of fresh water lenses (De Louw et al., 2013; Eeman et al., 2011; Schneider and Kruse, 2006). Numerical models often require detailed input data, expert knowledge and computing power, and therefore more simple approaches, often based on analytical solutions (Fetter, 1972; Vacher, 1988), have remained in use as well (e.g. Bailey et al., 2010; Dose et al., 2014; Stuyfzand, 2016; White and Falkland, 2010). Although such approaches usually only consider steady state situations and do not take details into account, their ease of use and general applicability make it possible to gain quick insight in basic characteristics of fresh water lens systems, such as average lens thickness.

In Chapter 2, it was shown how such a simple method can be used to estimate root zone salinization in areas with fresh water lenses in areas with saline seepage. The analytical solution of (Maas, 2007) is used to estimate the thickness of a fresh water lens under influence of saline seepage and the thickness of the mixing zone is estimated as proposed by (Cirkel et al., 2015) (Figure 6.1a). The cumulative precipitation deficit during the growing season is used to estimate fresh water lens depletion (Figure 6.1b). When depletion occurs, capillary rise will lead to salinization of the unsaturated zone. Root zone salinization is estimated as the result of mixing of the capillary rise, net precipitation and irrigation water, with their respective salinity loads using an adaptation of the leaching requirement (Richards et al., 1954) (Figure 6.1c). The chosen approach could be applied without the use of numerical models, and could be used for regional prioritization strategies from a management perspective. 

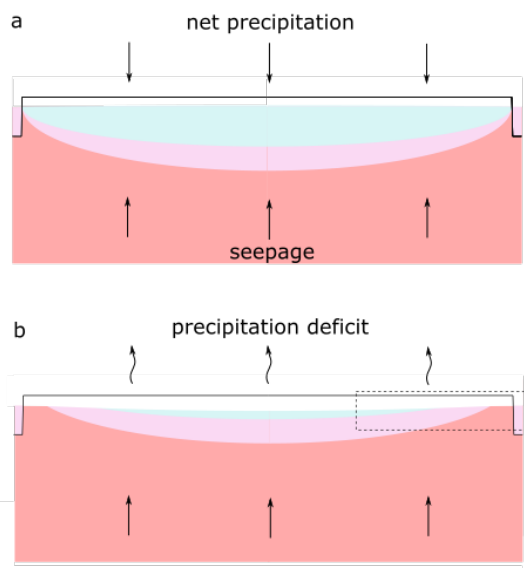

C

net precipitation and irrigation

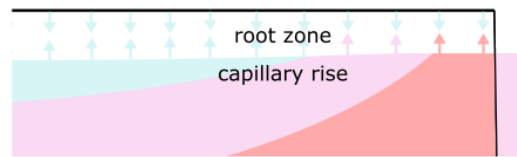

Figure 6.1 Schematic illustration of the processes that are discussed in Chapter 2. a. A cross-section of a field, delineated by two ditches, with a fresh water lens (blue) that is created by net precipitation, a mixing zone (purple) and saline groundwater (red) that seeps upward. $b$. The cumulative precipitation deficit is used to estimate maximum fresh water lens depletion. The marked rectangle is shown in c. c. Root zone salinization is attributed to the mixing of net precipitation, irrigation and capillary rise. The latter may become brackish or saline in zones where the lens has been depleted.

\subsubsection{Floating fen hydrology}

In the past decades, the hydrology of floating fens has been studied from an ecohydrological point of view. The rich fen type of vegetation (species-rich vegetation that depends on base-rich conditions) of these systems used to be associated with upwards seepage conditions, until (van Wirdum, 1991) showed that inflowing surface water could create similarly favourable base-rich conditions as well. Furthermore, it was shown that the zonation of the vegetation coincided with the chemistry of the root zone, which could range from mesotrophic, base rich conditions to more ombrotrophic conditions. The QUAGSOLVE model by (van Wirdum, 1991) simulated steady-state conservative transport, occurring laterally below the root mat and vertically within the root mat, to help explain the distribution of vegetation zones. Most research on floating fens after that focused on the conservation and restoration of floating fens, in which the hydrology was often not the focus of study, although many authors stress its importance (e.g. Beltman et al., 2011; 
Bootsma et al., 2002; Cusell et al., 2015; Dekker et al., 2005; Lamers et al., 2002; van Diggelen et al., 2015; Wassen et al., 1990).

Chapters 3 and 4 focus on the hydrology of floating fens in more spatial and temporal detail than has been done before, and attempt to show which properties of floating fens are important in explaining the flow dynamics. The most striking result is the difference between the floating parts of root mats and the parts that have attached to the subsurface.

The results of Chapter 3 showed that the floating part of the root mat partially moves up and down with the surface water level, with its buoyancy increasing with temperature and slightly decreasing as relative groundwater levels rise within the root mat. The groundwater levels in this part of the root mat remained at practically the same level as the surface water, and the groundwater fluctuations are not affected by any other process besides surface water level fluctuations as a result of a very quick vertical exchange with the water layer below the root mat (Chapter 4). The combined effect of the buoyancy and the quick exchange is a very stable groundwater level relative to the surface of the root mat, which means that moisture conditions for vegetation are very stable as well.

The part of the root mat that is attached to the subsurface shows much stronger dynamics in groundwater level, which is ascribed to the relative resistance between the root mat and the surface water due to distance and hydraulic conductivity (Chapter 4). In Chapter 3, we observed strong spatial differences in hydraulic conductivity, especially with depth. This layering can be explained by the higher degree of decomposition that is found in deeper layers, as new vegetation and organic matter accumulate on top of older layers. This heterogeneity results in a higher flow path density through the surface of the root mat, as lateral exchange takes place between the root mat and the surface water.

Our results show that the system characterization by (van Wirdum, 1991) with lateral flow below the root mat and vertical flow within the root mat applies well to the floating parts of root mats, which is the main component of the long, thin root mats that he studied. The hydrology of the part that is attached to the subsurface shows more resemblance to bog systems, with lateral water flow occurring mainly through the highly conductive top layer (Clymo, 2004; Ingram, 1982, 1978). 


\subsubsection{Effects of salinity on fen plants}

Most of what is known about the effects of salinity on plants, is based on research on agricultural crops, in which salt concentrations are related to decrease of yield, (e.g. Maas and Hoffman, 1977; Tanji and Kielen, 2002). The lesser economic value and the enormous diversity of ecosystems have contributed to the fact that less is known about the effects of salinity on wild plant species. Knowledge on tolerance of wild plants to abiotic conditions is often based on correlative data: the occurrence or abundance of species is related to measured or perceived site conditions, sometimes in the form of indicator values (Ertsen et al., 1998; Hennekens et al., 2010; Runhaar et al., 1997; Wamelink et al., 2002). Although correlation between non-occurrence of species and increased salinity levels may be related to intolerance, other variables, such as nutrient richness, may confound this result. For some fen species, salt sensitivity has been suggested in literature (Stofberg et al., 2014). This was, however, based on observed correlations and not supported by experimental results.

Chapter 5 discusses the result of a greenhouse experiment, in which five fen plant species (Comarum palustre, Myosotis scorpioides, Succisa pratensis, Thelypteris palustris and Viola palustris) were exposed to different levels of salinity. Salt concentrations above $500 \mathrm{mg} \mathrm{I}^{-1}$ $\mathrm{Cl}^{-}$resulted in growth reduction for three of these species. When the biomass of all five species was combined, a reduction was found at a salinity level of $200 \mathrm{mg} \mathrm{l}^{-1} \mathrm{Cl}^{-}$. These results confirm a causal relationship between relatively low salt concentrations and fen plant performance, which implies that fen ecosystems can be affected by exposure to salinity. While potential exposure to salinity could either consist of long term low exposure or short term high exposure, depending on local conditions, our results show that even relatively low concentrations may result in effects during relatively short timespans.

\subsection{Implications}

\subsubsection{Salinization in seepage polders}

The methods proposed in Chapter 2 can be used to compare salinization risks between areas, based on general properties of the areas. It should be noted that the underlying assumptions (in particular the long term averages and complete mixing) make these methods unsuitable to predict actual values of root zone salinity at particular moments in time, which complicates validation. Average values can be easily estimated, but actual salinity is likely to display strong spatial and temporal variations. Besides that, actual 
groundwater and root zone salinization may be more complicated than suggested, as additional processes might be involved. For example, saline seepage may occur as boils, resulting in local zones of increased seepage with high salt concentrations (De Louw et al., 2010). Additionally, flow in the root zone may be subject to preferential flow processes, causing infiltrating precipitation to bypass the soil matrix, not contributing to mixing (Brooks et al., 2009; De Louw et al., 2013).

Nonetheless, the methods can be used as a first approximation of the salinization risks between different areas and years with different cumulative precipitation deficits. The type of information that is needed for these methods, such as hydraulic conductivity, drainage density and seepage rates, is often available on maps. If these are unavailable, proxies could be used to estimate these values. For example, a soil map could be used to estimate the hydraulic conductivity of the soil. Applying the methods on these maps in a GIS environment would result in a rough overview of salinization risks for a larger area, which can be of use for prioritization.

Furthermore, the methods could be used as a tool to gain insight in the process of salinization, and how different measures may affect this process. Some measures that increase the fresh water lens thickness may be difficult to implement (such as raising the surface water levels to reduce seepage). However, others might be worth exploring, such as irrigation early in the year (to increase the thickness of the fresh water lens) or during a period of precipitation deficit (to reduce capillary rise), provided that enough fresh surface water is available.

\subsubsection{Risk of salinity in floating fens}

Salinity risks in floating fens are due to both the salinization of the root zone, and the effect of this salinization on the vegetation (Figure 6.1). Root zone salinization depends on three nested processes that operate at increasing finer spatial scales. The first two, salinization of the surface water and the water layer below the root mat, depend strongly on site-specific characteristics and surface water management. Salinization of the surface water (1) can only occur if surface water with increased salinity levels is supplied to the polder and if local flow patterns or mixing results in increased salinity in the (former) turf ponds or ditches surrounding the floating fens. The water layer below the root mat may receive water with increased salinity concentrations (2) through mixing processes close to the edge of the root mat, and further below the root mat if the recharge to the subsurface is larger than the precipitation surplus (van Wirdum, 1991). Salinization of the root zone (3) can occur during periods with precipitation deficit, when flow from the surface water 
into the root mat occurs. This process depends strongly on the root mat geometry, with strong differences between the floating part and the part of the root mat that is attached to the subsurface. At the edge of the root mat, surface water salinity may reach the root zone directly, while in zones farther away from the surface water it depends on the exchange with the water layer below the root mat. In the floating part of the root mat, transport may occur through short vertical flow paths, and only depends on the precipitation deficit, as any water that is lost through evapotranspiration will almost instantaneously be replaced by surface water flowing into the root mat. In the zone where the root mat is fixed to the subsurface, lateral flow through the upper layers of the root mat may occur. Here, the flow does not only depend on evapotranspiration, but also on root mat properties that determine the resistance of the flow path (length, conductivity). Plant species that are exposed to root zone salinity may respond, mostly depending on their sensitivity (4). Longer term effects of salinity, such as changes in vegetation composition, have been expected (Paulissen et al., 2007a, 2007b), but not confirmed by research.

These processes show that the vegetation zone at the edge of the root mat has the highest probability of being exposed to salinity in the case that brackish water is supplied to a polder with floating fens. This vegetation zone is likely to coincide with the rich fen zone, which depends on a close connection with the surface water.

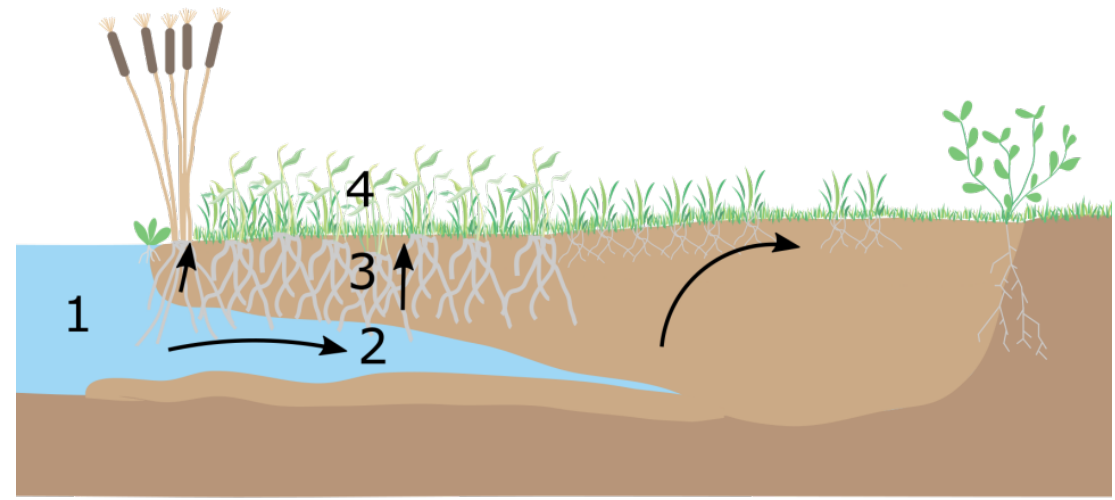

Figure 6.2 Schematic overview of the processes that determine salinization risk in floating fens. 1 . Salinization of the surface water, this is site-specific and strongly depends on water management decisions. 2. When the recharge rate is larger than the precipitation surplus, water will flow from the surface water into the layer below the root mat. 3. During precipitation deficits, water will flow into the root mat from the layer below. In the floating part, the exchange is vertical, over short flow paths, and in the part that is fixed to the subsurface, lateral flow occurs over longer flow paths into the root zone. 4. Sensitive plant species are affected by root zone salinity, leading to reduced growth and changes in biomass allocation, which could eventually affect vegetation composition. 


\subsection{Challenges and recommendations}

In this section, I discuss several remaining issues that would need to be addressed in order to gain full insight in the exposure and effects of salinization on vegetation in lowland polders.

Root zone exposure to salinization strongly depends on spatial and temporal variability. In some cases, this variability can be up-scaled, using some sort of average that provides a rough estimate, which is done in Chapter 2. However, as the effects of salinization on plants are non-linear and time-dependent (with thresholds from which damage starts to occur, and stronger effects during certain growth stages), it would be very useful to have better prediction of the duration and severity of salinization over time and space. Stochastic modelling approaches (e.g. Suweis et al., 2010) could improve the quantification of exposure to salt, while still taking the uncertainty into account that is introduced by the spatial and temporal variability.

Moreover, it may be interesting to apply the theory of fresh water lenses to floating fens. Rain water lenses that occur on top of buffered groundwater have been modelled for nonfloating fens by Schot et al. (2004). For similar cases, such as the non-floating parts of floating fens, rainwater lenses should develop as well. In case of upward seepage, the solution by Maas (2007) could be applicable, provided that the other assumptions apply. However, Schot et al. (2004) observed a strong effect of the thickness of the peat layer (which has a lower conductivity than the mineral soil below) on the lens thickness. Therefore, it is plausible that the strong heterogeneity of floating fens may affect the rain water lenses as well. Numerical models could illustrate the development and persistence of rain water lenses in floating fens. Although the heterogeneity would complicate the derivation of analytical solutions (such as the one by Maas, 2007), it may be useful to see if upscaling methods (choosing effective horizontal and vertical hydraulic conductivities) could lead to good estimation of rain water lens thicknesses in (floating) fens.

In the research that is presented in this thesis, transport phenomena have not been considered explicitly, except for the estimate of the mixing zone thickness of the fresh water lens of Chapter 1 , which depends on a longitudinal dispersivity and an assumed seasonal fluctuation. Salt transport and mixing in fresh water lenses can be affected by non-linear sorption processes, and be poorly represented by a linear Fick's type of law (Cirkel et al., 2015; Eeman et al., 2016). Besides that, preferential flow may affect root zone salinization, as was reported for root zones above fresh water lenses (De Louw et al., 2013). 
In the root mats of floating fens, such processes are expected as well. Peat soils often have macropores and have been shown to act as dual porosity media with strong retardation (Hoag and Price, 1997; Liu et al., 2016; Quinton et al., 2009). This could mean that solute intrusion from the surface water into a root mat may reach further into the root mat than expected only based on the hydrological modelling in Chapter 3 and 4. It may also mean that once salts (or other solutes) have entered the root zone, it would take very long before they are flushed out, especially as preferential flow is more likely to occur with outflow than with inflow due to the mostly larger flow rates of precipitation events compared to evapotranspiration (Koestel et al., 2012). To gain insight in these processes, different types of methods would need to be combined. Field studies with tracers would obviously give insight in the actual distribution of solutes, but to be able to predict these processes properly under different conditions using a model, the mechanisms must be understood as well. For this, laboratory studies, such as column experiments with tracers would be more useful. Additionally, it would be wise to check if other processes, such as temperature driven flow, which was found possible for bogs (Rappoldt et al., 2003), could be of importance in floating fens as well.

Furthermore, special attention is needed to investigate the effects of salinity on the physical properties of peat and soil organic matter. Literature from chemical sciences shows that humic acids (a main constituent of peat and soil organic matter) form different (macro)molecular structures under low and high salinity conditions (Baalousha et al., 2006; Myneni, 1999). In hydrological literature, positive effects of salinity on hydraulic conductivity are ascribed to changes in pore size distribution (macropores becoming larger as micropores become smaller) (Comas and Slater, 2004; Kettridge and Binley, 2010; Ours et al., 1997; van Dijk et al., 2016). More systematic experimental approaches could help explain this phenomenon, for example by making CT scans of soil samples (Kettridge and Binley, 2011) to provide insight in the pore structures. If these are affected by salinity, then also soil water retention and transport properties could be affected, besides hydraulic conductivity. If the observations can indeed be explained by changes in the macromolecular structures (as described in the chemical literature), multivalent ions (such as $\mathrm{Ca}^{2+}$ and $\mathrm{Mg}^{3+}$ ) that are often available in surface water and groundwater would be expected to have stronger effects on peat properties than $\mathrm{Na}^{+}$and $\mathrm{Cl}^{-}$.

The results of Chapter 5 have shown that salinity can affect the growth and survival of some fen plant species. However, to know how the vegetation would respond to exposure in the field, especially after longer timespans, the interaction between species would have to be taken into account. On longer timescales (decades), this interaction should be studied within the perspective of successional processes, which depend on the interaction with the hydrological and biogeochemical processes. Besides direct effects of salinity on 
vegetation, indirect effects are possible as well. Salinity may affect biogeochemical processes in peat and subsequently affect water quality, which can affect species composition as well (van der Welle et al., 2008; van Dijk et al., 2015). Additionally, increased salinity often correlates with increased sulphate concentration, which also affects the biogeochemical processes (Smolders et al., 2006; van Diggelen et al., 2014). For relatively short timescales (up to several years), some of these processes could possibly be studied in mesocosms or field enclosures. Besides studying the short and longer term effects of salinity, it would also be useful to look into recovery after the exposure has finished. However, experimental approaches cannot provide full understanding of the effects of salinization on fen vegetation, as too many processes and interactions between factors are involved, especially on longer time-spans. An alternative approach may consist of a comparison of different fen systems from all over the world. Typically, vegetation records are analysed to see if there is any correlation with measured abiotic factors such as water quality and depth. As the abiotic factors in fens can differ strongly with space and time, parameters must be chosen carefully, to truly represent a local system. For example, climate, seepage flux and system geometry may provide more useful information about water in the root zone than water levels or quality that was measured during a particular day. 


\section{Literature cited}


Abrol, I.P., Yadav, J.S.P., Massoud, F.I., 1988. Salt-Affected Soils and their Management. Food and agriculture organization of the United Nations, Rome.

Akkerman, J., Baas, R., Evers, N., Hoogeveen, A., Knoben, R., Sadat-Noorbakhsh, O., 2013. Limnodata Neerlandica [WWW Document]. Sticht. Toegep. Onderz. Waterbeheer. URL http://www.limnodata.nl (accessed 9.20.13).

Allaway, R.A.M.C., Ennings, S.T.C.P., 2003. Phenotypic plasticity and interactions among plants. Ecology 84, 1115-1128.

Allison LE, 1964. Salinity in relation to irrigation. Adv Agron 16:139-180.

Azza N, Denny P, Van De Koppel J, Kansiime F 2006. Floating mats: their occurrence and influence on shoreline distribution of emergent vegetation. Freshwater Biology 51: 1286-1297, doi:10.1111/j.1365-2427.2006.01565.x.

Baalousha, M., Motelica-Heino, M., Coustumer, P. Le, 2006. Conformation and size of humic substances: Effects of major cation concentration and type, $\mathrm{pH}$, salinity, and residence time. Colloids Surfaces A Physicochem. Eng. Asp. 272, 48-55. doi:10.1016/j.colsurfa.2005.07.010

Badon-Ghijben, W., 1888. Nota in verband met de voorgenomen putboring nabij Amsterdam. Tijdschr. Van K. Inst. Van Ingenieurs 5, 8-22.

Baird, A.J., Gaffney, S.W., 2000. Solute movement in drained fen peat: a field tracer study in a Somerset (UK) wetland. Hydrol. Process. 14, 2489-2503.

Baird AJ, Surridge BWJ, Money RP 2004. An assessment of the piezometer method for measuring the hydraulic conductivity of a Cladium mariscus-Phragmites australis root mat in a Norfolk (UK) fen. Hydrological Processes 18: 275-291, doi:10.1002/hyp.1375.

Bakker, G., Heinen, M., Wesseling, J.G., de Groot, W.J.M., Assinck, F.B.T., Hummelink, E.W.J., 2015. Bodemfysische gegevens in BIS. Alterra, Wageningen UR, Wageningen.

Bailey, R.T., Jenson, J.W., Olsen, A.E., 2010. Estimating the Ground Water Resources of Atoll Islands. Water 2, 1-27. doi:10.3390/w2010001

Bayley SE, Mewhort RL 2004. Plant community structure and functional differences between marshes and fens in the southern boreal region of Alberta, Canada. Wetlands 24: 277-294, doi:10.1672/0277-5212(2004)024.

Beersma, J.J., Buishand, T.A., de Goederen, S., Jacobs, P., 2005. Zout, zouter, zoutst. Statistiek van de externe verzilting in Midden-West Nederland. KNMI, De Bilt, Netherlands.

Beltman, B., Van Den Broek, T., Bloemen, S., Witsel, C., 1996. Effects of restoration measures on nutrient availability in a formerly nutrient-poor floating fen after acidification and eutrophication. Biol. Conserv. 78, 271-277. doi:10.1016/S00063207(96)00052-3 
Beltman, B., Omtzigt, N.Q.A., Vermaat, J.E., 2011. Turbary restoration meets variable success: does landscape structure force colonization success of wetland plants? Restor. Ecol. 19, 185-193. doi:10.1111/j.1526-100X.2010.00711.x

Boar RR, Crook CE, Moss B 1989. Regression of Phragmites australis reedswamps and recent changes of water chemistry in the Norfolk Broadland, England. Aquatic Botany 35: 41-55, doi:doi: 10.1016/0304-3770(89)90065-X.

Boels, D., van Gils, J.B.H.M., Veerman, G.J., Wit, K.E., 1978. Theory and system of automatic determination of soil moisture characteristics and unsaturated hydraulic conductivities. Soil Sci. 126, 191-199.

Bootsma MC, van den Broek T, Barendregt A, Beltman B 2002. Rehabilitation of Acidified Floating Fens by Addition of Buffered Surface Water. Restoration Ecology 10: 112121, doi:10.1046/j.1526-100X.2002.10112.x.

Bourbonniere, R.A., 2009. Review of water chemistry research in natural and disturbed peatlands. Can. Water Resour. J. 34, 393-414.

Bresler E, MacNeal B, Carter D, 1982. Saline and sodic soils: Principles-Dynamics-Modeling. Springer Verlag, New York

Brooks, J.R., Barnard, H.R., Coulombe, R., McDonnell, J.J., 2009. Ecohydrologic separation of water between trees and streams in a Mediterranean climate. Nat. Geosci. 3, 100104. doi:10.1038/ngeo722

Burgy, R.H., Pomeroy, C.R., 1958. Interception Losses in Grassy Vegetation. Trans. Am. Geophys. Union 39.

CBS, 2016. Landbouw; gewassen, dieren en grondgebruik naar regio [WWW Document]. URL https://www.cbs.nl/nl-nl/economie/landbouw (accessed 12.27.16).

Cendón DI, Larsen JR, Jones BG, et al (2010) Freshwater recharge into a shallow saline groundwater system, Cooper Creek floodplain, Queensland, Australia. J Hydrol 392:150-163.

Chevin, L.-M., Lande, R., Mace, G.M., 2010. Adaptation, plasticity, and extinction in a changing environment: towards a predictive theory. PLoS Biol. 8, e1000357.

Cirkel DG, Van Beek C, Witte JPM, Van der Zee S, 2014. Sulphate reduction and calcite precipitation in relation to internal eutrophication of groundwater fed alkaline fens. Biogeochemistry 117:375-393.

Cirkel DG, van der Zee S, Meeussen JCL, 2015. Front spreading with nonlinear sorption for oscillating flow. Water Resour Res 51:2986-2993.

Clymo, R.S., 2004. Hydraulic conductivity of peat at Ellergower Moss, Scotland. Hydrol. Process. 18, 261-274. doi:10.1002/hyp.1374

Comas, X., Slater, L., 2004. Low-frequency electrical properties of peat. Water Resour. Res. 40, n/a-n/a. doi:10.1029/2004WR003534 
Cusell C, Lamers LPM, van Wirdum G, Kooijman A 2013. Impacts of water level fluctuation on mesotrophic rich fens: Acidification vs. eutrophication. Journal of Applied Ecology doi:10.1111/1365-2664.12096.

Cusell, C., Mettrop, I.S., Loon, E.E. Van, Lamers, L.P.M., Vorenhout, M., Kooijman, A.M., 2015. Impacts of short-term droughts and inundations in species-rich fens during summer and winter: Large-scale field manipulation experiments. Ecol. Eng. 77, 127138. doi:10.1016/j.ecoleng.2015.01.025

De Lange WJ, Prinsen GF, Hoogewoud JC, et al, 2014. An operational, multi-scale, multimodel system for consensus-based, integrated water management and policy analysis: The Netherlands Hydrological Instrument. Environ Model Softw 59:98-108. doi: 10.1016/j.envsoft.2014.05.009

De Louw, P.G.B., Eeman, S., Oude Essink, G.H.P., Vermue, E., Post, V.E.A., 2013. Rainwater lens dynamics and mixing between infiltrating rainwater and upward saline groundwater seepage beneath a tile-drained agricultural field. J. Hydrol. 501, 133145. doi:10.1016/j.jhydrol.2013.07.026

De Louw, P.G.B., Eeman, S., Siemon, B., Voortman, B.R., Gunnink, J.L., van Baaren, E.S., Oude Essink, G.H.P., 2011. Shallow rainwater lenses in deltaic areas with saline seepage. Hydrol. Earth Syst. Sci. 15, 3659-3678. doi:10.5194/hess-15-3659-2011

De Louw, P.G.B., Oude Essink, G.H.P., Stuyfzand, P.J., Van Der Zee, S.E.A.T.M., 2010. Upward groundwater flow in boils as the dominant mechanism of salinization in deep polders, The Netherlands. J. Hydrol. 394, 494-506.

De Wit CT (1958) Transpiration and crop yields. Instituut voor Biologisch en Scheikundig Onderzoek van Landbouwgewassen, Wageningen

Dekker, S.C., Barendregt, A., Bootsma, M.C., Schot, P.P., 2005. Modelling hydrological management for the restoration of acidified floating fens. Hydrol. Process. 19, 39733984. doi:10.1002/hyp.5864

Delsman, J.R., Hu-a-ng, K.R.M., Vos, P.C., de Louw, P.G.B., Oude Essink, G.H.P., Stuyfzand, P.J., Bierkens, M.F.P., 2013. Palaeo-modeling of coastal salt water intrusion during the Holocene: an application to the Netherlands. Hydrol. Earth Syst. Sci. Discuss. 10, 13707-13742. doi:10.5194/hessd-10-13707-2013

Dose, E.J., Stoeckl, L., Houben, G.J., Vacher, H.L., Vassolo, S., Dietrich, J., Himmelsbach, T., 2014. Experiments and modeling of freshwater lenses in layered aquifers: Steady state interface geometry. J. Hydrol. 509, 621-630. doi:10.1016/j.jhydrol.2013.10.010

Dubroeucq D, Volkoff B 1998. From oxisols to spodosols and histosols: Evolution of the soil mantles in the Rio Negro basin (Amazonia). Catena 32: 245-280, doi:10.1016/S03418162(98)00045-9.

Eallonardo, A.S., Leopold, D.J., Fridley, J.D., Stella, J.C., 2013. Salinity tolerance and the decoupling of resource axis plant traits. J. Veg. Sci. 24, 365-374. 
Eeman, S., Leijnse, A., Raats, P.A.C., Van Der Zee, S.E.A.T.M., 2011. Analysis of the thickness of a fresh water lens and of the transition zone between this lens and upwelling saline water. Adv. Water Resour. 34, 291-302. doi:10.1016/j.advwatres.2010.12.001

Eeman, S., van der Zee, S.E.A.T.M., Leijnse, A., de Louw, P.G.B., Maas, C., 2012. Response to recharge variation of thin rainwater lenses and their mixing zone with underlying saline groundwater. Hydrol. Earth Syst. Sci. 16, 3535-3549. doi:10.5194/hess-163535-2012

Ellery K, Ellery WN, Rogers KH, Walker BH 1990. Formation, colonization and fate of floating sudds in the Maunachira river system of the Okavango Delta, Botswana. Aquatic Botany 38: 315-329, doi:http://dx.doi.org/10.1016/0304-3770(90)90027-I.

Ertsen, A.C.D., Alkemade, J.R.M., Wassen, M.J., 1998. Calibrating Ellenberg indicator values for moisture, acidity, nutrient availability and salinity in the Netherlands. Plant Ecol. 113-124.

Erwin, K.L., 2008. Wetlands and global climate change: the role of wetland restoration in a changing world. Wetl. Ecol. Manag. 17, 71-84. doi:10.1007/s11273-008-9119-1

Fetter CW (1972) Position of the saline water interface beneath oceanic islands. Water Resour Res 8:1307-1315.

Fitter, A.H., Peat, H.J., 1994. The Ecological Flora Database. J. Ecol. 82, 415 - 425.

Flowers, T.J., Galal, H.K., Bromham, L., 2010. Evolution of halophytes : multiple origins of salt tolerance in land plants. Funct. Plant Biol. 37, 604-612.

Flynn, K.M., Mckee, K.L., Mendelssohn, I.A., 1995. Recovery of freshwater marsh vegetation after a saltwater intrusion event. Oecologia 103, 63-72.

Fraser C, Roulet N, Lafleur M 2001. Groundwater flow patterns in a large peatland. Journal of Hydrology 246: 142-154, doi:10.1016/S0022-1694(01)00362-6.

Geurts, J.J.M., Sarneel, J.M., Willers, B.J.C., Roelofs, J.G.M., Verhoeven, J.T.A., Lamers, L.P.M., 2009. Interacting effects of sulphate pollution, sulphide toxicity and eutrophication on vegetation development in fens : A mesocosm experiment. Environ. Pollut. 157, 2072-2081. doi:10.1016/j.envpol.2009.02.024

Ghassemi, F., Jakeman, A.J., Nix, H.A., 1995. Salinisation of land and water resources. CAB International, Wallingford Oxon, UK.

Gippel CJ 1993. Hydrological management of a lake with floating islands near Pirron Yallock, Victoria, Australia. Journal of Environmental Management 37: 219-238.

Glenn, E., Thompson, T.L., Frye, R., Riley, J., 1995. Effects of salinity on growth and evapotranspiration. Aquat. Bot. 52, 75-91.

Gnatowski, T., Szatyłowicz, J., Brandyk, T., Kechavarzi, C., 2010. Hydraulic properties of fen peat soils in Poland. Geoderma 154, 188-195. doi:10.1016/j.geoderma.2009.02.021 
Goodman, A.M., Ganf, G.G., Dandy, G.C., Maier, H.R., Gibbs, M.S., 2010. The response of freshwater plants to salinity pulses. Aquat. Bot. 93, 59-67. doi:10.1016/j.aquabot.2010.03.004

Grattan SR, Grieve CM, 1992. Mineral element acquisition and growth response of plants grown in saline environments. Agric Ecosyst Environ 38:275-300. doi: 10.1016/01678809(92)90151-Z

Grover SPP, Baldock JA 2013. The link between peat hydrology and decomposition: Beyond von Post. Journal of Hydrology 479: 130-138, doi:10.1016/j.jhydrol.2012.11.049.

Gustafsson, J.P., Kleja, D.B., 2005. Modeling salt-dependent proton binding by organic soils with the NICA-Donnan and Stockholm humic models. Environ. Sci. Technol. 39, 5372-5377.

Haasnoot M, Vermulst JAPH, Middelkoop H, 1999. Impact of climate change and land subsidence on the water systems in the Netherlands. RIZA, Lelystad, the Netherlands

Hennekens, S.M., Smits, N.A.C., Schaminée, J.H.J., 2010. SynBioSys Nederland, versie 2. Alterra, Wageningen UR, Wageningen.

Herzberg, A., 1901. Die Wasserversorgung einiger Nordseebäder. Zeitung Gasbeleucht Wasserversorgung 44, 815-819.

Hoeksema, R.J., 2007. Three stages in the history of land reclamation in the Netherlands. Irrig. Drain. 56, S113-S126.

Hoag, R.S., Price, J.S., 1997. The effects of matrix diffusion on solute transport and retardation in undisturbed peat in laboratory columns. J. Contam. Hydrol. 28, 193205. doi:10.1016/S0169-7722(96)00085-X

Hogg EH, Wein RW 1988. The contribution of Typha components to floating mat buoyancy. Ecology 69: 1025-1031, doi:10.2307/1941258.

Hootsmans, M.J.M., Wiegman, F., 1998. Four helophyte species growing under salt stress: their salt of life? Aquat. Bot. 62, 81-94. doi:10.1016/S0304-3770(98)00085-0

Howard, R.J., Mendelssohn, I.A., 1999. Salinity as a constraint on growth of oligohaline marsh macrophytes. I. Species variation in stress tolerance. Am. J. Bot. 86, 785-794.

Hroudová, Z., Zákravský, P., Flegrová, M., 2014. The tolerance to salinity and nutrient supply in four European Bolboschoenus species (B. maritimus, B. laticarpus, B. planiculmis and B. yagara) affects their vulnerability or expansiveness. Aquat. Bot. 112, 66-75.

Ingram, H.A.P., 1982. Size and shape in raised mire ecosystems: a geophysical model. Nature 297, 300-303. doi:10.1038/297300a0

Ingram, H.A.P., 1978. Soil Layers in Mires: Function and Terminology. J. Soil Sci. 29, 224227. doi:10.1111/j.1365-2389.1978.tb02053.x 
Javaux M, Schröder T, Vanderborght J, Vereecken H, 2008. Use of a three-dimensional detailed modeling approach for predicting root water uptake. Vadose Zo J 7:10791088.

Jensen, K., Meyer, C., 2001. Effects of light competition and litter on the performance of Viola palustris and on species composition and diversity of an abandoned fen meadow. Plant Ecol. 155, 169 - 181.

Johns, C., Ramsey, M., Bell, D., Vaughton, G., 2014. Does increased salinity reduce functional depth tolerance of four non-halophytic wetland macrophyte species? Aquat. Bot. 116, 13-18.

Jolly ID, Narayan KA, Armstrong D, Walker GR, 1998. The impact of flooding on modelling salt transport processes to streams. Environ Model Softw 13:87-104. doi: http://dx.doi.org/10.1016/S1364-8152(98)00003-6

Katerji, N., van Hoorn, J.., Hamdy, a, Mastrorilli, M., 2003. Salinity effect on crop development and yield, analysis of salt tolerance according to several classification methods. Agric. Water Manag. 62, 37-66. doi:10.1016/S0378-3774(03)00005-2

Katschnig, D., Broekman, R., Rozema, J., 2013. Salt tolerance in the halophyte Salicornia dolichostachya Moss: Growth, morphology and physiology. Environ. Exp. Bot. 92, 3242. doi:10.1016/j.envexpbot.2012.04.002

Kaya, C., Kirnak, H., Higgs, D., Saltali, K., 2002. Supplementary calcium enhances plant growth and fruit yield in strawberry cultivars grown at high $(\mathrm{NaCl})$ salinity. Sci. Hortic. (Amsterdam). 93, 65-74. doi:10.1016/S0304-4238(01)00313-2

Kellner E, Waddington JM, Price JS 2005. Dynamics of biogenic gas bubbles in peat: Potential effects on water storage and peat deformation. Water Resources Research 41: 1-12, doi:10.1029/2004WR003732.

Kettridge, N., Binley, A., 2011. Characterization of peat structure using X-ray computed tomography and its control on the ebullition of biogenic gas bubbles. J. Geophys. Res. 116, G01024. doi:10.1029/2010JG001478

Kettridge, N., Binley, A., 2010. Evaluating the effect of using artificial pore water on the quality of laboratory hydraulic conductivity measurements of peat. Hydrol. Process. 24, 2629-2640. doi:10.1002/hyp.7693

Kettridge N, Kellner E, Price JS, Waddington JM 2012. Peat deformation and biogenic gas bubbles control seasonal variations in peat hydraulic conductivity. doi:10.1002/hyp.9369.

Klopstra, D., Versteeg, R., Kroon, T., 2005. Droogtestudie Nederland: Aard, ernst en omvang van watertekorten in Nederland. Lelystad.

KNMI, 2015. Klimaatatlas [WWW Document]. URL www.klimaatatlas.nl

KNMI, 2014 KNMI Klimaatscenarios. http://www.klimaatscenarios.nl.

KNMI, 2016a. KNMI Klimatologie [WWW Document]. URL http://www.knmi.nl/nederlandnu/klimatologie-metingen-en-waarnemingen 
KNMI, 2016b. Linking changes in hourly precipitation extremes to the Clausius-Clapeyron relation [WWW Document]. URL https://www.knmi.nl/kennis-endatacentrum/achtergrond/linking-changes-in-hourly-precipitation-extremes-to-theclausius-clapeyron-relation

Koerselman, W., 1989. Groundwater and surface water hydrology of a small groundwaterfed fen. Wetl. Ecol. Manag. 1, 31-43. doi:10.1007/BF00177888

Koerselman W, Claessens D, Den P, Winden E 1990. Dynamic hydrochemical and vegetation gradients in fens. Wetlands Ecology and Management 1: 73-84, doi:10.1007/BF00177282.

Koestel, J.K., Moeys, J., Jarvis, N.J., 2012. Meta-analysis of the effects of soil properties, site factors and experimental conditions on solute transport. Hydrol. Earth Syst. Sci. 16, 1647-1665. doi:10.5194/hess-16-1647-2012

Kuhlmann A, Neuweiler I, Zee S, Helmig R, 2012 Influence of soil structure and root water uptake strategy on unsaturated flow in heterogeneous media.

Kühn, I., Klotz, S., 2002. BIOLFLOR - Eine Datenbank zu biologisch-ökologischen Merkmalen der Gefäßpflanzen in Deutschland, Schriftenreihe für Vegetationskunde. Bundesamt für Naturschutz, Bonn.

Lambers, H., Chapin, F.S., Pons, T.L., 2008. Plant physiological ecology, 2nd ed. Springer, New York.

Lafleur, P.M., 1990. Evapotranspiration from sedge-dominated wetland surfaces. Aquat. Bot. 37, 341-353. doi:10.1016/0304-3770(90)90020-L

Lamers, L.P.M., Smolders, A.J.P., Roelofs, J.G.M., 2002. The restoration of fens in the Netherlands. Hydrobiologia 478, 107-130. doi:10.1023/A:1021022529475

Lamers, L.P.M., Vile, M.A., Grootjans, A.P., Acreman, M.C., van Diggelen, R., Evans, M.G., Richardson, C.J., Rochefort, L., Kooijman, A.M., Roelofs, J.G.M., Smolders, A.J.P., 2014. Ecological restoration of rich fens in Europe and North America: from trial and error to an evidence-based approach. Biol. Rev. Camb. Philos. Soc. doi:10.1111/brv.12102

Langevin, C.D., Thorne Jr, D.T., Dausman, A.M., Sukop, M.C., Guo, W., 2008. SEAWAT Version 4: A computer program for simulation of multi-species solute and heat transport. Geological Survey (US).

Lenssen, J.P.M., Menting, F.B.J., Van der Putten, W.H., 2003. Plant responses to simultaneous stress of waterlogging and shade: amplified or hierarchical effects? New Phytol. 157, 281-290.

Lieffers, V.J., 1984. Emergent plant communities of oxbow lakes in northeastern Alberta: salinity, water-level fluctuation, and succession. Can. J. Bot. 62, 310-316.

Littell, R.C., Milliken, G.A., Stroups, W.W., Wolfinger, R.D., Schabenberger, O., 2006. SAS for mixed models. SAS Institute Inc., Cary, NC, USA.

Liu, H., Janssen, M., Lennartz, B., 2016. Changes in flow and transport patterns in fen peat following soil degradation. Eur. J. Soil Sci. 1-10. doi:10.1111/ejss.12380 
Maas, E., Hoffman, G., 1977. Crop Salt Tolerance Current Assessment. J. Irrig. Drain. Div. 103, 115-134.

Maas, E. V, Poss, J.A., 1989. Salt sensitivity of cowpea at various growth stages. Irrig. Sci. 10, 313-320.

Maas, K., 2007. Influence of climate change on a Ghijben-Herzberg lens. J. Hydrol. 347, 223-228. doi:http://dx.doi.org/10.1016/j.jhydrol.2007.09.020

Macek, P., Lepš, J., 2007. Environmental correlates of growth traits of the stoloniferous plant Potentilla palustris. Evol. Ecol. 22, 419-435.

Macek, P., Rejmánková, E., 2007. Response of emergent macrophytes to experimental nutrient and salinity additions. Funct. Ecol. 21, 478-488.

Mälson K, Backéus I, Rydin H 2008. Long-term effects of drainage and initial effects of hydrological restoration on rich fen vegetation. Applied Vegetation Science 11: 99106, doi:10.3170/2007-7-18329.

Martinez ML, Psuty NP, 2008. Coastal Dunes Ecology and Conservation, Ecological. Springer

McCartney MP, de la Hera A. 2004. Hydrological assessment for wetland conservation at Wicken Fen. Wetlands Ecology and Management 12: 189-204, doi:10.1023/B:WETL.0000034069.34258.44.

Meissner R, Leinweber P, Rupp H, Shenker M, Litaor MI, Robinson S, Schlichting A, Koehn J 2008. Mitigation of diffuse phosphorus pollution during rewetting of fen peat soils: $A$ trans-European case study. Water Air and Soil Pollution 188: 111-126, doi:10.1007/s11270-007-9528-4.

Mitsch, W.J., Wilson, R.F., 1996. Improving the success of wetland creation and restoration with know-How, time and self-design. Ecol. Appl. 6, 77-83.

Morris PJ, Belyea LR, Baird AJ 2011. Ecohydrological feedbacks in peatland development: a theoretical modelling study. Journal of Ecology 99: 1190-1201, doi:10.1111/j.13652745.2011.01842.x.

Munns, R., Tester, M., 2008. Mechanisms of salinity tolerance. Annu. Rev. Plant Biol. 59, 651-81. doi:10.1146/annurev.arplant.59.032607.092911

Myneni, S.C., 1999. Imaging of Humic Substance Macromolecular Structures in Water and Soils. Science (80-. ). 286, 1335-1337. doi:10.1126/science.286.5443.1335

Nielsen, D.L., Brock, M.A., 2009. Modified water regime and salinity as a consequence of climate change: prospects for wetlands of Southern Australia. Clim. Change 95, 523533.

Nielsen, L., Jørgensen, N.O., Gelting, P., 2007. Mapping of the freshwater lens in a coastal aquifer on the Keta Barrier (Ghana) by transient electromagnetic soundings. J. Appl. Geophys. 62, 1-15. doi:10.1016/j.jappgeo.2006.07.002 
Ordoñez, J.C., van Bodegom, P.M., Witte, J.-P.M., Bartholomeus, R.P., van Dobben, H.F., Aerts, R., 2010. Leaf habit and woodiness regulate different leaf economy traits at a given nutrient supply. Ecology 91, 3218-3228.

Oude Essink, G.H.P., 2001. Salt water intrusion in a three-dimensional groundwater system in the Netherlands: A numerical study. Transp. Porous Media 43, 137-158. doi:10.1023/A:1010625913251

Oude Essink, G.H.P., Van Baaren, E.S., De Louw, P.G.B., 2010. Effects of climate change on coastal groundwater systems: A modeling study in the Netherlands. Water Resour. Res. 46, 1-16. doi:10.1029/2009WR008719

Ours, D.P., Siegel, D.I., Glaser, P.H., 1997. Chemical dilation and the dual porosity of humified bog peat. J. Hydrol. 196, 348-360.

Parida, A.K., Das, A.B., 2005. Salt tolerance and salinity effects on plants: a review. Ecotoxicol. Environ. Saf. 60, 324-49. doi:10.1016/j.ecoenv.2004.06.010

Paulissen, M.P.C.P., Schouwenberg, E., Velstra, J., Wamelink, W., 2007a. Hoe gevoelig is de Nederlandse natuur voor verzilting ? H2O 18, 34-38.

Paulissen, M.P.C.P., Schouwenberg, E.P.A.G., Wamelink, G.W.W., 2007b. Zouttolerantie van zoetwaterafhankelijke natuurdoeltypen; verkenning en kennislacunes. Alterra, Wageningen.

Pennings, S.C., Grant, M.-B., Bertness, M.D., 2005. Plant zonation in low-latitude salt marshes: disentangling the roles of flooding, salinity and competition. J. Ecol. 93, 159167.

Pfadenhauer J, Grootjans A 1999. Wetland restoration in Central Europe: Aims and methods. Applied Vegetation Science 2: 95-106, doi:10.2307/1478886.

Post, V.E.A., 2004. Groundwater salinization processes in the coastal area of the Netherlands due to transgressions during the Holocene. Ph.D. Thesis, Vrije Universiteit Amsterdam.

Price JS, Cagampan J, Kellner E 2005. Assessment of peat compressibility: is there an easy way? Hydrological Processes 19: 3469-3475, doi:10.1002/hyp.6068.

Price, J.S., Whittington, P.N., Elrick, D.E., Strack, M., Brunet, N., Faux, E., 2008. A method to determine unsaturated hydraulic conductivity in living and undecomposed moss. Soil Sci. Soc. Am. J. 72, 487. doi:10.2136/sssaj2007.0111N

Quinton, W.L., Elliot, T., Price, J.S., Rezanezhad, F., Heck, R., 2009. Measuring physical and hydraulic properties of peat from X-ray tomography. Geoderma 153, 269-277. doi:10.1016/j.geoderma.2009.08.010

Quinton W, Hayashi M, Carey S 2008. Peat hydraulic conductivity in cold regions and its relation to pore size and geometry. Hydrological Processes 22: 2829-2837, doi:10.1002/hyp.7027. 
Raats, P.A.C., 2015. Salinity management in the coastal region of the Netherlands: A historical perspective. Agric. Water Manag. 157, 12-30. doi:10.1016/j.agwat.2014.08.022

Rappoldt, C., Pieters, G.-J.J.M., Adema, E.B., Baaijens, G.J., Grootjans, A.P., van Duijn, C.J., 2003. Buoyancy-driven flow in a peat moss layer as a mechanism for solute transport. Proc. Natl. Acad. Sci. U. S. A. 100, 14937-42. doi:10.1073/pnas.1936122100

Rey Benayas, J.M., Newton, A.C., Diaz, A., Bullock, J.M., 2009. Enhancement of biodiversity and ecosystem services by ecological restoration: a meta-analysis. Science (80-. ). 325, 1121-1124.

Richards LA, Allison LE, Bernstein L, et al, 1954. Diagnosis and Improvement of Saline and Alkali Soils, Agric. Handbook vol. 60. USDA, Washington DC

Richburg, J.A., Patterson, W.A., Lowenstein, F., 2001. Effects of road salt and Phragmites australis invasion on the vegetation of a western Massachusetts calcareous lake-basin fen. Wetlands 21, 247-255.

Rodriguez-Iturbe I, Porporato A, 2004. Ecohydrology of water-controlled ecosystems: soil moisture and plant dynamics. Cambridge University Press, Cambridge, UK

Rozema, J., Flowers, T., 2008. Crops for a salinized world. Science (80-. ). 322, 1478-1480.

Runhaar, J., 2006. Natuur in de Verdringingsreeks. Alterra, Wageningen.

Runhaar, J., Van der Linden, M., Witte, J.P.M., 1997. Waterplanten en saliniteit. RIZA, Lelystad.

Rycroft DW, Williams DJA, Ingram HAP 1975. The Transmission of water through peat: I. Review. Journal of Ecology 63: 535-556.

Rydin, H., Jeglum, J.K., 2013. The biology of peatlands, 2nd ed. Oxford University Press, Oxford.

Sarneel, J.M., Soons, M.B., Geurts, J.J.M., Beltman, B., Verhoeven, J.T.A., 2011. Multiple effects of land-use changes impede the colonization of open water in fen ponds. J. Veg. Sci. 22, 551-563. doi:10.1111/j.1654-1103.2011.01281.x

Sasser CE, Visser JM, Evers DE, Gosselink JG 1995. The Role of Environmental Variables on Interannual Variation in Species Composition and Biomass in a Subtropical Minerotrophic Floating Marsh. Canadian Journal of Botany-Revue Canadienne De Botanique 73: 413-424.

Schinas S, Rowell DL (1977) Lime-induced chlorosis. J Soil Sci 28:351-368. doi: 10.1111/j.1365-2389.1977.tb02243.x

Schneider, J.C., Kruse, S.E., 2006. Assessing selected natural and anthropogenic impacts on freshwater lens morphology on small barrier Islands: Dog Island and St. George Island, Florida, USA. Hydrogeol. J. 14, 131-145. doi:10.1007/s10040-005-0442-9

Schot, P., Dekker, S., Poot, A, 2004. The dynamic form of rainwater lenses in drained fens. J. Hydrol. 293, 74-84. doi:10.1016/j.jhydrol.2004.01.009 
Schwärzel, K., Šimůnek, J., Stoffregen, H., Wessolek, G., van Genuchten, M.T., 2006. Estimation of the unsaturated hydraulic conductivity of peat soils. Vadose Zo. J. 5, 628. doi:10.2136/vzj2005.0061

Shah SHH, Vervoort RW, Suweis S, et al, 2011. Stochastic modeling of salt accumulation in the root zone due to capillary flux from brackish groundwater. Water Resour Res 47:W09506. doi: 10.1029/2010WR009790

Shani, U., Ben-gal, A., 2005. Long-term Response of Grapevines to Salinity: Osmotic Effects and Ion Toxicity 2, 148-154.

Shannon, M.C., Grieve, C.M., 1999. Tolerance of vegetable crops to salinity. Sci. Hortic. (Amsterdam). 78, 5-38.

Simon, E.W., 1978. The symptoms of calcium deficiency in plants. New Phytol. 80, 1-15.

Smolders, A.J.P., Lamers, L.P.M., Lucassen, E.C.H.E.T., Van Der Velde, G., Roelofs, J.G.M., 2006. Internal eutrophication: How it works and what to do about it-a review. Chem.

Ecol. 22, 93-111. doi:10.1080/02757540600579730

Somodi I, Botta-Dukát Z 2004. Determinants of floating island vegetation and succession in a recently flooded shallow lake, Kis-Balaton (Hungary). Aquatic Botany 79: 357-366, doi:10.1016/j.aquabot.2004.03.002.

Southern W, Ash J, Brodie J, Ryan P 1986. The flora, fauna and water chemistry of Tagimaucia crater, a tropical highland lake and swamp in Fiji. Freshwater Biology 16: 509-520, doi:10.1111/j.1365-2427.1986.tb00994.x.

Stanek W, Silc T 1977. Comparison of four methods for determination of degree of peat humification (decomposition) with emphasis on the von Post method. Canadian Journal of Soil Science 57: 109-117.

Stofberg, S.F., Klimkowska, A., Paulissen, M.P.C.P., Witte, J.P.M., 2014. Potential sensitivity of fen plant species to salinity. Knowledge for Climate, Utrecht.

Stofberg, S.F., van Engelen, J., Witte, J.P.M., van der Zee, S.E.A.T.M., 2016. Effects of root mat buoyancy and heterogeneity on floating fen hydrology. Ecohydrology 9, 12221234. doi:10.1002/eco.1720

Strack M, Kellner E, Waddington JM 2005. Dynamics of biogenic gas bubbles in peat and their effects on peatland biogeochemistry. Global Biogeochemical Cycles 19: 1-9, doi:10.1029/2004GB002330.

Strack M, Mierau T 2010. Evaluating spatial variability of free-phase gas in peat using ground-penetrating radar and direct measurement. Journal of Geophysical Research 115: 1-11, doi:10.1029/2009JG001045.

Stuyfzand, P.J., 2016. Observations and analytical modeling of freshwater and rainwater lenses in coastal dune systems. J. Coast. Conserv. 1-17. doi:10.1007/s11852-0160456-6

Suweis S, Rinaldo A, der Zee SEATM, et al, 2010. Stochastic modeling of soil salinity. Geophys Res Lett 37:n/a-n/a. doi: 10.1029/2010GL042495 
Swarzenski CM, Swenson EM, Sasser CE, Gosselink JG, 1991. Marsh mat flotation in the Louisiana delta plain. Journal of Ecology 79: 999-1011.

Szabolcs I, 1989. Salt Affected Soils. CRC Press, Boca Raton, Fla.

Tanji, K.K., Kielen, N.C., 2002. Agricultural drainage water management in arid and semiarid areas. FAO.

Thunqvist E, 2004. Regional increase of mean chloride concentration in water due to the application of deicing salt. Sci Total Environ 325:29-37. doi: 10.1016/j.scitotenv.2003.11.020

Toth T, 2008. Salt-affected soils in Hungary. In: Crescimanno G (ed) Needs and Priorities for Research and Education in Biotechnology Applied to Emerging Environmental Challenges in SEE Countries: Workshop Proceedings. UNESCO-BRESCE, Venice, Italy, pp 75-81

Tokida T, Miyazaki T, Mizoguchi M, 2005. Ebullition of methane from peat with falling atmospheric pressure. Geophysical Research Letters 32: 1-4, doi:10.1029/2005GL022949.

Tokida T, Miyazaki T, Mizoguchi M, Nagata O, Takakai F, Kagemoto A, Hatano R, 2007. Falling atmospheric pressure as a trigger for methane ebullition from peatland. Global Biogeochemical Cycles 21: 1-8, doi:10.1029/2006GB002790.

Underwood MR, Peterson FL, Voss Cl, 1992. Groundwater lens dynamics of Atoll Islands. Water Resour Res 28:2889-2902. doi: 10.1029/92WR01723

Vacher, H.L., 1988. Dupuit-Ghyben-Herzberg analysis of strip-island lenses. Geol. Soc. Am. Bull. 100, 580-591.

Van Asselen S, Roosendaal C, 2009. A New Method for Determining the Bulk Density of Uncompacted Peat from Field Settings. Journal of Sedimentary Research 79: 918-922, doi:10.2110/jsr.2009.091

Van Beek, E., Haasnoot, M., Meijer, K.M., Delsman, J.R., Snepvangers, J.J.J.C., Baarse, G., Van Ek, R., Prinsen, G.F., Kwadijk, J.C.J., Van Zetten, J.W., 2008. Verkenning kosteneffectiviteit van grootschalige maatregelen tegen droogteschade als gevolg van de G+ en W+ klimaatscenario's. Deltares, Delft.

Van Belle J, Barendregt A, Schot PP, Wassen MJ, 2006. The effects of groundwater discharge, mowing and eutrophication on fen vegetation evaluated over half a century. Applied Vegetation Science 195-204.

Van Dam, A.M., Clevering, O.A., Voogt, W., Aendekerk, T.G.L., van der Maas, M.P., 2007. Zouttolerantie van landbouwgewassen Deelrapport Leven met zout water. Praktijkonderzoek Plant \& Omgeving, Wageningen.

Van de Ven, G.P. (Ed.), 2004. Man made lowlands. History of water management and land reclamation in the Netherlands, Fourth. ed. Matrijs, Utrecht. 
Van den Brink, F.W.B., Van der Velde, G., 1993. Growth and morphology of four freshwater macrophytes under the impact of the raised salinity level of the Lower Rhine. Aquat. Bot. 45, 285-297. doi:http://dx.doi.org/10.1016/0304-3770(93)90029-V Van der Meijden, R., 2005. Heukels' Flora van Nederland, 23rd ed. Wolters-Noordhoff, Groningen, the Netherlands.

Van Der Veer P, 1977. Analytical solution for steady interface flow in a coastal aquifer involving a phreatic surface with precipitation. J Hydrol 34:1-11. doi: http://dx.doi.org/10.1016/0022-1694(77)90058-0

Van der Welle, M.E.W., Roelofs, J.G.M., Lamers, L.P.M., 2008. Multi-level effects of sulphur-iron interactions in freshwater wetlands in The Netherlands. Sci. Total Environ. 406, 426-9. doi:10.1016/j.scitotenv.2008.05.056

Van der Zee SEATM, Shah SHH, Vervoort RW, 2014. Root zone salinity and sodicity under seasonal rainfall due to feedback of decreasing hydraulic conductivity. Water Resour Res 50:9432-9446. doi: 10.1002/2013WR015208

Van Diggelen JMH, Bense IHM, Brouwer E, Limpens J, van Schie JMM, Smolders AJP, Lamers LPM 2015. Restoration of acidified and eutrophied rich fens: Long-term effects of traditional management and experimental liming. Ecological Engineering 75: 208216, doi:10.1016/j.ecoleng.2014.12.006.

Van Diggelen JMH, Lamers LPM, van Dijk G, Schaafsma MJ, Roelofs JGM, Smolders AJP 2014. New insights into phosphorus mobilisation from sulphur-rich sediments: timedependent effects of salinisation. PloS one 9: e111106, doi:10.1371/journal.pone.0111106.

Van Diggelen R, Molenaar WJ, Kooijman AM 1996. Vegetation Succession in a Floating Mire in Relation to Management and Hydrology. Journal of Vegetation Science 7: 809-820, doi:10.2307/3236459

Van Dijk, G., Nijp, J.J., Metselaar, K., Lamers, L.P.M., Smolders, A.J.P., 2016. Salinityinduced increase of the hydraulic conductivity in the hyporheic zone of coastal wetlands. Hydrol. Process. 1-11. doi:10.1002/hyp.11068

Van Dijk, G., Smolders, A.J.P., Loeb, R., Bout, A., Roelofs, J.G.M., Lamers, L.P.M., 2015. Salinization of coastal freshwater wetlands; effects of constant versus fluctuating salinity on sediment biogeochemistry. Biogeochemistry 126, 71-84. doi:10.1007/s10533-015-0140-1

Van Genuchten, M.T., Leij, F.J., Yates, S.R., 1991. The RETC code for quantifying the hydraulic functions of unsaturated soils. Riverside, California. doi:10.1002/9781118616871

Van Wirdum G 1990. Vegetation and hydrology of floating rich-fens. PhD Thesis, University of Amsterdam, Amsterdam. 
Vandenbohede A, Mollema PN, Greggio N, Antonellini M, 2014. Seasonal dynamic of a shallow freshwater lens due to irrigation in the coastal plain of Ravenna, Italy. Hydrogeol J 22:893-909. doi: 10.1007/s10040-014-1099-z

Vandenbohede, A., Mollema, P.N., Greggio, N., Antonellini, M., 2014. Seasonal dynamic of a shallow freshwater lens due to irrigation in the coastal plain of Ravenna, Italy. Hydrogeol. J. 22, 893-909. doi:10.1007/s10040-014-1099-z

Verhoeven, J.T.A., Bobbink, R., 2001. Plant diversity of fen landscapes in the Netherlands, in: Gopal, B., Junk, W.J., Davis, J.A. (Eds.), Biodiversity in Wetlands. Backhuys Publishers, Leiden.

Vervoort RW, van der Zee SEATM ,2008. Simulating the effect of capillary flux on the soil water balance in a stochastic ecohydrological framework. Water Resour Res 44:n/an/a. doi: 10.1029/2008WR006889

Voortman, B.R., Bartholomeus, R.P., van Bodegom, P.M., Gooren, H., van der Zee, S.E.A.T.M., Witte, J.P.M., 2014. Unsaturated hydraulic properties of xerophilous mosses: towards implementation of moss covered soils in hydrological models. Hydrol. Process. 6251-6264. doi:10.1002/hyp.10111

Vos PPC, 2015. Origin of the Dutch coastal landscapes. Utrecht University

Voss, C.I., Provost, A.M., 2010. SUTRA: a model for saturated-unsaturated, variabledensity ground-water flow with solute or energy transport, Water-Resources Investigations Report 02-4231. USGS, Reston, Virginia.

Waddington JM, Harrison K, Kellner E, Baird AJ 2009. Effect of atmospheric pressure and temperature on entrapped gas content in peat. Hydrological Processes 23: 29702980, doi:10.1002/hyp.7412.

Wamelink, G.W.W., Joosten, V., van Dobben, H.F., Berendse, F., 2002. Validity of Ellenberg indicator values judged from physico-chemical field measurements. J. Veg. Sci. 13, 269-278. doi:10.1111/j.1654-1103.2002.tb02047.x

Wassen, M.J., Barendregt, A., Schot, P.P., Beltman, B., 1990. Dependency of local mesotrophic fens on a regional groundwater flow system in a poldered river plain in the Netherlands. Landsc. Ecol. 5, 21-38. doi:10.1007/BF00153801

Werner, A.D., Bakker, M., Post, V.E.A., Vandenbohede, A., Lu, C., Ataie-Ashtiani, B., Simmons, C.T., Barry, D.A., 2013. Seawater intrusion processes, investigation and management: Recent advances and future challenges. Adv. Water Resour. 51, 3-26.

White, I., Falkland, T., 2010. Management of freshwater lenses on small Pacific islands. Hydrogeol. J. 18, 227-246. doi:10.1007/s10040-009-0525-0

Whittington PN, Price JS 2006. The effects of water table draw-down (as a surrogate for climate change) on the hydrology of a fen peatland, Canada. Hydrological Processes 20: 3589-3600, doi:10.1002/hyp.6375. 
Wilson, C., 2000. Growth Stage Modulates Salinity Tolerance of New Zealand Spinach (Tetragonia tetragonioides, Pall.) and Red Orach (Atriplex hortensis L.). Ann. Bot. 85, 501-509. doi:10.1006/anbo.1999.1086

Wind, G.P., 1968. Capillary conductivity data estimated by a simple method. Water unsaturated Zo. 1, 181-191.

Wirdum, G., 1993. An ecosystems approach to base-rich freshwater wetlands, with special reference to fenlands. Hydrobiologia 265, 129-153. doi:10.1007/BF00007265

Witte, J.P.M., Runhaar, J., van Ek, R., van der Hoek, D.C.J., Bartholomeus, R.P., Batelaan, O., van Bodegom, P.M., Wassen, M.J., van der Zee, S.E.A.T.M., 2012. An ecohydrological sketch of climate change impacts on water and natural ecosystems for the Netherlands: bridging the gap between science and society. Hydrol. Earth Syst. Sci. 16, 3945-3957. doi:10.5194/hess-16-3945-2012

Wright, I.J., Reich, P.B., Westoby, M., Ackerly, D.D., Baruch, Z., Bongers, F., CavenderBares, J., Chapin, T., Cornelissen, J.H.C., Diemer, M., Flexas, J., Garnier, E., Groom, P.K., Gulias, J., Hikosaka, K., Lamont, B.B., Lee, T., Lee, W., Lusk, C., Midgley, J.J., Navas, M.L., Niinemets, U., Oleksyn, J., Osada, N., Poorter, H., Poot, P., Prior, L., Pyankov, V.I., Roumet, C., Thomas, S.C., Tjoelker, M.G., Veneklaas, E.J., Villar, R., 2004. The worldwide leaf economics spectrum. Nature 428, 821-7.

Young ME, Macumber PG, Watts MD, Al-Toqy N, 2004. Electromagnetic detection of deep freshwater lenses in a hyper-arid limestone terrain. J Appl Geophys 57:43-61. doi: http://dx.doi.org/10.1016/j.jappgeo.2004.09.002

Zaadnoordijk W, Soetens A 2008. Rapportage grondwatermodel Wassenaarsche Polder e.o. (Leiden: Hoogheemraadschap van Rijnland).

Zedler, J.B., Kercher, S., 2005. Wetland resources: Status, trends, ecosystem services, and restorability. Annu. Rev. Environ. Resour. 30, 39-74. doi:10.1146/annurev.energy.30.050504.144248

Zelnik, I., Čarni, A., 2013. Plant species diversity and composition of wet grasslands in relation to environmental factors. Biodivers. Conserv. 22, 2179-2192.

Zwolsman, J.J.G., van Bokhoven, A.J., 2007. Impact of summer droughts on water quality of the Rhine River - a preview of climate change? Water Sci. Technol. 56, 45-55. doi:10.2166/wst.2007.535 


\section{English summary}

The lowland part of the Netherlands is and has been strongly influenced by human activities, as illustrated by the scars of peat mining, and meticulously managed water levels in polders. The peat mining and centuries of drainage have resulted in soil subsidence, and many agricultural polders are situated below sea level. Former peat mining areas that were not drained intensively now often have a relatively high position in the landscape. In the abandoned turf ponds, plants formed (partially) floating root mats, that host different vegetation zones, some with a high plant species diversity. These floating fens are nowadays designated as protected nature areas.

Both the deep agricultural and the elevated natural polder areas may be subject to salinization, through different processes. The deep agricultural polders often receive upward seeping groundwater, which may be brackish or saline. On top of the upward seeping groundwater, so called freshwater lenses develop as a result of the average precipitation surplus. If these lenses are very thin, they may disappear during periods of precipitation deficit and root zone salinization may occur. Besides groundwater salinization, surface water salinization may occur. Polders are regularly supplied with surface water to keep the water levels constant. The supplied water originates from the rivers or (indirectly) from other polders, and may have elevated salt concentrations. This salinized water could reach the fen root mats that (partially) float within the surface water.

In both types of areas, salinization is considered a threat, because salt concentrations in the root zone may harm plant growth, and could therefore affect crop yield or biodiversity. The risk of salinization depends on the exposure of the root zone to increased salt concentrations and the effects that these concentrations have on the vegetation.

In agricultural regions, the potential effects of salinization can be anticipated, because for many crops, the effect of salt concentrations on yield is roughly known. However, the exposure may differ strongly between areas and years. For the nature areas, it is rather unclear how salinized surface water could reach the root zone as the hydrological dynamics have not been described in sufficient detail. Furthermore, not much is known about the potential effect of salt on plant species that grow on the root mats.

The objectives of this thesis are (1) to provide general methods to estimate root zone salinization under different conditions in saline seepage areas, and (2) to assess the risk of 
salinization in floating fens by understanding the hydrological processes as well as the effects of increased salt concentration on plant species of floating fens.

In Chapter 2, we combined simple approaches to estimate the salinization in saline seepage areas. First, the average thickness of a fresh water lens is estimated, based on seepage rate, average net precipitation and site characteristics, as well as the thickness of the zone where fresh and saline or brackish water mix. The potential depletion of the fresh part of the lens under drought conditions is then estimated based on the maximum cumulative precipitation deficit that may develop in summer. In the case that (a part of) the lens disappears, long term root zone salinization is estimated as a weighted average of the salt concentrations of each of the water fluxes that enter the root zone: net precipitation, irrigation and the capillary rise from the groundwater. The chosen approach can be applied without the use of numerical models, which has the advantage of userfriendliness, short computation times, as well as transparency, and could be used for regional prioritization strategies from a freshwater management perspective.

Chapters 3 and 4 focus on the hydrology of floating fens, particularly to show which properties are important in explaining the flow dynamics. The most striking result is the difference between the floating parts of root mats and the parts that have attached to the subsurface. It was found that the floating part of the root mat partially moves up and down with the surface water level, with its buoyancy increasing with temperature and slightly decreasing as groundwater levels (relative to the surface) rise within the root mat. The groundwater levels in this part of the root mat remain at practically the same level as the surface water, and the groundwater fluctuations are exclusively affected by surface water level fluctuations, as a result of a very quick vertical exchange with the water layer below the root mat. The combined effect of the buoyancy and the quick exchange is a very stable groundwater level relative to the surface of the root mat, which means that moisture conditions for vegetation are very stable as well.

The part of the root mat that is attached to the subsurface shows much stronger dynamics in groundwater level, which is ascribed to the flow resistance between the root mat and the surface water that equals distance over hydraulic conductivity of the root mat material. Additionally, we observed strong spatial differences in hydraulic conductivity, especially with depth. This layering can be explained by the higher degree of decomposition of the organic material that is found in deeper layers, as new vegetation and organic matter accumulate on top of older layers. The heterogeneity results in a higher flow path density through the surface of the root mat, where the lateral exchange between the root mat and the surface water occurs. 
Chapter 5 discusses the results of a greenhouse experiment, in which five fen plant species (Comarum palustre, Myosotis scorpioides, Succisa pratensis, Thelypteris palustris and Viola palustris) were exposed to different levels of salinity. Salt concentrations above $500 \mathrm{mg} \mathrm{I}^{-1}$ $\mathrm{Cl}^{-}$resulted in growth reduction for three of these species. When the biomass of all five species was combined, a reduction was found at a salinity level of $200 \mathrm{mg} \mathrm{l}^{-1} \mathrm{Cl}^{-}$. These results confirm a causal relationship between relatively low salt concentrations and fen plant performance, which implies that fen ecosystems can be affected by low exposure to salinity. Salt stress in field conditions could be due to long term exposure to low levels or short term exposure to higher levels of salinity. Our results show that even relatively low concentrations may result in stress effects during relatively short timespans.

The combined results of Chapters 3, 4 and 5 show that if the surface water in the polders with nature areas becomes slightly more saline, e.g. from 100 to $200 \mathrm{mg} \mathrm{l}^{-1} \mathrm{Cl}^{-}$, plant species at the edges of the root mats are already likely to experience salt stress. The vegetation at the edge can be affected by relatively low salt concentrations within less than two months. The exposure of the vegetation further on the root mat depends on several factors, including the root mat geometry and groundwater seepage rate and direction. 


\section{Nederlandse samenvatting}

Het Nederlandse laagland is sterk beïnvloed door menselijke activiteiten, wat bijvoorbeeld te zien is aan de tekenen van vervening, en de nauwkeurige beheersing van de waterniveaus in de polders. De vervening en eeuwenlange ontwatering heeft geleid tot bodemdaling, waardoor veel landbouwpolders zich tegenwoordig onder de zeespiegel bevinden. Vroegere veenafgravingen die niet ontwaterd zijn hebben nu een relatief hoge ligging in het landschap. In de verlaten petgaten vormden planten (deels) drijvende wortelmatten (kraggen of zudden), waarop verschillende vegetatiezones te vinden zijn, waarvan sommigen met een hoge rijkdom in plantensoorten. Veel van deze laagveenverlandingen, waartoe o.a. trilvenen behoren, zijn tegenwoordig aangewezen als beschermd natuurgebied.

Door verschillende processen kunnen zowel de diepe landbouwpolders als de hoger gelegen natuurgebieden onderhevig zijn aan verzilting. De diepe landbouwpolders ontvangen kwellend grondwater, dat brak of zout kan zijn. Als gevolg van het gemiddelde neerslagoverschot kunnen zich bovenop het zoute of brakke grondwater zogenaamde zoetwaterlenzen ontwikkelen. Als deze lenzen erg dun zijn, kunnen ze verdwijnen tijdens perioden van neerslagtekort, waardoor de wortelzone kan verzilten. Naast grondwaterverzilting kan ook verzilting van het oppervlaktewater plaatsvinden. Polders worden regelmatig voorzien van oppervlaktewater om de waterniveaus constant te houden. Dit aangevoerde water is afkomstig uit de rivieren of (indirect) uit andere polders, en kan een verhoogde zoutconcentratie hebben. Hierdoor kan zout mogelijk de wortelmatten bereiken die (deels) in het water drijven.

In beide type gebieden wordt verzilting als bedreiging gezien, omdat zoutconcentraties in de wortelzone de plantengroei kunnen schaden, en zo de oogst of de biodiversiteit kunnen beïnvloeden. Het risico van zoutstress is afhankelijk van de blootstelling van de wortelzone aan verhoogde zoutconcentraties, en de effecten die de concentraties hebben op de vegetatie.

In de landbouwgebieden zijn de effecten van verzilting redelijk te voorzien, omdat voor veel gewassen het effect van zoutgehalten op de oogst grofweg bekend is. Maar de blootstelling kan erg verschillen tussen gebieden en jaren. Voor de natuurgebieden is het niet goed duidelijk hoe verzilt water de wortelzone bereikt, omdat de hydrologische dynamiek niet in voldoende detail bekend is. Daarnaast is ook weinig bekend over het mogelijke effect van zout op de natuurlijke vegetatie. 
De doelstellingen van dit proefschrift zijn (1) het aanreiken van algemene methoden om verzilting te schatten in gebieden met zoute kwel, onder verschillende omstandigheden en (2) het risico van verzilting in laagveenverlandingen vast te stellen door de hydrologische processen en de effecten van verhoogde zoutconcentraties op plantensoorten van laagvenen te beschrijven.

In hoofdstuk 2 combineerden we simpele benaderingen om verzilting te schatten in gebieden met zoute kwel. Eerst wordt de gemiddelde dikte van een zoetwaterlens geschat op basis van de kwelflux, gemiddelde netto neerslag en de eigenschappen van het gebied, en ook de dikte van de zone waar zoet en zout of brak water met elkaar gemengd worden. De mogelijke uitputting van het zoete deel van de lens onder droge omstandigheden wordt geschat op basis van het maximale cumulatieve neerslagtekort dat in de zomer kan ontstaan. In het geval dat (een deel van) de lens verdwijnt, kan langetermijnverzilting worden geschat als een gewogen gemiddelde van de zoutgehalten van elk van de waterfluxen die de wortelzone binnen komen: netto neerslag, irrigatie en capillaire opstijging uit het grondwater. De gekozen aanpak kan toegepast worden zonder het gebruik van numerieke modellen, wat als voordeel heeft dat het gebruiksvriendelijk is, snel berekend kan worden en transparant is, en zou gebruikt kunnen worden voor regionale prioritering van de zoetwaterverdeling.

Hoofdstuk 3 en 4 richten zich op de waterhuishouding van wortelmatten, waarbij met name wordt gekeken naar belangrijke eigenschappen die de stroming van water verklaren. Het opvallendste resultaat is het verschil tussen de drijvende delen van de wortelmatten, en de delen die aan de ondergrond vastgegroeid zijn.

Het drijvende deel van de wortelmat beweegt op en neer met het oppervlaktewater, met een drijfvermogen dat sterker wordt als de temperatuur stijgt en zwakker wanneer het grondwaterniveau (ten opzichte van het maaiveld) in de wortelmat stijgt. In dit deel blijft de grondwaterspiegel op praktisch hetzelfde niveau als het oppervlaktewater. Doordat er snelle uitwisseling plaatsvindt met de waterlaag onder de wortelmat, worden de grondwaterfluctuaties slechts beïnvloed door oppervlaktewaterfluctuaties. Het samengestelde effect van het drijfvermogen en de snelle uitwisseling is dat de grondwaterspiegel ten opzichte van de wortelmat zelf heel stabiel is, waardoor de vochtcondities voor de vegetatie dat ook zijn.

Het deel van de wortelmat dat is vastgegroeid aan de ondergrond heeft een grotere grondwaterstandsdynamiek, die verklaard wordt door de hydraulische weerstand tussen de wortelmat en het oppervlaktewater. Deze weerstand hangt af van de afstand tot het oppervlaktewater en de doorlatendheid van het bodemmateriaal. We hebben sterke 
ruimtelijke verschillen in doorlatendheid gezien, voornamelijk in de diepte. De verticale gelaagdheid hangt samen met de verdere staat van afbraak van het organisch materiaal in de diepere lagen, omdat nieuwe vegetatie en organisch materiaal bovenop de oude lagen ophopen. De heterogeniteit leidt ertoe dat meer stroombanen door het oppervlakkige deel van de wortelmat gaan.

Hoofdstuk 5 beschrijft de resultaten van een kasexperiment, waarin plantensoorten van wortelmatten (Comarum palustre, Myosotis scorpioides, Succisa pratensis, Thelypteris palustris en Viola palustris) werden blootgesteld aan verschillende zoutgehalten. Zoutconcentraties boven $500 \mathrm{mg} \mathrm{l}^{-1} \mathrm{Cl}^{-}$resulteerden in groeivermindering bij drie van deze soorten. Wanneer de biomassa van alle vijf soorten werd samengevoegd, vonden we een vermindering in totale biomassa vanaf $200 \mathrm{mg} \mathrm{l}^{-1} \mathrm{Cl}^{-}$. Deze resultaten bevestigen een oorzakelijk verband tussen relatief lage zoutconcentraties en de groei van laagveensoorten, wat impliceert dat de vegetatie van kraggen beïnvloed kan worden door blootstelling aan lage zoutconcentraties. Zoutstress in veldsituaties zou kunnen plaatsvinden als gevolg van langdurige blootstelling aan lage concentraties of kortdurende blootstelling aan hogere concentraties. Onze resultaten laten zien dat relatief lage concentraties al effect kunnen hebben tijdens relatief korte perioden.

De gecombineerde resultaten van hoofdstuk 3, 4 en 5 laten zien dat als het oppervlaktewater in de polders met natuurgebieden zouter wordt, bijvoorbeeld van 100 tot $200 \mathrm{mg} \mathrm{l}^{-1} \mathrm{Cl}^{-}$, dat de plantensoorten aan de randen van de wortelmatten waarschijnlijk blootgesteld worden. De vegetatie op de rand kan door relatief lage zoutgehalten beïnvloed worden in minder dan twee maanden. De blootstelling van de vegetatiezones verder op de wortelmatten hangt af van verschillende factoren, waaronder de geometrie van de wortelmat en de wegzijgingsflux. 


\section{Dankwoord, acknowledgements}

Eindelijk is het boekje klaar. Voordat ik naar Wageningen kwam, meer dan vijf jaar geleden, had ik geen idee wat een intense tijd het zou worden. Tijdens de afgelopen jaren heb ik vele uren in het veld, lab en in de kas doorgebracht, en nog veel meer achter een bureau, starend naar computerschermen. Desondanks heb ik veel geleerd, en fantastische mensen ontmoet.

Allereerst wil ik graag mijn promotor en dagelijks begeleider, Sjoerd van der Zee, bedanken, voor zijn hulp tijdens alle onderdelen van het onderzoek. Hij heeft me veel waardevols geleerd over wetenschap en ook om niet teveel last te hebben van alle zaken die er daaromheen bij schijnen te horen. Ik ben hem zeer dankbaar voor de inspiratie, het vertrouwen, geduld en de vriendschap die ik heb ervaren.

Ik wil graag mijn tweede promotor Flip Witte bedanken, zonder wie ik waarschijnlijk nooit in Wageningen terecht was gekomen, voor de inspirerende gesprekken (waaronder een gezellige trip naar een conferentie in Rennes) en goed advies. Agata Klimkowska, thank you for the interesting conversations and support in the field and greenhouse. Maurice Paulissen, bedankt voor de hulp en de goede discussies over ecologie. Toon Leijnse, dank je voor het geduld bij het uitpluizen van problemen met het modelleren en voor het laten begrijpen hoe een natuurkundige denkt.

Daarnaast wil ik mijn collega's bedanken die allerlei praktische hulp en adviezen hebben geboden. Henny Gertsen, het waren soms lange, maar altijd gezellige dagen in het veld! Harm Gooren, Piet Peters, Gerben Bakker, bedankt voor alle hulp in het lab en daarbuiten. Klaas Oostindie, wat is mijn proefschrift netjes opgemaakt, bedankt!

Ook hebben diverse studenten meegewerkt aan het onderzoek. Federica, Joeri and Hang, thank you for the hard work and helping me to increase my knowledge through teaching. Verder ben ik dank verschuldigd aan diverse coauteurs, collega's (o.a. SLM, Unifarm) en vele anderen, waaronder de mensen van Natuurmonumenten en diverse collegaonderzoekers, die hebben bijgedragen aan mijn onderzoek of aan de discussies het onderzoek verbeterden.

Veel heb ik ook te danken aan Coen Ritsema, voor het zorgen voor allerlei randvoorwaarden en de mogelijkheid dat mijn contract verlengd kon worden om het onderzoek af te ronden, terwijl ik daarnaast ook onderwijs gaf. Daarnaast dank aan alle 
toffe collega's van SLM, waaronder Violet, Aad, Michel, Martine, Jerry en alle anderen. In het bijzonder wil ik hier George, Klaas, Jos, Paul en Claudia noemen, met wie ik samen veel onderwijs gaf, bedankt voor de fijne samenwerking, ik heb veel van jullie geleerd. Speciale dank ook naar Annelies, Marnella, Trees, Esther, Siawash en Henny, die veel praktische zaken hebben geregeld.

Uiteraard kan ik mijn vrienden binnen SLM niet vergeten, met wie ik veel heb gedeeld. Corjan, Joep, het was super om met jullie een kantoor te delen en bijna dagelijks te 'associëren' (wandelen) tijdens de lunchpauze. Célia, thanks for being a wonderful friend. Xiaomei, Kaveh, Jianhong, Demie, Esther, Willemijn, Marieke, Bram, Jelmer, Hamid, Dieuwke, Gijsbert, Lingtong, Ricardo, Diana, Ammar, Karrar, Sameh, Pop, Rens, Nadia, Everton, Carlos, Marina, Coleen, Raoul, Severin, and all the others from the lunch group, the fun moments, squash games, dinners, EGU trip and everything else mean a lot!

Zonder mijn vrienden was het allemaal veel minder leuk geweest. Koen, Manuel, Sara, thank you for the fun evenings and for sharing PhD experiences. Laura, the 'very important work meetings' were a lot of fun! Karin, Mariëlle, Deborah, Silvia, Marcelo en alle anderen, bedankt voor de afleiding om even niet met het onderzoek bezig te zijn!

Zonder de steun van mijn familie zou ik het niet hebben gered. Arie, dank je wel voor het advies om voor 'de baan met de plantjes' te gaan. Jos, het was fijn om je de eerste periode part-time als huisgenoot te hebben. Dank je wel voor je steun. Papa, dank je wel voor alles wat je voor me gedaan hebt, helaas maak je dit niet meer mee. Mama, wat fijn dat je er altijd voor me bent en dat je altijd goede raad hebt, bedankt voor alles.

André, ik ken je pas sinds 'de laatste loodjes' van dit proefschrift, maar die waren een stuk minder zwaar dankzij jou. Dank je wel. 


\section{Curriculum Vitae}

Sija F. Stofberg,was born on 30 August 1984 in Rhoon, the Netherlands. She received her high school diploma from Marnix Gymnasium Rotterdam in 2002. She studied Social Work at the Hogeschool Rotterdam, from which she obtained her degree in 2006. After that, she switched to the natural sciences and obtained her BSc degree in Natural Environmental Sciences from Utrecht University in 2009. In 2011, she finished her MSc thesis about modelling nutrient transport in catchments. She received her MSc. diploma in Earth Sciences, track Earth Surface Hydrology from Utrecht University.

In 2011, she started as a PhD candidate at (then) the Soil Physics, Ecohydrology and Groundwater Management group, which is nowadays part of the Soil Physics and Land Management group of Wageningen University. During her PhD research, she gave presentations at several international conferences, supervised MSc and BSc students and gave lectures and practicals at several courses in Wageningen University. In 2015-2016, she also taught courses at the Vrije Universiteit Amsterdam. Currently, she works as a researcher at KWR Watercycle Research Institute. 


\section{Co-author affiliations}

Joeri van Engelen

Wageningen University, Soil Physics and Land Management, Environmental

Sciences Group, PO Box 47, 6700 AA Wageningen, the Netherlands

Agata Klimkowska

Eco-Recover, Ecosystem Restoration Advice, Labriehof 21, 6952 HW, Dieren, The Netherlands

Anton Leijnse

Soil Physics and Land Management, Wageningen University, P.O.Box 47, 6700 AA Wageningen

Perry G.B. de Louw

Department of Soil and Groundwater, Deltares, P.O. Box 85467, 3508 AL Utrecht, The Netherlands

Gualbert H.P. Oude Essink

Department of Soil and Groundwater, Deltares, P.O. Box 85467, 3508 AL Utrecht, The Netherlands

Department of Physical Geography, University of Utrecht, P.O. Box 80125, 3508

TC Utrecht, The Netherlands

Maurice P.C.P. Paulissen

Alterra, Wageningen University and Research Centre, PO Box 47, 6700 AA

Wageningen, The Netherlands

Pieter S. Pauw

Department of Soil and Groundwater, Deltares, P.O. Box 85467, 3508 AL Utrecht, The Netherlands

Soil Physics and Land Management, Wageningen University, P.O.Box 47, 6700 AA Wageningen

Jan-Philip M Witte

KWR Watercycle Research Institute, PO Box 1072, 3430 BB Nieuwegein, the Netherlands

VU University, Department of Systems Ecology, Institute of Ecological Science, de Boelelaan 1085, 1081 HV Amsterdam, the Netherlands

Sjoerd E.A.T.M. van der Zee

Soil Physics and Land Management, Wageningen University, P.O.Box 47, 6700 AA Wageningen

School of Chemistry, Monash University, Melbourne, VIC 3800, Australia 


\section{Sense Certificate}

\section{SENSE}

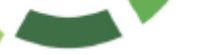

Netherlands Research School for the

Socio-Economic and Notural Sciences of the Environment

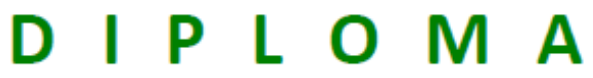

For specialised PhD training

The Netherlands Research School for the Socio-Economic and Natural Sciences of the Environment

(SENSE) declares that

\section{Sija Francisca Stofberg}

born on 30 August 1984 in Rhoon, the Netherlands

has successfully fulfilled all requirements of the Educational Programme of SENSE.

Wageningen, 7 June 2017

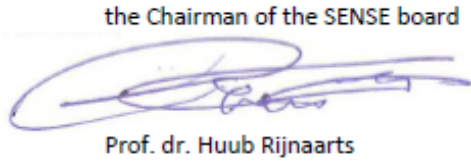

Prof. dr. Huub Rijnaarts

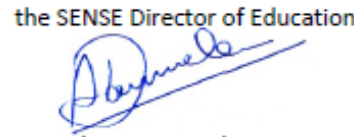

Dr. Ad van Dommelen

The SENSE Research School hos been accredited by the Royal Netherlands Academy of Arts and Sciences (KNAW)

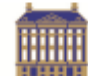

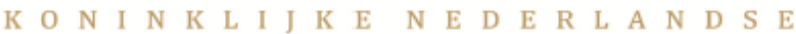

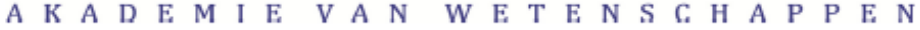




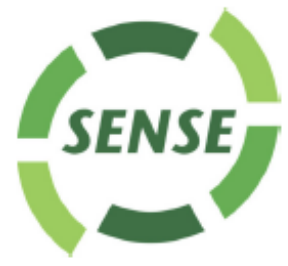

The SENSE Research School declares that Ms Sija Stofberg has successfully fulfilled all requirements of the Educational PhD Programme of SENSE with a work load of $43.3 \mathrm{EC}$, including the following activities:

\section{SENSE PhD Courses}

- Environmental research in context (2012)

- Research in context activity: 'Co-organising WIMEK/SENSE symposium on Water \& energy cycles at multiple scales' (2012)

- Workshop Valorization of PhD research in Climate Sciences (2014)

\section{Other PhD and Advanced MSc Courses}

Design of experiments, Wageningen University (2012)

Summer school for flow and transport in terrestrial systems, University Heidelberg (2012)

Project and time management, Wageningen University (2012)

Information literacy including EndNote introduction, Wageningen University (2012)

- Physical modelling, Wageningen University (2014)

\section{Management and Didactic Skills Training}

- Supervising three MSc students with theses entitled ' Hydraulic characterization of a floating fen soil' (2012), 'A further investigation into the hydrology of the kragge system' (2013) and 'Effects of salinity in organic soils' (2015)

- Supervising BSc student (2014)

- Guest lectures for course Subsurface solute transport (2013)

- Guest lectures for course Land degradation (2015)

- Teaching course Advanced hydrological system analysis (2015)

- Assisting computer practicals of the course Hydrogeology (2011-2016)

- Assisting practicals of the course Advanced hydrological system analysis (2016)

\section{Oral Presentations}

- Meten aan waterstroming in laagveenverlandingen. NHV symposium Ecohydrologie van Veenlandschappen, 22 November 2012, Utrecht, the Netherlands

- Hydraulic characterisation of floating fen root mats. HydroEco 2013, the $4^{\text {th }}$ international, multidisciplinary conference on ecology and hydrology: 'Hydrology \& Ecology: Emerging patterns, breakthroughs and challenges', 13-16 May 2013, Rennes, France

- Low salinity levels in Dutch lowland fresh-water fens: Effects on plant species. International Conference Deltas in times of climate change, 25-26 September 2014, Rotterdam, the Netherlands

- Physical characteristics and groundwater dynamics of floating fens. Boussinesq Lecture 2014, 23 October 2014, Amsterdam, Netherlands

\section{SENSE Coordinator PhD Education}

